\title{
Rethinking Wife Abuse: Violence, Resistance, and Public Policy in
} Canada

\author{
By Stephanie L. Paterson \\ A dissertation submitted to \\ The School of Public Policy and Administration \\ Carleton University, \\ Ottawa, Ontario \\ Canada
In partial fulfillment of the requirements for the degree of
Doctor of Philosophy

@ Stephanie L. Paterson, 2006 


$\begin{array}{ll}\begin{array}{l}\text { Library and } \\ \text { Archives Canada }\end{array} & \begin{array}{l}\text { Bibliothèque et } \\ \text { Archives Canada }\end{array} \\ \begin{array}{l}\text { Published Heritage } \\ \text { Branch }\end{array} & \begin{array}{l}\text { Direction du } \\ \text { Patrimoine de l'édition }\end{array} \\ \begin{array}{l}\text { 395 Wellington Street } \\ \text { Ottawa ON K1A ON4 }\end{array} & \begin{array}{l}\text { 395, rue Wellington } \\ \text { Ottawa ON K1A ON4 } \\ \text { Canada }\end{array}\end{array}$

Your file Votre référence ISBN: 978-0-494-27108-7 Our file Notre référence ISBN: 978-0-494-27108-7

NOTICE:

The author has granted a nonexclusive license allowing Library and Archives Canada to reproduce, publish, archive, preserve, conserve, communicate to the public by telecommunication or on the Internet, loan, distribute and sell theses worldwide, for commercial or noncommercial purposes, in microform, paper, electronic and/or any other formats.

The author retains copyright ownership and moral rights in this thesis. Neither the thesis nor substantial extracts from it may be printed or otherwise reproduced without the author's permission.
AVIS:

L'auteur a accordé une licence non exclusive permettant à la Bibliothèque et Archives Canada de reproduire, publier, archiver, sauvegarder, conserver, transmettre au public par télécommunication ou par l'Internet, prêter, distribuer et vendre des thèses partout dans le monde, à des fins commerciales ou autres, sur support microforme, papier, électronique et/ou autres formats.

L'auteur conserve la propriété du droit d'auteur et des droits moraux qui protège cette thèse. $\mathrm{Ni}$ la thèse ni des extraits substantiels de celle-ci ne doivent être imprimés ou autrement reproduits sans son autorisation.
In compliance with the Canadian

Privacy Act some supporting forms may have been removed from this thesis.

While these forms may be included in the document page count, their removal does not represent any loss of content from the thesis.
Conformément à la loi canadienne sur la protection de la vie privée, quelques formulaires secondaires ont été enlevés de cette thèse.

Bien que ces formulaires aient inclus dans la pagination, il n'y aura aucun contenu manquant.

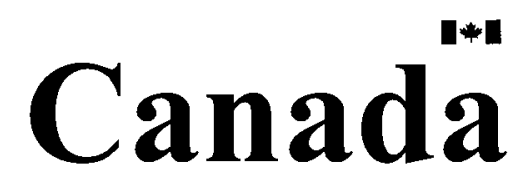


Abstract: How does public policy influence wife abuse? This dissertation attempts to answer this question by using the lens of women's resistance to analyse the Canadian anti-wife abuse policy framework. It is argued that the goal of the current anti-violence policy framework is protection, instrumental to which is departure, imposing exit on women. Resistance is narrowly defined only as departure from the household, falsely dichotomizing women who leave as resistors and women who stay as victims. In doing so, public policy benefits only a few women, those who want to and can leave. Other women, those who do not want the relationship to end and those who cannot sustain themselves without their partner, are defined away from the policy framework. In addition, the policy framework is premised on "choice" but fails to account for the context in which choice takes place. This construction of resistance places a number of barriers on women attempting to resist abuse, which are shown analytically, using a feminist bargaining approach coupled with outside options theory, and empirically, using data from the General Social Survey on Victimization 1999 to test binary logit and tobit models, as well as independent samples tests. It is demonstrated that women's resistance is not a question of agency, but rather of public policy. Thus, by shifting the goal of policy away from protection/exit towards the broader objective of prevention/enabling women to live without violence, a much broader scope of resistance strategies is accommodated. 


\section{TABLE OF CONTENTS}

\section{$\underline{\text { Page }}$}

Acknowledgements iv

$\begin{array}{ll}\text { List of Tables } & v\end{array}$

List of Charts and Figures vi

List of Appendices vii

Chapter 1: Violence, Resistance and Public Policy in Canada: An Introduction

Chapter 2: Violence and Bargaining within Families: The Role of Absolute and Relative Resources in Stimulating Violent Behaviour

Chapter 3: (De)Constructing Resistance in Canada's Anti-Violence Policy Framework: The Limits (and Strengths) of Exit as a Bargaining Strategy

Chapter 4: Household Structure and Wife Abuse: An Empirical Analysis of Violence and Resistance Options in Canada

Chapter 5: (Re)Constructing Women's Resistance: Resources, Strategy Choice, and Implications of and for Public Policy

Chapter 6: Conclusion: Contributions and Areas for Future Work

Appendix 1: A List of Relevant Questions from the 1999 General Social Survey on Victimization, Cycle 13.

Bibliography 


\section{Acknowledgments}

I would like to thank Carleton University and the Ontario government for providing financial assistance for this project. In addition, several individuals provided financial support throughout my dissertation, including Bruce Doern, Les Pal, and Stephan Schott. I also owe a great deal of gratitude to my dissertation committee, Lisa Mills and Stanley Winer, and my external examiners, Martha MacDonald and Janet Siltanen, for their support, encouragement, and valuable insights. Most importantly, I'd like to thank my thesis supervisor, Frances Woolley, who proved to be an invaluable mentor. 
Table 1.1: Wife Abuse Policy in Canada 7

Table 4.1: Descriptive Statistics: The 1999 General Social Survey on 133

Victimization

Table 4.2: The Probability of Experiencing Violence 155

Table 4.3: The Severity of Violence $\quad 156$

Table 4.4: The Probability of Experiencing Violence - Age Only 157

Table 4.5: The Severity of Violence - Age Only 158

Table 4.6: The Probability of Experiencing Violence - Relationship Length 159

Only

Table 4.7: The Severity of Violence - Relationship Length Only 160

Table 5.1: Resource Type and Resistance $\quad 170$

Table 5.2a: Characteristics of Women Using Particular Resistance 179

Strategies

Table 5.2b: Education Profile of Women Using Particular Resistance $\quad 180$

Strategies

Table 5.3: Transition Homes and Shelters in Canada

189 
$\begin{array}{ll}\text { Chart 5.1: Strategy Usage } & 177\end{array}$

Chart 5.2a: Reasons for Not Using Public Services $\quad 185$

Chart 5.2b: Reasons for Not Using the Police 186

List of Figures $\quad \underline{\text { Page }}$

Figure 1.1: Continuum of Violence $\quad 20$

Figure 1.2: Continuum of Resistance $\quad 24$

Figure 2.1: A Two-Person Cooperative Nash Bargaining Game 52

Figure 2.2: RKS vs. Nash $\quad 54$

Figure 2.3: A Two-Person Cooperative Game: The Raiffa-Kalai- 55

Smorodinsky Solution

Figure 2.4: The Effects of Violence 1: Fallback Positions Decrease 59

Figure 2.5: The Effects of Violence 2: Total Household Well-Being Falls $\quad 61$

Figure 2.6: Comparison 1: Households with High Gains from Cooperation $\quad 63$

Compared to Households with Low Gains from Cooperation

Figure 2.7: Comparison 1, continued: The Effects of Shifting Fallback 64

Positions

Figure 2.8: Comparison 1, continued: The Effects of Shifting Fallback 65

Position and WPF

Figure 2.9: Comparison 2: Households with Male Breadwinners Compared 66

to Households with Female Breadwinners

Figure 2.10: Comparison 2, continued: The Effects of Shifting Fallback $\quad 66$

Positions

Figure 2.11: Comparison 2, continued: The Effects of Shifting Fallback

Position and WPF

Figure 3.1: $\mathbf{T}_{0}$ : A Two-Person Cooperative Game with Outside Options $\quad 96$

Figure 3.2: $T_{1}$ : The Effects of Violence 1: Female Fallback Position and 101

Voice Decrease

Figure 3.3: $\mathbf{T}_{2}$ : The Effects of Violence 2: Total Gains from Cooperation

Fall

Figure 3.4: $T_{3}:$ The Effects of Police Intervention 108

Figure 3.5: $T_{3}$ : Resistance with Non-Binding Outside Options and 111

Cooperation

Figure 3.6: $T_{3}$ : Resistance with Non-Binding Outside Options and Non- 112

Cooperation

Figure 5.1: Resistance and Resource Profile

Figure 5.2: The Political Economy of Anti-Wife Abuse Policy 195 


\section{CHAPTER 1:}

\section{WIFE ABUSE, RESISTANCE AND PUBLIC POLICY IN CANADA: AN INTRODUCTION}


How does public policy influence wife abuse? Underlying this question is the assumption that abusive relationships are dynamic, not static, thus implicating an interface between macro- and micro-structural forces that shape and are shaped by individuals within households. On the macro-level, state, market, and social forces must be considered in creating the conditions for violence, all of which are underlined by public policies. On the micro-level, the ways in which individuals in couples interact with each other must be considered. If it is true that violence is dynamic, then it is not enough to view the ways in which male behaviour responds to state interventions, or lack thereof. The ways in which women respond to abuse must also be explored, not to blame them, but rather to consider the effectiveness of policy in helping women live a life without violence.

Emphasis on women's responses to violence has only recently appeared in the literature on wife abuse. ${ }^{1}$ Most of these studies have documented women's experiences

${ }^{1}$ See L.H. Bowker, Beating Wife Beating (Lexington, MA: Lexington Books, 1983); E.W. Gondolf and E. R. Fisher, Battered Women as Survivors: An Alternative to Treating Learned Helplessness (Lexington, MA: Lexington Books, 1988); L.A. Hoff, Battered Women as Survivors (London: Routledge, 1990); A. Sev'er, Fleeing the House of Horrors: Women Who Have Left Abusive Partners (Toronto: University of Toronto Press, 2002); A.L. Horton and B.L. Johnson, "Profile and Strategies of Women who have Ended Abuse," Families in Society 74:8 (1993) 481-492; L. Goodman, M.A. Dutton, N. Vankos, K. Weinfurt, "Women's Resources and Use of Strategies as Risk and Protective Factors for Reabuse over Time," Violence Against Women 11:3 (March 2005) 311-336; C. Kaukinen, “The Help-Seeking Strategies of Female Violent-Crime Victims: The Direct and Conditional Effects of Race and the Victim-Offender Relationship," Journal of Interpersonal Violence 19:9 (September 2004) and "The Help-Seeking of Women Violent Crime Victims: Findings from the Canadian Violence Against Women Survey," International Journal of Sociology and Social Policy 22:7/8 (2002). 
as they cope with violence, giving voice to a group of women who had earlier been characterized by "learned helplessness". Early work by Bowker (1983) and Gondolf and Fisher (1984) illuminated the typologies of resistance strategies available to abused women, challenging the assumption that abused women lack social agency. Gondolf and Fisher (1988: 3) write, "We suggest that battered women demonstrate tremendous resiliency, persistence, and strength which press for a less pathological orientation to 'victims'." Following these works, Hoff (1990) revealed the importance of embedded values and norms in social networks, especially families, in helping women escape abusive relationships. Similarly, Sev'er's (2002) study of Canadian women documented the experiences of women as they left violent households. A number of studies have examined the role of women's resources in influencing women's resistance efforts, especially particular services such as the criminal justice system and transition homes. ${ }^{3}$

No study, however, has attempted to examine the impact of a particular policy regime on fostering or hindering women's resistance. A policy regime is simply an

${ }^{2}$ L. Walker, The Battered Woman (New York: Harper Collins, 1979). For a general discussion on the implications of the battered women's syndrome, see E. Connack, "Do We Need to Syndromize Women's Experiences? The Limitations of the "Battered Woman Syndrome," in Violence Against Women: New Canadian Perspectives, K.M.J. McKenna and J. Larkin (eds.), (Toronto: Ianna Publications, 2002) 277-284.

${ }^{3}$ Goodman et al (2005); D. Ford, "Prosecution as a Victim Power Resource: A Note on Empowering Women in Violence Conjugal Relationships," Law \& Society Review 25:2 (1991); J.E. Ursel, "Mandatory Charging: The Manitoba Model," Unsettling Truths: Battered Women, Policy, Politics and Contemporary Research in Canada, eds. K. Bonneycastle and G.S. Rigakos (Vancouver: Collective Press, 1998); A. Farmer and J. Tiefenthaler, "Domestic Violence: The Value of Services as Signals," American Economic Review 86:2 (1996). 
overarching framework, including the institutions, practices, and ideologies, giving shape to particular policy outputs. The goal of this dissertation is to speak to this gap, by illuminating the ways in which particular policies (or lack thereof), and the norms and assumptions underlying them, shape the experiences, the "lived effects", of abused women in key ways. ${ }^{4}$ The analysis is situated within a political economy framework, which, in the context of wife abuse, refers to the role of both economic and social resources, as they are (re)produced and distributed by states, markets, and families, in creating the conditions for violence and its resistance. Central to this perspective is uncovering who does and does not benefit from particular policies, how, and why. Working under the assumption that women resist, it will be demonstrated that women's resistance, or lack thereof, is not a question of women's agency, but rather a question of public policy.

Doing this requires an overview of the Canadian anti-wife abuse policy framework to first consider the types of policies in place, and then an exploration of the explicit and implicit values, norms, ideologies and interests upon which the policies are premised. Core concepts guiding this study and an outline of the dissertation will follow.

\section{CANADA'S ANTI-WIFE ABUSE POLICY FRAMEWORK}

Since its inception in the 1980 s, the Canadian anti-wife abuse policy framework has changed very little. ${ }^{5}$ Before wife abuse gained official recognition from policy

\footnotetext{
${ }^{4}$ See C. Bacchi, Women, Policy and Politics: The Construction of Policy Problems (Sage Publications, 1999).

${ }^{5}$ Despite a shift in spending priorities, there has been very little qualitative change in the framework. For example, Burt and Mitchell (1998) observe that successive governments have renamed the issue, from "wife abuse" to "wife assault" to "family violence", and that each reflects different policy
} 
makers, transition homes had been operated since the 1970s by women's organizations, some of which were funded in part by the Women's Program housed within the Secretary of State, while others received funding through provincial programs supplemented by the Canada Assistance Plan, replaced by the Canada Health and Social Transfer in 1996, and other initiatives. ${ }^{6}$ But it would take nearly a decade for the issue to appear on the policy agenda after the publication of a report issued by the Canadian Advisory Council on the Status of Women (CACSW). Although at first the state was apathetic to wife battering, to the degree that male legislators laughed and jeered when the CACSW report was tabled, increasing public attention brought renewed seriousness to the issue, which by the end of the decade had been co-opted from grass-roots feminist organizations and institutionalized in the state. ${ }^{7}$ The result was that as women's voices were increasingly

priorities. For a discussion, see S. Burt and C. Mitchell, "What's in a Name?: From Sheltering Women to Protecting Communities," How Ottawa Spends 1998-99: Balancing Act: The Post Deficit Mandate, ed. L. Pal (Toronto: Oxford University Press, 1998) and M. Morrow, O. Hankivsky, and C. Varcoe, "Women and Violence: The Effects of Dismantling the Welfare State," Critical Social Policy Vol. 24:3 (2004).

${ }^{6}$ Burt and Mitchell (1998). Note that the CAP included funding arrangements for shelters, whereas the CHST gave more discretion to the provinces to allocate funds (Burt and Mitchell 1998: 279). Under the Martin Liberals, the CHST was subsequently split into two separate transfers: the Canada Health Transfer and the Canada Social Transfer.

${ }^{7}$ See A. Levan, "Violence Against Women" Women and Public Policy in Canada, ed. Janine Brodie (Toronto: Harcourt Brace, 1996) 329; and M. Eliasson and C. Lundy, "Organizing to Stop Violence Against Women in Canada and Sweden," Women's Organizing and Public Policy in Canada and Sweden, eds. L Brisken and M. Eliasson (Montreal: McGill-Queen's University Press, 1999). See G. Walker, “The Conceptual Politics of Struggle: Wife Battering, the Women's Movement and the State," Studies in Political Economy 33 (Autumn 1990). Reprinted in Studies in Political Economy: Developments in 
marginalized, wife abuse became less about patriarchal structures giving rise to violence and more about individual pathology or deviance within families. ${ }^{8}$ The gender-neutral language dominating policy discourse further masked the social conditions giving rise to violence. ${ }^{9}$

Canada's anti-wife abuse policy framework includes inputs from federal, provincial and territorial, and municipal levels of government. It is governed simultaneously by two policy regimes, criminalization and public health, and includes both targeted and general policies and legislation, summarized in Table 1.1. Criminalization emerged during the 1980s from the dialogue between feminists, calling for protection from male violence, and professionals, calling attention to deviance within

Feminism, eds. C. Andrew, P. Armstrong, H. Armstrong, W. Clement, and L. Vosko (Toronto: Women's Press, 2003) for an excellent analysis of the process through which wife abuse gained recognition from policy makers. Walker describes the ways in which the issue was co-opted from feminist organizations by professionals, resulting in a conceptualization of wife abuse as an individual problem rather than a structural one, and the ways in which the state responded. In effect, this work contains an excellent discussion of the ways in which problems get named, resulting from political struggle, and represented in public discourse.

${ }^{8}$ J. Barnsely, "Feminist Action, Institutional Reaction," Resources for Feminist Research 17, 3 (1988); and Levan (1996).

${ }^{9}$ Ibid., See also Walker (1990). The use of gender neutral language was largely advocated by liberal feminists, who insisted on formal equality as a necessary prerequisite for substantive equality. The position taken here is akin to radical and Marxian traditions, in which formal equality is recognised as necessary but not sufficient for substantive equality, pointing instead to institutional and structural changes that are also required. 
families. ${ }^{10}$ In addition to amending section 244 of the Criminal Code, which identifies common assault, the criminalization of abuse is complemented by pro-arrest and proprosecutorial policies for the police and the crown. Similar policies have been adopted by provincial police and courts, as well as by many municipal police departments.

\section{Table 1.1:}

\section{Wife Abuse Policy in Canada}

The criminalization regime also includes alternative justice measures, such as community-level restorative justice projects, and a variety of victim's services accessible through the police or the courts, including programs to deal with compensation and remedies, batterer intervention, and family treatment. ${ }^{11}$ Several provinces have also initiated domestic violence courts to deal specifically with abuse cases. ${ }^{12}$ While criminalization represents an important symbolic shift in societal views toward wife abuse, many argue that it neglects the social context in which abuse occurs. ${ }^{13}$

${ }^{10}$ Walker (1990).

${ }^{11}$ For an overview of these services, see Federal-Provincial-Territorial Ministers Responsible for Justice. Spousal Abuse Policies and Legislation: Final Report of the Ad Hoc Federal-ProvincialTerritorial Working Group Reviewing Spousal Abuse Policies and Legislation (National Clearinghouse on Family Violence, Ottawa, Canada, 2003).

12 Ibid.

${ }^{13}$ For excellent critiques of the criminalization regime and institutionalization of violence, see Barnsley (1988); B. Snider, "Struggles for Social Justice: Criminalization and Alternatives," Unsettling Truths: Battered Women, Policy, Politics and Contemporary Research in Canada; Currie (1993) and Gotell (1998); D. Martin and J.Mosher, "Unkept Promises: Experiences of Immigrant Women with the Neo-Criminalization of Wife Abuse," Canadian Journal of Women and the Law 8 (1995); L. Lakeman, "Why 'Law and Order' Cannot End Violence Against Women; and Why the Development of Women's (Social, Economic and Political and Civil) Rights Might," Canadian Woman Studies October (2000) for an 
Unlike criminalization, the public health regime attempts to uncover the social conditions giving rise to violence by emphasizing prevention over treatment. ${ }^{14}$ The Health Promotion and Protection Branch of Health Canada houses the National Clearinghouse on Family Violence, established in 1982, which promotes the education and awareness of abuse. And as a result of an emerging discourse of "risk management", it also offers information for identifying "at-risk" individuals and families. ${ }^{15}$ In addition, since 1992, the Alliance of Canadian Research Centres on Violence, a network of five research centres throughout Canada, has coordinated research and partnerships, encouraging dialogue between academics, professionals, and front-line workers. While the public health regime emphasizes prevention over treatment, to date, the bulk of public monies have been spent on research, a trend observed by Burt and Mitchell (1998) which simply removes money from service provision, meaning less money for women in need.

The objectives of the anti-violence policy framework are twofold in character, attempting on one hand to deter violence and on the other hand to offer emergency protection to victims. To date, there is considerable debate about the efficacy of

excellent critique of the criminal justice system. See G. Walker (1990) and C. Bacchi (1999) for a discussion regarding the implications of naming particular social problems. Also, for a literature review of the feminist response to mandatory charging see T. Brown, Charging and Prosecution Policies in Case of Spousal Assault: A Synthesis of Research, Academic and Judicial Responses, Final Report. Rr2001-5e (Department of Justice Canada. Ottawa, Canada, 2000).

${ }^{14}$ For a discussion, see L. MacLeod and D. Kinnon, "Taking the Next Step to Stop Woman Abuse: From Violence Prevention to Individual Family, Community and Societal Health," Family Violence Prevention Division, Health Canada, Ottawa, Canada, 2000.

${ }^{15}$ See Bacchi (1999) for an analysis of the discourse on risk. 
Canada's anti-violence response among academics, field workers and survivors of abuse. ${ }^{16}$ For example, evidence of deterrent effects is mixed. In Canada, a study conducted by Jaffe et al (1991) in London, Ontario found that the implementation of procharge and pro-arrest policies was met by a decline in levels of violence. This corroborated the findings of a similar study conducted by Sherman and Berk (1984) in Minneapolis, Minnesota. On the other hand, Plecas et al (2000), analyzing the impact of such policies in British Columbia, found no conclusive results to support the presence of deterrent effects. Furthermore, Tauchen et al (1995), an American study using the same data as the Sherman and Berk study, found that while there were short term declines in re-offence rates, there were no significant declines in the long term.

In addition to the debate about deterrent effects, a number of studies question the ability of the Canadian system to protect women from violence. ${ }^{17}$ Part of the problem is limited access to wife abuse services, including both the criminal justice system and shelters, which varies by geography, race, class, ability and sexuality. ${ }^{18}$ Wife abuse, and

\footnotetext{
${ }^{16}$ See Brown (2001) for a review of the literature.

${ }^{17}$ See Lakeman (2000) and Burt and Mitchell (1998). For a comparative analysis, see Bacchi
} (1999).

${ }^{18}$ For discussions of race and geography on access to social services, see the following: $\mathrm{H}$. Bannerji, "A Question of Silence: Reflections of Violence Against Women in Communities of Colour," Violence Against Women: New Canadian Perspectives, eds. K.M.J. McKenna and J. Larkin (Toronto: Inanna Publications and Education Inc., 2002); D.J. Forsdick Martz, and D. Bryson Saraurer, "Domestic Violence and the Experiences of Rural Women in East Central Saskatchewan," Violence Against Women: New Canadian Perspectives; J. Hornosty, "Wife abuse in rural regions: structural problems in leaving abusive relationships (a case study in Canada)," With a Rural Focus, ed. F. Vanclay (Wagga Wagga, Australia: Charles Sturt University, Centre for Rural Social Research, 1995); T. Logan, L. Evans, E. 
indeed domestic violence in general, is a crime like no other. Women in abusive relationships are often in a precarious position, where they are often reliant on their abusers for financial support, help in child-rearing, and even love and emotional support. It is often difficult for women to establish and maintain "autonomous households", 19 especially when children are present, creating a tension for women wanting the violence the end, on the one hand, and having their means of support removed from the home, on the other hand. Even where women are employed in the paid economy, the link between divorce and women's poverty is irrefutable. ${ }^{20}$ Furthermore, shelters, if accessible, are often limited in capacity and as a result, can offer only short-term relief to women escaping violent partners. ${ }^{21}$

Stevenson, and C. Jordan, "Barriers to Services for Rural and Urban Survivors of Rape," Journal of Interpersonal Violence 20:5 (May 2005); D. Martin and J. Mosher (1995); and M.R. Yoshioka and D.Y. Choi, "Culture and Interpersonal Violence Research: Paradigm Shift to Create a Full Continuum of Domestic Violence Services," Journal of Interpersonal Violence 20:4 (April 2005).

${ }^{19}$ A. Orloff, "Gender and the Social Rights of Citizenship: The Comparative Analysis of Gender Relations and Welfare States," American Sociological Review 58:3 (1993).

${ }^{20}$ See Lorraine Davies et al, “Social Policy, Gender Equality and Poverty," Status of Women Canada (Ottawa: 2001); Wanda Weigers, "The Framing of Poverty as 'Child's Poverty' and its Implications for Women," Status of Women Canada, 2002, available at http://www.swc-cfc.gc.ca/; and Clarence Lockhead and Katherine Scott, "The Dynamics of Women's Poverty in Canada," Status of Women Canada (Ottawa: 2000).

${ }^{21}$ See Ontario Association of Interval and Transition Homes, "Locked In, Left Out: Impacts of the Budget Cuts on Abused Women and their Children," Violence Against Women: New Canadian Perspectives, for a discussion of the impact of budget cuts on abused women in terms of victims services. For a discussion of various access barriers, see D.J. Forsdick Martz and D. Bryson Saraurer (2002); J. Hornosty (1995); and Logan et al (2005). See also H. Bannerji, “A Question of Silence: Reflections of 
Making this worse, state restructuring and priority given to criminalization has meant less money for these services. ${ }^{22}$ In addition, fear of spousal retribution and loss of income, as well as social stigma often prevent women from calling the police or escaping to a transition home. ${ }^{23}$ Pro-charging and pro-prosecution policies intensify this fear for at least two reasons. First, the removal of the man from the home, even temporarily, usually means a large reduction in family income. Second, releases due to bail and short sentences perpetuate the fear of retribution. ${ }^{24}$ Ignoring these crucial social conditions

Violence Against Women in Communities of Colour," Violence Against Women: New Canadian Perspectives; J. Vickers, "Thinking About Violence," Gender, Race, and Nation: A Global Perspective, eds. V. Dhruvarajon and J. Vickers (Toronto: University of Toronto Press, 2002); and E.D. La Rocque, "Violence in Aboriginal Communities," Violence Against Women: New Canadian Perspectives.

${ }^{22}$ Morrow et al (2004) and Burt and Mitchell (1998).

${ }^{23}$ K. Makin, Kirk, Globe and Mail, January 11, 2003; D. Elliott "Criminal Justice Procedures in Family Violence Crimes," Family Violence, eds. L. Ohlin and M. Tonry (Chicago: University of Chicago Press, 1989); and D. Martin and J. Mosher, "Unkept Promises: Experiences of Immigrant Women with the Neo-Criminalization of Wife Abuse," Canadian Journal of Women and the Law 8 (1995) 3-44. Burt and Mitchell (1998) and Vickers (2002) note that First Nations women, immigrant women, and women of colour are less likely to call the police.

${ }^{24}$ Dugan et al conducted a study on the impact of domestic abuse policies on rates of femicide. They discovered that where there was no cool down period, rates of femicide were significantly higher, suggesting retaliation. Similarly, women are much more likely to be murdered by their partners during a separation. See L. Dugan, D.S. Nagin, and R. Rosenfeld, "Exposure Reduction or Retaliation? The Effects of Domestic Violence Resources on Intimate-Partner Homicide," Law \& Society Review 37:1 (2003). Also refer to M. Wilson and M, Daly, "Spousal Homicide Risk and Estrangement," Violence and Victims, 8 (1993) and M. Dawson, Examination of the Declining Rates of Intimate Partner Homicide Rates: A Literature Review, Rr2001-10e (Ottawa: Department of Justice Canada, 2001). 
raises questions about the extent to which criminalization and existing social services can protect women from abuse.

\section{REPRESENTING (ABUSED) WOMEN}

When these policies are analyzed from the perspective of women's resistance, the defining elements of the policy framework are revealed. In 2003, the federal government introduced new legislation to protect women from violent partners. The new program, entitled the New Identities Program, would be analogous to the Witness Protection Program, allowing women and their children to obtain new identities and relocate, living a life away from their abuser. The ad hoc multilateral program is governed by the RCMP, the Canada Revenue Agency, and Human Resources and Skills Development Canada. To date, more than 200 women and their families have entered the program. ${ }^{25}$ The New Identities Program on the surface appears to be an extreme solution for women facing extreme violence. But in the context of the anti-violence policy framework, the program is not qualitatively different from previously existing policies and programs. Like criminalization and the shelter system, it offers protection through separation. The goal, then, of the policy framework, is not ending violence, but rather encouraging women to leave. Before the implications of this are considered, what undergirds this framework should be considered.

Emerging at the height of neo-liberal doctrine in Canada, official public policy has always emphasized the individualist nature of violence against women rather than the systemic conditions that give rise to it in the first place. The institutional and ideological

\footnotetext{
${ }^{25}$ Attempts to interview representatives from the Royal Canadian Mounted Police, Canada
} Revenue Agency, and Human Resources and Skills Development Canada were declined. 
underpinnings of the framework reveal a number of operating assumptions. First, it assumes that once the woman has left her abuser the violence ends, which has a limited empirical basis. Leaving often triggers the onset or the escalation of abuse, with $20 \%$ of women reporting that abuse began when she attempted to leave and $35 \%$ reporting that violence increased when she attempted to leave. ${ }^{26}$ Further, risk of femicide increases significantly upon separation. ${ }^{27}$ Obviously, leaving often fails to offer a protective alternative to abused women.

The second assumption is that women lack agency, revealing the insidious ways in which ideologies about gender have shaped the state's responses to violence. Gotell's (1998) critique of the Canadian Panel on Violence Against Women and its subsequent report is illustrative. She writes,
In assigning ontological primacy to violence as the essence of gender relations, the Report radically simplifies social complexity and works to create a climate of sexual fear. In collapsing gender inequity into the absorptive category "violence against women," a whole range of issues related to the systemic discrimination are subsumed. Through the Report's narrative, women become victims lacking political agency and victimization is constituted as a new condition of social entitlement. ${ }^{28}$

This has had important implications for public policy development in Canada. Procharge and pro-prosecution policies were initiated to prevent women from dropping

\footnotetext{
${ }^{26}$ Statistics Canada, Canadian Violence Against Women Survey (Ottawa, Canada, 1993).

${ }^{27}$ Wilson and Daly (1993).

${ }^{28}$ L. Gotell, "A Critical Look at State Discourse on "Violence Against Women": Some
} Implications for Feminist Politics and Women's Citizenship," Women and Political Representation in Canada, eds. Manon Tremblay and Caroline Andrew (Ottawa: University of Ottawa Press, 1998) 41. 
charges and returning to their partners. ${ }^{29}$ It was feared that women, guided by emotion, not rationality, would fail to prosecute their partners, leading many officials to ask, "Why does she stay?" and in turn use this question to guide policy development. ${ }^{30}$

Such a question is problematic for a number of reasons. First, it implicitly places the onus of ending violence on women rather than the state, which reinforces the publicprivate dichotomy that has served to protect the concept of "family" from radical transformation. ${ }^{31}$ In doing so, it also absolves men of responsibility for ending violence, signifying the tendency at the social level to blame women for their predicament. Second, it implies not only that there are opportunities to leave, but also that leaving is a one-shot incident. Rather, leaving is the outcome of a long process in which various

${ }^{29}$ See the FPT Working Group Final Report (2003), where they note that one of the objectives of such policies is to remove responsibility and blame for reporting abuse.

${ }^{30}$ A number of academic works have also been driven by this question. See C.A. Faver and E.B. Strand, “To Leave or to Stay? Battered Women's Concern for Vulnerable Pets," Journal of Interpersonal Violence 18:12 (2003) 1367-1377; O.W. Barnett, "Why Battered Women do not Leave, Part 2: External Inhibiting Factors - Social Support and Internatl Inhibiting Factors," Trauma, Violence, \& Abuse 2:1 (2001) 3-35; J. Hornosty, "Wife Abuse in Rural Regions: Structural Problems in Leaving Abusive Relationships (a case study in Canada)," in With a rural focus, F. Vanclay (ed.) (Waga Waga, Australia: Charles Sturt University, Centre for Rural Social Research, 1995) 21-33.

${ }^{31}$ See Morrow et al (2004); K.A. Kelly, Domestic Violence and the Politics of Privacy (Ithaca: Cornell University, 2003); Barnsely (1988) for discussions of the public-private divide and violence. For a discussion on the family more generally in this context see C. Pateman, The Sexual Contract (Stanford, CA: Stanford University Press, 1988) and M. Marx Ferree, "Beyond Separate Spheres: Feminism and Family Research," in Journal of Marriage and the Family 52:4 (Nov. 1990). 
resistance strategies are tried and discarded. In addition, many women feel compelled to return to their abusers due to social and economic circumstances.

Finally, such a question is problematic because it constructs resistance only as departure from the household, falsely dichotomizing women who leave as resisters and women who stay as victims. Where women stay, they either do so by "choice", from which it is inferred that the abuse they experience is not bad enough to leave, or by "helplessness", in which case exit becomes the desired outcome.

The implications of this are significant when it is considered who benefits from public policy. Since policy is designed to encourage women to leave, where it is assumed that violence ends when she departs, once they do so, they are defined away from the policy framework. They no longer need "protection." However, welfare state restructuring in the areas of social assistance and legal aid limit the degree to which women can live independently of their partners. ${ }^{32}$ In addition, the state's limited ability to deal with stalking and criminal harassment, especially where children are involved, has long-term implications for women's ability to live without abuse, even when she does leave. ${ }^{33}$ Similarly, unless women want to (and can) leave, there is little "protection" through the state. Indeed, most intervention and treatment programs, which would enable the relationship to remain intact, are accessible only through the criminal justice system,

32 Morrow et al (2004).

${ }^{33}$ R. Gill and J. Brockman, "A Review of Section 264 (Criminal Harassment) of the Criminal Code of Canada (Ottawa: Department of Justice Canada, 1996). The study identifies several issues emerging from the implementation of section 264. In particular, the authors found that although police and prosecutors frequently use the legislation, more than half of the cases were withdrawn or stayed before trial and only a quarter of those reaching trial received a jail term (vii). 
which requires separation. ${ }^{34}$ Instead, Canada's anti-wife abuse policy framework is premised on the assumption that all women can and should leave. Never is it considered that women might not want to leave or that they simply cannot, due to social and/or economic constraints.

What this reveals is that potentially very few women actually benefit from public policy. Unless women want to and can leave, there are very few measures in place to ensure that they can live without violence. These women have simply been defined away from the policy framework. From this perspective, there is a very obvious answer to the question guiding policy development in Canada: Women must be better off, or at least perceive themselves to be better off, within the relationship than outside of it, suggesting constraints external to the relationship influencing women's resistance to violence. Rational choice theorists assert that agents choose the options that maximize utility. But while rational choice might ensure that agents are "better-off" this is not necessarily sufficient to ensure that agents are "well-off." Where individuals have a very limited or undesirable set of options, shaped by age, race, gender, abililty, etc., it is not clear that any choice will make them well-off. The problem, then, is not necessarily with the choices that women make, but rather the alternatives made available to them by states, markets, and families.

\section{RETHINKING AGENCY, POWER AND RESISTANCE}

There is considerable debate about the determinants of wife abuse, ranging from individualistic, pathological explanations to structuralist accounts. ${ }^{35}$ Early feminist

\footnotetext{
34 FPT Working Group Final Report (2003).

${ }^{35}$ See Sev'er (2002) and Vickers (2002) for overviews of theories of violence.
} 
explanations rooted abuse in patriarchy, a tool of oppression. ${ }^{36}$ Third wave scholars, however, emphasized the complexity of oppression, demonstrating the important intersections of class, race, gender, sexuality, nationality, etc., and therefore the existence of multiple masculinities and femininities. ${ }^{37}$ Wife abuse came to be seen not only as an instrument of patriarchy, but as an instrument (and abuse) of power, as determined by various axes. ${ }^{38}$

As a concept, abuse, an instrument of "power", includes household violence between both parents and parents and offspring, and institutional, cultural, and state violence. This "continuum of violence" reveals violence as a power resource, where power is derived from political economic relations. ${ }^{39}$ Thus, any discussion of violence implicates a discussion of power. ${ }^{40}$ What is it and from where does one get it?

\footnotetext{
${ }^{36}$ For an overview of this literature, see Sev'er (2002), pp. 51-58.

${ }^{37}$ For example, see b. hooks, Feminist Theory: From Margin to Center, $2^{\text {nd }}$ ed.( Cambridge, MA:
} South End Press, 2000); K. Crenshaw, Mapping the Margins: Intersectionality, Identity Politics, and Violence Against Women of Colour," Stanford Law Review 43:6 (1991); N. J. Sokoloff and I. Dupont, "Domestic Violence at the Intersections of Race, Class, and Gender: Challenges and Contributions to Understanding Violence Against Marginalized Women in Diverse Communities," Violence Against Women 11:1 (2005); L. McCall, "The Complexity of Intersectionality," Signs 30:3 (2005). Also important here is I.M. Young, Justice and the Politics of Difference (New Jersey: Princeton, 1990).

\footnotetext{
${ }^{38}$ Ibid. Also, see Vickers (2002).

${ }^{39}$ To suggest that violence is a power resource is not to be confused with power resource theory,
} as articulated by W. Goode, "Force and Violence in the Family," Journal of Marriage and the Family 33:4 (1971). Power resource theory offers a particular hypothesis to explain violence - that violence will be used when other power resources are low. However, there are several other explanations, including feminist and exchange theory, for example, that also consider violence as a power resource. Thus, power 
Power is often defined in terms of influence or the ability to impose one's will on another. ${ }^{41}$ In this conceptualization, power is determined by several elements, including economic (financial endowments and education), political (official rules), cultural (tradition), and personal (charisma) factors. Violence then becomes another way through which to gain and maintain influence over others.

This conceptualization is complicated somewhat when the motivations for violence are considered. Violence can be either expressive or instrumental. Expressive violence is motivated by affect. It is used where it is pleasurable or gratifying to do so; for example, when an individual channels feelings of frustration into abuse or engages in sadomasochism. In contrast, instrumental violence is used to impose a particular outcome, either behavioural or allocative. These distinctions are important analytically, since they have significant implications for the ways in which abuse is modeled, explained, and, ideally, prevented. For example, where instrumental violence is driven by resource acquisition, it can be potentially constrained by redistributing resources, which will have little impact on violence that is driven by affect.

\footnotetext{
resource theory is one theory in an entire family of political economic explanations of violence that attempt to explain violence in the context of power and resources.

${ }^{40}$ For a literature regarding feminist analysis of power, refer to A. Allen, The Power of Feminist Theory: Domination, Resistance, Solidarity (Boulder: Westview Press, 1999);

${ }^{41}$ See C. Kaukinen, "Status Compatability, Physical Violence, and Emotional Abuse in Intimate Relationships," Journal of Marriage and the Family 66 (2004) for a discussion of this in terms of resource theory and violence against women. For a more general discussion of the implications of this conceptualization of power, see Allen (1999).
} 
Despite these important distinctions, however, it is perhaps best to conceptualize the relationship between these motivations as a continuum rather than as dichotomous. For example, since not all individuals or states are violent, it is not arbitrary to assume that those who are experience some level of gratification or satisfaction from its use. In other words, even when violence is used instrumentally, it can have expressive effects. Similarly, expressive violence can have instrumental effects. By creating an environment of fear, abusers usurp control and dominate others. As a consequence, all violence, regardless of its motivation, is rooted in domination. ${ }^{42}$

Because of this relationship these motivations sit nicely with the concept of the continuum of violence, shown in Figure 1.1. Whether or not abuse takes place on individual (i.e, household) or collective (i.e., states, workplaces) levels, institutional configurations, including democratic versus dictatorial states, capitalism, patriarchy, etc., structure individual motivations for abuse through incentives and constraints. Since this study is primarily concerned with violence at the household level, the present discussion is situated in that context; however, it is important to keep in mind the linkages between the various locations of abuse. Thus the term "wife abuse" has been adopted for this study to capture the particular form of violence under analysis. ${ }^{43}$ The term "wife" refers to women in conjugal relationships, where a home is shared with her partner whether or not the couple is legally married or common-law. The term "abuse" refers to the harmful

\footnotetext{
${ }^{42}$ See S. Ruddick, "Injustice in Families: Assault and Domination," Justice and Care: Essential Readings in Feminist Ethics, ed. V. Held (Boulder: Westview Press, 1995) and Young (1990).

${ }^{43}$ Refer to Walker (1990) and Bacchi (1999) for excellent discussions on the importance of naming the problem of wife abuse. For an analysis of the policy implications of naming in Canada, see Burt and Mitchell (1998).
} 
nature of these relationships, where male behaviour is controlling, domineering, and, in many cases, physically violent. Unless otherwise noted, the term "violence" is used interchangeably with "wife abuse", capturing both psychological and physical abuse.

\section{Figure 1.1: \\ A Continuum of Violence}

Violence as an instrument of power has changed our thinking about violence, its motivations, causes, and its locations. But because of the narrow definition of power employed in these discussions, an unintended effect has been to obscure the power (and empowerment) of the oppressed. Where power was defined as the ability to impose one's will on another, by implication it was assumed that the oppressed were powerless. However, Foucault (1990: 95) wrote, "Where there is domination, there is resistance $[\ldots],{ }^{44}$ which inspired a reconceptualization of power by political economists and feminists alike. ${ }^{45}$

From this perspective, power is not simply the ability to impose one's will on another, but also capabilities and functionings. ${ }^{46}$ Capabilities refer to one's ability for

\footnotetext{
${ }^{44}$ I use this quotation for illustrative purposes only. I am not suggesting that my analysis of violence is compatable with Foucaultian analysis. See M. Foucault, The History of Sexuality, Volume 1: An Introduction (New York: Random House Inc., 1990).

${ }^{45}$ See J. Scott, Weapons of the Weak: Everyday Forms of Peasant Resistance (New Haven: Yale University Press, 1985); B. Agarwal, A Field of One's Own: Gender and Land Rights in South Asia (Cambridge: Cambridge University Press, 1993); and B. Agarwal, “'Bargaining' and Gender Relations: Within and Beyond the Household." Feminist Economics 3:1 (1997). See also Allen (1999) for an excellent discussion on power in feminist theory.

${ }^{46}$ Note that this reflects a particular conceptualization of power, "positive freedom", as articulated by capabilities theorists. See Agarwal (1993; 1997), A. Sen, "Gender and Cooperative Conflicts,"
} 
purposeful action, the ability to define one's goals and act upon them. ${ }^{47}$ They refer to all of the things one can do or be. Functionings, in contrast, result from one's capabilities, ranging from basic (health, food, etc.) to complex (self-esteem). ${ }^{48}$ They refer to all of the things one does or becomes. Acts such as nurturing, reflecting, and resisting are acts of power. In other words, as much as power can be negative, preventing someone from doing something or forcing someone to do something, it can also be positive, creating, reflecting and acting in various ways. ${ }^{49}$

Underlying this reconceptualization of power is a simultaneous reconceptualization of agency. ${ }^{50}$ Instead of the fully formed rational actor, agency includes much more than one's realized choices, as assumed in orthodox utilitarianism, and envelopes mechanisms of positive and informal power and indirect freedom. ${ }^{51}$ Both

Persistent Inequalities: Women and World Development, ed. I. Tinker (New York: Oxford University Press, 1990); M. Nussbaum and A. Sen (eds.), The Quality of Life (Oxford: Oxford University Press, 1993). Other feminist thinkers, however, have used similar concepts to decentre the negative definition of power. For examples, see Allen (1999); hooks (2000); E. Janeway, Powers of the Weak (New York: Morrow Quill, 1981).

${ }^{47}$ See D. Gasper and I. Van Staveren, "Development as Freedom - and as What Else?" Feminist Economics 9:2-3 (2003) 137-161 for a discussion and critique of this central principle.

${ }^{48}$ See V. Iverson, "Intrahousehold Inequality: A Challenge for the Capabilities Approach?"

Feminist Economics 9:2-3 (2003) 93-115 for a discussion

${ }^{49}$ hooks (2000).

${ }^{50}$ See R. Lister, Poverty (United Kingdom: Polity Press, 2004) for an excellent analysis of agency in sociology and political economy.

${ }^{51}$ Iversen (2003) and P. Pettit, "Capability and Freedom: A Defence of Sen," Economics and Philosophy, 17:1 (2001). 
agency and power are relational, multifaceted and adaptive, shaped and constrained by social relations derived in the political economy. Following the approaches of Sen (1990), Agarwal (1993), Folbre (1996) and Bowles and Gintis (1993; 2001; 2002), agency becomes less about what one gets, and more about how one gets it. Kabeer (1999: 438) defines agency as:

[...] the ability to define one's goals and act upon them. Agency is about more than observable action; it also encompasses the meaning, motivation and purpose which individuals bring to their activity, their sense of agency, or "the power within." [...] It can take the form of bargaining and negotiation, deception and manipulation, subversion and resistance, as well as more intangible, cognitive processes of reflection and analysis.

A similar definition has been adopted by Agarwal (1997), for whom agency, and indeed resistance, is often covert and subtle, instead emphasizing external constraints preventing women from "acting overtly in their self-interest" such as fear, coercion and sex-role assignment (Agarwal 1997: 25).

When power and agency are reconsidered, it becomes clear that the power of women to overcome violence is considerable. In the context of wife abuse, women's resistance is a crucial, yet often neglected, side of the story. Noted above, it was previously thought that women lacked both power and agency. ${ }^{52}$ Early work on women's resistance began to challenge this assumption, observing the ways in which women respond and adapt accordingly, often strategically. ${ }^{53}$ Resistance then is not a question of women's agency, or lack thereof, but rather of the political economy. And if resistance is

\footnotetext{
${ }^{52}$ See L. Walker (1979) for a classic example.

${ }^{53}$ As noted above, see Bowker (1983) and Gondolf and Fisher (1988) for early discussions of women's resistance. More recently, see Hoff (1990), Ford (1991), Farmer and Tiefenthaler (1998), and Sev'er (2002).
} 
a question of the political economy, then it can be manipulated and fostered by public policy levers.

Resistance is any attempt to reduce or eliminate violence. A number of studies have documented the various ways in which women resist, ranging from intra-, inter-, and extra-household options. ${ }^{54}$ Intrahousehold strategies include activities such as compliance, deception, and retaliation. These are what Bowker (1983) would call "personal strategies". Interhousehold strategies include informal outreach and intervention, such as help-seeking from friends and family. Bowker's (1983) study focused on intra and inter-household strategies, exploring the effects of these strategies on levels of violence. Hoff's (1990) study focuses on the inter-household level, exploring the impact of norms and values among kin and peer groups in shaping women's responses to violence. Extra-household strategies include what Bowker (1983) would call "formal strategies", seeking help from formal service providers such as transition homes and shelters, counsellors, police intervention, separation, etc. Farmer and Tiefenthaler (1998) explored the role of social services in enabling women to "signal" to their partner's their intention to leave. Sev'er's (2002) insightful study documents the stories of women who eventually left their partners, emphasizing the importance of both inter- and extra-household options.

These studies reveal that, like violence, resistance can also take place at individual and institutional, or collective, levels, as demonstrated in Figure 1.2, and is perhaps best conceptualized along a continuum. It can include both "coping" and

${ }^{54}$ Ibid. 
"preventative/strategic" measures. ${ }^{55}$ Coping mechanisms at the individual level (intrahousehold) include, as examples, compliance and drug and/or alcohol abuse, whereas preventative/strategic acts include exposure reduction, police intervention, divorce or separation, and retaliatory physical violence. At the institutional level (extra-household), coping measures include community level support groups and information dissemination and strategic acts include service delivery and advocacy. As in the relationship between the motivations for violence, the line between these types of resistance is arguably blurred: coping measures might have strategic effects and vice versa. Similarly, while the focus of this study is on resistance at individual levels, it is important to acknowledge that this type of resistance can have implications for collective action and vice versa. This discussion, refining concepts of agency, power and resistance, illuminates considerable implications for public policy.

\section{Figure 1.2:}

\section{Continuum of Resistance}

\section{RETHINKING PUBLIC POLICY}

Underlying this discussion, and indeed previous studies of women's resistance, is the assumption that resistance works to constrain violence in some way. In other words, violence and resistance can be conceptualized as unity - they represent a dynamic process in which the acts of one influence the other. This complexity needs unravelling to be useful in a policy context. On the one hand, it is important to explore how a

\footnotetext{
${ }^{55}$ This terminology and the following continuum were inspired by Ruth Lister's (2004) similar analysis of agency in the context of poverty, as well as James Scott's (1985) analysis of peasant resistance. See J. Scott, Weapons of the Weak: Everyday Forms of Peasant Resistance (New Haven: Yale Univesrity Press, 1985.
} 
particular policy regime fosters or hinders women's resistance. For example, does the narrow construction of resistance as exit in Canada's anti-violence policy framework impose barriers on women as they attempt to resist abuse? If so, policy development and reform must attempt to eliminate these barriers by using the lens of women's resistance as it is shaped by factors such as ethnicity and culture, class, age, and (dis)ability.

On the other hand, it is important to consider which strategy works best at reducing or eliminating violence. Policy reform must not only eliminate barriers to resistance, but also ensure that all women, regardless of age, race or culture, etc., have access to effective strategies. The key here is not to force women to use particular strategies, but to give them a basis on which to credibly threaten their use. ${ }^{56}$ Doing so shifts the focus away from women as victims, acknowledging that the power of women is often constrained not by will but by conditions established within the political economy. In Canadian context, this requires a shift in policy goals, away from protection or getting women to leave towards prevention, which will enable women to live without violence.

This reform, however, is no easy task as every level of government in Canada has developed anti-violence policies and programs. Advocates of reform must consider this framework so as to avoid the disarticulation of policies and programs between various levels of government. Ideally, reform requires a comprehensive division of labour

\footnotetext{
${ }^{56}$ One can think here of designing policy to develop one's "capability" for resistance. Of key concern is the capability and the functionings it enables, not whether or not one actually uses it. For a brief discussion, see P. England and N. Folbre, "Reconceptualizing Human Capital," MacArthur Network on the Family and the Economy Working Paper, presented at the annual meetings of the American Sociological Association, Toronto, 1997. See also the collection of essays contained in Nussbaum and Sen (1993) and the special volume of Feminist Economics 9:2-3 (2003) for articulations of capabilities theory.
} 
implicating a strong role for both communities and governments. Communities can offer flexible, responsive programs, developed around the specific needs of constituents. Similarly, researchers are now beginning to pay attention to informal support systems, including family, friends, neighbours, etc., that help women resist violence, and are often developed at the community level. ${ }^{57}$ Thus, the role for government is not only to provide direct services and programs, but also to foster communities and community-based programs.

As a result, women would be less vulnerable to violence since their options outside the family provide the basis on which to credibly threaten the use of particular strategies, which itself will constrain violence. This does not require the actual use of particular strategies, but rather the ability to use them. In contrast, where outside alternatives are limited, higher levels of violence are expected due to the inability to credibly threaten divorce/separation, police intervention, etc. Thus, even where women do not want to dissolve the relationship, the ability to do so will offer her considerable leverage in negotiating levels of violence within the home.

\section{OUTLINE OF THE DISSERTATION}

The goal of the dissertation is to consider the ways in which Canadian public policy shapes women's resistance efforts. Before turning to an in-depth analysis of the role of public policy, the onset of violence and its effects are considered. In the following chapter, the conditions under which violence occurs and its impact on intra-household

\footnotetext{
${ }^{57}$ See S. Budde and P. Schene, "Informal Social Support Interventions and Their Role in Violence Prevention An Agenda for Future Evaluation," Journal of Interpersonal Violence 19:3 (March 2004); C. Kaukinen (2002); and Hoff (1990).
} 
power are examined, which informs the thinking in later chapters about the dynamics of abusive relationships. It is argued that household structure, including both the total gains from the relationship and relative status, gives rise to violence, which in turn disempowers women by reducing their position in the household. The model is informed by two streams of literature: intra-household bargaining and feminist resource theory. Intra-household bargaining models have been instrumental in broadening our understanding of family dynamics. ${ }^{58}$ Bargaining approaches allow space for agency without sacrificing structure, enabling researchers to assess the degree to which external factors condition relations within the household, and conversely, the ways in which household relations pattern relations outside the household.

This approach is not new to the domestic violence literature. ${ }^{59}$ Indeed, at the core of all exchange and resource theory is a bargaining problem. Debates among resource theorists concern the role of relative resources, where, on the one hand, some posit that increasing female status will decrease violence, and, on the other hand, others argue the opposite. ${ }^{60}$ Feminist interpretations of resource theory have integrated these tenets with

${ }^{58}$ For excellent reviews of this literature, refer to Agarwal (1997) and E. Katz, "The Intrahousehold Economics of Voice and Exit," Feminist Economics 3:3 (1997).

${ }^{59}$ See Farmer and Tiefenthaler (1996), "An Economic Analysis of Domestic Violence," in Review of Social Economy LV:3 (Fall 1997) 337-358, and "Explaining the Recent Decline in Domestic Violence," in Contemporary Economic Policy 21:2 (April 2003) 158-72; H. Tauchen, A. Dryden Witte, and S. Long "Domestic Violence: A Nonrandom Affair," International Economic Review 32:2 (1991) 491-511; and F. Bloch and V. Rao, "Terror as a Bargaining Instrument: A Case Study of Dowry Violence in Rural India," American Economic Review 92:4 (2002) 1029-43 for analyses of wife abuse using game theoretic models.

${ }^{60}$ See Goode (1971) for a classic articulation of resource theory. For those arguing the former, see Tauchen, Witte, and Long (1991), Farmer and Tiefenthaler (1996), and J. Kingston-Reichers, “The 
gender theory to explain male and female differentials in the use of violence. ${ }^{61}$ However, there are two problems with resource theory. First, it fails to adequately explore the relationship between household structure and abuse. Household structure includes both the total gains from the relationship and relative status. Resource theory, however, reduces household structure, and patterns of gender relations, to relative status. Clearly not all women are equally vulnerable to abuse, nor are all men equally likely to be violent. For example, are women in homes generating high gains from the relationship more or less likely to experience violence? It is argued here that the total gains from the relationship, as well as relative status, will be crucial determinants of violence.

This analysis constitutes just one element in the dynamics of abusive relationships. Women's resistance and the role of public policy in enabling women to respond effectively to abuse must also be considered. In chapter 3 , the analysis of abuse presented in chapter 2 is refined by allowing for resistance in the context of the Canadian

Association Between Socio-Economic Characteristics and the Frequency of Wife Assault," Working Paper Series, Department of Economics, McMaster University (1999). For those arguing the latter, see C.M. Allen and M.A. Straus, "Resources, Power, and Husband-Wife Violence," The Social Causes of HusbandWife Violence, eds. M.A. Straus and G.T. Hotaling (Minneapolis: University of Minnesota Press, 1980); M. Atkinson, T. Greenstein, and M. Monahan Lang, "For Women, Breadwinning Can be Dangerous: Gendered Resource Theory and Wife Abuse," Journal of Marriage and the Family 67 (2005) 1137-1148; K. Anderson, "Gender, Status, and Domestic Violence: An Integration of Feminist and Family Violence Approaches," in Journal of Marriage and the Family 59:3 (August, 1997); and L.A. McCloskey, "Socioeconomic and Coercive Power within the Family," in Gender and Society 10:4 (1996) 449-463 as examples.

${ }^{61}$ For examples of feminist applications of resource theory, refer to M. Atkinson, T. Greenstein, and M. Monahan Lang (2005); Anderson (1997); and McCloskey (1996). 
anti-violence policy framework. Within the policy sciences, two approaches have been particularly influential in our understanding of wife abuse: problem representation, inspired by the literature on the construction of social problems, and political economy. While problem representation approaches illuminate the ways in which particular problem representations construct the subject, political economy approaches, in contrast, emphasize the role of resource distribution in creating the conditions for violence. The analysis presented here integrates these two approaches, applying insights from a problem representation approach, as articulated by Bacchi (1999), to a feminist political economy framework, developed by Sen (1990) and Agarwal (1994; 1997), to elucidate the ways in which resistance is conceptualized in public policy and its implications for women. If the policy framework constructs subjects, i.e., resisters, in specific ways, what are the "lived effects" of this construction?" What does it mean for both those women who have been constructed as "subjects" and those who have been defined away from the framework? It is demonstrated that the current policy framework potentially exacerbates women's vulnerability to violence by imposing barriers on them as they attempt to resist abuse.

The hypotheses generated in chapters two and three are explored empirically in the remaining chapters. Using cycle 13 of the General Social Survey, conducted in 1999, in chapter four binary logit and tobit models are developed and applied to explore the role of household structure and exit options, as varied by age, race and culture, and ability, in determining a woman's vulnerability to abuse. The analysis reveals three areas for policy

\footnotetext{
${ }^{62}$ See Bacchi (1999)
} 
reform, including resource redistribution, targeting vulnerable groups, and transforming gender relations.

In chapter five, the GSS is used to explore women's patterns of resistance more specifically. In this chapter, hypotheses about the effects of the narrow construction of resistance on public service usage and strategy choice are tested. Using independent samples tests, it is revealed that the ways in which patterns of resistance are shaped by political economic determinants. This analysis leads to a discussion of policy reform, central to which is shifting the goal of policy away from getting women to leave towards ending violence. In addition to the three key areas of policy reform discussed in chapter 4, two additional areas are illuminated in this chapter: public service reform and community-level initiatives.

Using quantitative analysis raises some potential problems. Feminist methodology requires that the "subject" is privileged, listening to women's voices and experiences, which has led to a preference for qualitative methods including interviews, participant-observation, and histories. In contrast, quantitative methodology is premised on traditional philosophy of science, in which objectivity is key. This has a number of implications. First, it imposes a hierarchy on researchers and participants, antithetical to the feminist articulation of science. Second, this opens room for bias in both the construction of research questions and in their interpretation. Finally, it diminishes women's voices by revealing only statistical relationships. It does not in and of itself reveal causes and effects. Thus researchers are left to interpret the results through a particular theoretical lens. 
At the same time, however, feminist methodology is as diverse as feminist thought. There is no "feminist method" any more than there is a monolithic feminism. ${ }^{63}$ What is distinct about feminist analysis, according to Harding (1987: 6-10), is empirical and theoretical attention to women's experiences, women-centred research projects, and acknowledging the limits of objectivity. This project interprets women's experiences with abuse and resistance through a feminist lens, adapting and modifying existing theoretical and empirical frameworks to focus on women. In an attempt to dismantle the hierarchy of "science", both statistical and substantive significance are reported. Statistical significance reveals the likelihood of observing a particular relationship in any given population, whereas substantive significance measures the size of the effect. ${ }^{64}$ Most of all, it is not professed that this analysis discovers any one universal truth, but rather some interesting insights into the concept of women's resistance that can in turn offer insights into policy reform.

${ }^{63}$ See S. Harding, "Introduction: Is there a Feminist Method?" Feminism and Methodology, ed. S. Harding (Bloomington and Indianapolis: Indiana University Press, 1987); L. Thompson, "Feminist Methodology for Family Studies," Journal of Marriage and the Family 54:1 (1992): 3-18. For an overview of the feminist critique of quantitative methods, see A. Oakley, "Gender, Methodology and People's Ways of Knowing: Some Problems with Feminism and the Paradigm Debate in Social Science," Sociology 32:4 (1998): 707-731; G. Letherby, "Quoting and Counting: An Autobiographical Response to Oakely," Sociology 38:1 (2004): 175-189. For a review of recent debates in feminist epistemology and methodology, see Signs 30:4 (2005) New Feminist Approaches to Social Science Methodologies.

${ }^{64}$ For an excellent discussion on statistical and substantive significance in economics, see S. T. Ziliak and D. N. McCloskey, "Size Matters: The Standard Error of Regressions in the American Economic Review," Econ Journal Review 1:2 (2004). 
In sum, the goal is to stimulate dialogue on an issue that has only recently gained theoretical and empirical attention, illuminating the transformative potential of public policy to enable women to live without violence. In doing so, an agenda for policy reform is outlined, which begins with reorienting policy away from getting women to leave towards enabling women to live without violence. Adopting a much broader policy goal necessarily captures departure, but will also enable women to remain where they choose to do so. The focus on resistance is by no means intended to blame women for their situation or to place the onus of ending violence on them, but rather to deflect the blame that is implicitly placed on women through the policy framework. By revealing that women's resistance is an issue of public policy, not agency, the onus of ending violence shifts from women to the state. 
TABLE 1.1:

WIFE ABUSE POLICY IN CANADA

\begin{tabular}{|c|c|c|c|}
\hline \multicolumn{4}{|c|}{ Targeted (Core) Policies } \\
\hline $\begin{array}{l}\text { Justice } \\
\text { System }\end{array}$ & \multicolumn{2}{|c|}{ Social Services } & $\begin{array}{c}\text { Awareness } \\
\text { and Research }\end{array}$ \\
\hline $\begin{array}{l}\text {-Criminal Code } \\
\text {-Pro-arrest } \\
\text { Policies } \\
\text {-Pro-charge } \\
\text { Policies } \\
\text {-New Identities } \\
\text { Program } \\
\text {-Alternative } \\
\text { Measures } \\
\text {-Victim's } \\
\text { Services }\end{array}$ & \multicolumn{2}{|c|}{$\begin{array}{l}\text {-Transition } \\
\text { homes and } \\
\text { shelters } \\
\text {-Crisis lines } \\
\text {-Counselling } \\
\text { services } \\
\text {-Community } \\
\text { /family centres }\end{array}$} & $\begin{array}{l}\text {-NCFV } \\
\text {-Research } \\
\text { Centres on } \\
\text { Family } \\
\text { Violence }\end{array}$ \\
\hline \multicolumn{4}{|c|}{ General (Peripheral) Policies } \\
\hline \multicolumn{2}{|l|}{$\begin{array}{l}\text { Justice } \\
\text { System }\end{array}$} & \multicolumn{2}{|c|}{ Social Services } \\
\hline \multicolumn{2}{|c|}{$\begin{array}{l}\text {-Legal Aid } \\
\text {-Divorce legislation } \\
\text {-Child/Spousal Support } \\
\text { guidelines }\end{array}$} & \multicolumn{2}{|c|}{$\begin{array}{l}\text {-Social assistance } \\
\text {-childcare } \\
\text {-affordable housing } \\
\text {-language training } \\
\text {-programs for new } \\
\text { Canadians }\end{array}$} \\
\hline
\end{tabular}


FIGURE 1.1:

A CONTINUUM OF VIOLENCE

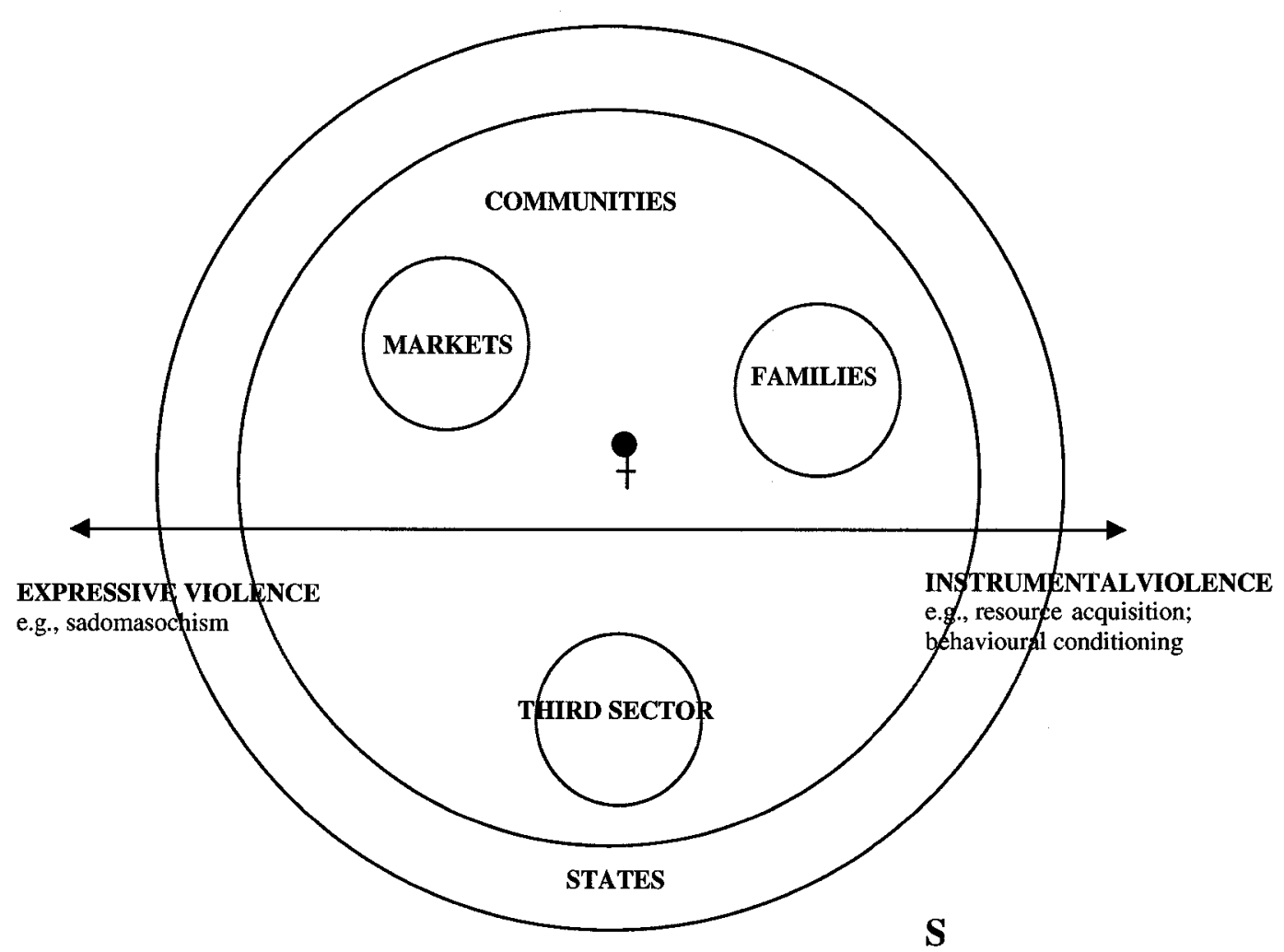


FIGURE 1.2:

\section{A CONTINUUM OF RESISTANCE}

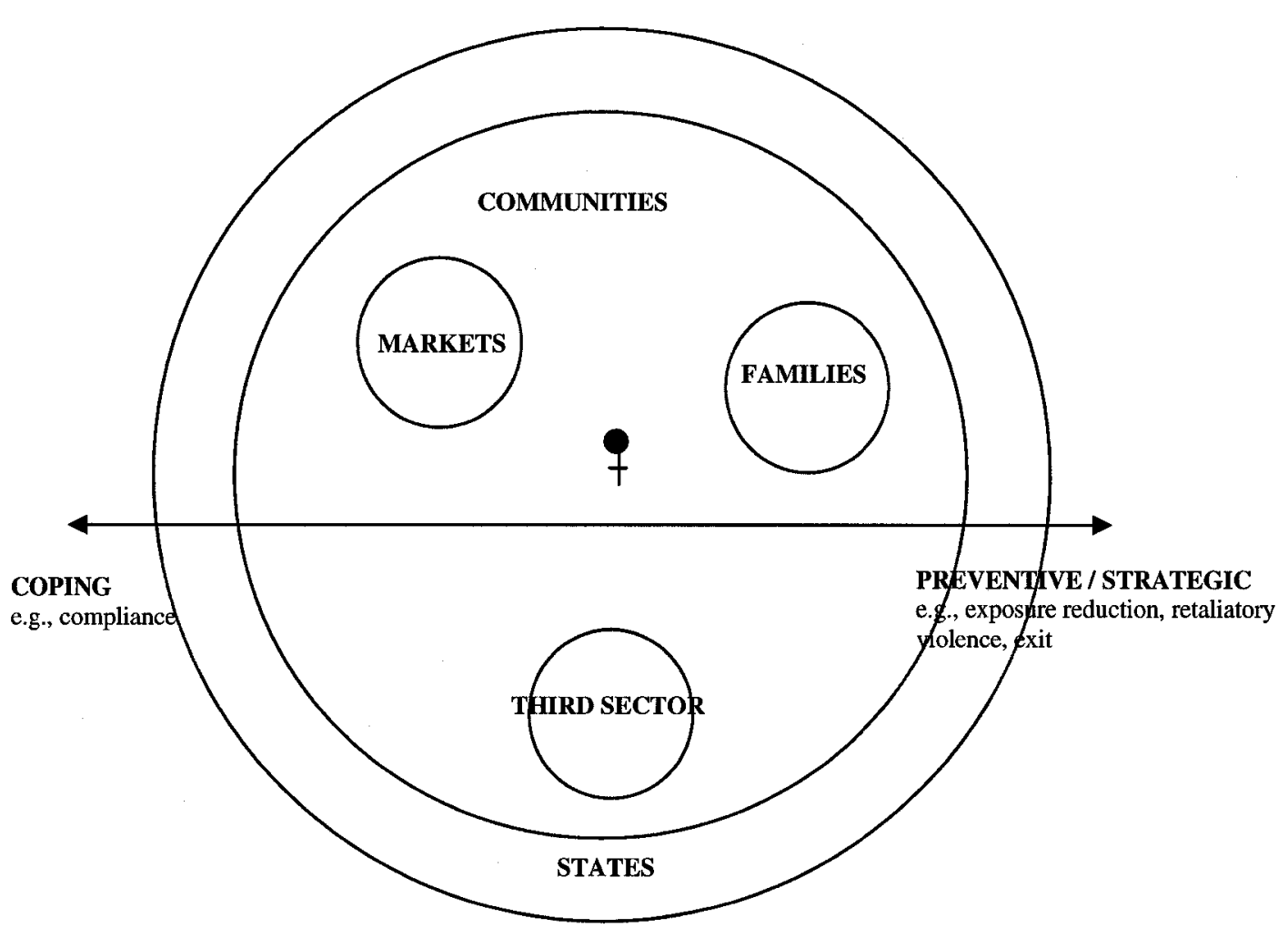




\section{CHAPTER 2:}

\section{VIOLENCE AND BARGAINING WITHIN FAMILIES: THE ROLE OF ABSOLUTE AND RELATIVE RESOURCES IN STIMULATING VIOLENT BEHAVIOUR}


The role of resources in creating the conditions for violence has stimulated considerable attention among academics. ${ }^{1}$ A key debate has emerged regarding the role of absolute household versus relative personal resources in the onset of abuse. On the one hand, frustration theory suggests that when absolute household resources are low, violence will be more likely. ${ }^{2}$ On the other hand, relative resource theorists argue that the relative position of each spouse is the crucial determinant of abuse. Within this particular school of thought there is disagreement over the direction of the relationship between female relative status and abuse. Some researchers argue that increasing female status will decrease abuse, ${ }^{3}$ while others posit the opposite effect. ${ }^{4}$ In this chapter, it is argued

\footnotetext{
${ }^{1}$ For excellent literature reviews of resource theory, see C. Kaukinen, "Status Compatability, Physical Violence, and Emotional Abuse in Intimate Relationships," Journal of Marriage and the Family 66 (2004) and L. Cubbins and D. Vannoy, "Socioeconomic Resources, Gender Traditionalism, and Wife Abuse in Urban Russian Couples," Journal of Marriage and the Family 67 (2005). Kaukinen reviews frustration theory (absolute household resources), also known simply as 'resource theory' as well as comparative resource theory (relative resources).

${ }^{2}$ See L. Gordon, Heroes of their Own Lives (New York: Viking, 1988), K. Anderson, “Gender, Status and Domestic Violence: An Integration of Feminist and Family Violence Approaches, "Journal of Marriage and the Family, 59 (1997); K.L Hoffman, D.H. Demo, and J.N. Edwards, "Physical Wife Abuse in a Non-Western society: An Integrated Theoretical Approach," Journal of Marriage and the Family, 56 (1994); G.T. Hotaling and D.B. Sugarman, "An Analysis of Risk Markers in Husband to Wife Violence: The Current State of Knowledge," Violence and Victims, 1 (1986) and R.D. Conger, G.H. Elder, F.O. Lorenz, K.J. Conger, R.L. Simons, S.H. Whitbeck, S. Huck, and J.N. Melby, 'Linking Economic Hardship to Marital Quality and Instability," Journal of Marriage and the Family 52 (1990) 643-56.

${ }^{3}$ For examples, see H. Tauchen, A. Dryden Witte and S. Long, "Domestic Violence: A Nonrandom Affair," International Economic Review 32:2 (1991); J. Kingston-Reichers, "The Association Between Socio-Economic Characteristics and the Frequency of Wife Assault," Working Paper Series,
} 
that understanding the dynamics of wife abuse requires an analysis that can adequately accommodate both total household resources and relative status. In what follows, an overview of the relevant political economic literature on wife abuse is provided, followed by the development of a conceptual model of the household to analyse the conditions under which violence will emerge. Here it will be demonstrated that household structure, including the total gains from the relationship and the relative status of the spouses, will

Department of Economics, McMaster University (1999); A. Farmer and J. Tiefenthaler, “An Economic Analysis of Domestic Violence." Review of Social Economy LV:3 (Fall 1997). Note, however, that Tauchen, Witte, and Long discovered that in high income families where females earn the bulk of household income, an increase in female earnings increased violence. This was an exception to their findings, however, which largely support the negative correlation between female income and abuse.

${ }^{4}$ This hypothesis was first articulated by Allen and Straus (1980), which modifies Goode's (1971) classic resource theory. Refer to W. Goode, "Force and Violence in the Family," Journal of Marriage and the Family, 33:4 (1971) and C.M. Allen and M. A. Straus, "Resources, Power, and Husband-Wife Violence," The Social Causes of Husband-Wife Violence, eds. M.A. Straus and G.T. Hotaling (Minneapolis: University of Minnesota Press, 1980). Recently, feminist interpretations of this approach root its hypotheses in constructs of masculinity and femininity. For examples, see M. Atkinson, T. Greenstein, and M. Monahan Lang, "For Women, Breadwinning Can be Dangerous: Gendered Resource Theory and Wife Abuse," Journal of Marriage and the Family 67 (2005) 1137-1148; K. Anderson, “Gender, Status, and Domestic Violence: An Integration of Feminist and Family Violence Approaches," in Journal of Marriage and the Family 59:3 (August, 1997); L.A. McCloskey, "Socioeconomic and Coercive Power within the Family," in Gender and Society 10:4 (1996) 449-463. Atkinson et al explore the role of varying constructs of masculinity, finding support for relative resource theory only when men have traditional attitudes about masculinity. Anderson, in contrast, links gender theory with resource theory to explain why women are not traditionally violent towards their partners. McCloskey examines the role of class and relative resources. 
be an important determinant of violence. The chapter concludes with a brief discussion of the implications for policy reform. The analysis contained herein, while not explicitly dealing with the anti-violence policy regime, is an important first step in the analysis of the dynamics of abusive households, which will yield areas for policy reform.

\section{HOUSEHOLD STRUCTURE AND VIOLENCE}

Wife abuse has been on the policy agenda in Canada only since the 1980 s.

Growing awareness due to the women's movement and the battered women's movement brought widespread public attention to an issue that had previously been hidden in the household, couched in terms of "normal" gender relations. Official recognition resulted in a coordinated effort between federal, provincial and municipal governments. To date, the anti-wife abuse policy framework includes the criminal justice system, an array of social services, research and awareness campaigns, and counselling and intervention programs, as shown in Table 1.1.

At the same time as wife abuse was gaining official recognition, household formation and structures began undergoing tremendous change. A number of interrelated trends have emerged: women's labour force participation and attachment rates, among women of all classes and races, are converging with those of men's; fewer couples are choosing to marry or marry much later than previous generations, with many opting for cohabitation before or in lieu of legal marriage; fertility rates have decreased

\footnotetext{
${ }^{5}$ See S. Burt and C. Mitchell, "What's in a Name?: From Sheltering Women to Protecting Communities," in Pal, Leslie ed., How Ottawa Spends 1998-99: Balancing Act: The Post Deficit Mandate (Toronto: Oxford University Press, 1998); and M. Morrow, O. Hankivsky, and C. Varcoe, "Women and Violence: The Effects of Dismantling the Welfare State," in Critical Social Policy 24:3 (2004) for an overview of wife abuse policy in Canada.
} 
significantly, reducing family size; and family forms are increasingly diverse, with more single-headed households and more visible same-sex households than ever before. ${ }^{6}$ For the most part, these trends have translated into higher social and economic status for women than in previous decades, which has had significant effects on intra-household relations. In particular, higher status outside of the household has given women more bargaining power within their relationships, which in turn has given them greater ability to negotiate family size and resource allocation, ${ }^{7}$ as well as the norms and values that shape initial endowments. ${ }^{8}$

\footnotetext{
${ }^{6}$ For an overview of these trends in Canada, see Statistics Canada, "Women in Canada: A
} Gender-Based Statistical Report," ( Ottawa: Statistics Canada, 2006) and in the United States, see F.D. Blau, M.A. Ferber, and A.E. Winkler, The Economics of Women, Men and Work $5^{\text {th }}$ ed. (New Jersey: Pearson, 2006).

${ }^{7}$ It is interesting to note, however, that despite significant increases in men's household labour, women's share of that labour has been quite rigid M. MacDonald, S. Phipps, and L. Lethbridge, "Taking its Toll: The Influence of Paid and Unpaid Work on Women's Well-being," Feminist Economics 11:1 (March 2005). See also I. Bakker, Unpaid Work and Macroeconomics: New Discussion, New Tools for Action (Ottawa: Status of Women Canada, 1998) available on-line at www.swc-cfc.gc.ca and I. Bakker, Gender Budget Initiatives: Why They Matter in Canada (Ottawa: Canadian Centre for Policy Alternatives, 2005) available at:

http://www.policyalternatives.ca/Reports/2005/09/ReportsStudies1183/index.cfm?pa=19933261 for a discussion of the implications of state restructuring and women's unpaid labour.

${ }^{8}$ For an excellent analysis, refer to B. Agarwal, A Field of One's Own: Gender and Land Rights in South Asia (Cambridge: Cambridge University Press, 1993) and B. Agarwal, “'Bargaining' and Gender Relations: Within and Beyond the Household," Feminist Economics 3:1 (1997). 
While these trends tend to benefit women, and no doubt their children, ${ }^{9}$ paradoxically, they have meant that there are now fewer gains from marriage or cohabitation for both women and men. There are a number of economic incentives to form families. ${ }^{10}$ For example, when individuals form a household they generate economies of scale or externalities, resulting in gains from the relationship. It is cheaper to live as a couple than it is to live as two individuals, simply because it is cheaper to have one dwelling unit, one set of appliances, etc. Appliances or other goods jointly consumed by several household members can be thought of as household goods, analogous to public goods, which individuals might not be able to get elsewhere or to produce as efficiently. Many goods within households can take on the quality of a public good, meaning that consumption by one person does not diminish the amount available for other household members, including the presence of children, spending leisure time together, etc. Similarly, families benefit from risk-pooling and marital investments, which increase individual gains. In addition, some economists have argued that through a division of labour, couples can save considerable time on household labour. ${ }^{11}$ These

${ }^{9}$ See F. Woolley, "Why Pay Child Benefits to Mothers?" Canadian Public Policy 30:1 (2004); Z. Chen and F. Woolley, “A Cournot-Nash Model of Family Decision Making," Economic Journal 111 (2001); and S. Lundberg and R. Pollak, "Separate Spheres Bargaining and the Marriage Market," Journal of Political Economy 101:6 (1993).

${ }^{10}$ For a discussion of the economic incentives of families, see Blau et al (2006).

${ }^{11}$ See G. Becker, A Treatise on the Family (Cambridge: Harvard University Press, 1981 and 1991). For excellent critiques of Becker's work, see B. Bergmann, "Becker's Theory of the Family: Preposterous Conclusions," in Feminist Economics 1:1 (1995); F. Woolley, "Getting the Better of Becker," in Feminist Economics 2:1 (1996); N. Folbre, Who Pays for the Kids?: Gender and the Structures of Constraint (London: Routledge, 1994); N. Folbre, "Of Patriarchy Born: The Political Economy of 
gains, either monetary or temporal, increase over time because over time each spouse gets better at doing 'what they do best' and become what individuals bargain over within marriage, contributing to the total household resources. ${ }^{12}$ With both men and women now more likely to be engaged in some form of market work, there are potentially fewer gains from the relationship. In other words, the material base of family formation has been altered significantly.

Households differ in the gains they generate, implicating important differences between families. Similarly, individuals within families do not benefit equally from these gains. Resource allocation within families reflects and reinforces power differentials within (and outside) of the household. ${ }^{13}$ Individuals with higher bargaining power, determined by access to resources, as well as political and social institutions, generally do better within the relationship, since they are able to negotiate a higher share of the gains from cooperation.

Interestingly, little academic literature has called attention to the gains from families in creating the conditions for violence. ${ }^{14}$ Instead, emphasis has focused primarily on either combined household income or relative status. For example, noted

Fertility Decisions," in Feminist Studies 9 :2 (1983); and E. Katz, “The Intra-household Economics of Voice and Exit," Feminist Economics 3:3 (1997).

${ }^{12}$ For an excellent reviews of marital bargaining models, see Katz (1997) and J. Seiz, 1991. "The Bargaining Approach and Feminist Methodology," Review of Radical Political Economics 23:1\&2 (1991).

13 Ibid.

14 Tauchen, Witte and Long (1991) analyse a situation in which both individuals gain from the relationship and its implications for abuse via income transfers. 
above, frustration theorists, also known as family stress theorists, posit that poverty is a determinant of violence. ${ }^{15}$ From this perspective, the strain of financial resources causes individuals to lash out at their partners. In addition, violence could be a way to reassert control over one's environment by punishing a partner instead of, say, an employer.

Although there is considerable empirical evidence to support the relationship between absolute resources and wife abuse, such an approach is problematic for at least two reasons. First, as noted above, it reduces household resources to combined incomes and assets, neglecting the gains generated from the relationship. This is potentially important in the onset of violence: Are women in families generating high gains from cooperation as vulnerable to abuse as women in families with low gains from cooperation? By focusing attention only on combined income and assets, the importance of family structure in creating incentives for violent behaviour is obscured.

This leads to the second problem with the absolute resource hypothesis: it neglects the importance of intra-household relations and the ways in which relative

\footnotetext{
${ }^{15}$ See L. Gordon, Heroes of their Own Lives (New York: Viking, 1988), K. Anderson, "Gender, Status and Domestic Violence: An Integration of Feminist and Family Violence Approaches, " Journal of Marriage and the Family, 59 (1997); K.L Hoffman, D.H. Demo, and J.N. Edwards, "Physical Wife Abuse in a Non-Western society: An Integrated Theoretical Approach," Journal of Marriage and the Family, 56 (1994); G.T. Hotaling and D.B. Sugarman, "An Analysis of Risk Markers in Husband to Wife Violence: The Current State of Knowledge," Violence and Victims, 1 (1986) and R.D. Conger, G.H. Elder, F.O. Lorenz, K.J. Conger, R.L. Simons, S.H. Whitbeck, S. Huck, and J.N. Melby, "Linking Economic Hardship to Marital Quality and Instability," Journal of Marriage and the Family 52 (1990) 643-56.
} 
resources shape and constrain decision-making and behaviour. ${ }^{16}$ Again, this is important from the perspective of violence: Are women with higher bargaining power, who can negotiate better deals within marriage, as vulnerable to abuse as women with lower bargaining power? Such a question reveals the potential of family dynamics to foster or hinder violence.

A number of studies have attempted to address this shortcoming by focusing on relative resources, calling attention to the role of intra-household dynamics in the onset of violence. As noted above, within this group, interesting debates have emerged regarding the influence of women's status on the use of violence. Some suggest that as female income increases, violence will decrease. This hypothesis generally arises from economic analyses of the family, where violence directly and indirectly alters male (increases) and female (decreases) utility within marriage. ${ }^{17}$ Since violence reduces female utility from marriage, female income increases require the abuser either to reduce violence or increase intra-household transfers to keep her utility from marriage high enough to stay.

There is considerable evidence for this hypothesis. For example, Tauchen, Witte, and Long's classic study (1991) discovered a negative relationship between women's income and abuse. ${ }^{18}$ Similarly, Kingston Reichers' (1998) application of this model to a

${ }^{16}$ For an analysis of the roles of both absolute and relative resources, see G.L. Fox, M.L. Benson, A.A. DeMaris, and J. Van Wyk, "Economic Stress and Intimate Partner Violence: Testing Family Stress and Resources Theories," Journal of Marriage and the Family 64 (2002).

${ }^{17}$ For examples, see Tauchen, Dryden Witte, and Long (1991); Kingston-Reichers (1999); and Farmer and Tiefenthaler (1997).

${ }^{18}$ See fn 3 for an explanation. 
Canadian sample revealed that education, rather than income, was a better indicator of violence. Kaukinen (2004) discovered that increasing female income and education reduced the likelihood of both physical and emotional abuse.

This is an interesting hypothesis, suggesting that all women would benefit from higher resources since they would be able to credibly threaten departure. ${ }^{19}$ However, it is potentially problematic for a number of reasons. First, most of these models focus on traditional economic resources, such as personal income, employment and education. However, as noted by Agarwal (1994; 1997) and Panda and Agarwal (2005), the resources of social networks, communities and states are also important here. Similarly, social resources, such as emotional support (or lack thereof) will be crucial in helping families cope with abuse. ${ }^{20}$ Thus focusing only on narrowly defined economic resources is potentially problematic. For example, what happens when a woman's social network increases, but her income remains the same? Violence in this context is potentially

${ }^{19}$ Note that a number of scholars extend this analysis to include resources beyond income, such as social services and property. For examples of the former, see A. Farmer and J. Tiefenthaler, "Domestic Violence: The Value of Services as Signals," American Economic Review 86:2 (May 1996) Papers and Proceedings of the Hundredth and Eighth Annual Meeting of the American Economic Association; D. Ford, "Prosecution as a Victim Power Resource: A Note on Empowering Women in Violence Conjugal Relationships," Law \& Society Review 25:2 (1991); J.E. Ursel, "Mandatory Charging: The Manitoba Model," Unsettling Truths: Battered Women, Policy, Politics and Contemporary Research in Canada, eds. K. Bonneycastle and G.S. Rigakos (Vancouver: Collective Press, 1998). For an example of the latter, refer to P. Panda and B. Agarwal, "Marital Violence, Human Development, and Women's Property Status in India," World Development 33:5 (2005).

${ }^{20}$ L.A. Hoff, Battered Women as Survivors (London: Routledge, 1990). 
constrained since the abuser now faces increased risk and the victim's access to social resources has increased, meaning that she now needs more to remain in the marriage. ${ }^{21}$

In addition, this approach often neglects the role of economic abuse whereby men extract their wives' income in an attempt to exert and maintain control. In this context, it is not entirely obvious that simply increasing women's wages or employment opportunities would reduce violence. Similarly, Panda and Agarwal (2005) point out many limits to the use of traditional economic resources, such as market forces, arguing instead in favour of immovable economic property, such as homes or land. Thus, analyses must expand the conceptualization of resources beyond simple economic measures.

It is also important to note that not all resources might work to the same effect. For example, Goodman et al (2005) found general support for the hypothesis, but revealed that where social support systems offered women protection from abuse, resources offering women opportunities for overt resistance increased the risk of violence. Similarly, a study conducted by Dugan et al (2002) on femicide demonstrated that domestic violence policies requiring a cool down period are much more likely to reduce homicides than those that do not.

Second, the models, or lack thereof, underlying these studies obscure the gains from marriage and their role in creating the conditions for violence. For example, many of the economic analyses adopt a non-cooperative model of household decision-making,

${ }^{21}$ See Farmer and Tiefenthaler (1996) for an interesting discussion of the role of social services in enabling women to misrepresent their threat points, which will allow them to negotiate lower levels of violence. 
which does not demonstrate the gains from marriage other than emotion or joint consumption. ${ }^{22}$ In contrast, many of the sociological analyses do not explicitly analyse the dynamics of household decision-making, thus neglect household structure, including the gains from cooperation, and its contribution to violent behaviour. But, as argued above, if violence is in part instrumental, then researchers must be careful to consider what the abuser gains and how these gains vary across households. Thus, it is reasonable to assume that these gains from cooperation will have determinative effects on violence, as will be shown below.

Finally, these studies largely treat the bargaining structure as exogenous, where it remains unaffected by violence. But if violence reduces household well-being or alters the bargaining position of either partner, as demonstrated below, then the bargaining structure not only shapes violence, but is also shaped by violence. Analyses must accommodate the ways in which violence pervades the bargaining structure, altering both the individual positions of the partners and the outcomes available.

In contrast to the "positive relative resource" hypothesis, which suggests that violence decreases as female income increases, others, most of whom are sociologists, suggest that as female income increases, violence will increase. ${ }^{23}$ This is usually interpreted as a response to threats to masculinity, whereby men must "equalise" relations within the household. McCloskey (1996) explains:

This framework perceives men's abuse of women and children as compensatory for their threatened sense of masculine identity; the exercise of socially sponsored proprietary rights restores their

${ }^{22}$ See Tauchen, Witte, and Long (1991); Farmer and Tiefenthaler (1997); and Kingston-Reichers (1998) for examples.

${ }^{23}$ See fn. 4. 
otherwise unstable sense of being men. As women's earning power increases, they transform the domestic sphere of power [...]. Violence, therefore, becomes an equalizer for men [...].,24

Compared to the positive approach, this approach explores the symbolic importance of gender systems in creating and sustaining power within families. Violence is used as a power resource.

Evidence for this hypothesis is mixed. Although Allen and Straus (1980), McCloskey (1996), and Anderson (1997) find evidence to support resource theory, other studies have been less conclusive. For example, Atkinson et al (2005) find support only when males have traditional ideologies about gender. In addition, Kaukinen (2004) finds support only for emotional abuse. Finally, it has been suggested that the hypothesis is culturally specific: Cubbins and Vannoy (2005) tested the theory in the former Soviet Union and found no supporting evidence. Instead, they discovered that male absolute resources were best indicator of violence against women.

Not only is there a lack of consistent empirical evidence, the theoretical basis of this approach is, like the positive resource hypothesis, potentially problematic. The "negative relative resource" approach, typically called comparative or ultimate resource theory, implicates the material base on which masculinity and its privilege rest but gives it no careful analysis. Masculinity is not a monolithic ideological construct; it is premised on a material basis on which "power" and privilege are erected, and is mediated by race, sexuality, ability, and class. ${ }^{25}$ Clearly, some men might have more to gain from the use of violence than other men. And these gains are not simply symbolic. Thus this hypothesis fails to convincingly explain why some men are violent while others are not.

\footnotetext{
${ }^{24}$ McCloskey (1996) pg. 451.

${ }^{25}$ See Atkinson et al (2005)
} 
A problem emerging from both of the relative resource hypotheses is that they cannot distinguish between various types of households. ${ }^{26}$ As "relative resource" hypotheses, they ignore absolute resources. ${ }^{27}$ For example, according to this approach, men with low relative resources residing in households with higher absolute resources will be as likely to resort to violence as men in households with lower absolute resources. However, we know empirically that this is false. This problem stems from the neglect of household structure on creating the conditions for violence, a problem that is equally apparent in the "positive relative resource" hypothesis. For example, both hypotheses are silent on the degree to which violence is conditioned by the overall gains from the relationship, which are generated by economies of scale and externalities in consumption and production, as described above.

It is suggested here that household structure is a key determinant of violence, which includes but is not isolated to relative resources within households. In the following section, a household bargaining model is developed to demonstrate the role of household structure in creating the conditions for violence. Specifically, it is argued that

${ }^{26}$ An exception here is Tauchen, Witte and Long (1991), who consider the impact of rising female income on violence in various scenarios, including high and low income households, relationships in which the female is held at her reservation utility, and relationships in which both male and female gain. In all but one scenario, high earning households where the female earns the bulk of household income, female income increases decrease violence.

${ }^{27}$ Recent studies have explored the competing role of absolute and relative resources in predicting wife abuse. See McCloskey (1996) and Atkinson et al (2005), who discovered that relative resources are better predictors of wife abuse. See also Cubbins and Vannoy (2005), who, using data from Russia, discover that absolute, rather than relative resources, is a better predictor of wife abuse. To my knowledge, no study attempts to consider interactions between absolute and relative resources. 
violence will be more likely in households where a) the gains from cooperation are low and b) the status of the male is equal or low relative to his wife. Furthermore, it will be demonstrated that elements of the bargaining structure, described below, are endogenous with respect to violence.

\section{CONCEPTUAL FRAMEWORK}

As outlined in chapter 1 , violence is about domination, about gaining control and influence. ${ }^{28}$ Central, then, to any discussion of violence is how one comes to dominate and why. Since violence almost always has an instrumental component, without diminishing the role of social learning through intergenerational effects, ${ }^{29}$ it is important to focus on the distribution of resources within households. As described above, when individuals form a household they tend to generate gains from cooperation through economies of scale or externalities and/or specialization in production. When living as a couple, individuals can allocate their time and money to their personal enjoyment or to the household. In general, individuals face a trade off between these two resources: time or money spent on the household means less time or money on oneself. And when time or money is allocated to the household, all members of the household get to enjoy the goods produced. In effect, this time or money contributes to what is analogous to a

${ }^{28}$ See I.M. Young, Justice and the Politics of Difference (New Jersey: Princeton, 1990); S .Ruddick, "Injustice in Families: Assault and Domination," Justice and Care: Essential Readings in Feminist Ethics, ed. V. Held (Boulder: Westview Press, 1995); and K. Crenshaw, Mapping the Margins: Intersectionality, Identity Politics, and Violence Against Women of Colour," Stanford Law Review 43:6 (1991).

${ }^{29}$ See R. Pollak, "An Intergenerational Model of Domestic Violence," Journal of Population Economics (2004). 
public good. And like all public goods, individuals want to enjoy them but do not want to contribute to them. So if individuals can, through bargaining that is either explicit or implicit, get the other person to contribute more of his or her time or money to the household, then they get to spend more of their own money or time on themselves and still enjoy the same amount of the household good. Similarly, if individuals can get the other person to sacrifice his or her own personal time or money for our personal consumption, given that a minimum level of household good is provided, then they benefit even more. The gains from families, either monetary or temporal, capture what each individual gains from the relationship and become what individuals bargain over, as noted above.

Both absolute and relative resources are important in generating and dividing these gains. With high absolute resources, families can invest in time or money saving products or services, which would generate higher gains from cooperation than families that cannot. In contrast, with higher relative resources, individuals can reap more of the benefits from the relationship. For example, with higher bargaining power, determined in part by relative status, women can negotiate the division of household labour, delegating more and more work to their partners. ${ }^{30}$ Thus, families differ considerably in the gains they generate and how they are divided. And it is this allocation, including both quantitative and qualitative dimensions, that provides the rationale for violence. ${ }^{31}$

\footnotetext{
${ }^{30}$ See Moller Okin (1989) and MacDonald (2005)

31 To clarify, consider an example. Violence is often correlated with pregnancy, although there is considerable debate surrounding this issue. See Statistics Canada, Wife Assault: The Findings of a National Survey (Ottawa, Canada, 1994) (prepared by Karen Rodgers); and J. Janiski, "Pregnancy and Violence Against Women: An Analysis of Longitudinal Data," Journal of Interpersonal Violence 16:7
} 
To consider the conditions under which violence arises, a simple bargaining framework is useful, shown diagrammatically in Figure 2.1. A non-linear well-being possibilities frontier (WPF) is assumed, which is negatively sloped and concave to the origin. The WPF represents all of the possible combinations of male $W_{m}$ and female $W_{f}$ well-being, where well-being is derived by consuming both private and public goods. The amount of each good consumed is constrained by each individual's personal budget constraint, which reflects the total resources available to each individual and the prices of each good they wish to consume. All combinations of $W_{m}$ and $W_{f}$ along the WPF are Pareto efficient, where it is not possible to make one person better off without making the other person worse off, and all combinations falling within the WPF are inefficient.

\section{Figure 2.1:}

\section{A Two-Person Cooperative Nash Bargaining Game}

In traditional bargaining approaches, emphasis is placed on the fallback positions, or threat points, of each individual. Fallback positions, represented by $W_{i}^{\prime}$ in the diagrams, determine what each person will get in the event of disagreement. While fallback positions are often conceptualized as personal endowments, such as income and access to education, they can also include the resources of kinship networks,

(July 2001). Pregnancy and childrearing require a tremendous amount of time and money. More specifically, it requires allocations of time and money that, while one might reap benefit from, is spent largely on another individual. In terms of intra-household relations, pregnancy and childrearing occupy the mother's time and, often, her money, which means that her time and money are diverted from her partner. Refer to the 'good mother hypothesis' articulated by F. Woolley and Z. Chen (2001); Lundberg and Pollak (1993). In this context, violence can be seen as an instrument through which to direct the allocations of her time and money. 
communities, and states. ${ }^{32}$ In addition, there is also a non-monetary element to them, reflecting age, beauty, strength, as well as external valuations of one's contributions, etc. ${ }^{33}$ In Nash $(1950 ; 1953)$ models, the solution to the bargaining game is determined by maximizing the product of the joint gains from cooperation.

The Nash approach, although dominant in household bargaining literature, ${ }^{34}$ is not without controversy. Perhaps the most controversial aspect of Nash's approach is the axiom stating the independence of all irrelevant alternatives. This axiom in many ways makes intuitive sense. Consider the case where two individuals are trying to decide which film to see. Faced with the choices A, B, and C, they both chose A. If for some reason, $\mathrm{B}$ is no longer showing, the axiom implies that there will be no change in the solution, since the presence of B has no effect on the preference for $\mathrm{A}$.

However, a number of scholars have pointed to problems with this particular axiom, proposing a number of alternatives. ${ }^{35}$ One particular approach is that offered by

${ }^{32}$ See Agarwal (1993); (1997).

${ }^{33}$ See Folbre (1994) and Sen (1990).

${ }^{34}$ See S. Lundberg and R. Pollak, "Bargaining and Distribution in Marriage," Journal of Economic Perspectives 10:4 (Autumn 1996); S. Lundberg and R. Pollak, "Noncooperative Bargaining Models of Marriage," American Economic Review 84:2 (May 1994), Papers and Proceedings of the Hundred and Sixth Annual Meeting of the American Economic Association; and Katz (1997) for extensive literature reviews of household bargaining models. See also T. Bergstrom (1995) "A Survey of Theories of the Family" available at http://repositories.cdlib.org/ucsbecon/bergstrom/1995D and V. Jacobsen, L. Fursman, J. Bryant, M. Claridge, and B. Jensen (2004), "Theories of the Family and Policy," New Zealand Treasury Working Paper04/02 available at www.treasury.govt.nz

${ }^{35}$ For an overview of the criticisms and alternative approaches, refer to H.J.M. Peters, Axiomatic Bargaining Game Theory (Boston: Kluwer Academic Publishers, 1992). 
Luce and Raiffa (1957) and later Kalai and Smorodinsky (1975), simply named the Raiffa-Kalai-Smorodinsky (RKS) solution, which suggests that there are specific conditions that violate this axiom. For example, like Nash, Kalai and Smorodinsky (1975) demonstrate that each player strives for the maximum payoff from the game, or the total gains from cooperation. However, where this payoff is higher for one player than for the other, the player with the higher potential payoff will naturally want more from the final settlement. Thus, this maximum payoff is not, as Nash would posit, an independent irrelevant alternative. Rather, it has a determinative effect on the solution point. As a result, changes to this point will impact the outcome of the game.

To see a comparison of the Nash and RKS models, see Figure 2.2. ${ }^{36}$

\section{Figure 2.2:}

\section{RKS vs. Nash}

If the solution set changes from $\mathrm{ZBC}$ to $\mathrm{ZDC}$, under the Nash solution, the payoff for player 2 does not change. Under the RKS solution, however, the payoff for player 2 changes, reflecting a proportional solution. Since the solution set is now larger, it is posited that both players 1 and 2 seek to achieve the total gains from cooperation. Thus with a larger solution set, player 2 would naturally want a higher payoff. The RKS solution overcomes this problem by introducing an alternative axiom, monotonicity, which simply implies that if the maximum payoffs for player 1 increase, without simultaneously increasing the maximum payoffs for player 2 , then player 1 will receive a larger share of the gains from cooperation. ${ }^{37}$

\footnotetext{
${ }^{36}$ This is the example published in E. Kalai and M. Smorodinsky, “ Econometrica 43:3 (May
} 1975) 513-518.

${ }^{37}$ See Friedman (1986). 
The maximum payoff for each player is called the aspiration point, represented by $\mathrm{A}_{i}$ in Figure 2.3. Each player aspires to capture all of the gains from cooperation. However, there is no point along the WPF that will simultaneously award both players this payoff, as shown by point $\mathrm{A}$ in the diagram. Hence the bargaining problem; individuals must bargain over how to share the gains from cooperation. Thus the RKS solution is unique in that it has two reference points, the aspiration point and the fallback position. The solution is not simply a "split the difference" point, but rather a point that is proportional to their fallback and aspiration points.

\section{Figure 2.3:}

\section{A Two-Person Cooperative Game: The Raiffa-Kalai-Smorodinsky Solution}

To clarify, consider an example: two individuals have to divide $\$ 10$. Both would ideally like the full $\$ 10$, but there is no way in which to grant each player $\$ 10$. Thus, they must engage in bargaining to decide how to share this money. The RKS solution rewards the players proportionally. In other words, the individual with the highest fallback position and the highest potential payoff gets a higher share of the money. The Nash solution only makes reference to the fallback positions (threat points), where the individual with the highest fallback, s/he who benefits the most outside the relationship, also benefits the most inside the relationship.

With these tenets, the RKS solution offers interesting possibilities for studying familial and gender relations, since it can be easily assumed that men and women experience different payoff structures within, as well as outside, the household. The RKS solution implies that with increases to household resources, all members in the household are awarded a share of the increase, which is not necessarily captured by the Nash model. 
In addition, the RKS solution also offers the possibility to explore the impact of gender on household bargaining. As with Nash models, which have been modified to reflect the ways in which gender influences opportunities for exit and voice, ${ }^{38}$ in the RKS approach, gender is an important analytic lens through which to interpret the model. The parameters of the model capture important gender differences. Fallback positions of men and women will often reflect significant differences in access to income and employment, as well as the resources of social networks, states, and communities. In addition, socially valued attributes, such as status, beauty or age, might carry different weights for men and women. For example, in societies where men are valued for their economic contributions and women for their youth and attractiveness, gender as determined by these characteristics will manifest in both the process and outcome of bargaining.

These insights will also have important implications for feminist interpretations of the aspiration point. For example, in a patriarchal society women might be discouraged from bargaining under the shadow of their aspiration point. Similarly, there might be important gender differences in what each player "aspires to" within the relationship. Although these raise interesting theoretical questions, it is beyond the scope of this chapter to explore them in depth and thus will not be dealt with here. For the purposes of this chapter, focus will remain on the gendered implications of the relationship between aspiration points and fallback positions from the perspective of violent relationships. Note the inverse relationship between the aspiration point of one player and the fallback of the other. Should the fallback position of one player decrease, given the slope of the WPF, then the aspiration point of the other player increases. This holds particular appeal

\footnotetext{
${ }^{38}$ See Katz (1997).
} 
in terms of what each sees as the possible gains from the relationship: The aspiration point can be thought of as a dictatorial solution, representing what one gets if s/he controls the household. The weaker one's fallback position, the more dictatorial the other person can be.

The importance of gender here is obvious: where individuals are more likely to resort to violence, due to either will or ability, then violence becomes a tool with which to achieve the aspiration point. Thus this approach might be more appropriate in explaining incentives for violent behaviour than other models of the household and, because of its ability to accommodate a range of familial and gender relations, could easily be adapted to study violence in a variety of situations, including same-sex households and violence against children.

In addition to these theoretical insights, the RKS model does not require the specification of a functional form, which means that resulting hypotheses do not hinge on assumptions about a particular equation. In effect, the RKS approach offers a transparent model, producing obvious results graphically with no or little mathematical specifications. For these reasons the RKS solution offers a more intuitive approach to studying families than the Nash model.

Mentioned above, the goal of bargaining is to get the most from the bargain as one possibly can, constrained and determined by the factors listed above. Using the RKS solution, the solution to the game can be found by the distribution of the gains from cooperation that awards each player a share that is proportional to her/his aspiration point and fallback position, as shown by point $S_{0}$ in Figure 2.3. The solution is found at the 
point at which the line passing through the fallback position with a slope of $\sigma$, equation (1), intersects the WPF. :

$$
\sigma=\frac{A_{m}-W_{m}^{\prime}}{A f-W_{f}^{\prime}}
$$

Where $A_{i}$ reflects each individual's aspiration point and $W_{i}^{\prime}$ represents each individual's fallback position. This point, which divides the total possible gains from the relationship of one player by the total possible gains of the other, represents each player's level of well-being in equilibrium.

The simple RKS model reveals how, in general, families will divide the gains from cooperation, as defined above. The questions to explore, however, are when is violence going to be used and why. To answer these questions, one must hypothesize about what violence is going to do to this process and its solution. Note from the remaining discussion that it is assumed that the abuser uses violence when he thinks that violence will make him better off. In other words, he expects that the relationship between violence and his well-being is monotonic.

Violence is going to have a number of effects on the bargaining process, which will ultimately alter the unique solution. First, it is known that violent partners often restrict access to employment, income, and family and friends through threats of abuse and through forms of emotional or psychological abuse. ${ }^{39}$ For example, extreme jealousy or manipulation, as well as name-calling can reduce one's self-esteem or trigger depression, which will potentially limit one's contact with others through social and

${ }^{39}$ See A.M. Moe and M.P. Bell, "Abject Economics: The Effects of Battering and Violence on Women's Work and Employability," Violence Against Women 10:1 (2004). 
employment networks. In other words, it is known that abusers attempt to control how their partners spend their time and money. Employment and access to social networks contribute to the resources a woman will need in the event that negotiations break down; they constitute part of her fallback position, $W_{f}^{\prime}$. What this suggests is that threats of violence and non-physical forms of abuse will reduce her fallback position, shifting it to the left from $W_{f}^{\prime}$ to $W_{f}^{\prime \prime}$ as shown on Figure 2.4.

\section{Figure 2.4:}

\section{The Effects of Violence 1: Fallback Positions Decrease}

From the diagram, leftward shifts in her fallback position change the slope of the line described in (1) and shift the solution from $S_{0}$ to $S_{1}$, representing a positive gain for the attacker. Shifts in the fallback reduce her bargaining power, leaving her less able to negotiate how she spends her time or money. With more relative bargaining power, he is able to ensure that her time or money is spent on the household or given to him directly via intra-household transfers, leaving more (less) of his (her) income for personal consumption.

Shifts in her fallback position have a twofold effect. On the one hand, as shown in Figure 2.4, it increases the difference between her aspiration point, $A_{f}$, and her fallback, $W_{f}^{\prime \prime}$, meaning that she now has more to gain from staying in the relationship than she did before, making her increasingly vulnerable. On the other hand, reducing her fallback position increases the maximum payoff to him if he were to capture all of the gains from cooperation. From Figure 2.4, reducing her fallback position to

$W_{f}^{\prime \prime}$ implicates a simultaneous increase in his aspiration point, from $A_{m}$ to $A_{m}^{\prime}$, which 
effectively means that the proportion of the gains from cooperation awarded to him are increasing relative to the proportion awarded to her. The magnitude of this change depends on the slope of the WPF at the point at which it is intersected by the aspiration point. Where the slope is less than one, the change in the aspiration point will be less than the change in the fallback position. In contrast, where the slope is greater than one, the changes in the aspiration point will be greater than the change in the fallback position.

Note that if violence goes beyond threats and emotional abuse to actual physical violence, the WPF will also shift inward reflecting a reduction in household well-being, the second effect of violence. In cases of extreme violence, both short and long-term disabilities or disfigurement would be expected, which can potentially place severe restrictions on how time is spent, limiting household consumption and production. ${ }^{40}$ For

\footnotetext{
${ }^{40}$ J.C. Campbell and K.L. Soeken, “Women's Responses to Battering Over Time: An Analysis of Change," in Journal of Interpersonal Violence 14:1 (January 1999); P.A., Ratner, "Modelling Acts of Aggression and Dominance and Exploring their Adverse Health Effects," in Journal of Marriage and the Family 60:2 (May 1998); T. Day and K.M.J. McKenna, “The Health-Related Economic Costs of Violence Against Women in Canada," Violence Against Women: New Canadian Perspectives, eds. K.M.J. McKenna and J. Larkin (Toronto: Inanna Publications and Education Inc., 2002); T. Day, The Health Related Costs of Violence Against Women in Canada: The Tip of the Iceberg (London: Centre for Research on Violence Against Women and Children, 1995); L. Greaves, O. Hankivsky, and J. KingstonReichers, Selected Estimates of the Costs of Violence Against Women (London: Centre for Research on Violence Against Women and Children, 1995); and S. Lloyd, "The Effects of Domestic Violence on Women's Employment," Law and Policy (1991).
} 
example, abused women often report absenteeism from work due to severe beatings. ${ }^{41}$ In addition, lack of sleep, stress, etc., would reduce productivity in either paid or unpaid labour. ${ }^{42}$ If she is unable to work productively in household or market labour, reductions in her fallback will be subsequently met with reductions in the possibilities within marriage, resulting in an inward shift in the WPF, as shown in Figure 2.5. The result is that the solution will not reach $S_{1}$, but rather $S_{2}$ as shown in Figure 2.5.

\section{Figure 2.5:}

\section{The Effects of Violence 2: Total Household Well-Being Falls}

Note from Figure 2.5 that inward shifts of the WPF mitigate some of the positive gains from violence. This raises interesting questions about when physical violence will be used and why. Recall that expressive violence enters the male well-being function directly; that is, he experiences direct gratification from the use of violence. From this, it is reasonable to conclude that males engaging in physical abuse are driven primarily by expression rather than instrumentality. In other words, his well-being from violence stems directly from its use rather than the resources he can acquire. Thus, what he loses in resources via the reduction in total household well-being, he gains in direct well-being. This also explains why the shift in the WPF is not proportional. Physical violence will be used only when she will bear the bulk of the cost.

Note also from Figure 2.5 that he is still better off using violence than if he had not. Although this need not be the case, especially in the long-run, recall from above that

${ }^{41}$ See S. Lloyd (1991); Greaves et al (1995); A. Sev'er, Fleeing the House of Horrors: Women Who Have Left Abusive Partners (Toronto: University of Toronto Press, 2002). See also Farmer and Tiefenthaler (1996) for a discussion of the negative effects of violence on women's employment.

${ }^{42}$ See Moe et al (2004). 
it is assumed that the abuser will only use violence when he assumed that the relationship between violence and his well-being is positive; that is, he experiences positive gains from its use. By implication, it is assumed that he will not use violence if it makes him worse off.

Together these effects, reductions in her fallback position and the WPF, describe the net gains from violence for the abuser. What they do not reveal, however, is which types of households are most vulnerable to violence. In other words, are there conditions under which the gains from violence are higher for some men than for others? Mentioned above, one potential problem with the absolute resource hypothesis is that it reduces resources to combined income and assets. Similarly, both the positive and negative versions of the relative resource hypothesis not only neglect the role of absolute resources, but they also reduce analyses of household structure to relative status. These approaches have neglected the potential importance of the total gains from the relationship as both cause and effect of violence. As a result, neither approach can adequately explain differential levels of violence occurring between different types of households. It is argued here, however, that understanding the dynamics of abusive relationships requires attention to household structure, which includes both relative status and total gains from the relationship. When this concept is introduced, it becomes clear that what each person gains within the relationship, both in absolute and relative terms, will be at least as important as what each person gets outside of the relationship in determining abuse.

To see this, consider two scenarios. In the first scenario, represented in Figures 2.6 though 2.8 , there are two households where the male and female are in relatively 
equal bargaining positions. The difference between the two households is the gains from cooperation. The couple generating high gains from cooperation are marked by $W_{m h}^{\prime}$, $W_{f h}^{\prime}, A_{m h}$, and $A_{f h}$, which represent male and female threat and aspiration points, respectively. Conversely, the couple generating low gains from cooperation are marked by $W_{m l}^{\prime}, W_{f l}^{\prime}, A_{m l}$, and $A_{f l}$. And as mentioned above, gains from cooperation arise from economies of scale, household technology, joint investments, household (public) good production, risk-pooling, and specialization in production.

\section{Figure 2.6: \\ Comparison 1: Households with High Gains from Cooperation Compared to Households with Low Gains from Cooperation}

Implied by the negative relative resource hypothesis, where increases to female resources will increase violence, is the suggestion that both of the households represented by Figures 2.6 would be equally likely to experience violence, since in both cases men's position is threatened by the high relative status of his wife. ${ }^{43}$ From Figures 2.7 and 2.8, however, this is clearly not the case. Figure 2.7 illuminates the impact of equal absolute shifts in the female fallback positions. Equal absolute shifts in female fallbacks result in much larger gains from violence for the household with low gains from cooperation. ${ }^{44}$ This couple would be much more vulnerable to violence than the other couple, for whom

\footnotetext{
${ }^{43}$ Atkinson et al (2005) integrate gender and resource theory to reflect varying degrees of masculinities among men. In particular, they argue that men holding more traditional values towards families and masculinity will be more likely to use violence when relative status is low.

${ }^{44}$ This assumption is not arbitrary since we can also assume that equal levels of force bring equal levels of pain. In other words, well-being is separable in pain (emotional or physical). A punch in the face hurts regardless of whether or not one is rich, poor, Black, white, etc.
} 
the gains from violence are relatively low, achieving a solution of $S_{1 l}$ compared to $S_{1 h}$, achieved by the couple with high gains from cooperation.

\section{Figures 2.7:}

\section{Comparison 1: The Effects of Shifting Fallback Positions}

This occurs because of the position of the male aspiration point on the WPF. Recall from above that the magnitude of the change in his share of the gains from the relationship will depend on whether or not the slope of the WPF at the aspiration point is less or greater than one. The aspiration point for the male in the high gain household, $A_{m h}$, falls on a much flatter portion of the WPF than the aspiration point of male in the low gain household, $A_{m l}$, which means that the total change in the aspiration point, the difference between $A_{m h}^{\prime}$ and $A_{m h}$, is less than the total change in her fallback position, the difference between $W_{f}^{\prime}$ and $W_{f}^{\prime \prime}$. In comparison, the aspiration point of the male in the low gains household falls on a very steep portion of the WPF, which means that the total change in his aspiration point, the difference between $A_{m l}$ and $A_{m l}{ }^{\prime}$, will be greater than the total change in her fallback. Thus, the change in the proportion of resources awarded to the male in the low gain household is greater than the proportion awarded to the male in the high gain household.

When abuse escalates from threats and emotional abuse to physical violence, total household well-being is reduced, represented by an inward shift in the WPF, shown in Figure 2.8. The effect is to shift the aspiration points of both males and both females, from $A_{m i}^{\prime}$ to $A_{m i}^{\prime \prime}$ and $A_{f i}$ to $A_{f i}^{\prime}$, respectively. Where the male aspiration point increased with an inward shift of her fallback, an inward shift of the WPF reduces his 
aspiration point, reflecting the lower level of total household well-being now available. The solution for the household with low (high) gains from cooperation moves from $S_{0}$ to $S_{2 l}\left(S_{2 h}\right)$. Although shifts in the WPF mitigate some of the gains from violence for both households, the net gain from violence is still highest for the male in the household with low gains from cooperation, which can be seen by the vertical distance between $S_{2 l}$ and $S_{2 h}$

\section{Figure 2.8:}

\section{Comparison 1: The Effects of Shifting Fallback Position and WPF}

What this analysis demonstrates is that not all households are equally vulnerable to abuse. The example demonstrated that the gains from cooperation, rather than the equal bargaining position of the two spouses, were a strong predictor of abuse. The gains from violence are higher for men in households marked by low gains from cooperation, and thus higher rates of abuse among these households would be expected than among households with high gains from cooperation. What does this mean for the negative relative resource hypothesis?

To consider this question, one would want to explore the case where two households have relatively equal gains from cooperation, but the individuals are in relatively unequal bargaining positions, as shown in Figures 2.9 through 2.11. In Figure 2.9 the first couple signifies a traditional household, marked by a clear male breadwinner, represented by $W_{m b}^{\prime}, W_{f}^{\prime}, A_{m b}$ and $A_{f}$. Before violence takes place, the allocative outcome for this couple is represented by $S_{0 m b}$, as shown in Figure 2.9. The second 
couple is a non-traditional couple with a female breadwinner, represented in the diagrams by $W_{m}^{\prime}, W_{f b}^{\prime}, A_{m}$ and $A_{f b}$, with an allocative outcome of $S_{0 f b}$.

From Figure 2.10, it is clear that equal absolute shifts in female fallback positions result in higher gains from violence for the attacker in the household with the female breadwinner, which is consistent with the negative relative resource hypothesis and are easily demonstrated using the RKS solution. The new solution point for the nontraditional household $S_{1 f b}$ reflects a much higher gain to the male in this household than the new solution point for the traditional household, $S_{1 m b}$.

\section{Figure 2.9:}

\section{Comparison 2: Households with Male Breadwinners Compared to Households with Female Breadwinners}

\section{Figure 2.10: \\ Comparison 2: The Effects of Shifting Fallback Positions}

Again, this results from the position of the male aspiration point in the non-

traditional household. Here the male, $W_{m}^{\prime}$, is positioned along a steeply sloped portion of the WPF, much steeper than in the traditional household, $W_{m b}{ }^{\prime}$. Thus, proportional changes in the aspiration point will be much higher in the non-traditional household than in the traditional household. This means that as the female fallback shifts from $W_{f b}$ to $W_{f b}^{\prime \prime}$ in the non-traditional household and from $W_{f}^{\prime}$ to $W_{f}^{\prime \prime}$ in the traditional household, the gains from violence awarded to the male in the non-traditional household are higher than those awarded to the male in the traditional household.

When the effect of the reduction in total household well-being is added to this, represented by an inward shift of the WPF, as in the previous example, the total gains 
from violence are offset slightly. The effect of physical violence is to shift the WPF inward, reducing male and female aspiration points. Figure 2.11 clearly demonstrates, however, that the net gains from violence are greater for the male in the non-traditional household than for the male in the traditional household, represented by the vertical

distances between $S_{0 f b}$ and $S_{2 f b}$ and $S_{0 m b}$ and $S_{2 m b}$, respectively. From this comparison, it can be argued that the relative bargaining position of the spouses is only important when the gains from cooperation across households are equal.

\section{Figure 2.11:}

\section{Comparison 2: The Effects of Shifting Fallback Position and WPF DISCUSSION AND POLICY IMPLICATIONS}

The preceding analysis revealed that, in general, violence will be used where there is the most to gain from doing so, which implicates a complex interplay between absolute and relative resources. Where families can generate large gains from cooperation, violence will be less likely. At the same time, however, it was also shown that where these gains from cooperation are equal across households, high female relative status stimulates the use of violence, again because the attacker has more to gain. Before briefly discussing the policy implications of this insight, a potential theoretical limit should be addressed. The analysis above begs the question of violence by women. If women have traditionally had fewer resources than men, why do not they use violence to appropriate a larger share of household resources, as the model would predict? Here is where gender is really important. Even if it is assumed that women have the same propensity for abuse as men, it would not likely be used to the same effect. For example, it is not likely that female violence would result in shifts in male fallback positions and the well-being possibility frontier, simply due to differences in size and strength between 
men and women. The violence perpetuated by women would not likely cause the same degree of physical damage as the violence perpetuated by men. In addition, social learning could be important here. Not only in terms of learned violence, but also in terms of gender identities. Concepts of masculinity and femininity, in as much as they are tied to resource control, will mediate the use of violence as a resource.

Since violence has a material base, as demonstrated above, efforts to reduce it must also have a material base. Efforts to raise awareness and consciousness, while wellintended, will be of limited effect. However, policymakers must consider a number of issues that come from the analysis above. For example, from both comparisons above, between high and low gain households and between traditional and non-traditional households, it is clear that simply increasing female resources will increase violence. In the first comparison, increasing female resources improves the female's fallback position, which will reduce the total gains from cooperation. In reducing these gains, the gains from violence increase. Similarly, in the second comparison, as women start to earn a larger share of household resources, the gains from violence also increase. This is especially important in the post-industrial economy, since male-status is increasingly threatened. With economic insecurity rising, families are increasingly reliant on female incomes, suggesting the potential for wife abuse to increase in the post-industrial era. In the following chapters, consideration is given to how the relationship between female resources and violence changes when resistance is introduced, but at this point it is clear that policy reform must not only improve female status, discussed in more detail in chapters 3 and 5, but also work to eradicate strains on families. These include tax breaks, as well as work-life balance policies, which have the potential to increase the 
gains from families. Similarly, since violence is used to equalize relations between men and women, policymakers need to think about new ways to deal with this. It is then crucial to reduce wage inequalities, not only within families, between men and women, but also between families and between social groups.

\section{CONCLUSION}

The previous analysis demonstrated the material base of violence. It was argued that household structure, which includes but is not isolated to relative resources, is a key determinant of violence. In summary, it was shown that the gains from cooperation, that is the total gains from the relationship, are instrumental in creating the conditions for

violence. It was also demonstrated that relative status is only a determinant of violence when the gains from cooperation between households are equal. This represents a significant contribution to both economic and sociological theory in the area of wife abuse. 
Figure 2.1:

A Two-Person Cooperative Nash Bargaining Game

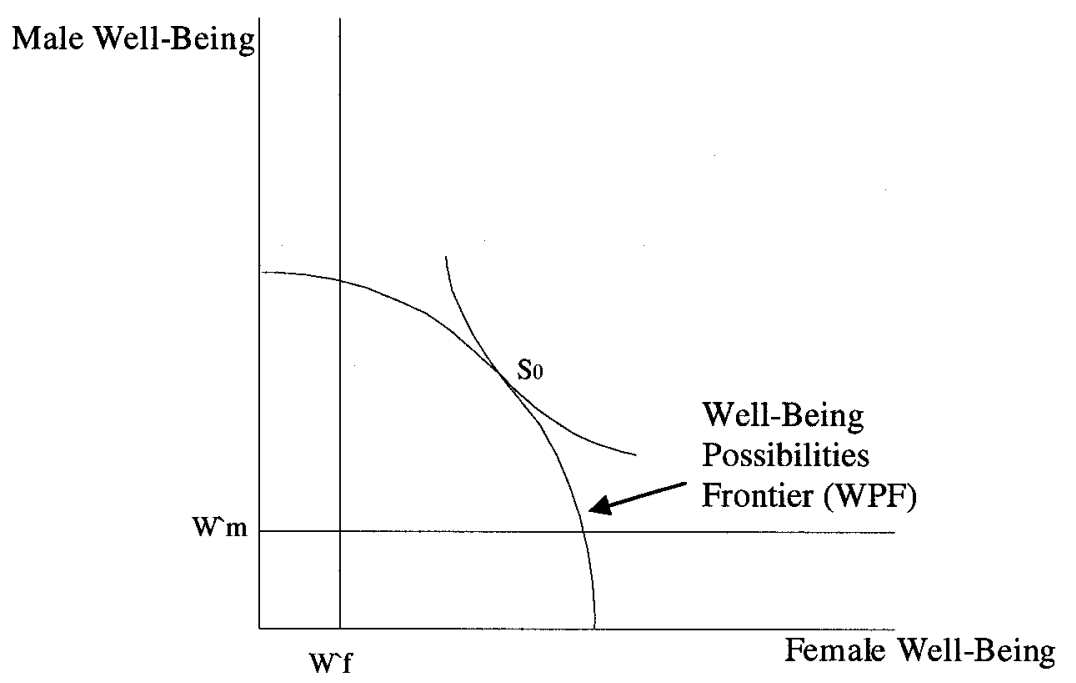

Figure 2.2:

RKS vs. Nash

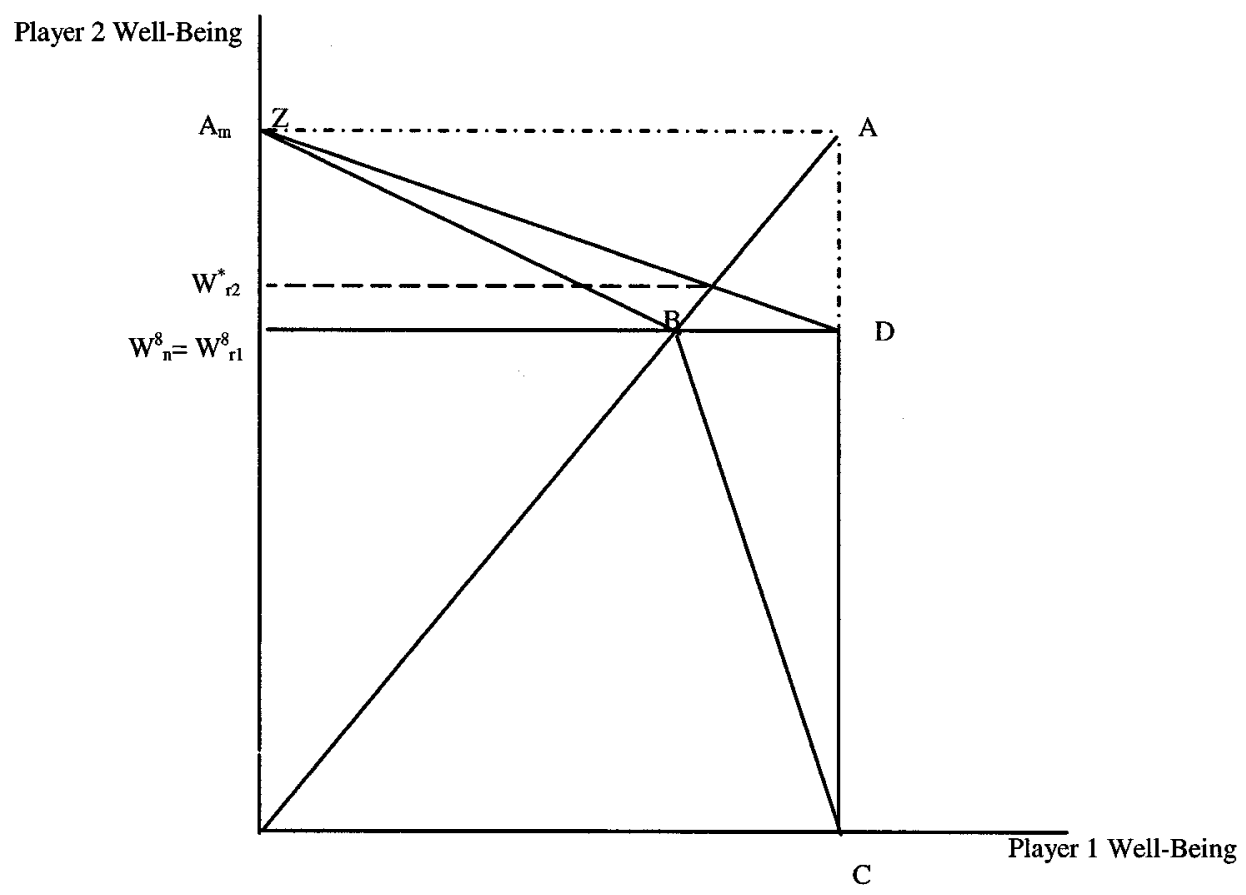




\section{Figure 2.3:}

\section{A Two-Person Cooperative Game: The Raiffa-Kalai-Smorodinsky}

Solution

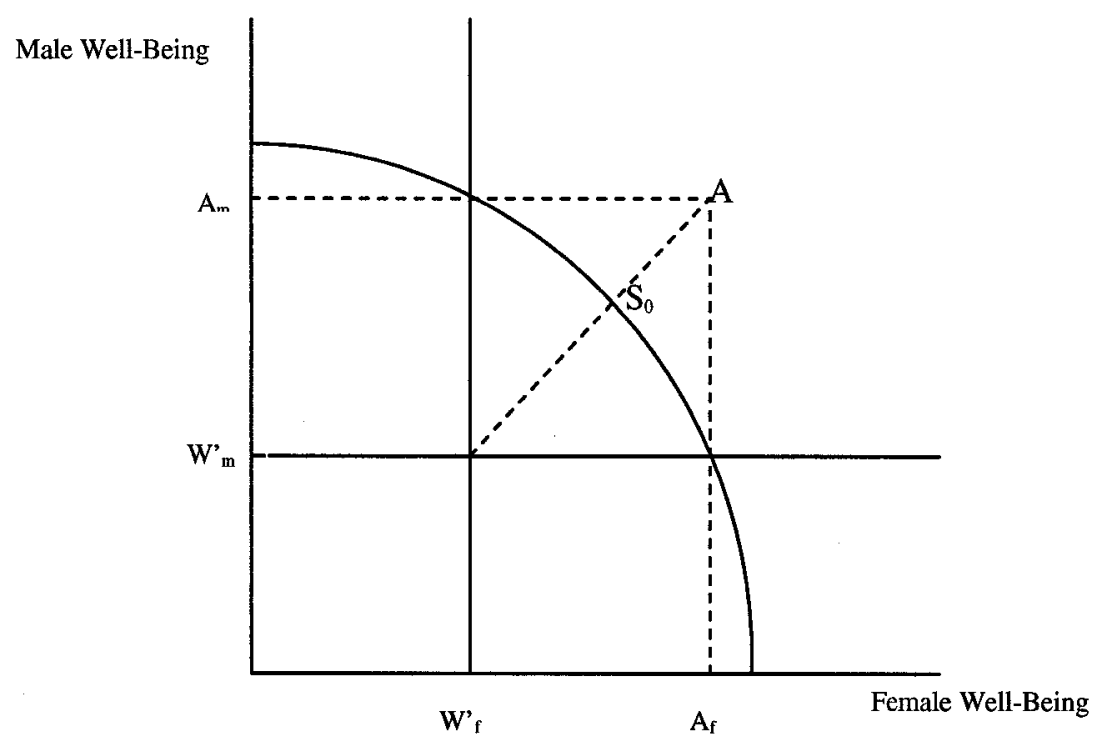


Figure 2.4:

The Effects of Violence 1: Fallback Positions Decrease

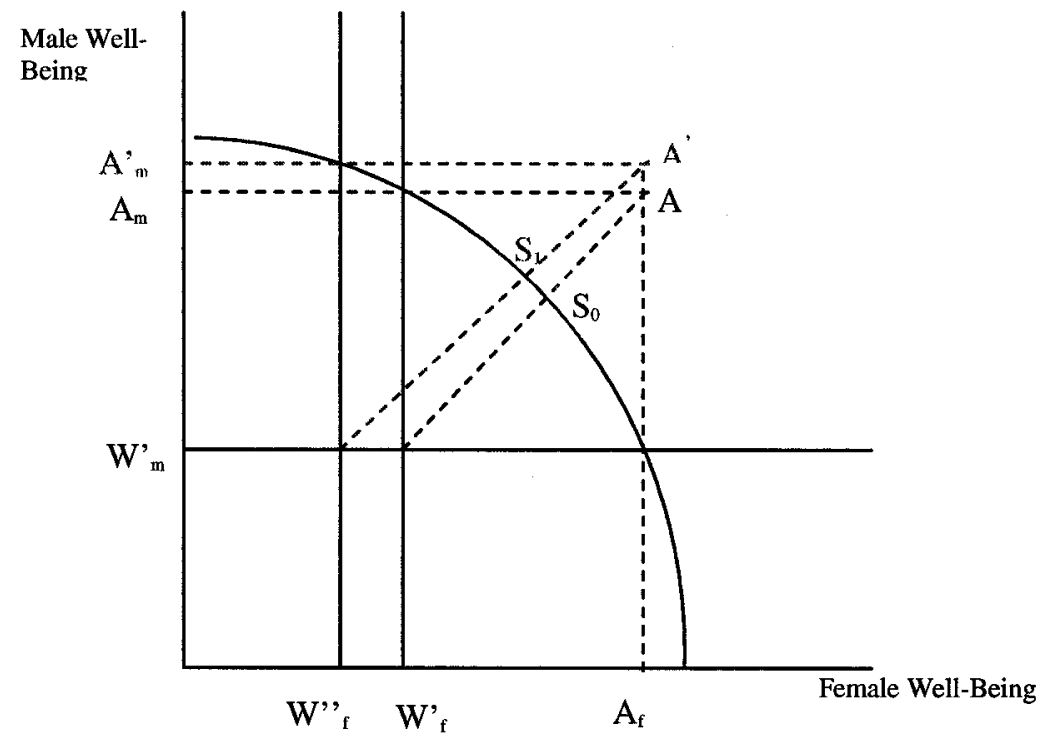


Figure 2.5:

The Effects of Violence 2: Total Household Well-Being Falls

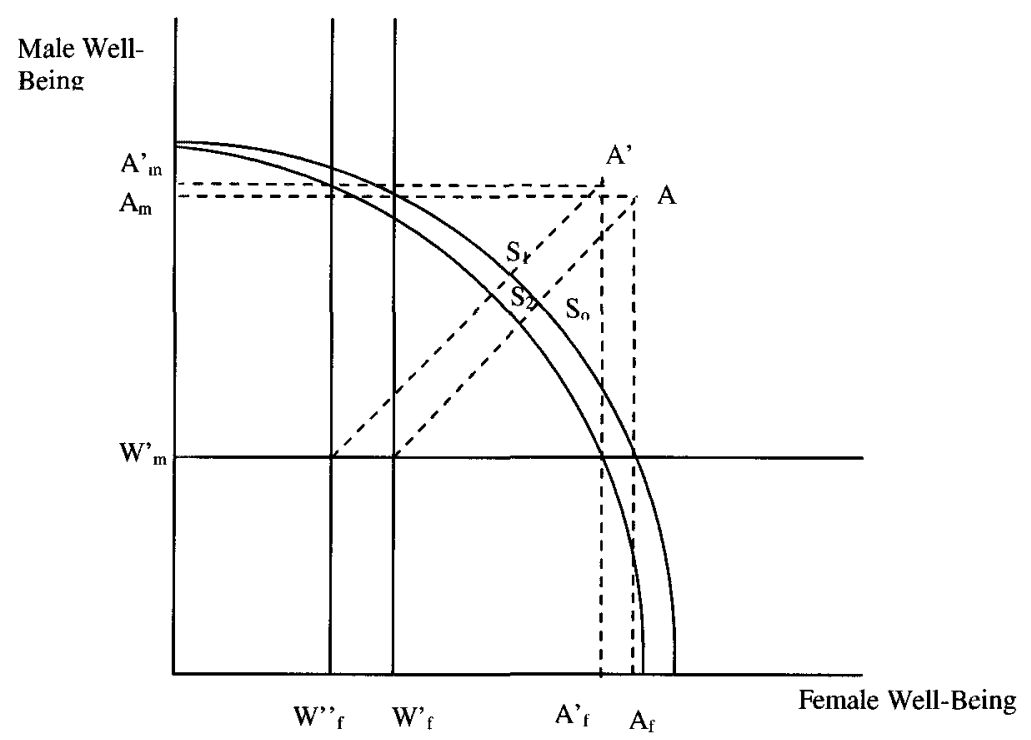


Diagram 2.6:

Comparison 1: Households with High Gains from Cooperation Compared to Households with Low Gains from Cooperation

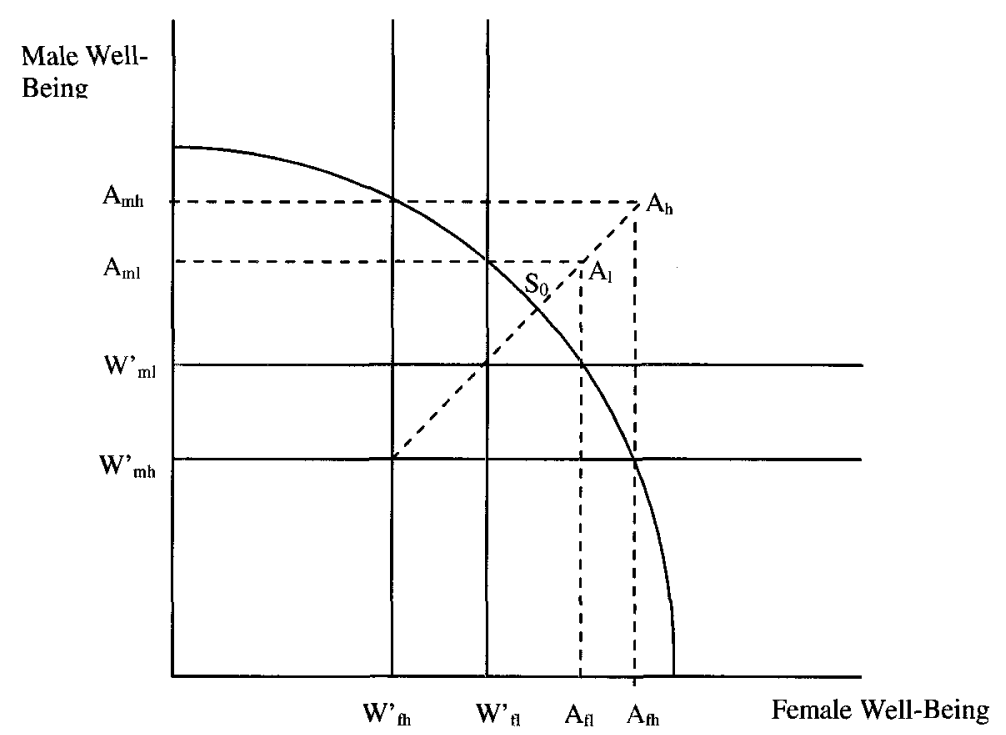


Figure 2.7:

Comparison 1, Cont'd.: The Effects of Shifting Fallback Positions

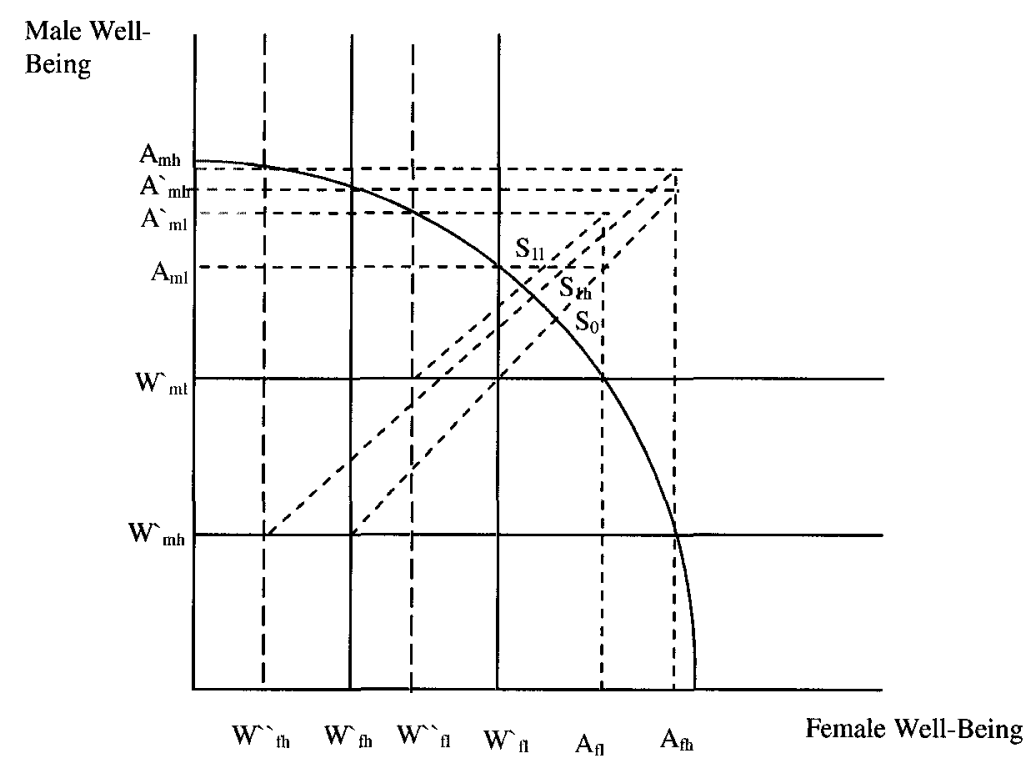


Diagram 2.8:

Comparison 1, continued: The Effects of Shifting Fallback Position and WPF

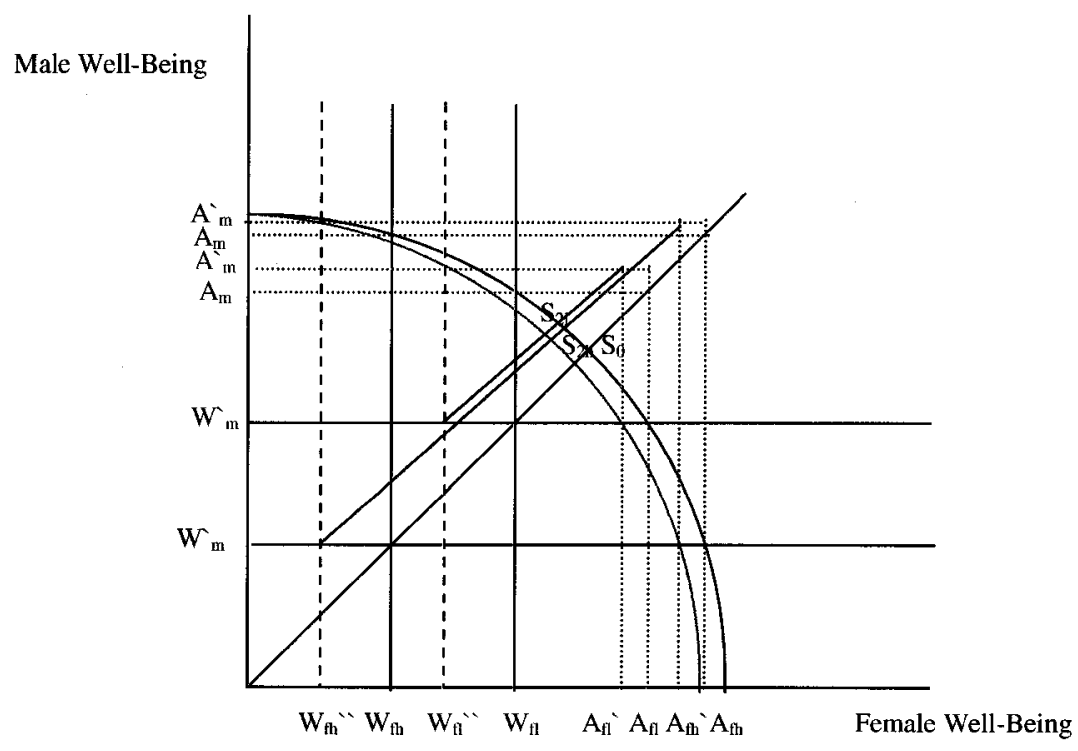


Figure 2.9:

Comparison 2: Traditional Households Compared to NonTraditional Households with Equal Gains from Cooperation

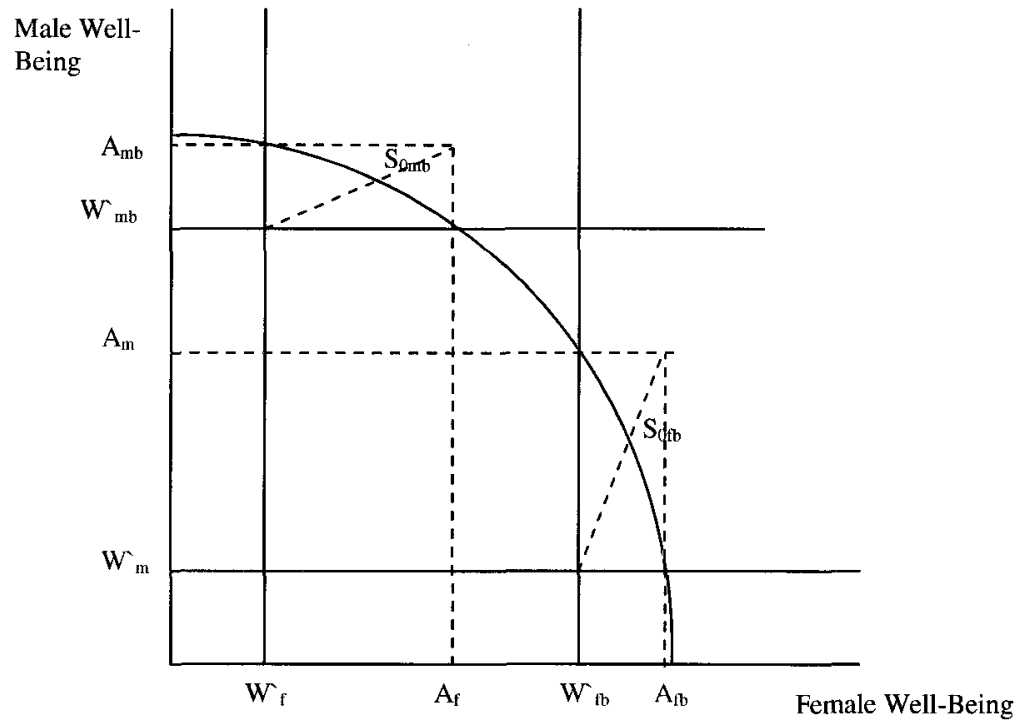


Figure 2.10:

Comparison 2, Cont'd.: The Effects of Shifting Fallback Positions

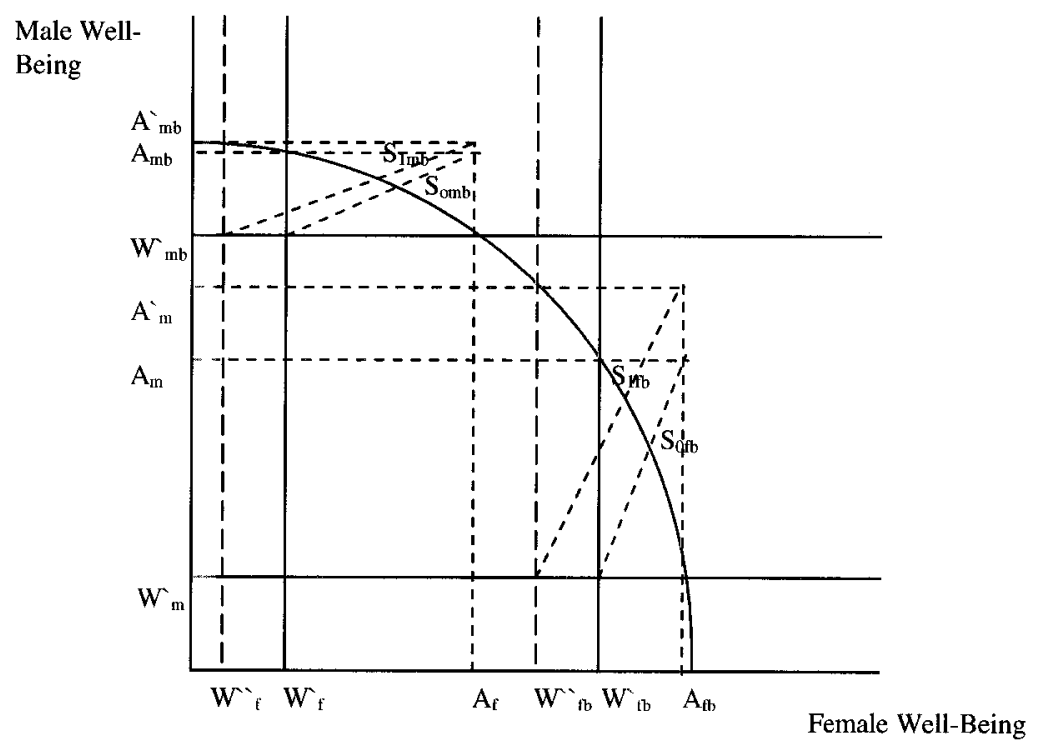


Figure 2.11:

Comparison 2, continued: The Effects of Shifting Fallback

Position and WPF

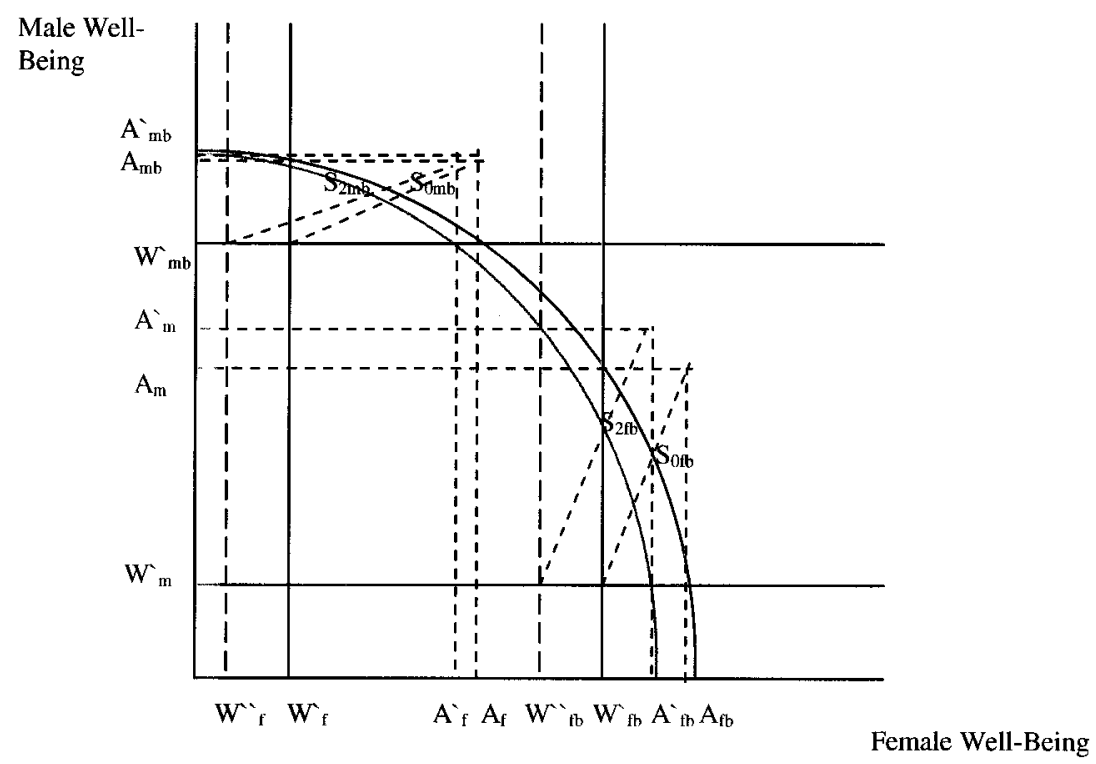




\section{CHAPTER 3:}

\section{(DE)CONSTRUCTING RESISTANCE IN CANADA'S ANTI- WIFE ABUSE POLICY FRAMEWORK: THE LIMITS (AND STRENGTHS) OF EXIT AS A BARGAINING STRATEGY}


In the previous chapter, the conditions under which violence is most likely were analysed, and it was argued that household structure is a crucial determinant in abusive relationships. The dynamics of abusive relationships were also explored, by describing the ways in which violence pervades the bargaining structure, altering the relative position of the agents. In this chapter, that analysis will be expanded, refining the concepts to allow for women's resistance in order to analyse the impact of the current anti-violence policy framework on women's resistance, and thus levels of violence.

Women's resistance to violence is a relatively new study in the field of wife abuse. Aptly named "survivor theory", this nascent theoretical approach challenges the assumption of the helpless victim spawned by early theoretical work in the area, ${ }^{1}$ demonstrating the potential of women to overcome abuse even in the most dire of circumstances. ${ }^{2}$ To date,

${ }^{1}$ See L. Walker, The Battered Woman (New York: Harper Collins, 1979).

${ }^{2}$ See L. H. Bowker, Beating Wife Beating (Lexington, MA: Lexington Books, 1983); E.W. Gondolf and E. R. Fisher, Battered Women as Survivors: An Alternative to Treating Learned Helplessness (Lexington, MA: Lexington Books, 1988); L.A. Hoff, Battered Women as Survivors (London: Routledge, 1990); A.L. Horton and B.L. Johnson, "Profile and Strategies of Women who have Ended Abuse," Families in Society 74:8 (1993) 481-492; A. Sev'er, Fleeing the House of Horrors: Women Who Have Left Abusive Partners (Toronto: University of Toronto Press, 2002); A. Farmer and J. Tiefenthaler, "Domestic Violence: The Value of Services as Signals," American Economic Review 86:2 (May 1996), Papers and Proceedings of the Hundredth and Eighth Annual Meeting of the American Economic Association, 274-279; M. Mahoney, "Exit: Power and the Idea of Leaving in Love, Work, and the Confirmation Hearings," Southern California Law Review 65:3 (1992) 1283-1319, "Legal Images of Battered Women: Redefining the Issue of Separation," Michigan Law Review 90:1 (1991) 1-94, "Victimization or Oppression? Women's Lives, Violence, and Agency," in Fineman, M. and Mykituik, R. 
most of the literature in this area attempts to document the particular experiences of women, with only a few exploring the implications of and for public policy. ${ }^{3}$ This chapter integrates insights from a social constructionist approach, inspired by Bachhi (1999) and Mahoney $(1991 ; 1992 ; 1996)$, into a feminist political economy framework, as articulated by Agarwal (1993; 1997) and Sen (1990), to consider the ways in which the Canadian anti-violence policy framework constructs women's resistance as exit and the "lived effects" of this construction. ${ }^{4}$ The analysis starts with three assumptions: First, that exit does not imply an end to violence. Second, that resistance can potentially constrain violence. And finally, that resistance is shaped by political economic determinants and is thus malleable to policy interventions. It will be demonstrated that the limits imposed on women by the anti-wife abuse policy framework can potentially exacerbate their vulnerability to violence, demonstrating that women's resistance, or lack thereof, is not a question of women's agency, but rather of public policy. The chapter concludes with a brief discussion on policy reform.

(eds.) The Public Nature of Private Violence: The Discovery of Domestic Abuse (New York: Routledge, 1994) 59-92.

${ }^{3}$ See Mahoney $(1991 ; 1992 ; 1996)$, C. Bacchi, Women, Policy and Politics: The Construction of Policy Problems (Sage Publications, 1999) and L. Lakeman, "Why "Law and Order" Cannot End Violence Against Women; and Why the Development of Women's (Social, Economic and Political and Civil) Rights Might," in Canadian Woman Studies (October 2000) for analyses of public policy in this area. See Farmer and Tiefenthaler (1996); Bowker (1983); Gondolf and Fisher (1988); Hoff (1990); Sev'er (2002); and L. Goodman, M.A. Dutton, N. Vankos, and K. Weinfurt, “Women's Resources and Use of Strategies as Risk and Protective Factors for Reabuse Over Time," Violence Against Women 11:3 (2005) 311-336 for analyses of women's resistance.

${ }^{4}$ See Bacchi (1999). 


\section{RESISTANCE AND CANADIAN PUBLIC POLICY}

As discussed in chapter 1 , resistance can be loosely defined as any activity with which women attempt to reduce or eliminate violence and takes place at both micro and macro levels. At the micro-level, the focus of this study, acts of resistance range from coping mechanisms, such as drugs and alcohol ${ }^{5}$, counselling, and compliance ${ }^{6}$, to strategic and/or preventive behaviours, such as deception, informal and formal outreach and intervention, exposure reduction, police intervention, departure from the household and retaliatory violence, including homicide, shown diagrammatically in Figure 1.2 in chapter 1. This diagram suggests that the relationship between these forms of resistance is best thought of as a continuum rather than as a dichotomy, since acts of coping can have strategic effects and vice versa. Interestingly, however, these myriad resistance options are neither recognized nor supported in the Canadian anti-wife abuse policy framework. Rather, antiwife abuse policy in Canada constructs and reinforces the notion of women as victims, thereby neglecting, and often hindering, the multitude of resistance strategies used by abused women. Central to this construction is the implicit characterization of women's agency and power.

It was previously thought by both academics and policy makers that abused women had no agency, that they were helpless victims. ${ }^{7}$ From this perspective, however, agency is

\footnotetext{
${ }^{5}$ The use of drugs and alcohol might be used to deal with the stress of the relationship, thus its
} inclusion as a coping strategy.

${ }^{6}$ Although it seems odd to include compliance as a resistance strategy, one can easily imagine an individual complying with demands to avoid physical pain.

${ }^{7}$ See Walker (1979). 
very narrowly defined, reduced to one's realized choices. ${ }^{8}$ Individuals, or agents, are fully rational, able to exercise "free choice." It is only from this perspective that we can ask the question, "Why do women stay?" and in turn use this question as a tool with which to guide policy. Such a question reveals a lot about the way we think about abused women. First, asking such a question implies that we think that agential abused women will leave.

Certainly no reasonable woman, a woman exercising agency, where agency is reduced to one's realized choices, would stay with an abusive partner. Second, and related to the first, asking such a question reveals that we think that abused women should leave. Where they do not, they have made a conscious "choice" or they simply lack agency. ${ }^{10}$ Thus, policy has been targeted to these women - women without agency. Women "with agency" leave or consciously stay and are thus defined away from the core policy framework. Mahoney's similar analysis (1992) led her to characterize this dichotomization as the following: "Either you are on the playing field of liberal competition, in which case you require no protection, or you prove into a category as a victim who is being kept off the field" (1306; cited in Bacchi 1999: 169).

Not only are "women with agency" defined away from the policy framework, so too are the options facing women. Because it is assumed that any woman with agency will freely choose exit, the context in which choice is made is obscured. Bacchi (1999: 170171), in an analysis of Mahoney's work on the discourse of choice, suggests that such a

\footnotetext{
${ }^{8}$ For an excellent discussion of agency in sociological literature, see R. Lister, Poverty (United
} Kingdom: Polity Press, 2004).

${ }^{9}$ See Mahoney $(1991 ; 1992 ; 1996)$ for an analysis of exit and choice discourse in anti-violence policy.

$$
{ }^{10} \text { Ibid. }
$$


perspective "[...] presumes that choice is a possibility. Hence, if the woman stays, it is assumed that she 'chose' to do so - in which case things mustn't have been so bad - or she had become so traumatized that she was incapable of choice. The power of a 'choice' discourse [...] avoids consideration of the structural prerequisites for meaningful choice [...]." Never is it considered that women simply do not have a choice, due to social and economic resource distribution, fear, etc.; rather they are conceptualized as lacking agency, that they are unable to define their goals and act upon them.

It is these women who have been the targets of public policy. Thus, the Canadian policy framework has been premised on "awareness" and "protection."11 Women who stay, especially women "without agency", have been targeted by awareness campaigns to inform them of their situation, since it is assumed that they are not aware of their circumstances. In addition, because resistance is constructed as exit, where exit is erroneously assumed to end violence, policies have been developed in an attempt to make it easier for women "without agency" to leave. This suggests that leaving, rather than simply ending violence, is the goal of the anti-wife abuse policy framework. The goal of policy, however, should not be imposing exit on women, but rather eliminating violence from their lives, regardless of whether or not they want to leave. Instead, no-drop policies, transition homes and shelters, and the New Identities Program are all examples of the ways in which anti-wife abuse policy imposes exit on women and falsely dichotomizes the women who leave as resistors and the women who stay as victims.

\footnotetext{
${ }^{11}$ See S. Burt and C. Mitchell, "What's in a Name?: From Sheltering Women to Protecting Communities," in Pal, Leslie (ed.) How Ottawa Spends 1998-99: Balancing Act: The Post Deficit Mandate (Toronto: Oxford University Press, 1998) 271-292, for a discussion on the shifts in policy from protection to crime prevention under the Chretien Liberals.
} 
Such a perspective not only removes violence from its social, political, and economic context, neglecting the conditions under which abuse occurs, but it also fails to acknowledge and accommodate women's resistance in its various forms. In other words, such a reductionist approach to agency, institutionalized in the anti-wife abuse policy framework, has defined away the myriad ways in which women make attempts to resist their partners, perpetuating and reinforcing the dichotomy of resistance as exit and victimization as staying. When agency is reconsidered as something much more broad, such actions become central, implicating the importance of intersectional axes of oppression, such as gender, class, race and culture and (dis)ability, in shaping women's resistance. As noted in chapter 1, following the approaches of Sen (1990), Agarwal (1993; 1997), Folbre (1996) and Bowles and Gintis $(1993 ; 2001 ; 2002)$, agency includes much more than one's realized choices, enveloping mechanisms of informal power and indirect freedom. ${ }^{12}$ Agency becomes less about what one gets, and more about how one gets it. Kabeer (1999: 438) defines agency as:

[...] the ability to define one's goals and act upon them. Agency is about more than observable action; it also encompasses the meaning, motivation and purpose which individuals bring to their activity, their sense of agency, or "the power within." [...] It can take the form of bargaining and negotiation, deception and manipulation, subversion

\footnotetext{
${ }^{12}$ Sen (1990: 127) makes a distinction between well-being and agency, noting that "Although
} there are obvious links between a person's well-being and the fulfillment of his or her other objectives, the overall success as an agent may not be closely connected - and certainly may not be identified - with that person's own well-being”. Refer to A. Sen, “Gender and Cooperative Conflicts,” I. Tinker (ed.), Persistent Inequalities: Women and World Development (New York: Oxford University Press, 1990) 123149. See also V. Iversen, "Intrahousehold Inequality: A Challenge for the Capability Approach?” Feminist Economics 9:2/3 (2003) 93-116 and P. Pettit, "Capability and Freedom: A Defence of Sen," in Economics and Philosophy 17:1 (2001) 1-20, for an interesting discussion of the implications of Sen's conceptualization of indirect freedom. 
and resistance, as well as more intangible, cognitive processes of reflection and analysis.

A similar definition has been adopted by Agarwal $(1993 ; 1997)$, for whom agency, and indeed resistance, is often covert and subtle.

For Janeway (1980) and hooks (1984; 2002), the rejection of an external identification of oneself as "powerless" is a powerful form of resistance in itself. hooks writes, "Women need to know that they can reject the powerful's definition of their reality that they can do so even if they are poor, exploited, or trapped in oppressive circumstances. They need to know that the exercise of this basic personal power is an act of resistance and strength." ${ }^{13}$ In challenging the victim-agent dichotomy characterizing much of the literature on wife abuse, Lempert (1997: 291) writes: "[...] the "victims" are also active agents defining, interpreting, and negotiating with their partners and with others. As "victims" they are not entirely passive and as "agents" they are not co-acting equals in their interactions with male partners." Implicit here is also a reconceptualization of "power" from a negative association of simply command and control to a positive association including acts that are "creative and life affirming", ${ }^{14}$ focusing on capabilities and functionings. ${ }^{15}$

${ }^{13}$ b. hooks, bell, Feminist Theory: From Margin to Center, $2^{\text {nd }}$ ed. (Cambridge, MA: South End Press, 2000) 92.

${ }^{14}$ Ibid. 85. See also A. Allen, The Power of Feminist Theory: Domination, Resistance, Solidarity (Boulder: Westview Press, 1999), who reconceptualizes power along lines similar to the capabilities approach, as developed by Nussbaum and Sen (1993), which conceives of power as multidimensional. Allen's approach includes 'power-over', 'power-with', and 'power-to'. See M. Nussbaum and A. Sen (eds.), The Quality of Life (Oxford: Oxford University Press, 1993).

${ }^{15}$ Sen (1990). See also Nussbaum and Sen (1993) and Allen (1999). 
The point here is that if women are agents, in the broad sense, then they are by implication self-aware. And if they are self-aware, they are cognizant of their adverse circumstances. If this is the case, then women's resistance is shaped and constrained not by a lack of agency, caused by, for example, false consciousness, but rather by external constraints, including political, economic and social opportunities structures. ${ }^{16}$ Thus, when agency is reconstructed, and simultaneously conceptualizations of power, women's resistance is not a question of agency, or lack thereof, but rather a question of public policy. Furthermore, like violence, resistance is perhaps best thought of along a continuum. The question then is not either/or, but rather how much and to what effect.

If women resist and if resistance is shaped and constrained by public policy, then an important inquiry regards how certain policy regimes impact the lives of women. In other words, how well or how poorly does the current anti-violence policy framework help women in their attempt to eliminate violence from their lives? If a particular policy framework constructs women's agency, and consequently resistance, in a constricting way, what does this mean for both the targets of this framework and those who have been defined away from it? The rest of this chapter is devoted to demonstrating the perilous effects of such policy construction. In what follows, a household bargaining framework is adopted to illuminate the various tensions placed on women as they attempt to resist violence. It will be shown that far from making it easier for women to leave, the current anti-violence policy framework not only makes it difficult for women to leave, but it also has the potential to

${ }^{16}$ See Sen (1990; 1993); J. Scott, Weapons of the Weak: Everyday Forms of Peasant Resistance (New Haven: Yale University Press, 1985); B. Agarwal, A Field of One's Own: Gender and Land Rights in South Asia (Cambridge: Cambridge University Press, 1993) and "'Bargaining' and Gender Relations: Within and Beyond the Household," Feminist Economics 3:1 (1997) 1-51. 
hinder all resistance attempts. Finally, it will be shown that policy must seek to achieve the elimination of violence, which might or might not include departure from the household. Doing this will require an explicit accommodation of various resistance attempts, as well as providing women with the tools of exit, which will require radical political economic restructuring. Without policy reform, resistance attempts will be of limited effect in reducing violence.

\section{RESISTANCE AND HOUSEHOLD BARGAINING}

To analyse the effects of this construction of resistance, a framework is required which can accommodate these concepts of power, agency and constraints. In other words, a framework that can accommodate both negative and positive forms of power, one that offers room for strategic action and emphasizes constrained choice. It is suggested this framework can be found in the game theoretic approach. Game theoretic approaches are useful to us for several reasons. ${ }^{17}$ First, because they accommodate both negative and positive forms of power, they offer researchers a way through which to analyse the actions of both the oppressor and the oppressed. Second, while traditional bargaining approaches implicate only political-institutional and/or economic contexts in which bargaining takes places, more

\footnotetext{
${ }^{17}$ Applied to wife abuse, game theoretic approaches have been used to explore the role of income increases among both women and men, the effect of violence on labour supply, and the use of social services as signalling devices to negotiate lower levels of violence. This literature has been instrumental in revealing the power of women to resist to violence. See Farmer and Tiefenthaler (1996), "An Economic Analysis of Domestic Violence," in Review of Social Economy LV:3 (Fall 1997) 337-358, and "Explaining the Recent Decline in Domestic Violence," in Contemporary Economic Policy 21:2 (April 2003) 158-72; H. Tauchen, Long and A. Dryden Witte, “The Dynamics of Domestic Violence," The American Economic Review 85:2 (1995) 414-418.
} 
recent heterodox approaches include elements of the social environment that shape not only the procedural dimensions of bargaining, but also the substantive dimensions of negotiations, depicting strategic action as both product and determinant of social relations situated within the political economy. ${ }^{18}$ One of these approaches, cooperative-conflicts, informs the following conceptual framework of violence and resistance.

Inspired by both orthodox and neo-Marxian economics, as well as political theorists such as James Scott $(1985 ; 1990)$, cooperative-conflicts is an approach deriving from, but inherently critical of, cooperative game theory. Households are marked by both cooperation, actions and processes which benefit the group, and conflict, actions and processes which benefit the self at the expense of the group. ${ }^{19}$ Cooperative-conflicts approaches seek to reveal how individuals in households both cooperate and conflict and to what effect. Individuals must bargain over how to share the gains from cooperation. In traditional cooperative games, allocative outcomes are driven by each agent's fallback position (threat point), which defines what each agent receives in the event of disagreement. The fallback/threat point is typically characterized by material endowments such as accumulated wealth, income and other assets. Cooperative games are solution oriented, in that they assume an efficient outcome and work backwards to determine the conditions necessary to arrive at that solution. They are often characterized by perfect information and symmetry in voice and exit.

${ }^{18}$ Sen (1990); Agarwal (1993; 1997); and E. Katz, “The Intra-household Economics of Voice and Exit," in Feminist Economics 3:3 (1997) 25-46.

${ }^{19}$ See H. Hartmann, "The Family as the Locus of Gender, Class, and Political Struggle: The Example of Housework," in Feminism and Methodology, S. Harding (ed.) (Bloomington and Indianapolis: Indiana University Press, 1987) 109-134; and Sen (1990: 129). 
In contrast, cooperative conflicts, as developed by Amartya Sen (1990), highlights the importance of social, economic, and political contexts, which generate power imbalances, thereby abandoning the assumption of symmetry of voice and exit in traditional games. This approach also discards the assumption of an efficient outcome. Compared to traditional cooperative games, cooperative conflicts approaches expand the fallback position to include not only personal economic variables, such as access to education, income and employment, but also economic resources belonging to social networks, communities, and states, ${ }^{20}$ as well as social resources, such as physical strength, age, beauty, ${ }^{21}$ and perceptions about one's contributions and interests. ${ }^{22}$ In addition, cooperative conflicts approaches emphasize the importance of intra- and inter-group norms and values in determining the bargaining context. Mentioned above, this context determines not only the procedural context of bargaining, but also its substantive dimensions. In other words, legitimacy, as determined by families, communities, and states, conditions both the rules of the game and what can actually be bargained over. ${ }^{23}$ As a result, power imbalances originating in the political economy, through multiple axes of oppression premised on gender, race, age, etc.,

${ }^{20}$ Agarwal $(1993 ; 1997)$

${ }^{21}$ N. Folbre, Who Pays for the Kids: Gender and the Structures of Constraint (London: Routledge, 1994).

${ }^{22}$ Regarding perceived interests, Sen (1990) allows for false perceptions of individual needs and interests, where Agarwal $(1993 ; 1997)$ rejects this position. Instead, Agarwal argues that it is not false perceptions of one's own needs and/or interests that prevents them from acting overtly in their own self interest, but rather external constraints, including material and social elements. The analysis offered in the present study adopts Agarwal's approach.

${ }^{23}$ Agarwal (1997). 
will filter into the bargaining process and outcome in key ways. Finally, in cooperative conflicts, all bargaining is dynamic - the outcome of one session will influence the outcomes of all future sessions.

This approach, with an emphasis on power imbalances derived from social relations and enforced by states and markets, is a useful approach with which to study abusive relationships. It offers a metaphor for intra-household relations, demonstrating the various ways in which individuals try to get what they want. By situating violence and its resistance in the material world, implicating the political, economic, and social conditions that give rise to abuse and shape its resistance, it provides the basis through which to expose the inner workings of these relationships, as well as the necessary linkages to the political economy which will inform prescriptions for public policy reform in this area.

In the present analysis, this approach is used to develop a two-stage "game". In stage 1 , at time $T_{0}$ the couple enters a cohabitating relationship. At this time, the couple must bargain over the gains from cooperation. It is at this point that the gains from violence become obvious to the abuser, who must then decide whether or not to use violence in order to increase his well-being. If the expected payoffs from abuse, in the form of either direct gratification or resource control, exceed what he can get if he does not use violence, then he will engage in violent behaviour. As defined in chapter 1, violence is as any form of controlling and/or abusive behaviour or threats thereof that imposes harm on its victims, and is motivated by both expression and instrumentality. ${ }^{24}$ Violent behaviour can include emotional abuse, economic abuse, and physical violence and its threat.

\footnotetext{
${ }^{24}$ See chapter 1 for a more thorough discussion of violence.
} 
It is important at this point to make a couple of observations about the nature of violent relationships. First, not all violent relationships are characterized by physical abuse. Indeed, the most common forms of abuse are non-violent (and legal), including emotional, psychological and financial. ${ }^{25}$ Second, physically violent relationships often do not begin that way; rather, violence escalates from non-physical (or non-severe forms of physical violence, such as slapping) to physical forms of abuse. ${ }^{26}$ For these reasons it can reasonably be assumed that abusive relationships begin with non-physical forms of abuse and might or might not become physically violent. In addition, it can be assumed that different forms of abuse have different effects on the bargaining process, discussed in chapter 2 and elaborated below.

From these assumptions, it follows that if the attacker engages in violent behaviour, he begins at $T_{1}$ using threats of violence, non-physical and/or non-severe forms of abuse. This can take various forms, including name-calling, controlling and/or manipulative behaviour and jealousy, limiting access to family income, slapping, and threats of physical violence to his partner or third parties, such as friends, family member, and pets. This situation reflects the majority of abusive relationships. However, at time $T_{2}$, the attacker decides whether or not to engage in actual physical violence, which, it will be shown, can potentially reduce total household well-being while keeping him better off than if he had not used violence. Thus, in stage 1 , the attacker uses violence to increase his well-being within marriage.

${ }^{25}$ See Statistics Canada, Family Violence in Canada: A Statistical Profile (Ottawa: Statistics Canada, 2000-2005).

${ }^{26}$ Sev'er (2002: 80). 
Up until this point, it has been assumed that the woman is not resisting. In stage 2, however, the couple will "bargain over violence", where women's resistance is introduced. Here it is shown the various ways in which resistance, both exit and non-exit, can constrain violence by altering the expected gains from violence articulated in the first period, as well as the ways in which resistance itself is constrained by conditions arising from the political economy, largely through the policy framework. Thus, at time $T_{3}$, the woman must choose her resistance strategy. Her choice will reflect both the options available to her, including the constraints imposed on her by the anti-wife abuse policy framework, and the expected outcome from the strategy. In other words, it is assumed that resistance constrains violence, but the degree to which it does so varies by strategy. Each of these stages will be discussed in depth, illuminating areas for policy reform.

\section{Stage 1: Bargaining over Resources}

To consider the conditions under which violence arises is to consider what abusers have to gain from such actions. Thus, researchers must consider the gains from relationships, as argued in chapter 2 , and explore the impact of violence on distributing these gains. As described above, at $T_{0}$ the cohabitating relationship begins and the couple must allocate resources through bargaining. The goal of bargaining is to ensure that one remains at least as well off within the marriage than outside of it, where well-being is determined by some combination of private and household goods. Household goods are analogous to public goods in that they are non-excludable: one person's use of the good does not preclude the other person's use of the good. By implication, a large number of goods can fall under this description, including a clean house and common rooms, as well as market goods such as appliances and entertainment. 
In general, individuals face a trade-off between private and household goods, as shown by the shape of the well-being possibilities frontier (WPF) in Figure 3.1. The WPF represents all of the possible combinations of male $W_{m}$ and female $W_{f}$ well-being from marriage. In traditional cooperative games, all combinations of $W_{m}$ and $W_{f}$ falling along the WPF are Pareto efficient, that is, it is not possible to make one person better off without making the other person worse off, and all combinations falling within the frontier are inefficient. As explained in chapter 2, money or time spent on personal production or consumption cannot be spent on household production or consumption and vice versa. And when time or money is allocated to the household, all members of the household get to enjoy the goods produced. So if individuals can, through bargaining that is either explicit or implicit, get the other person to contribute more of his or her time or money to the household, then they get to spend more of their money or time on themselves and still enjoy the same amount of the household good. Similarly, if individuals can get the other person to sacrifice his or her own personal time or money for their personal consumption, given that a minimum level of household good is provided, then they benefit even more. For example, sacrificing time with friends and family to prepare a meal for her partner. These gains, either monetary or temporal, capture what each individual gains from the relationship and become what individuals bargain over. And it is this allocation, including both quantitative and qualitative dimensions, that provides the rationale for violence. ${ }^{27}$

\footnotetext{
${ }^{27}$ To clarify, consider an example. Violence is often correlated with pregnancy, although there is considerable debate surrounding this issue. See Statistics Canada, Wife Assault: The Findings of a National Survey (Ottawa, Canada, 1994) (prepared by Karen Rodgers); and J. Janiski, "Pregnancy and Violence Against Women: An Analysis of Longitudinal Data," in Journal of Interpersonal Violence 16:7
} 


\section{Figure 3.1: \\ $T_{0}:$ A Two-Person Cooperative Game with Outside Options}

Bargaining is driven by voice, fallback positions, and outside options. Voice captures one's ability to bargain. It is determined by politico-legal institutions, such as gender equity legislation, as well as social norms and values; as a result, voice will vary historically and culturally, as well as by gender. It not only reflects a person's ability to enter the game, but also their ability to initiate the game. In effect, some individuals are able to determine the substantive dimensions of bargaining while others are not. In Figure 3.1, voice is depicted in the shape of the isoquants, $v_{i}$, which represent all of the combinations of $W_{m}$ and $W_{f}$ that yield the same total gains from bargaining. As female voice decreases the isoquants become less steep, pushing the solution point in favour of the male. At this stage, however, it is assumed that individuals are symmetric in voice. ${ }^{28}$

Fallback positions, also referred to as threat points, $W_{m}{ }^{\prime}$ and $W_{f}{ }^{\prime}$, reflect what each individual gets in the event of a breakdown in bargaining. In traditional games, they are (July 2001) 712-733. Pregnancy and childrearing require a tremendous amount of time and money. More specifically, it requires allocations of time and money that, while one might reap benefit from, is spent largely on another individual. In terms of intra-household relations, pregnancy and childrearing occupy the mother's time and, often, her money, which means that her time and money are diverted from her partner. Refer to the 'good mother hypothesis' analysed in F. Woolley, "Why Pay Child Benefits to Mothers?" Canadian Public Policy 30:1 (2004); Z. Chen and F. Woolley, “A Cournot-Nash Model of Family Decision Making," Economic Journal 111 (2001); and S. Lundberg and R. Pollak, "Separate Spheres Bargaining and the Marriage Market," Journal of Political Economy 101:6 (1993). In this context, violence can be seen as an instrument through which to direct the allocations of her time and money.

${ }^{28}$ This is not to suggest that abusive relationships are egalitarian to start, but rather to have a simple baseline with which to begin analysis. 
determined by an individual's access to employment, income, and education. In cooperative-conflicts approaches, as mentioned above, fallback positions include not only personal endowments, such as access to employment, income, and education, but also the endowments of social networks, communities and states. ${ }^{29}$ In addition, they can include social dimensions, such as perceived contributions and internal/external valuation of those contributions, ${ }^{30}$ as well as socially valued attributes such as beauty, youth, and physical strength. $^{31}$ In general, individuals with better fallback positions do better in bargaining. Early literature on household bargaining modelled threat points as a divorce option, where breakdowns in bargaining are met with literal exit. ${ }^{32}$ Criticism has focused on two key problems, however. On the one hand, it was noted that the nature of household bargaining is not always conducted in the shadow of divorce. For example, bargaining over who does the dishes will not necessarily lead to divorce if the couple cannot agree. ${ }^{33}$ In other words, the use of a divorce threat is not a realistic formulation for household bargaining. On the other hand, the divorce threat was acknowledged to be Western-centric,

\footnotetext{
${ }^{29}$ Agarwal (1993; 1997)..
}

${ }^{30}$ See Sen (1990).

${ }^{31}$ See Folbre (1994).

${ }^{32}$ See M. Manser and M. Brown, "Marriage and Household Decision Making: A Bargaining Analysis," in International Economic Review 21:1 (1980) 31-44 and M. McElroy and Mary Jean Horney, "Nash-Bargained Household Decisions: Towards a Generalization of the Theory of Demand." International Economic Review 22:2 (1981) 333-49.

${ }^{33}$ See Woolley (1988) and Lundberg and Pollak (1993). 
where it was assumed not only that all women had access to exit options, but also that access to exit was symmetric to her partner's. ${ }^{34}$

The results of these criticisms were twofold. First, researchers shifted to the use of non-cooperative games to model household interaction, which are strategy driven as opposed to solution driven. ${ }^{35}$ Second, where cooperative games were used, a number of studies adopted a non-cooperative equilibrium as the fallback position, which results in temporary exit from bargaining, not the relationship. ${ }^{36}$ In non-cooperation, individuals underinvest in or underprovide household goods. Rather than both benefiting from the gains from cooperation, each takes the other person's contribution as given. As in public goods games, each individual's contribution is made on the assumption about the other person's contribution, which leads to underprovision. In this situation, couples remain in the relationship but do not benefit as much as if they cooperated.

While these shifts reflect a considerable improvement over the early divorce threat models, the effect of outside options as analytically distinct from the fallback remains

\footnotetext{
${ }^{34}$ See Katz (1997).

${ }^{35}$ See S. Lundberg and R. Pollack, "Bargaining and Distribution in Marriage," Journal of Economic Perspectives 10:4 (Autumn 1996) 139-158 and "Noncooperative Bargaining Models of Marriage," American Economic Review 84:2 (May 1994) 132-137.

${ }^{36}$ See F. Woolley, “A Non-cooperative Model of Family Decision Making” (London: London School of Economics Manuscript, 1988); Woolley and Chen (2001); Lundberg and Pollak (1993; 1994; 1996); and A. Muthoo, Bargaining Theory with Applications (Cambridge, UK: Cambridge University Press, 1999)
} 
understudied. ${ }^{37}$ Where fallback positions are non-exit points, reflecting exit from bargaining but not the relationship, outside options represent an individual's actual exit options, depicted as $E_{f}$ in Figure 3.1. Fallback positions reveal what each individual automatically gets when bargaining breaks down; however, individuals only receive their outside options if they take them. Outside options must be acted on to benefit from them. Thus, unlike fallback positions, outside options have no determinative effect on the solution point. ${ }^{38}$ Rather, they constrain the solution to a minimum level of well-being. This constraint is binding if and only if the outcomes are better than that offered from within the relationship. If bargaining outcomes cannot provide this minimum level of well-being, the individual exits and remains at least as well off as they would have been from the bargain.

Key here is that as long as one's outside options are worse than what is offered by staying married, the options are ineffective in imposing a particular outcome; the constraint is not binding. For example, if divorce provides an alternative that is worse than remaining married, a woman will not divorce her partner. If bargaining breaks down in this case, individuals end up with the level of well-being offered by their fallback. Importantly, the threat of divorce is not credible and thus irrelevant in the bargaining context.

The key insight of outside option theory is that the threat of exit has no effect on outcomes unless women are willing and able to leave, and will be instructive in our analysis of the Canadian policy framework. Furthermore, outside options have not previously been

${ }^{37}$ See Muthoo (1999) for an application of this concept to household bargaining. Note also that Tauchen, Witte and Long's, (1991) classic study explored the impact of opportunities outside the household in the context of violent relationships, but used a non-cooperative model.

${ }^{38}$ Muthoo (1999). 
incorporated into cooperative-conflict theories of marriage, and thus provide an excellent opportunity to consider the impact on allocative outcomes within households. Mentioned above, in the context of the household, taking one's options would not only reflect an exit from bargaining, but also from the relationship. From the perspective of violent relationships in Canada, outside options include both the ability to divorce or separate and police intervention. ${ }^{39}$ Note that police intervention is included as an outside option here because of the pro-arrest and pro-prosecution, "no drop" policies, that characterize police and court intervention in Canada. Under these policies, if a woman calls the police she has committed to an exit strategy, regardless of whether or not she wants to, or can, exit. This will be discussed in more detail below. For simplicity, it is assumed that only the woman has outside options available to her and that these options only become important in stage 2 , where individuals bargain over violence. Figure 3.1 above, reveals a typical solution to a household bargaining game and provides the starting point for the analysis.

Recall from the discussion above that an attacker will use violence when his expected payoffs from doing so exceed what he will get at $S_{0}$, shown in Figure 3.1, the outcome he will get if he does not use violence. Since violence is both expressive and instrumental, these payoffs do not come only from gratification. Thus, violence must do something to the allocative outcome arrived at in $T_{0}$.

Recall from above that it was assumed that when violence begins, it takes the form of non-physical abuse, which can include emotional or psychological abuse, as well as financial abuse and threats of violence to the woman or third parties such as family members, friends, and pets. At $T_{1}$, then, non-physical violence is used to obtain a better

\footnotetext{
${ }^{39}$ Outside options can also include homicide, which is not addressed by the present study.
} 
payoff from bargaining than offered by $S_{0}$. Such abuse often takes for form of controlling behaviour, such as restricting her access to employment, income, and family and friends, as argued in chapter $2 .{ }^{40}$ Employment and access to social networks contribute to the resources a woman will need in the event that negotiations break down; they constitute part of her fallback position. In effect, this form of violence results in an inward shift of her fallback, moving from $W_{f}^{\prime}$ to $W_{f}^{\prime \prime}$ in Figure 3.2.

Figure 3.2:

\section{$T_{1}$ : The Effects of Violence 1: Female Fallback Positions and Voice Decrease}

Shifts in the fallback will reduce her bargaining power, shifting the solution from $S_{0}$ to $S_{1}$. Essentially, she will be less able to negotiate how she spends her time or money. With more relative bargaining power, he is able to ensure that her time or money is spent on the household or given to him directly via intra-household transfers, leaving more (less) of his (her) income for personal consumption.

In addition, this type of abuse often includes demeaning and degrading behaviour, such as name-calling and humiliation. For example, it is not uncommon for abusers to control the types of activities that are engaged in (i.e., sex, household labour, etc.), in addition to the ways in which those activities are done, such as wearing specific clothes, demanding specific behaviours, etc. ${ }^{41}$ The consequences of these acts are significant from a

${ }^{40}$ See A.M. Moe and M.P. Bell, “Abject Economics: The Effects of Battering and Violence on Women's Work and Employability," Violence Against Women 10:1 (2004) 29-56.

${ }^{41}$ See Sev'er (2002); Tauchen, Witte, and Long (1991)_ make a similar assumption in their now classic article on the dynamics of abusive relationships. They suggest that abusers derive utility from controlling certain behaviours of their spouse. 
bargaining perspective. Sev'er (2002: 82) summarizes the experiences of the abused women with whom she spoke during a study of resistance as the following, "From what I heard, understood, and felt, most of these women's core sense of self was eroded through their partners' constant put-downs and criticisms." This finding echoes previous stories and studies of abused women. ${ }^{42}$ Consider the following story:

Roy would go out and sometimes not come back for a few days. Nancy
would never know where he went, and she never knew why she was not
included in these escapades. When she complained, Roy would ignore her.
If she continued to complain, Roy would get aggressive. A number of times
she was slapped right on the mouth. 'Close that trap, you bitch!' he could
say. More than once, Nancy was choked and pinned to the door or the wall. ${ }^{43}$

This type of behaviour not only has the effect of restricting the bargaining space, limiting what can actually be bargained over, but also determining who has the power to initiate bargaining. In other words, this type of behaviour restricts her voice.

The effect of this is to reduce the slope of the isoquants, which represent all of the combinations of $W_{m}$ and $W_{f}$ that yield the same total gains from bargaining. With abuse, the slope of the original isoquant, $v_{0}$, becomes less steep, reflected in $v_{1}$ in Figure 3.2. By restricting what can be bargained over, the abuser is able to manipulate the allocative outcome in his favour, shifting the solution upward again to $S_{2}$. With both of these effects, reducing female fallback positions and voice, the attacker is able to control her allocation to ensure that he benefits from both personal and household consumption.

In some cases, abusers might think they can still do better than $S_{2}$, in which case they will resort to more severe forms of abuse at $T_{2}$. The effect of more severe forms of

\footnotetext{
${ }^{42}$ See L. Walker (1979), Hoff (1990).

${ }^{43}$ Sev'er (2002: 90).
} 
abuse is to reduce total household well-being. As discussed in chapter 2, this type of violence might be driven by his desire to have a larger share of a smaller pie, allowing him to be more dictatorial in the household. In contrast, the use of severe forms of abuse might reflect violence that is driven primarily by expression rather than instrumentality, since the gains in male well-being stem from gratification rather than resource acquisition. Despite this loss in total household well-being, however, he can still remain better off from using violence than if he had not. Net gains from violence need not always be the case, however, depending on the time horizon over which violence takes place and its cumulative effects. For example, individuals with a limited ability for self-restraint might not foresee the longterm consequences of their actions. ${ }^{44}$

In cases of extreme violence, both short and long-term disabilities or disfigurement would be expected, which can potentially place severe restrictions on how time is spent. ${ }^{45}$

\footnotetext{
${ }^{44}$ Neo-classical economists would refer to this in terms of discount rates, where the abuser values the present more than the future.

${ }^{45}$ J.C. Campbell and K.L. Soeken, "Women's Responses to Battering Over Time: An Analysis of Change," in Journal of Interpersonal Violence 14:1 (January 1999) 21-40; P.A., Ratner, "Modelling Acts of Aggression and Dominance and Exploring their Adverse Health Effects," in Journal of Marriage and the Family 60:2 (May 1998) 453-465; T. Day and K.M.J. McKenna, "The Health-Related Economic Costs of Violence Against Women in Canada," in K.M.J. McKenna and J. Larkin (eds.), Violence Against Women: New Canadian Perspectives, 313-337; T. Day, The Health Related Costs of Violence Against Women in Canada: The Tip of the Iceberg (London: Centre for Research on Violence Against Women and Children, 1995); L. Greaves, O. Hankivsky, and J. Kingston-Reichers, Selected Estimates of the Costs of Violence Against Women (London: Centre for Research on Violence Against Women and Children, 1995); and S. Lloyd, "The Effects of Domestic Violence on Women's Employment," Law and Policy 19:2 (1997) 137-167.
} 
For example, abused women often report absenteeism from work due to severe beatings. ${ }^{46}$ In addition, lack of sleep, stress, etc., would reduce productivity in either paid or unpaid labour. ${ }^{47}$ By limiting her access to income or by limiting her time in household production, reductions in her fallback position will be subsequently met by reductions in the total gains from cooperation, reducing total household well-being. This is represented by an inward shift in the WPF, as shown in Figure 3.3. ${ }^{48}$ With this type of violence, the solution will not reach $S_{2}$, but rather $S_{3}$ as shown in Figure 3.3.

\section{Figure 3.3:}

\section{$\mathbf{T}_{2}$ : The Effects of Violence 2: Total Gains from Cooperation Fall}

Together these effects determine the "gains from violence" for the abuser. ${ }^{49}$ As violence progresses, it is met with a decrease in female bargaining power through reductions in her fallback position and in her voice, as well as reductions in total household well-being. Now that the effects of violence have been considered, the question is what does resistance do to these gains and how effective is the policy framework in providing women with the tools of resistance?

\section{Stage 2: Bargaining Over Violence}

${ }^{46}$ See Sev'er (2002), Greaves et al (1995); and Lloyd (1991).

${ }^{47}$ See Moe et al (2004).

${ }^{48}$ Violence might also generates inefficiencies, for example by underinvesting in household goods and children or if male gains from violence do not equal female losses.

${ }^{49}$ An interesting question, beyond the scope of this paper, is the degree to which the gains from violence vary across households, for example, by household structure. See chapter 2 , for a specific analysis of this question, where it is posited that households generating lower gains from cooperation are more vulnerable to violence, implicating a complex interplay of both absolute and relative resources in creating the conditions for violence. 
Since violence is used as a mode of domination, ${ }^{50}$ it can be posited that where there is violence, there is resistance. ${ }^{51}$ Thus, at $T_{3}$, resistance in introduced and its constraining effects on violence are considered. At this stage, then, the female must choose her resistance strategy from the scope of options available to her, which include both exit (outside) and non-exit options. Here it is important to consider the differences between these two analytically distinct types of options and the effectiveness of the Canadian anti-violence policy framework in providing them.

As argued above, the goal of the Canadian policy framework is to get women to leave their partners. Also recall two key problems with this framework. First, the antiviolence policy framework obscures the context in which "choice" is made, neglecting the quality of exit options facing women. Second, the framework defines away a number of women who in turn are offered no protection or services from the state. For example, women with agency, those who stay "by choice" are given no assistance from the state. Similarly, women who leave by "by choice" are offered no assistance through core or targeted policies, and only little through general or peripheral policies, such as social

${ }^{50}$ See See I.M. Young, Justice and the Politics of Difference (New Jersey: Princeton, 1990); S .Ruddick, "Injustice in Families: Assault and Domination," Justice and Care: Essential Readings in Feminist Ethics, ed. V. Held (Boulder: Westview Press, 1995); and K. Crenshaw, Mapping the Margins: Intersectionality, Identity Politics, and Violence Against Women of Colour," Stanford Law Review 43:6 (1991).

51 This is inspired by Foucault's (1990: 95) statement: "Where there is domination, there is resistance." However, this statement serves as inspiration only; I am by no means suggesting that my work is comparable to Foucaultian analysis. See M. Foucault, The History of Sexuality, Volume 1: An Introduction (New York: Random House Inc., 1990). 
assistance, subsidized or affordable housing, and legal aid. These insights suggest considerable implications for women's resistance to abuse.

In focusing on exit and choice, the Canadian anti-violence policy framework has defined away the context in which choices are made. Policies such as pro-arrest and proprosecution attempt to offer women outside options, making it easier for them to leave. However, the policy framework targets only the procedural aspects of departure; it does not consider the quality of exit once she departs. This suggests that the outside options provided by the state are not options at all, that is, the constraints are not binding, and as a result, will have no impact on violence.

To see this, consider the analytical framework developed in stage 1 to explore a couple of cases. In the first case, consider divorce/separation. As an outside option, divorce/separation is determined by access to resources, such as those earned in the market as well as those of families, states and communities. Thus, general, or peripheral, policies described in Table 1.1 are crucial in determining the quality of the divorce option for women, represented by line $E_{f}$ in Figure 3.1. If the solution $S_{3}$ at $T_{2}$ is worse than that offered at $E_{f}$ then the woman can credibly threaten divorce/separation at $T_{3}$. In this case, the abuser will receive only the level of well-being offered by his fallback position. Where this threat is credible, it will constrain the solution point to a level of female well-being at least as high as $E_{f}$, which will constrain the use of violence.

If, however, the quality of the outside option is poor, that is, where the level of wellbeing offered by the option is worse than staying in the relationship, it will have no constraining effect on the solution. And there is reason to believe that this is the case in Canada. For example, for many women in Canada, exit will be met with social isolation 
from community and kin groups, especially in small, isolated communities in which violence is most prevalent. ${ }^{52}$ In addition, divorce/separation is one of the most crucial indicators of a woman's economic status, exacerbated by welfare state restructuring and retrenchment. A study conducted by Morrow et al (2004) argued that recent cuts to social services such as social assistance, affordable housing, and legal aid, especially severe in British Columbia, Alberta and Ontario, placed considerable strain on women as they attempt to leave abusive relationships. Finally, to date, the criminal justice system has been ineffective in ensuring women's safety once they leave. ${ }^{53}$ Indeed, many abused women report an escalation of violence during separations. ${ }^{54}$ Furthermore, risk of femicide increases dramatically upon separation. ${ }^{55}$ The inability of the justice system to protect

\footnotetext{
${ }^{52}$ For discussions on the role of culture and abuse, see D. Hassouneh-Phillips, "Polygamy and
} Wife Abuse: A Qualitative Study of Muslim Women in America," Health Care for Women International 22:8 (2001) 735-748; and M.R. Yoshioka and D.Y. Choi, "Culture and Interpersonal Violence Research: Paradigm Shift to Create a Full Continuum of Domestic Violence Services," Journal of Interpersonal Violence 20:4 (April 2005) 513-519. For discussions on the role of norms and values in women's responses to abuse, see Hoff (1990) and S. Woods, "Normative Beliefs Regarding the Maintenance of Intimate Relationships among Abused and Non-Abused Women," Journal of Interpersonal Violence 14:5 (May 1999) 479-491. A recent study conducted by Statistics Canada (2006) revealed that violence against women is most prevalent among Aboriginal women and women living in the territories within Canada. See Statistics Canada, Measuring Violence Against Women: Statistical Trends (Ottawa: Statistics Canada, 2006).

${ }^{53}$ R. Gill and J. Brockman, “A Review of Section 264 (Criminal Harassment) of the Criminal Code of Canada" (Ottawa: Department of Justice Canada, working paper, 1996).

${ }^{54}$ See Statistics Canada. Canadian Violence Against Women Survey. Ottawa, Canada, 1993.

${ }^{55}$ See M. Wilson and M. Daly, "Spousal Homicide Risk and Estrangement," Violence and Victims 8 (1993) 3-15. 
women during separation reduces the quality of exit options. In addition, if women are unwilling or unable to take up their options, discussed in more detail below, the divorce threat will be of little impact in constraining abuse.

In addition to divorce or separation, women have the option of calling the police. If a woman calls the police at $T_{3}$, there would be a number of effects on the allocative outcome determined in $T_{2}$. Calling the police is a particularly costly strategy for the abuser, so, in theory, the threat of police intervention should constrain violence. For example, incarceration reduces his employment possibilities in both the short and long term. In addition, shame or stigma will affect not only his employment possibilities, but also his social networks. The effect of this is to reduce his fallback position, reflected in the downward shift from $W_{m}^{\prime}$ to $W_{m}^{\prime \prime}$, as shown in Figure 3.4. Similarly, reductions in income will result in an inward shift of the WPF inward. This mitigates some of the effect that violence has on the allocative outcome for the female, by shifting the solution from $S_{3}$ to $S_{4}$

\section{Figure 3.4:}

\section{$\mathrm{T}_{3}$ : The Effects of Police Intervention}

On the other hand, however, if calling the police is costly for the abuser, it is also costly for the abused. Part of her well-being in the event of exit is determined by his resources, either time or money. In addition, calling the police is a very public strategy that might cause her to feel shame or stigma, due to either the public revelation of the violence she has endured or the perceived inappropriateness of calling the police on one's partner. In either case, social networks are compromised. This means that should she call the police and he is arrested, not only is his fallback reduced, but so too is hers. Her fallback position 
would shift again from $W_{f}^{\prime \prime}$ to $W_{f}^{\prime \prime \prime}$ in Figure 3.4 , shifting the solution to $S_{4}$. In effect, calling the police makes her worse off. Thus the outside option is worse than her fallback position, as shown in Figure $3.4{ }^{56}$ A woman anticipating these costs will be less likely to call the police. Exacerbating this is distrust of the criminal justice system. Not only are racial biases and personal safety concerns, but also are sentencing rates. For example, Statistics Canada (2005) recently released a study demonstrating that intimate partner assault perpetrators were least likely to be sentenced and where sentences were handed down, they were among the lowest of all assault cases. What this suggests then is that designing the criminal justice system as an outside option is ineffective for many women. ${ }^{57}$ It does not offer a binding constraint on her well-being and thus provides her little with which to negotiate violence: her threats of exit are not credible and thus violence is left unconstrained.

${ }^{56}$ Note that this is an extreme case: The option is ineffective if it falls anywhere to the left of the solution since it will not constrain the outcome.

${ }^{57}$ See K. Makin, Globe and Mail, January 11, 2003; D. Elliott "Criminal Justice Procedures in Family Violence Crimes," in L. Ohlin and M. Tonry (eds.), Family Violence (Chicago: University of Chicago Press, 1989). It is also important to highlight the cultural implications of no-drop policies. See D. Martin and J. Mosher, "Unkept Promises: Experiences of Immigrant Women with the Neo-Criminalization of Wife Abuse," Canadian Journal of Women and the Law 8 (1995) 3-44. Burt and Mitchell (1998) and J. Vickers, "Thinking About Violence," in Dhruvarajon, V. and Vickers, J. Gender, Race, and Nation: A Global Perspective (Toronto: University of Toronto Press, 2002) note that First Nations women, immigrant women, and women of colour are less likely to call the police. My own empirical work reveals that police use varies by income, race and ability. For example, women who call the police have much higher incomes than women who do not, suggesting that women anticipate the costs of police intervention, see chapter 5 . 
In addition to the ineffectiveness of the outside options provided by the Canadian anti-violence policy framework, it was noted above that the framework defines away many women, for example women who do not want to leave. When the state defines resistance only as exit and develops policies to achieve this end, there are a number of the women who are unwilling or unable to take up these options; these women are in effect defined away from the policy framework. This is crucial in exploring the degree to which public policies enable women to live a life without violence: Recall from above that outside options have to be taken up to be effective; if one is unwilling or unable to use them, they will do nothing to constrain the solution. For example, where resistance is constructed only as exit, it is possible that many women experience violence that in their perception does not warrant departure. Emotional and psychological abuse or less severe forms of physical abuse might not be seen as enough cause to end the relationship. In other words, becoming a subject, a "resister" in this case, is determined by the degree of violence the woman experiences. Women who do not want to or cannot leave, "non-subjects", are offered little from the policy framework and must rely on non-exit strategies, which will do little to constrain violence.

To demonstrate, consider the case where there are no exit options, including women who will not or cannot sustain an independent household. Here it must be considered what non-exit forms of resistance will do to the outcome determined in stage 1 at $T_{2}$. Two possible scenarios emerge with the use of non-exit strategies. On the one hand, women can remain cooperative, contributing to the household good, but bargain over violence. On the other hand, women can stop cooperating and revert to a non-cooperative equilibrium, which 
results in an exit from bargaining, but not from the relationship. These will be discussed in turn.

In the first case, the woman remains cooperative at $T_{3}$, but bargains over violence. A woman resorting to a non-exit strategy can choose from various strategies, including, but not limited to defiance, compliance, third-party outreach and intervention, and exposure reduction. Non-exit strategies can potentially undercut the gains from violence by mitigating reductions in her fallback position and voice. For example, short-term exits from the household and other exposure reduction strategies will mitigate shifts in her fallback position, as shown in the movement from $W_{f}^{\prime \prime}$ to $W_{f}^{\prime \prime \prime}$ in Figure 3.5. In addition, intervention or treatment programs could potentially help batterers to use less coercive methods in bargaining, thus preventing reductions in her voice, as shown by the change in the shape of isoquant to $v_{2}$. With less violence, reductions in welfare resulting from her losses will also be circumvented.

Figure 3.5:

\section{$\mathrm{T}_{3}$ : Resistance with Non-Binding Outside Options and Cooperation}

In addition to these effects, there might also be a redistribution of the costs of resistance from her to him, caused by, for example, the impact on the abuser's social networks or issues stemming from the moral economy. Third-party intervention and outreach could increase the risk of exposure through fear of stigma, shame or guilt. Similarly, detection could result in isolation from social and employment networks. In effect, this would represent a downward shift in his fallback position, as shown by the movement from $W_{m}^{\prime}$ to $W_{m}^{\prime \prime}$. This could also result in reductions in welfare, the costs of which are borne by him, as shown by an inward shift of the WPF in Figure 3.5. Together, 
these shifts can offset the gains from violence, shifting the solution from $S_{3}$ to $S_{4}$, making him worse off in $T_{3}$ than in $T_{0}$.

However, greater costs can be imposed on him if the woman refuses to cooperate. By reverting to the non-cooperative equilibrium, gains from cooperation are eliminated, resulting in a "figurative" exit from bargaining, in which case the solution is $S_{N}$. If she couples non-cooperation with another non-exit strategy, she can increase her own well-being and offset the gains from violence incurred by him during the first stage, thus making him worse off. As demonstrated in Figure 3.5, non-exit strategies have the potential to mitigate reductions in her fallback position, shown in the movement from $W_{f}^{\prime \prime}$ to $W_{f}^{\prime \prime \prime}$, and reduce his fallback position, represented by the shift $W_{m}^{\prime}$ to $W_{m}{ }^{\prime \prime}$ in Figure 3.5. The solution shifts from $S_{N}$ to $S_{N}^{\prime \prime}$, improving her well-being at her fallback, but reducing his, as shown in Figure 3.6. Thus, if she can credibly threaten to withdraw her household contributions, which will reduce his gains from marriage and make him worse off, she might be able to constrain violence.

Figure 3.6:

\section{$\mathbf{T}_{3}$ : Resistance with Non-Binding Outside Options and Non-Cooperation}

The potential of non-exit strategies to constrain violence, however, is questionable. In the context of abusive relationships, the proximity to danger might limit the degree to which this strategy will work in the absence of literal exit options. For example, reverting to non-cooperation might trigger an increase in violence in future periods, where he increases violence in order to prevent her from exiting the game. Thus, even at the disagreement point, she will still endure abuse, which means that she is actually better off to remain 
cooperative, since she will still gain from the marriage. The escalation of violence is only preventable if she has some sort of recourse, such as divorce or police intervention, outside options, which will constrain the solution to a minimum level of well-being. Thus, while non-cooperative strategies are useful here, they are contingent on the credibility of a literal exit threat, or outside options. Without such options, women will be unlikely to use non-exit strategies simply because their use can potentially make them worse off. And as demonstrated above, the provision of effective outside options is poor.

From this analysis, the provision of outside options is crucial for constraining violence, yet poorly developed in the Canadian anti-violence policy framework. By neglecting the substantive dimensions of exit and defining a number of women out of sight, the policy framework leaves many abused women with very little state assistance. In real terms, these conditions can potentially exacerbate violence simply because it is subject to the fewest constraints. Within this context, it is easy to see why women who are economically and socially vulnerable are more likely to experience violence, since it is these conditions that determine exit options. And it is these conditions that are completely neglected by the policy framework.

\section{CONCLUSION: DIRECTIONS FOR POLICY REFORM}

The preceding analysis demonstrated that the goal of anti-wife abuse policy in Canada is to get women to leave their partners rather than ending violence. This is problematic for a number of reasons. First, it narrowly constructs resistance only as departure from the household, falsely dichotomizing women who leave as resisters and women who stay as victims. As a result, the policy framework has defined a number of women away, thus offering them no protection and no services with which to attempt to 
resist violence. Second, an emphasis on the liberal paradigm of choice has neglected the context in which choice is made and has obscured the structural prerequisites for meaningful choice. In effect, policy has offered women the formal or procedural dimensions of exit, but has failed to enact policies to ensure the substantive dimensions of exit, including both economic and social (i.e., fear, social isolation, etc.) elements. These outside options, then, are ineffective for many women, since they offer no basis on which credible exit threats can be made. This has the potential to increase women's vulnerability to violence, simply because violence is subject to the fewest constraints.

Policy reform requires a shift away from policies designed to get women to leave towards policies designed to end violence. From the model above, policy must ensure that the constraint, the outside option, is binding. Doing this requires a multisectoral approach that moves away from treating violence as a discrete phenomenon and moves towards treating violence as a symptom of gender inequality. ${ }^{58}$ Thus, anti-violence policy must be seen as a gender equality initiative. Intuitively, doing this will provide women with the tools of exit, which will be crucial even for women who have no intention of leaving. Key here is the ability to exit, the ability to credibly threaten departure. Where this threat is not credible, that is, where the ability to exit is low, violence will be most likely because it is subject to the fewest constraints. Reconstructing policy, then, requires intersectional analysis into the determinants of exit, ensuring that all women have outside options available to them. This is not to privilege exit. Rather, it is to suggest that the scope of anti-violence policy must

\footnotetext{
${ }^{58}$ For a discussion on multisectoral policy and the implications of welfare state restructuring for wife abuse, see M. Morrow, O. Hankivsky, and C. Varcoe, "Women and Violence: The Effects of Dismantling the Welfare State," in Critical Social Policy 24:3 (2004) 358-384.
} 
expand considerably to enable women to resist violence. This is also not to place the onus of ending violence upon women but to explore the potential of public policy, i.e., the state, to transform the basis on which violence and its resistance is premised. 


\section{Figure 3.1:}

$T_{0}$ : A Two-Person Cooperative-Conflicts Game with Outside Options

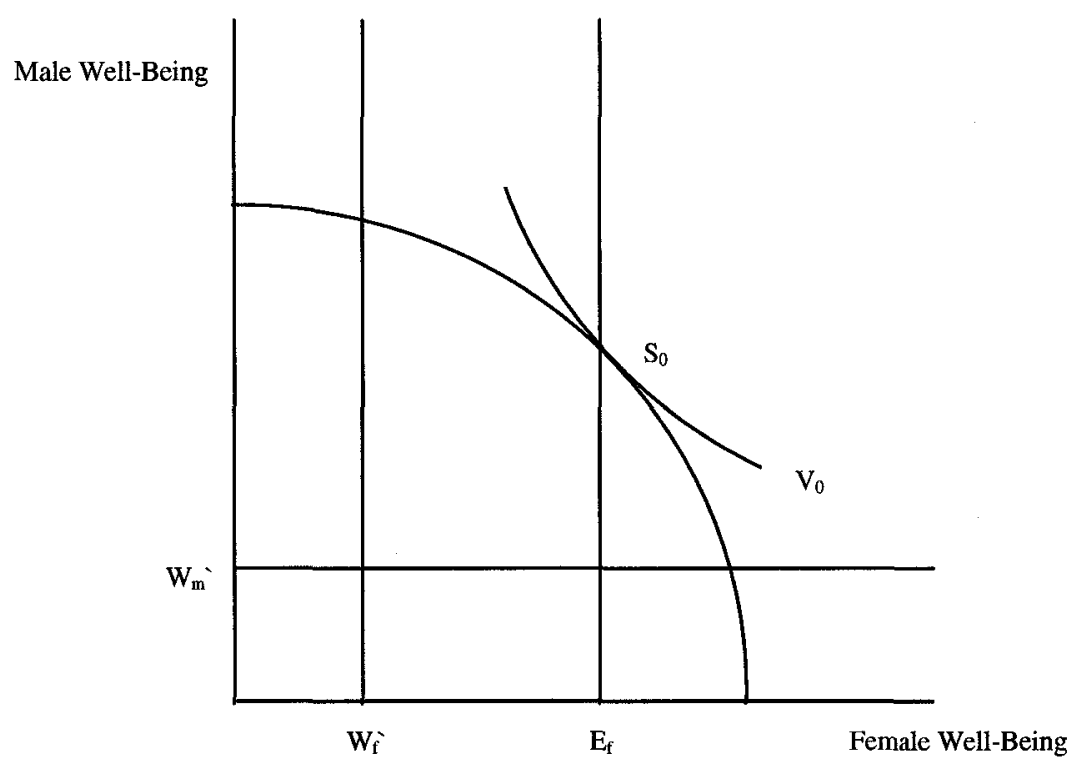


Figure 3.2:

$T_{1}$ : The Effects of Violence 1: Female Fallback Position and Voice Decrease

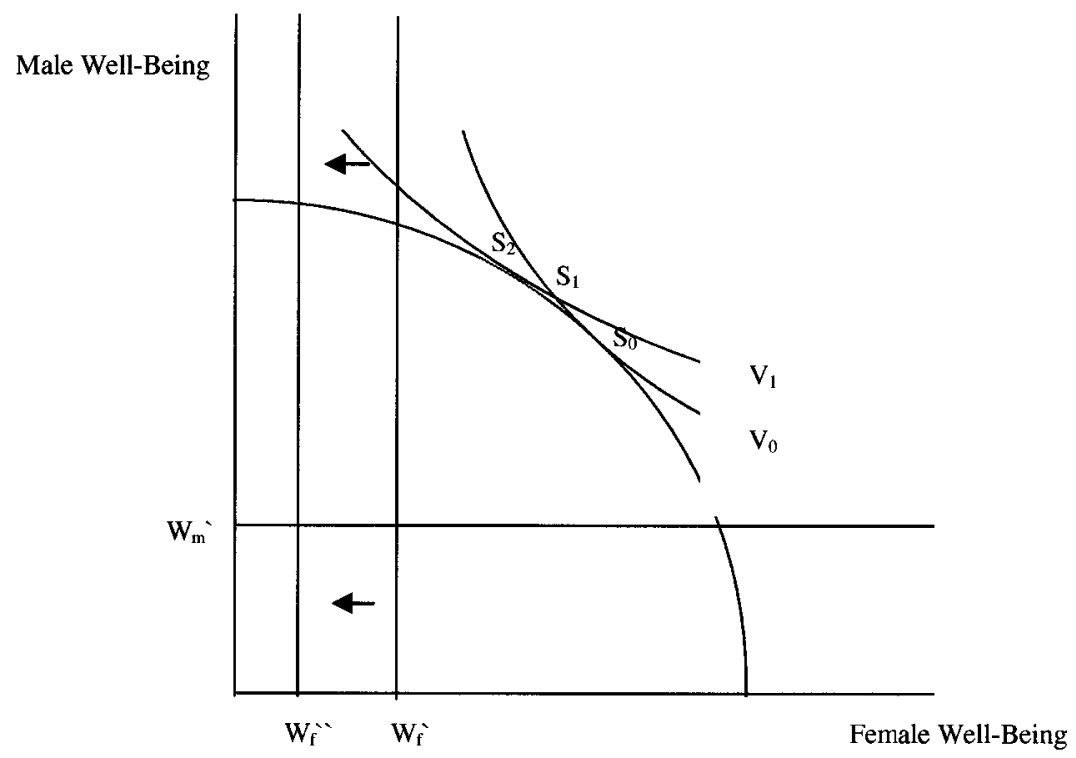


Figure 3.3:

$\mathbf{T}_{2}$ : The Effects of Violence 2: Total Gains from Cooperation Fall

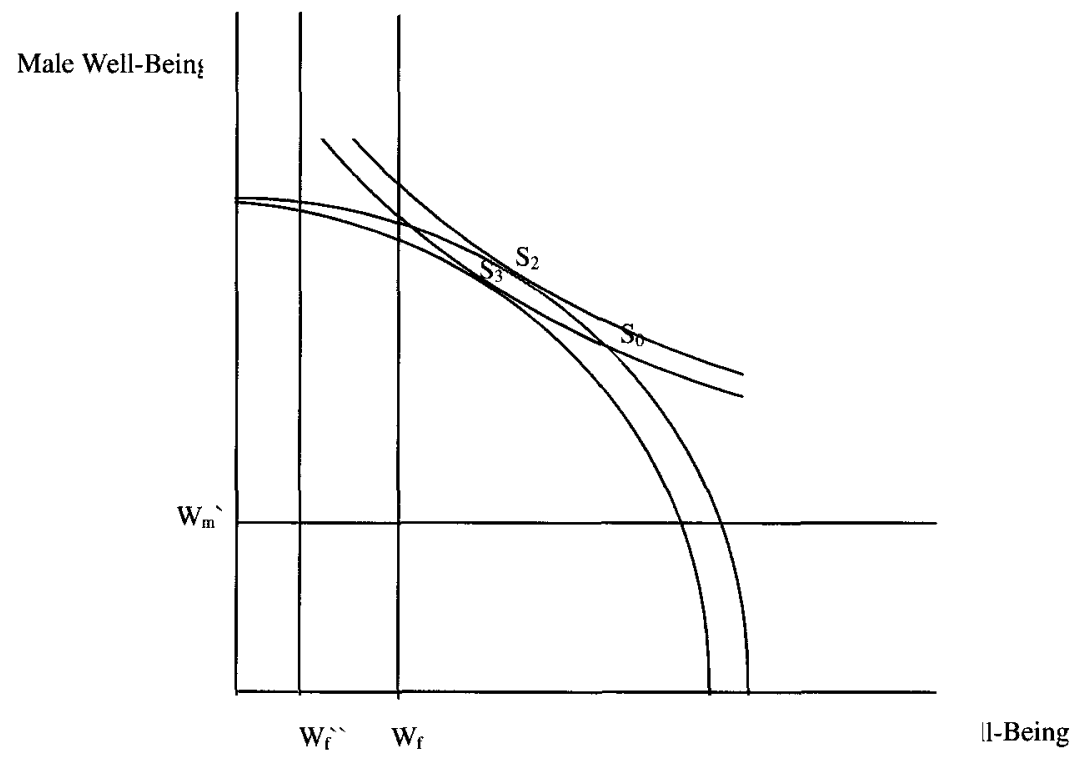


Figure 3.4:

$\mathbf{T}_{3}$ : The Effects of Police Intervention

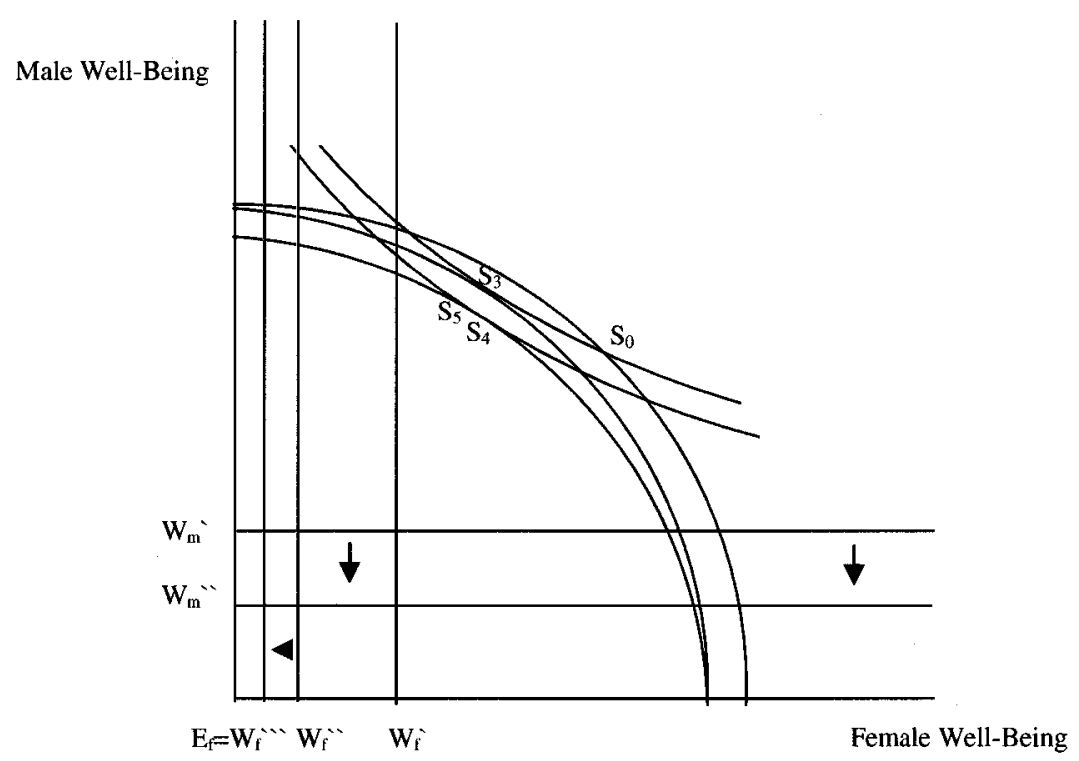


Figure 3.5:

$\mathbf{T}_{3}:$ Resistance with Non-Binding Outside Options and Cooperation

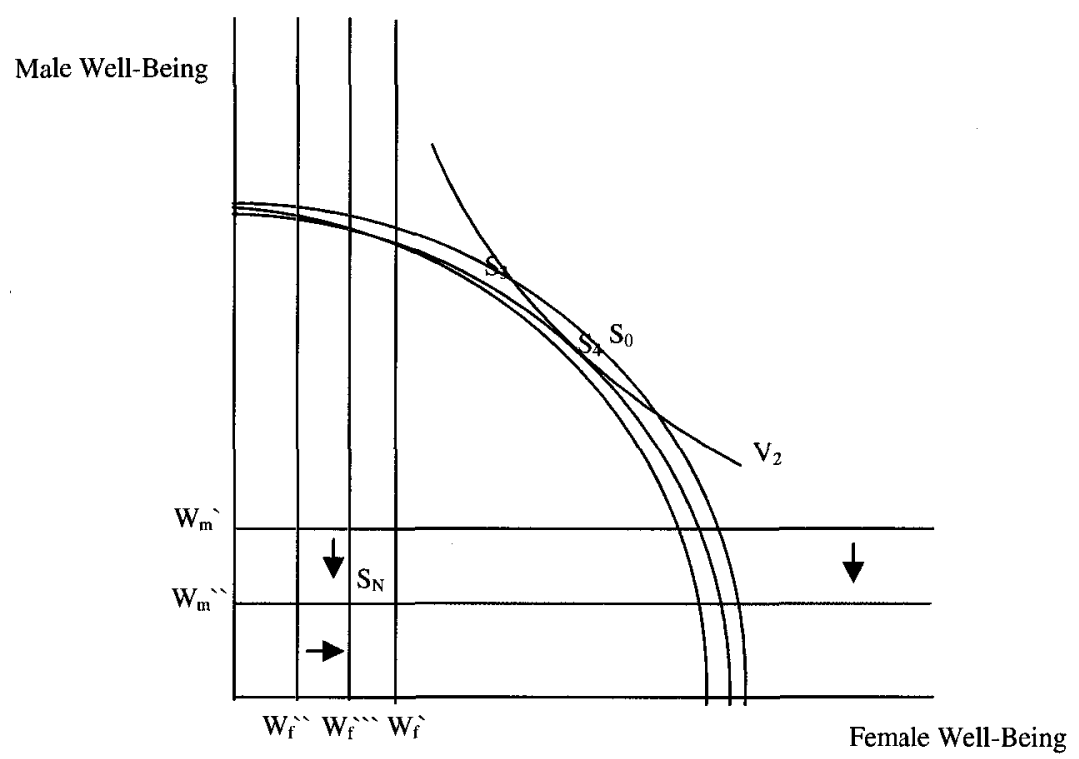


Figure 3.6:

$\mathbf{T}_{3}$ : Resistance with Non-Binding Outside Options and Non-Cooperation

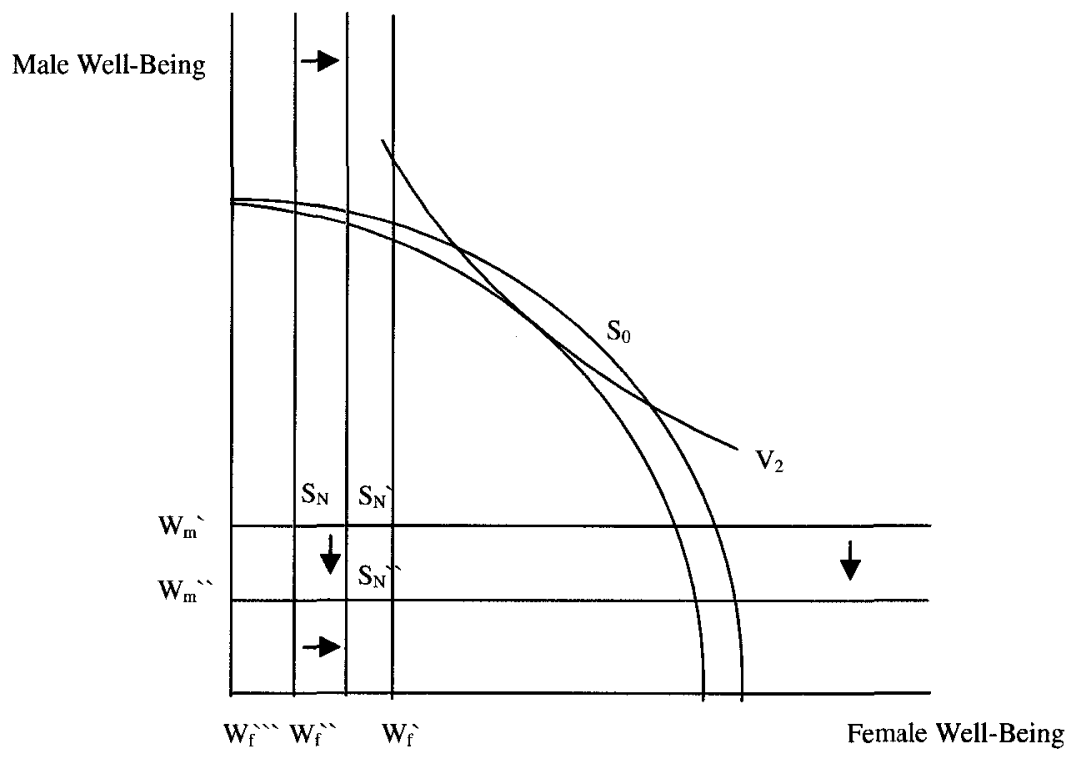




\section{CHAPTER 4:}

\section{HOUSEHOLD STRUCTURE AND WIFE ABUSE: AN EMPIRICAL ANALYSIS OF VIOLENCE AND RESISTANCE OPTIONS IN CANADA}


Surveying the literature on wife abuse reveals a number of explanations for the emergence and persistence of violence against women including individualistic and structural approaches spanning all disciplines within the social sciences. ${ }^{1}$ As demonstrated in chapter 2 , within political economy approaches, one of the key debates involves the role of resources in creating the conditions for violence. More specifically, what is the role of absolute versus relative resources and does women's rising status increase or decrease their vulnerability to abuse? Using data from the 1999 General Social Survey (GSS), this chapter argues that the conditions for violence are created through a complex interplay of both absolute and relative resources and that household structure is a key determinant of abuse. The paper is divided into four sections, beginning with a theoretical justification for the argument and followed by an overview of the data and methodology employed in this chapter. From there, the results of the analysis are reported before moving to a discussion of potential areas for policy reform.

\section{VIOLENCE IN THE POLITICAL ECONOMY}

Mentioned above, a number of studies have revealed a relationship between violence and resources. For example, both theoretical and empirical analyses have

\footnotetext{
${ }^{1}$ See A. Sev'er, Fleeing the House of Horrors: Women Who Have Left Abusive Partners (Toronto: University of Toronto Press, 2002) for an overview of this literature. See also J. Vickers, “Thinking About Violence," in Gender, Race, and Nation: A Global Perspective, V. Dhruvarajon and Vickers, J. (eds.) (Toronto: University of Toronto Press, 2002) for a review of feminist approaches to violence.
} 
revealed a relationship between absolute household resources and wife abuse. ${ }^{2}$ Financial strain and exploitation in the labour market, it is hypothesized, create the conditions under which men, in an attempt to gain control, attack their spouses. This is an interesting approach, and one that is corroborated with statistical evidence; however, it neglects the ways in which gender relations within the household can shape and constrain violence.

In response to this short-coming, a number of studies have attempted to shed light on the dynamics of abusive relationships by focusing on relative resources. This, too, however, has led to a debate about the precise role of relative resources in shaping and constraining violence. On the one hand, some scholars have argued that as women's relative status increases, vulnerability to violence decreases. ${ }^{3}$ Couched in game theoretic models of the household, these analyses show that as women's wages increase, utility from marriage decreases, which requires an increasing level of intra-household transfers from the abuser to remain in the relationship. In other words, as female wages increase, violence becomes more expensive for the abuser. On the other hand, other scholars have

${ }^{2}$ See L. Gordon, Heroes of their Own Lives (New York: Viking, 1988). See also L. McCloskey, "Socioeconomic and Coercive Power Within the Family," Gender and Society 10:4 (1996) 449-463 for a review of literature dealing with financial stress and marital quality.

${ }^{3}$ See H. Tauchen, Long and A. Dryden Witte, "The Dynamics of Domestic Violence," The American Economic Review 85:2 (1995) 414-418; A. Farmer and J. Tiefenthaler. 1997. “An Economic Analysis of Domestic Violence," Review of Social Economy LV:3 (1997) 337-358; A. Farmer and J. Tiefenthaler, "Explaining the Recent Decline in Domestic Violence," Contemporary Economic Policy 21:2 (2003) 158-72; and J. Kingston-Reichers, "The Association Between Socio-Economic Characteristics and the Frequency of Wife Assault," Working Paper Series, Department of Economics, McMaster University, (1999). 
suggested that as women's relative status increases, vulnerability to violence increases. ${ }^{4}$ Increasing female status threatens conventional notions of masculinity, causing men to lash out at their partners in an attempt to reassert authority.

These studies have illuminated a number of interesting dimensions of violent households. First, they have demonstrated that violence, for the most part, is rational and, in being rational, can be constrained. Second, they show that gender relations within households can be as important in determining violence as gender relations outside of households. Both of these findings have important policy implications. More specifically, if violence can be constrained, researchers should be exploring what in particular can constrain it and what policy levers are available to harness these constraints.

But while these studies have been invaluable to our understanding of violent relationships, they are not without their limits. Most importantly, if the absolute resource hypothesis neglects relative resources, then the relative resource hypothesis neglects absolute resources. This has led to a much more serious problem: Failure to illuminate the complex interplay of both absolute and relative resources has obscured the degree to which various households differ in their vulnerability to violence, argued in chapter 2.

\footnotetext{
${ }^{4}$ See M. Atkinson, T. Greenstein, and M. Monahan Lang, "For Women, Breadwinning Can be Dangerous: Gendered Resource Theory and Wife Abuse," Journal of Marriage and the Family 67 (2005) 1137-1148; C. Kaukinen, "Status Compatability, Physical Violence, and Emotional Abuse in Intimate Relationships," Journal of Marriage and the Family 66 (2004); K. Anderson, "Gender, Status, and Domestic Violence: An Integration of Feminist and Family Violence Approaches," in Journal of Marriage and the Family 59:3 (August, 1997); L.A. McCloskey, "Socioeconomic and Coercive Power within the Family," in Gender and Society 10:4 (1996) 449-463.
} 
Clearly not all women are equally vulnerable to violence. Neither are all men equally likely to be violent. So what distinguishes households from one another? It is argued here, as in chapter 2, that the distinguishing factor is household structure. Household structure determines the extent of the gains from the relationship and who benefits most from those gains. It is determined by social relations embedded in the political economy, and thus is shaped by various factors such as gender, class, race, sexuality, etc.

Household structure will not only define the initial gains from violence, but it will also establish the conditions for women's resistance, which, if effective, will mitigate any potential gains from abuse.

To clarify, consider the economic incentives for forming a household. Forming a household offers several advantages to individuals that they might otherwise not receive. For example, households benefit from economies of scale, externalities, household (public) good production and consumption, marital investments, risk-sharing, etc. ${ }^{5}$ In addition, through a division of labour, couples can save considerable time on household labour. These gains provide economic incentives to individuals to form families.

As noted in chapter 2, both absolute and relative resources are important in generating and dividing these gains. With high absolute resources, families can invest in time or money saving products or services. In contrast, with higher relative resources, individuals can reap more of the benefits from the relationship. For example, with higher bargaining power, determined in part by relative status, women can negotiate the division

\footnotetext{
${ }^{5}$ See F.D. Blau, M.A. Ferber, and A.E. Winkler, The Economics of Women, Men and Work $5^{\text {th }}$ ed.
} (New Jersey: Pearson, 2006). 
of household labour, delegating more and more work to their partners. ${ }^{6}$ Thus, families differ considerably in the gains they generate and how they divide these gains.

What does this mean for creating the conditions for violence? A game-theoretic treatment of the household is useful to answer this question. Individuals must bargain over the gains from the relationship. As described in chapters 2, bargaining is driven by fallback positions (threat points) and aspiration points. ${ }^{7}$ Fallback positions determine what each person will get in the event that bargaining breaks down. They typically include access to income and education, but can also include access to the economic and social resources of friends and families, communities and states, ${ }^{8}$ as well as socially valued elements such as strength, beauty, and the external valuation of one's contributions. ${ }^{9}$ Aspiration points refer to the maximum value of the gains from the relationship. ${ }^{10}$ Each person would ideally like to get the total amount of the gains but

${ }^{6}$ See also S. Moller Okin, Justice, Gender, and the Family (USA: Basic Books, 1989) for a discussion of women's economic well-being within families and M. MacDonald, S. Phipps, and L. Lethbridge, “Taking its Toll: The Influence of Paid and Unpaid Work on Women's Well-being," Feminist Economics 11:1 (March 2005).

${ }^{7}$ Note this analysis is premised on the Kalai-Smorodinsky model. See E. Kalai and M. Smorodinsky, “ Econometrica 43:3 (May 1975) 513-518.

${ }^{8}$ B. Agarwal, A Field of One's Own: Gender and Land Rights in South Asia (Cambridge: Cambridge University Press, 1993) and B. Agarwal, "'Bargaining' and Gender Relations: Within and Beyond the Household," Feminist Economics 3:1 (1997).

${ }^{9}$ See N. Folbre, Who Pays for the Kids?: Gender and the Structures of Constraint (London: Routledge, 1994) and A. Sen, "Gender and Cooperative Conflicts," Persistent Inequalities: Women and World Development ed. I Tinker (New York: Oxford University Press, 1990).

${ }^{10}$ See Kalai-Smorodinsky (1975) and Friedman (1986) for a discussion of this model. 
there is no allocation that can simultaneously award each player the maximum amount. Thus, they need to bargain.

It is argued that this is where violence comes in. Recall from Figure 1.1 in chapter 1 , the continuum of violence, that it is assumed that violence is always premised to some degree on both expression and instrumentality, and thus is always about control and domination. ${ }^{11}$ As a result, violence will have a number of effects on the bargaining process and its outcome, as described in chapter 2. First, because attackers often isolate their partners from friends and family and employment networks, as well as taking control of the household income, it can be posited that with threats of violence, the female's fallback position is reduced. This has the effect of increasing the total gains from cooperating within the relationship and increases the abuser's aspiration point. In doing so, the abuser receives a higher share of household resources.

The second effect of violence is to reduce household well-being, by reducing the production/consumption possibilities within marriage, which will reduce the total gains from cooperation. Here it is important to consider the use of violence as a mechanism for control and the construction of gender. If violence is used as a mode of domination, then the abuser will be content with a larger share of a smaller pie. Similarly, as long as the costs of the reduction in welfare are primarily borne by her or the children, the maximum

${ }^{11}$ See I.M. Young, Justice and the Politics of Difference (New Jersey: Princeton, 1990); S .Ruddick, "Injustice in Families: Assault and Domination," Justice and Care: Essential Readings in Feminist Ethics, ed. V. Held (Boulder: Westview Press, 1995); and K. Crenshaw, Mapping the Margins: Intersectionality, Identity Politics, and Violence Against Women of Colour," Stanford Law Review 43:6 (1991). 
available to him might not change. In addition, it is possible that violence which reduces the total level of household well-being is driven primarily by expression rather than instrumentality. In this situation, the gains from violence are reflected in direct increases in male well-being.

At the same time, however, chapter 3 revealed the potential for resistance to mitigate the gains from violence by imposing costs on the abuser. It was demonstrated that credible exit had the most potential to offset the gains from violence since it eliminates any gains from the relationship and has the potential to impose additional costs on him. For example, Canada's pro-charge and pro-prosecution policies mean that once the police are called, they are mandated to make an arrest where appropriate. In addition, the crown lays charges, not the woman, which means that abuse cases will be tried in court. ${ }^{12}$ Publicity and possible incarceration limits his access to social and employment networks, in addition to reducing his income stream. In effect, police intervention reduces his fallback position. Thus, where exit is possible, it is expected that women would be less likely to experience abuse. Similarly, it is expected that women with credible exit options would experience less severe forms of abuse. Knowing that she can leave might force an otherwise physically abusive attacker to use more subtle forms of abuse, such as emotional or economic abuse.

The analysis led to two hypotheses about when violence will be used and why, both of which relate to household structure. First, violence will be more likely in

12 This is not to suggest that these policies are effective, indeed, a study conducted by Statistics Canada (2005) revealed that, of all assault perpetrators, intimate-partner abusers were the least likely to be sentenced and when sentences were handed down, they received the lightest sentences possible. 
households where the gains from cooperation are low. In practical terms, this means that modern or non-traditional households will be most vulnerable to violence because men in these relationships have the most to gain from violence. Second, where households have equal gains from cooperation, violence will be most likely when male relative status is low. This means that households that are egalitarian or where there is a female breadwinner will be most vulnerable to violence. ${ }^{13}$ Men in these households will have more to gain from using violence than men in households that are marked by a more traditional division of labour. In an attempt to reassert dominance and control, the foundations of masculinity, men will use violence as a bargaining strategy.

What needs to be acknowledged at this point, however, is that women in either or both of these situations have the least to lose in the event of bargaining breakdown and thus will be most likely to resist. But willingness and ability are two different things. The ability to exit is determined within the political economy along the lines of gender, age, race and culture, class, and (dis)ability. Thus, an analysis of exit options and their constraining effects on violence requires an intersectional analysis of political economic determinants. In effect, like violence, resistance will be determined by a complex interplay of absolute and relative resources. In sum, it is expected that women's vulnerability to violence due to low gains from cooperation and/or relative status would be mitigated to some degree by high absolute resources.

\section{DATA AND METHODS}

Testing these hypotheses requires a representative sample of households, varied by class, life cycle, race, etc. The GSS is conducted annually and provides a random

\footnotetext{
${ }^{13}$ See chapter 2 for a graphical analysis.
} 
sample of Canadians. ${ }^{14}$ More than 25,000 men and women over the age of 15 comprise the final sample, all of whom were selected randomly and contacted by telephone throughout 1999. Because of the complex data collection methods, which include stratification, and issues with non-responses, the sample is not truly representative. To remedy this, we have employed the weighting schemed suggested by Statistics Canada. ${ }^{15}$ The purpose of the GSS is to gather information on the well-being of Canadians and point to areas of interest for policy makers. Cycle 13 specifically addresses perceptions of and experiences with family violence. Based on the Conflict Tactics Scale (CTS), the survey probes both past and present experiences with abuse ranging from emotional and financial abuse to severe physical and sexual violence. ${ }^{16}$ In addition, the survey also includes socio-economic variables, which are useful to help us determine the whether or not some groups of individuals are more vulnerable to violence than others. Refer to Appendix 4.1 for a list of relevant questions.

Although the GSS is useful to test the hypotheses outlined above, there are a number of potential limitations. ${ }^{17}$ First, use of the CTS is controversial. The CTS does

${ }^{14}$ At the time of writing, the 2005 GSS on Violence was not yet available for analysis.

${ }^{15}$ The weight is found by determining the average person weight for sample participants included in the analysis, and then dividing individual person weights by the average. This factor is then applied to the sample.

${ }^{16}$ It is important to note that the list of questions is not presented in this order.

${ }^{17}$ For an excellent discussion of the GSS and its limitations, refer to Y. Jiwani, "The 1999 General Social Survey on Spousal Violence: An Analysis," Violence Against Women: New Canadian Perspectives, McKenna, K.M.J. and Larkin, J. (eds.) (Toronto: Inanna Publications and Education Inc., 2002) 63-72. 
not ask respondents to discuss violence openly and it never uses the terms 'violence' or 'abuse' directly, but rather asks specific questions regarding certain acts, such as throwing something, hitting, choking, etc. ${ }^{18}$ While the CTS includes the most obvious forms of abuse, it does not address newly recognized forms of abuse, such as stalking, harassment, threats and/or violence towards third parties (including pets), etc. In addition, the CTS removes violence from its context and fails to address specific injuries resulting from the incident (Se'ver 2002). However, it should be noted that the GSS does attempt to counter this by asking about fear and injuries resulting from the abuse.

The second issue with the GSS is that it is biased toward individuals speaking French or English and households who have access to a telephone. As a result, there is no access to those individuals who are perhaps most vulnerable to abuse, such as those who cannot speak either of Canada's official languages, those who live in extreme poverty, and transients.

Despite these limitations, there are several issues in obtaining data in this field. Given the sensitivity of the issue, it would be extremely difficult to obtain a representative sample of women and men on which to base the present analysis. And while some studies have garnered important insights on abuse using police or hospital files, to gain an accurate picture of abuse and women's ability to resist it requires a heterogeneous representative sample of women. ${ }^{19}$ In addition, the survey includes both

\footnotetext{
${ }^{18}$ While this is potentially problematic, it should also be noted that by not asking respondents explicitly about violence, the GSS is able to counter non-responses due to denial.

${ }^{19}$ Although Hoff's (1990) sample of interviewees was large, the sub-sample of abuse survivors included only nine women, Sev'er (2002) interviewed 39 women. See L.A. Hoff, Battered Women as
} 
abused and non-abused women, offering some insights into the prevalence of violence and possible points of comparison between these two groups of women. And because it contains information on various forms of abuse, the GSS provides information on forms of abuse not accounted for in police files, such as verbal and financial abuse, as well as non-severe forms of physical violence. Finally, the GSS has not been mined to the degree that the Canadian Violence Against Women Survey has, which provides an opportunity to explore the issue in more depth. Accordingly, survey data is the best alternative.

Since the concern here is with household structure, including both the gains from the relationship and relative status, the present study analyses violence only among currently married or cohabitating heterosexual women. The sample includes 7194 women, $11 \%$ of whom report abuse by their current spouse. Table 4.1 summarizes the descriptive statistics.

\section{Table 4.1: \\ Descriptive Statistics: The 1999 General Social Survey on Victimization}

To test the hypotheses described above, a two-stage analysis was conducted, first to explore the probability of experiencing abuse using a binary logit model and second to probe the severity of abuse using a tobit model. ${ }^{20}$ For the first stage, a dichotomous

Survivors (London: Routledge, 1990). Similarly, Tauchen, Long and Witte's 1995 study is based on women who sought help. Their 1995 study was based on police data.

${ }^{20}$ Binary logit models are used when the dependent variable assumes only two values. Because such relationships violate several assumptions underlying linear models (OLS), such as homoskedisticity and normality, linear models are deficient in predicting values. In addition, non-linear relationships are not adequately captured by linear models, leading to biased estimates. The coefficients reflect the loglikelihood of experiencing a particular event, in this case, abuse. These can sometimes be difficult to 
variable for abuse incidence was constructed from a series of GSS questions. The GSS asks respondents to indicate whether or not they have experienced any of the following behaviours by their partners in the previous five years: emotional or financial abuse, throwing objects, pushing, slapping, kicking, hitting, beatings, choking, using or threatening the use of knives or guns, and/or forcing sexual activity. For the second stage, an index variable for abuse severity was created. The GSS includes variables for the number of incidents, ranging from 0 (no incidents) to 11 (which includes more than 10 episodes), as well as the severity of these incidents ranging from 0 (no assault) to 10 (forced sex) during the previous five years. ${ }^{21}$ The index variable was constructed simply by multiplying these two variables, giving a range from 0 to 110 . These variables were used as dependent variables to test the hypotheses outlined above.

interpret, so we have included marginal effects in the tables. Marginal effects determine the degree to which a unit change in the independent variable increases the probability of experiencing abuse. For example, marginal effects tell us the impact on the probability of experiencing violence if age increases by one year. Tobit models, in contrast, are used when the dependent variable is strictly non-negative or censored. In the present study, for example, it is not possible to experience negative levels of abuse. Similarly, the sample of women in whom we are interested fall within a small range of the total sample distribution. As explained by Greene (2000: 906), "Conventional regression models fail to account for the qualitative difference between the limit (zero) observations and nonlimit (continuous) observations." Because we are interested in the effect of the independent variables on the dependent variable when the dependent variable is greater than zero, we have also included the marginal effects. See W. Greene, Econometric Analysis $4^{\text {th }}$ ed. (New Jersey: Prentice Hall, 2000) for a discussion of both approaches. See also L. Sigelman and L. Zeng, "Analyzing Censored and Sample-Selected Data with Tobit and Heckit Models," Political Analysis 8:2 (1999) 167-182.

${ }^{21}$ See Appendix 1 for a list of GSS questions used in this study. 
To test the importance of the gains from cooperation, as well as relative status, several variables were created. The GSS asks respondents to identify their main activity in the last twelve months, which includes options such as working for pay, looking for work, studying, caring for children, household labour, retired, maternity/paternity leave, long-term illness and other. A dummy variable to proxy the gains from cooperation was developed by combining responses to caring for children, household labour, retired, and maternity/paternity leave with a full time working spouse. The variable is labelled 'traditional household' in the tables below. If individuals were performing any of these activities while their partner worked full time, it is hypothesized that gains from cooperation will be high.

In addition, the gains from cooperation likely increase as relationship length increases. For example, couples who have been together for a long time will likely exhibit more patterned behaviour than new couples. Similarly, the length of time one has been in one's relationship will impact marital capital, or marriage specific investments, such as homes and other accumulated assets, children, etc., which increase the benefits to being married. For these reasons, a variable for relationship length has been included.

Relative status variables include measures for relative age, education and income. A dummy variable was created to indicate those households where the male is older than the female. This was created by using the two categorical variables for age for both males and females and subtracting female age from male age. Relative education was calculated by subtracting male education from female education. A ratio scale variable was then created to include only those cases where female education is higher than her partner's. Finally, relative income was calculated in the following way: There are two 
categorical before tax income variables, personal income and household income. ${ }^{22}$ Each category was converted into its median value and then personal income was divided by household income, thereby expressing personal income as a proportion of household income.

In addition to these variables, several socio-economic variables were included that, in part, attempt to proxy exit options. The number of children under 16 was included, since it is suspected that the presence of young children will place more demands on the time of the parents, especially mothers, and make it less likely that she can credibly threaten departure. Three dummy variables were created to capture families with one, two, or three plus children under the age of 16. Similarly, since levels of abuse are known to vary geographically, a variable was included to indicate urban residence.

In addition, younger women are more vulnerable to abuse, hence a variable for age has been included, as well as the variable for relationship length. The difference between these two variables is potentially significant. Where age reflects physical and generational differences, relationship length reflects the impact of time on the dynamics of the relationship, potentially resulting in higher gains from cooperation, mentioned above. Thus, it is reasonable to expect a negative relationship between abuse and relationship length, since it is hypothesized that higher gains from cooperation reduce the incentive for abusive behaviour. At the same time, however, the higher benefits accorded to women from the duration of their relationship might make it more difficult to leave the relationship, therefore increasing her vulnerability to abuse. For this reason, it is

22 The highest possible value was $\$ 100,000$ or more. Because this value was not banded, we simply restricted the analysis to women earning less than this value. 
theoretically possible to witness a positive correlation between abuse and relationship length, depending on which effect, the disincentive effect or the resistance effect, is stronger. Finally, to the degree that women leave abusive partners, ${ }^{23}$ it is expected that violent relationships are shorter than those where there is no violence present.

At the same time, however, age and relationship length are highly correlated, which suggests that it will be difficult to isolate the separate impact of each variable in a multiple regression model. For this reason, separate sets of models have been included, one that includes only age and one that includes only relationship length, in Tables 4.4 through 4.7 in Appendix 4.1. It is important to note that although these tables reveal a strong correlation between age and relationship length, removing one of these variables has little impact on the other parameter estimates. Furthermore, the removal of either age or relationship length increases the statistical and substantive significance of the other variable.

Finally, a number of variables were included to indicate whether or not the respondent was a person with a disability, Aboriginal, a person of colour, or resides in a household where the primary language is neither French nor English. Variables for personal education, spousal education, and personal income were also included. The education variables are categorical, ranging from "some high school" to "university degree." The personal income variable is also categorical, as described above. ${ }^{24}$

${ }^{23}$ See Kingston-Reichers (1998) and A. Bowlus and S. Seitz, "The Economics of Abuse" (London, ON: University of Western Ontario Working Paper, 2000) for discussions on the relationship between abuse and divorce and separation.

${ }^{24}$ The GSS asks only about personal and household income; it does not include a separate variable for spousal income. To capture the effects of total household resources, we also ran all of these regressions 


\section{RESULTS}

Two sets of four regressions were run, one to determine the probability of experiencing violence, using a binary logit model (models A through D), and one to determine the severity of violence, using a tobit model (models A1 through D1). The results are summarized in Tables 4.2 and 4.3 below. Since the results are similar for both sets of regressions, they will be discussed together. The base model includes basic economic variables including the absolute income of the respondent and education levels of both spouse and respondent. In addition, a number of controls have been added, including age, relationship length and the number of children under the age of sixteen.

As shown in models A and A1 in the first column of Tables 4.2 and 4.3, violence, its probability and severity, is negatively correlated with age and relationship length. As demonstrated by the marginal effects analysis, for each year a woman ages, the likelihood of experiencing abuse decreases by $0.2 \%$, although with the relationship length variable included in the model, this figure is not statistically significant. As noted above, if relationship length is removed, as shown in Table 4.4, however, the coefficient for the age variable increases in both substantive and statistical significance. Similarly, for each year the couple remains together, the probability of experiencing abuse decreases by $0.2 \%$, significant at the $5 \%$ level. This figure also gains in substantive and statistical significance when age is removed, as shown in Table 4.6, suggesting a strong degree of

using household income rather than personal income. The results are not included here because they did not have any qualitative effect on the models, perhaps because of Canada's divorce legislation, which, if determined in a public court, requires a 50/50 split of marital assets. 
collinearity between the two variables. This suggests that the disincentive effect is potentially stronger than the resistance effect, discussed in detail below.

Regarding severity, there appears to be an inverse relationship between both age and relationship length. For example, in model A1, we see that as women age, they experience an almost $3 \%$ reduction in the severity of abuse. Although this figure is not statistically significant, when we remove relationship length, shown in Table 4.5, we see that not only does age become strongly statistically significant, but its substantive impact also increases. Similarly, , model A1 shows that for each year the relationship continues, severity decreases by $8 \%$, significant at the $5 \%$ level. When age is removed from the regression, as in Table 4.7, the relationship between the severity of abuse and relationship length increases in terms of both substantive and statistical significance. .

The severity of abuse also appears to decrease as female income increases, consistent with previous studies. ${ }^{25}$ From the coefficients on the personal income variable in Tables 4.2 and 4.3, it is clear that as women enter higher income bands, the probability of experiencing abuse is reduced by almost $1 \%$ for each approximately $\$ 10,000$ increase in income, significant at $5 \%$ level, and the severity of violence decreases by almost $4 \% .{ }^{26}$ These findings lend support to the hypothesis about women's resistance: with higher

${ }^{25}$ See Tauchen, Long and Witte (1995); Farmer and Tiefenthaler (1997); Farmer and Tiefenthaler (2003); and Kaukinen (2004).

${ }^{26}$ Incomes between $\$ 20,000$ and $\$ 60,000$ are measured in $\$ 10,000$ bands, for example, personal income $=5$ corresponds to income between $\$ 30,000$ and $\$ 40,000$. . However, very low and moderately high to high incomes are measured in smaller and larger bands, respectively. For example, income between zero and $\$ 20,000$ is measured in increments of $\$ 5,000$ and income between $\$ 60,000$ and $\$ 100,000$ is measured in bands of $\$ 20,000$. Finally, the last category captures incomes higher than $\$ 100,000$. 
incomes women can more credibly threaten exit, discussed in more detail below. However, we should be cautious in interpreting these results, since the coefficient is not precisely estimated in model A1 due to collinearity. When age or relationship length is removed from the model, shown in Tables 4.5 and 4.7 respectively, we see that personal income loses its significance in predicting severity of abuse.

Violence is also negatively correlated to the education variables. Spousal education is strongly significant in both substantive and statistical terms. As the male education level increases, for example, from some high school to high school, or from college diploma to university degree., the probability of experiencing violence decreases by almost $3 \%$. The severity of violence decreases by nearly $50 \%{ }^{27}$ Similarly, as female education increases, the probability of experiencing violence decreases by $1.4 \%$ and its severity decreases by just under $8 \%$. These figures are statistically significant in models A and A1, but when age or relationship length is removed from the analysis, the relationship between female education and the severity of abuse loses its statistical significance.

The relationship between violence and education could be due to a number of factors. First, it is possible with higher education levels individuals are better able to express themselves without resorting to violence, which implicates bargaining skill. Similarly, individuals with higher education might be better able to deal with lifeproblems more generally, due to a stronger ability to problem solve, etc. Second, higher

${ }^{27}$ Kingston Reichers (1998) obtained a similar result using data from the Canadian Violence Against Women Survey. However, she reported that education variables were stronger indicators of violence than income, in contrast to Tauchen, Long and Witte (1995), who report a stronger correlation between income and abuse. 
education levels might lead to better jobs, which offer more lucrative benefits and therefore expand the gains from families therefore reducing the incentives for abuse. In addition, better jobs might be less stressful and/or offer more opportunities for work-life balance, which will reduce stress levels. ${ }^{28}$ Finally, women with higher education might be more aware of the services and programs available to them and thus are more likely to threaten exit, which will constrain violence and limit the likelihood of its use.

The threat of exit could be compromised by the presence of children. With children, resources are scarcer, making it more difficult to sustain an autonomous household. In addition, women might be hesitant to remove children from their neighbourhoods and/or schools, which will also impede the ability to exit thus increasing vulnerability to violence. It is therefore not surprising that children have an effect on violence. Interestingly, however, the presence of children is a strong, significant indicator of the severity of violence, but is not significant in predicting the likelihood of abuse. With the presence of three or more children, the severity of abuse increases by nearly $50 \%$, a result that retains its statistical significance even when age or relationship length is removed from the analysis, demonstrated in Tables 4.5 and 4.7. However, it is reasonable to assume that the degree to which resistance is possible is determined by socio-economic variables, which, apart from income, are not entered until models D and D1, discussed below.

${ }^{28}$ Fox et al (2002) analyse the influence of job type on violence and discover that job stress increases the likelihood of abuse. Refer to Fox, M.L. Benson, A.A. DeMaris, and J. Van Wyk, "Economic Stress and Intimate Partner Violence: Testing Family Stress and Resources Theories," Journal of Marriage and the Family 64 (2002). 
In models B and B1, summarized in the second column of Tables 4.2 and 4.3 , the traditional household variable was included, which captures the gains from cooperation. Recall that it was hypothesized that diminished gains from cooperation would increase the likelihood of violence, since it was suggested that abusers in these households will have the most to gain by using violence. By reducing her fallback position, he can increase his share of the total gains from the relationship. In Table 4.2, households marked by a traditional division of labour, with a male breadwinner and a female homemaker, are less likely to experience abuse. Couples in these households are almost $8 \%$ less likely to experience abuse than other couples, a finding that is strongly statistically significant and remains strong even when age or relationship length is removed from the model, shown in Tables 4.4 through 4.7 .

As noted above, relationship length also proxies gains from cooperation. Consistent with model A, the relationship between the probability of abuse and relationship length is negative, resulting in a $0.3 \%$ reduction in the probability of experiencing abuse for every year a woman remains in the relationship. In Table 4.6, we see that by removing age from the analysis, this figure increases slightly in terms of both statistical and substantive significance.

It was also argued that the gains from cooperation would influence the severity of violence. It was suggested that women in households with low gains from cooperation would not only be most vulnerable to abuse, but would also be most likely to resist, because they have the least to lose by doing so. The findings summarized in Table 4.3 suggest that the gains from cooperation do have an impact on the severity of violence; women residing in traditional households, where the gains from cooperation would be 
highest, experience much less severe forms of abuse, a finding that is statistically significant. It is interesting to note that this figure increases in terms of statistical significance when age or relationship length is removed. Relationship length also reduces the severity of violence. As the length of the relationship increases by one year, the severity of violence decreases by more than $8 \%$, a figure that is strongly statistically significant and remains strong even when age is removed, shown in Table 4.7.

The negative relationship between relationship length and abuse suggests that the disincentive effect is stronger than the resistance effect. Recall from above that is was noted that relationship length potentially proxies both the gains from cooperation and a woman's ability to leave, suggesting that the result could go in either direction, negatively, if the disincentive effect resulting from higher gains from cooperation is stronger than the resistance effect, or negative, if the reverse is true. From the findings, it appears that the effect of higher gains from cooperation is stronger than the ties nurtured through longer relationships, resulting in a negative relationship between abuse and relationship length.

The next hypothesis concerns the role of relative status, where it was argued that after controlling for the gains from cooperation, relative status would indeed be a strong indicator of abuse. It was suggested that where male status was low, that is, where female relative income and education was high and where the male is younger, violence would be more likely. From models $\mathrm{C}$ and $\mathrm{C} 1$ in the third column of Tables 4.2 and 4.3, there is some evidence to support this hypothesis, most notably in terms of relative income. As female income increases relative to male income, that is, as she earns an increasing proportion of household income, the likelihood of experiencing abuse also 
increases, a finding that is strongly statistically significant. Women earning the total share of household earnings are about $26 \%$ more likely to experience abuse than women earning none of the household income, a figure that remains strong when age or relationship length is removed. Similarly, as female education rises relative to male education, the likelihood of experiencing abuse increases by about $3 \%$, a figure that is not statistically significant.

Regarding the severity of abuse, similar results emerge; however, none of the figures are statistically significant. The marginal effect of the 'relative income' variable suggests that women earning all of the household earnings experience abuse that is more than $60 \%$ more severe than women earning none of the household income. In addition, the variable 'relative education' suggests that as we move, for example, from couples where the male and female are equally educated to couples where the female has one level more education than the male, abuse severity increases by more than $50 \%$. These findings, in particular relative income, lend support to the hypothesis that relative status is a potential indicator of abuse.

Models D and D1, summarized in the fourth column of Tables 4.2 and 4.3, include socio-economic and demographic variables such as racial and linguistic status, ability, and urban residence. In addition to the relationships between violence and income and education witnessed in Model A, the probability of violence is strongly correlated with the socio-economic variables, which proxy exit options. Aboriginal women are almost $18 \%$ more likely to experience violence than other women. In comparison, women of colour are almost $10 \%$ more likely to experience abuse. Finally, women with disabilities are almost $14 \%$ more likely to experience abuse than other 
women. These figures reflect the high levels of violence found in these communities in other studies. ${ }^{29}$ Similarly, urban women are about $9 \%$ more likely to experience abuse. ${ }^{30}$ All of these figures are strongly significant and remain strong when age or relationship length is removed.

These variables are also strong indicators of severity of violence. The violence experienced by Aboriginal women is more than $300 \%$ the severity of other women. Similarly, urban women and women with disabilities experience violence that is more than $100 \%$ as severe as other women. Women of colour also experience more severe forms of abuse, reporting violence that is nearly $66 \%$ more severe than other women. With the exception of women of colour, these variables are all strongly statistically significant and remain strong when we remove age or relationship length.

In the context of the theoretical model, outlined above, it is not surprising that these groups of women are more vulnerable to abuse. As mentioned above, women's resistance options are determined in part by socio-economic variables, which will be probed in more depth in chapter 5. However, women with the best outside options, exit opportunities, would be least likely to experience violence because they can use the threat of exit to constrain abuse, as discussed in chapter 3 . But the credibility of the threat

\footnotetext{
${ }^{29}$ For an analysis of violence against women in Aboriginal communities, see D. Brownridge, "Male Partner Violence Against Women in Aboriginal Women in Canada: An Empirical Analysis," Journal of Interpersonal Violence 18:1 (2003) 65-83; and E.D. La Rocque, "Violence in Aboriginal Communities," Violence Against Women: New Canadian Perspectives.

${ }^{30}$ For a brief discussion on rates of violence between urban and sub-urban and rural areas, see W. Sabol, C. Coulton, and J. Korbin, "Building Community Capacity for Violence Prevention," Journal of Interpersonal Violence 19:3 (March 2004) 322-340.
} 
depends on absolute resources, including access to income and financial resources, as well as social resources such as services and emotional support. For example, social exclusion and racism experienced in accessing social services, discussed in chapter 5 , would mean that threats of exit are less credible and therefore increase the likelihood and severity of violence. ${ }^{31}$ For Aboriginal women and women of colour, the cost of losing one's community might limit their willingness to leave, thus reducing the credibility of the exit threat. At the same time, however, additional issues characterize Aboriginal communities, which might contribute to higher levels of stress and thus abuse, including high levels of drug and alcohol use, widespread unemployment, low education, and loss of culture and identity. Similarly, mobility issues and limits to access limit the credibility of the exit threat among women with disabilities. Lacking the resources necessary to ensure long-term departure from the household, her threat of exit will not be credible and will have no effect on violence.

Interesting is the relationship between abuse and relative and absolute resources. As suspected, where the gains from cooperation are high, the likelihood and severity of abuse is low. In addition, as female absolute income increases, her vulnerability to violence decreases. As her status increases in absolute terms, she is in a better position to 'negotiate' violence. However, as her income increases relative to her partner's, her vulnerability to violence increases. This suggests that female income reduces vulnerability to violence only if her partner's status is high relative to hers and/or if her income is high enough to enable her to credibly threaten departure.

\footnotetext{
${ }^{31}$ See Vickers (2002) for a discussion of access to services.
} 


\section{IMPLICATIONS AND POLICY REFORM}

The previous analysis revealed the importance of household structure in creating the conditions for violence. On the one hand, it was demonstrated that where the total gains from the relationship were low, violence was more likely and more severe. On the other hand, it was demonstrated that, after controlling for the gains from the relationship, where male relative status, in particular, male relative income, was low, violence was more likely. It was also shown that these factors condition women's resistance, implicating a complex relationship between absolute and relative resources. This suggests that there are several things going on within abusive households. First, abusers are using violence rationally, that is, to increase their position within the household. Second, where women can credibly threaten departure, violence will be least likely and least severe.

These findings are especially timely, considering the emergence of the postindustrial economy and its implications for male and female labour, as noted in chapter 2. The displacement of low-skilled, male workers and the increasing reliance on female labour suggest that both the gains from families and male relative status are decreasing, which will increase the likelihood of abuse. In addition, despite rising relative status, female absolute status has not improved significantly, especially with the increase of "bad jobs" due to the increasing reliance on precarious female employment. ${ }^{32}$ Female relative status, then, is increasing due to absolute decreases in male status. This suggests

${ }^{32}$ For a historical analysis of the gendered nature of the "precarious employment relationship," see L. Vosko, Temporary Work: The Gendered Rise of a Precarious Employment Relationship (Toronto: University of Toronto Press, 2000). 
that although the probability of abuse is increasing, the ability to resist it is decreasing. Both of these factors increase women's vulnerability to abuse. Unless steps are taken to remedy these problems, violence will potentially increase in the post-industrial economy.

To address these issues, the analysis reveals three strategic areas for policy reform. The first policy area concerns general resource provision. Central to combating violence against women is resource distribution that facilitates gender equality to provide women with exit options, which will ultimately constrain violence, even if women have no intention of leaving, as outlined in chapter $3 .{ }^{33}$ Recall from above that there is a strong negative correlation between female income and abuse. From models D and D1, for every income band into which women move, the likelihood of experiencing abuse decreases by about $1 \%$ and its severity by almost $13 \%$; however, this last figure is not statistically significant. Key to reducing violence then will be to remedy the wage gap between men and women, including labour market policies to address issues such as occupational segregation, both vertical and horizontal, and pay inequity. Similarly, work-life balance policies providing incentives to fathers to take parental leaves would be beneficial in terms of redistributing the long-run effects on wages from such breaks, usually taken by women, as well as redistributing household labour. At the same time, however, care must be taken to also ensure that women who perform caring labour at home are not left without the resources necessary to live autonomously. ${ }^{34}$

${ }^{33}$ See A. Farmer and J. Tiefenthaler, "Domestic Violence: The Value of Services as Signals," American Economic Review 86:2 (May 1996), Papers and Proceedings of the Hundredth and Eighth Annual Meeting of the American Economic Association, 274-279.

${ }^{34}$ An interesting proposal is a Guaranteed Liveable Income, which would offer individuals who perform caring labour an income. However, without also altering the social relations in which caring 
Childcare also has a large role to play here. As the number of children increase, the severity of abuse increases. For example, women with three or more children experience abuse that is more than $60 \%$ more severe than other women. It was argued that as the number of children increase, the ability to exit decreases, therefore limiting the degree to which women can credibly threaten departure. Thus important in any antiviolence program will be accessible, affordable, quality childcare, which will stimulate female labour force participation and attachment and reduce the strains on families.

In addition to income and childcare, female education is a good indicator of the probability of experiencing abuse. From models D and D1 in Tables 4.2 and 4.3, , increasing the level of female education reduces the likelihood of experiencing abuse by just under $2 \%$. Policies stimulating human capital accumulation for women will also work towards reducing violence.

Finally, since families experiencing the highest gains from cooperation are less likely to experience abuse and experience much less severe forms of violence, policies should work towards reducing the strain on families and increasing these gains. For example, work-life balance to help families cope with the tension between family and the labour market, as well as provisions to foster economies of scale and marital investments, which would increase the gains from cooperation. As noted in chapter 2, tax policy can be potentially useful here, offering tax incentives to families, such as those that mitigate the costs of large purchases, including homes, appliances, etc., and those that encourage a

\footnotetext{
labour is distributed and performed, such a proposal has the potential to further entrench the sexual division of labour within households. Such an initiative would thus require supplemental policies to encourage the redistribution of caring labour, such as mandated father's leaves, etc.
} 
more equitable division of household labour, for example, by paying spousal tax credits to those who are dependent or by abandoning official recognition of spousal relationships within the Income Tax Act. ${ }^{35}$ With higher gains from families, there are fewer incentives for abuse.

The second policy area is the targeting of vulnerable groups. Note from above the presence of three vulnerable groups of women, including Aboriginal, women of colour and women with disabilities, as shown in Tables 4.3 and 4.4. Noted above, the abuse experienced by Aboriginal women is $365 \%$ more severe than other women. Similarly, women with disabilities experience levels of abuse that are $145 \%$ more severe than other women. Policies and programs must be designed from the perspectives of these women and intersections between them, including race, class and (dis)ability. Access to services are important, which means ensuring that there are enough of them and that they can accommodate a variety of circumstances, including language, culture, ability, and children. Equally important are programs that attempt to decrease social exclusion, which will expand the outside options available to women and provide better opportunities with which to credibly threaten exit. Most crucially, there must be

\footnotetext{
${ }^{35}$ For an analysis, see C. Young, "Women, Tax and Social Programs: The Gendered Impact of Funding Social Programs Through the Tax System," Status of Women Canada (2000: 33), available at http://www.swc-cfc.gc.ca/ and C. Young, "Close and Personal Relationships between Adults: What's Sex got to do with It? Tax and the "family" (May 2000). See also C. Vincent and F. Woolley, "Taxing Canadian Families: What's Fair, What's Not," Choices, 6:5 (2000).
} 
particular attention to ability, race and culture to ensure that all individuals have access to the labour market and social services. ${ }^{36}$

In addition to increasing resources and targeting vulnerable groups, policy must work towards altering gender relations. ${ }^{37}$ The analysis above demonstrated a strong correlation between relative status, especially relative income, and abuse. As women earn higher proportions of household income, their vulnerability to abuse increases and they are more likely to experience severe forms of abuse. Indeed, from models D and D1, women earning all of the household income are $0.7 \%$ more likely to experience abuse than women who are completely dependent on their partners. This relationship suggests that while increasing female economic resources is necessary to reduce women's vulnerability to abuse, it is by no means sufficient. Rather, policy must work towards destablising gender binaries, which are remarkably tenacious in assigning male and female tasks within households. In addition to transforming economic relations, policy must also work to transform social relations, what Fraser (1997) refers to 'transformative public policy'.

At the very least, this requires labour market and social policy reform that attempts to redistribute caring labour. As noted above, work-family balance policies, childcare, and policies encouraging an active role for fathers would be crucial here. In addition, the time has come to think seriously about involving men in the process of

\footnotetext{
${ }^{36}$ See C. Gabriel, "One or the Other? "Race," Gender, and the Limits of Official Multiculturalism," in Brodie, J. (ed.) Women and Canadian Public Policy (Toronto: Harcourt Brace and Company, 1996) for a discussion of the limits of multicultural policy in Canada.

${ }^{37}$ As we will see in the following chapter, policies designed to alter race relations are also required.
} 
change. ${ }^{38}$ By removing the material base of masculinity, it is possible to disconnect the relationship between relative status and violence.

These reforms are far removed from the criminal justice system, which is the cornerstone of anti-violence policy in Canada. ${ }^{39}$ Increasing emphasis has been paid to multisectoral policy, which includes not only targeted anti-violence policies and programs, but also general social services. ${ }^{40}$ However, as Morrow, Hankivsky, and Varcoe (2004) demonstrate, cuts to general social services in the spirit of neo-liberalism or its successor have serious implications for women attempting to escape abusive relationships. Policy analysis must pay careful attention to the effects of policy changes on abused women, as they vary by class, race and culture, and ability. Ultimately, only with gender equality will violence end.

${ }^{38}$ See R. W. Connell, "The Role of Men and Boys in Achieving Gender Equality," United Nations and ILO (Brazil, 2003) and "Change Among the Gatekeepers: Men, Masculinities, and Gender Equality in the Global Arena," Signs 30:3 (2005) 1801-1825.

${ }^{39}$ See S. Burt and C. Mitchell, "What's in a Name?: From Sheltering Women to Protecting Communities." In Pal, Leslie ed. How Ottawa Spends 1998-99: Balancing Act: The Post Deficit Mandate (Toronto: Oxford University Press, 1998) 271-292, for an overview of wife abuse policy in Canada.

${ }^{40}$ See chapter 1 for a discussion on the distinction between core and peripheral policies within the anti-violence framework. See also, M. Morrow, O. Hankivsky, and C. Varcoe, "Women and Violence: The Effects of Dismantling the Welfare State," in Critical Social Policy 24:3 (2004) 358-384, for an analysis of the implications of cuts to social services such as legal aid and social assistance on abused women. 


\section{CONCLUSION}

It has been argued that both the gains from cooperation and relative status are important determinants of violence. Accordingly, both absolute and relative resources are crucial in determining violence, since both are important in generating and dividing the gains from cooperation. With higher absolute resources, households tend to generate higher gains from cooperation since they can afford to specialize or to invest in time or money saving products and services. At the same time, however, with higher relative status, individuals can get more from household bargaining. Furthermore, women with high absolute resources can more credibly threaten exit, which will constrain violence by making it more expensive for the abuser. In the post-industrial era, it is expected that violence will increase. Policy reform must focus on resource redistribution, targeting vulnerable groups, and transforming social relations. 
Table 4.1:

Descriptive Statistics: The 1999 General Social Survey on Victimization

\begin{tabular}{|c|c|c|c|}
\hline $\begin{array}{l}\text { Characteristics } \\
\text { (population averages) }\end{array}$ & Sample $(N=7194)$ & $\begin{array}{l}\text { Non-Abused Women } \\
(\mathrm{N}=6032)\end{array}$ & $\begin{array}{l}\text { Abused Women } \\
(\mathrm{N}=793)\end{array}$ \\
\hline Age & 45.57 & 45.7 & 42 \\
\hline Age of youngest child & 10 & 10 & 9 \\
\hline $\begin{array}{l}\text { Average Number of } \\
\text { Children Under } 16\end{array}$ & .64 & .79 & .63 \\
\hline Relationship Length & 21 & 21 & 18 \\
\hline Personal Tncome & 25410 & 25877 & 22304 \\
\hline Household Income & $\$ 40,000-49,000$ & $\$ 40,000-49,000$ & $\$ 40,000-49,000$ \\
\hline $\begin{array}{l}\text { Proportion of } \\
\text { Houschold Income }\end{array}$ & $37.5 \%$ & $40 \%$ & $37 \%$ \\
\hline Personal Education & Some University & High School & Some University \\
\hline Spouse Pdication & High School & High School & High School \\
\hline Urbail & $76 \%$ & $75 \%$ & $76 \%$ \\
\hline Aborigmal & $2 \%$ & $1.6 \%$ & $4.6 \%$ \\
\hline Person of Colour & $8.6 \%$ & $7.7 \%$ & $11.5 \%$ \\
\hline Disability & $15.6 \%$ & $14.8 \%$ & $22.4 \%$ \\
\hline $\begin{array}{l}\text { Household Language } \\
\text { other than Erench or } \\
\text { English }\end{array}$ & $12 \%$ & $11 \%$ & $14 \%$ \\
\hline
\end{tabular}


Table 4.2:

Probability of Experiencing Violence

\begin{tabular}{|c|c|c|c|c|c|c|c|c|}
\hline Variable & Model & & Model & & Mode & & $\overline{\text { Model }}$ & \\
\hline & B (SE) & $\overline{M E}$ & B (SE) & $\overline{\text { ME }}$ & B (SE) & ME & B (SE) & ME \\
\hline Age & $-.007(.006)$ & -.002 & $\begin{array}{l}.007 \\
(.006)\end{array}$ & -.001 & $\begin{array}{l}.009 \\
(.007)\end{array}$ & -.001 & $\begin{array}{l}-.016 \\
(.007)^{* *}\end{array}$ & -.002 \\
\hline $\begin{array}{l}\text { Relationship } \\
\text { Length }\end{array}$ & $\begin{array}{l}-.012 \\
(.006)^{* *}\end{array}$ & -.002 & $\begin{array}{l}-.013 \\
(.006) * *\end{array}$ & -.003 & $\begin{array}{l}-.012 \\
(.007)^{*}\end{array}$ & -.002 & $\begin{array}{l}-.007 \\
(.007)\end{array}$ & -.001 \\
\hline One Child & $.031(.126)$ & .007 & $.055(.127)$ & .013 & $.017(.138)$ & .003 & $\begin{array}{l}-.001 \\
(.140)\end{array}$ & -.000 \\
\hline $\begin{array}{l}\text { Two } \\
\text { Children }\end{array}$ & $.109(.124)$ & .024 & $.160(.125)$ & .038 & $.081(.140)$ & .017 & $.080(.142)$ & .014 \\
\hline $\begin{array}{l}\text { Three + } \\
\text { Children }\end{array}$ & $.079(.175)$ & .018 & $.163(.178)$ & .038 & $.290(.188)$ & .059 & $.278(.192)$ & .049 \\
\hline $\begin{array}{l}\text { Personal } \\
\text { income }\end{array}$ & $\begin{array}{l}.035 \\
(.018)^{* *}\end{array}$ & -.007 & $\begin{array}{l}-.063 \\
(.021)^{* * *}\end{array}$ & -.013 & $\begin{array}{l}-.139 \\
(.032)^{* * *}\end{array}$ & -.019 & $\begin{array}{l}-.102 \\
(.033)^{* * *}\end{array}$ & -.013 \\
\hline $\begin{array}{l}\text { Spousal } \\
\text { education }\end{array}$ & $\begin{array}{l}-.149 \\
(.034)^{* * *}\end{array}$ & -.028 & $\begin{array}{l}-.141 \\
(.034)^{* * * *}\end{array}$ & -.028 & $\begin{array}{l}-.009 \\
(.070)\end{array}$ & -.002 & $\begin{array}{l}-.027 \\
(.071)\end{array}$ & -.004 \\
\hline $\begin{array}{l}\text { Female } \\
\text { Education }\end{array}$ & $-.070(.037)^{*}$ & -.014 & $\begin{array}{l}-.067 \\
(.037)^{*}\end{array}$ & -.015 & $\begin{array}{l}-.130 \\
(.069)^{*}\end{array}$ & -.021 & $\begin{array}{l}-.138 \\
(.069)^{* *}\end{array}$ & -.018 \\
\hline $\begin{array}{l}\text { Traditional } \\
\text { Household }\end{array}$ & - & - & $\begin{array}{l}-.342 \\
(.125)^{* * *}\end{array}$ & -.079 & $\begin{array}{l}-.259 \\
(.141)^{*}\end{array}$ & -.051 & )$^{-.190(.142}$ & -.032 \\
\hline $\begin{array}{l}\text { Relative } \\
\text { Income }\end{array}$ & - & - & - & - & $\begin{array}{l}1.110 \\
(.251)^{* * *}\end{array}$ & .01 & $\begin{array}{l}.907 \\
(.257)^{* * *}\end{array}$ & .007 \\
\hline $\begin{array}{l}\text { Relative } \\
\text { Education }\end{array}$ & - & - & - & - & $.150(.102)$ & .033 & $.151(.103)$ & .029 \\
\hline Male Older & - & - & - & - & $.016(.105)$ & .003 & $\begin{array}{l}.002 \\
(.107)\end{array}$ & -.000 \\
\hline Aboriginal & - & - & - & - & - & - & $\begin{array}{l}.843 \\
(.259)^{* * * *}\end{array}$ & .177 \\
\hline $\begin{array}{l}\text { Visible } \\
\text { Minority }\end{array}$ & - & - & - & - & - & - & $\begin{array}{l}.496 \\
(.194)^{* *}\end{array}$ & .097 \\
\hline Disability & - & - & - & - & - & - & $\begin{array}{l}.683 \\
(.125)^{* * *}\end{array}$ & .139 \\
\hline $\begin{array}{l}\text { Household } \\
\text { Language }\end{array}$ & - & - & - & - & - & - & $.004(.178)$ & .001 \\
\hline Urban & - & - & - & - & - & - & $\begin{array}{l}.419 \\
(.121)^{* * *}\end{array}$ & .085 \\
\hline Constant & $\begin{array}{l}.693 \\
(.258)^{* *}\end{array}$ & & $\begin{array}{l}.513 \\
(.265)^{* *} \\
\end{array}$ & & $\begin{array}{l}.947 \\
(.327)^{* * *}\end{array}$ & & $\begin{array}{l}-1.250 \\
(.338)^{* * *}\end{array}$ & \\
\hline $\begin{array}{l}-2 \log \\
\text { likelihood }\end{array}$ & 3681.272 & & 3668.540 & & 3012.188 & & 2948.996 & \\
\hline Count $\mathrm{R}^{2}$ & .88 & & .88 & & .875 & & .875 & \\
\hline \multicolumn{9}{|l|}{$\begin{array}{l}* * * \mathrm{p}=.005 \\
* * \mathrm{p}=.050 \\
*_{\mathrm{p}}=.100\end{array}$} \\
\hline \multicolumn{9}{|c|}{ Marginal effects are calculated at the sample means. } \\
\hline
\end{tabular}


Table 4.3:

Severity of Violence

\begin{tabular}{|c|c|c|c|c|c|c|c|c|}
\hline \multirow[t]{2}{*}{ Variable } & \multicolumn{2}{|c|}{ Model A1 } & \multicolumn{2}{|c|}{ Model B1 } & \multicolumn{2}{|c|}{ Model C1 } & \multicolumn{2}{|c|}{ Model D1 } \\
\hline & B (SE) & ME & B (SE) & $\mathbf{M E}$ & B (SE) & ME & B (SE) & $\overline{\mathbf{M E}}$ \\
\hline Age & $-.225(.257)$ & -.027 & $\begin{array}{l}-.202 \\
(.256)\end{array}$ & -.024 & $-.116(.267)$ & -.014 & $-.258(.271)$ & -.031 \\
\hline $\begin{array}{l}\text { Relationship } \\
\text { Length }\end{array}$ & $\begin{array}{l}-.662 \\
(.250)^{* *}\end{array}$ & -.080 & $\begin{array}{l}-.700 \\
(.250)^{* * *}\end{array}$ & -.084 & $\begin{array}{l}-.805 \\
(.269) * * *\end{array}$ & -.098 & $\begin{array}{l}-.668 \\
(.268)^{* *} \\
\end{array}$ & -.081 \\
\hline One Child & $\begin{array}{l}6.215 \\
(4.650)\end{array}$ & .766 & $\begin{array}{l}7.630 \\
(4.672)\end{array}$ & .949 & $\begin{array}{l}3.780 \\
(5.056)\end{array}$ & .468 & $\begin{array}{l}4.343 \\
(5.025)\end{array}$ & .533 \\
\hline $\begin{array}{l}\text { Two } \\
\text { Children }\end{array}$ & $\begin{array}{l}4.441 \\
(2.191)^{* *}\end{array}$ & .537 & $\begin{array}{l}5.481 \\
(2.223) *\end{array}$ & .660 & $\begin{array}{l}4.927 \\
(2.363)^{*}\end{array}$ & .602 & $\begin{array}{l}5.236 \\
(2.356) * *\end{array}$ & .633 \\
\hline $\begin{array}{l}\text { Three + } \\
\text { Children }\end{array}$ & $\begin{array}{l}4.106 \\
(2.022) * *\end{array}$ & .496 & $\begin{array}{l}5.122 \\
(2.064) *\end{array}$ & .617 & $\begin{array}{l}6.119 \\
(2.120)^{* * *}\end{array}$ & .748 & $\begin{array}{l}5.962 \\
(2.136)^{* * *}\end{array}$ & .721 \\
\hline $\begin{array}{l}\text { Personal } \\
\text { income }\end{array}$ & $-.316(.676)$ & -.038 & $\begin{array}{l}-1.195 \\
(.775)\end{array}$ & -.144 & \begin{tabular}{|l|}
-1.588 \\
$(1.216)$
\end{tabular} & -.194 & $\begin{array}{l}-1.051 \\
(1.230)\end{array}$ & -.127 \\
\hline $\begin{array}{l}\text { Spousal } \\
\text { education }\end{array}$ & $\begin{array}{l}-3.895 \\
(1.281) * * *\end{array}$ & -.470 & $\begin{array}{l}-3.457 \\
(1.284)^{* *}\end{array}$ & -.416 & $\begin{array}{l}.550 \\
(2.614)\end{array}$ & -.067 & $\begin{array}{l}-1.108 \\
(2.597)\end{array}$ & -.134 \\
\hline $\begin{array}{l}\text { Female } \\
\text { Education }\end{array}$ & $\begin{array}{l}-.644 \\
(1.416)\end{array}$ & -.078 & $\begin{array}{l}.697 \\
(1.420) \\
\end{array}$ & -.084 & \begin{tabular}{|l|}
-2.376 \\
$(2.534)$ \\
\end{tabular} & -.290 & $\begin{array}{l}-2.301 \\
(2.519) \\
\end{array}$ & -.278 \\
\hline $\begin{array}{l}\text { Traditional } \\
\text { Household }\end{array}$ & - & - & $\begin{array}{l}-11.781 \\
(4.791)^{*}\end{array}$ & -1.375 & $\begin{array}{l}-10.552 \\
(5.098)^{*}\end{array}$ & -1.253 & $\begin{array}{l}-9.226 \\
(5.043)^{* *}\end{array}$ & -1.087 \\
\hline $\begin{array}{l}\text { Relative } \\
\text { Income }\end{array}$ & - & - & - & - & $\begin{array}{l}5.012 \\
(9.901) \\
\end{array}$ & .613 & $\begin{array}{l}1.227 \\
(10.006)\end{array}$ & .148 \\
\hline Male Older & - & - & - & - & $\begin{array}{l}2.321 \\
(3.815)\end{array}$ & .285 & $\begin{array}{l}1.943 \\
(3.809)\end{array}$ & .236 \\
\hline $\begin{array}{l}\text { Relative } \\
\text { Education }\end{array}$ & - & - & - & - & $\begin{array}{l}4.430 \\
(3.675) \\
\end{array}$ & .542 & $\begin{array}{l}3.973 \\
(3.670)\end{array}$ & .480 \\
\hline Aboriginal & - & - & - & - & - & - & $\begin{array}{l}26.384 \\
(8.520)^{* * *}\end{array}$ & 3.657 \\
\hline $\begin{array}{l}\text { Visible } \\
\text { Minority }\end{array}$ & - & - & - & - & - & - & $\begin{array}{l}5.296 \\
(7.257)\end{array}$ & .656 \\
\hline Disability & - & - & - & - & - & - & $\begin{array}{l}11.495 \\
(4.818)^{* *}\end{array}$ & 1.450 \\
\hline $\begin{array}{l}\text { Household } \\
\text { Language }\end{array}$ & - & - & - & - & - & - & $\begin{array}{l}2.161 \\
(6.649)\end{array}$ & .264 \\
\hline Urban & - & - & - & - & - & - & $\begin{array}{l}14.656 \\
(4.440)^{* * * *}\end{array}$ & 1.720 \\
\hline Constant & $\begin{array}{l}-59.339 \\
(10.501)^{* * *}\end{array}$ & & $\begin{array}{l}54.851 \\
(10.596)^{* * *}\end{array}$ & & $\begin{array}{l}-63.538 \\
(12.871)^{* * *}\end{array}$ & & $\begin{array}{l}-72.265 \\
(13.270)^{* * *}\end{array}$ & \\
\hline $\begin{array}{l}-2 \text { log } \\
\text { likelihood }\end{array}$ & -1613.7538 & & -1603.2011 & & -1347.4001 & & -1333.0841 & \\
\hline \multicolumn{9}{|l|}{$\begin{array}{l}* * * \mathrm{p}=.005 \\
* * \mathrm{p}=.050 \\
* \mathrm{p}=.100\end{array}$} \\
\hline \multicolumn{9}{|c|}{$\begin{array}{l}\text { Marginal effects are calculated at the sample means of the non-truncated sample. Since we are concerned with } \\
\text { severity of abuse, the marginal effect captures the effect of a change in x on y when y is greater than zero. See L. } \\
\text { Sigelman and L. Zeng, "Analyzing Censored and Sample-Selected Data with Tobit and Heckit Models," } \\
\text { Political Analysis 8:2 (1999): 167-182. }\end{array}$} \\
\hline
\end{tabular}




\section{APPENDIX 4.1: \\ SUPPLEMENTARY TABLES}

Table 4.4:

Probability - Age Only

\begin{tabular}{|c|c|c|c|c|}
\hline Variable & Model A & Model B & Model C & Model D \\
\hline & B (SE) & B (SE) & B (SE) & B (SE) \\
\hline Age & $-.017(.004)^{* * * *}$ & $-.018(.004)^{* * * *}$ & $-.018(.004)^{* * *}$ & $-.022(.004)^{* * * *}$ \\
\hline One Child & $.039(.126)$ & $.062(.126)$ & $.025(.138)$ & $.008(.140)$ \\
\hline $\begin{array}{l}\text { Two } \\
\text { Children }\end{array}$ & $.111(.124)$ & $.160(.125)$ & $.081(.140)$ & $.083(.142)$ \\
\hline $\begin{array}{l}\text { Three + } \\
\text { Children }\end{array}$ & $-.087(.175)$ & $.071(.177)$ & $.297(.187)$ & $.288(.191)$ \\
\hline $\begin{array}{l}\text { Personal } \\
\text { income }\end{array}$ & $-.029(.018)^{*}$ & $-.058(.020)^{* * *}$ & $-.136(.032)^{* * *}$ & $-.100(.033)^{* * *}$ \\
\hline $\begin{array}{l}\text { Spousal } \\
\text { education }\end{array}$ & $-.148(.033)^{* * *}$ & $-.140(.034)^{* * *}$ & $-.006(.070)$ & $-.026(.071)$ \\
\hline $\begin{array}{l}\text { Female } \\
\text { Education }\end{array}$ & $-.061(.037)^{*}$ & $-.058(.037)$ & $-.120(.069)^{*}$ & $-.129(.069)^{*}$ \\
\hline $\begin{array}{l}\text { Traditional } \\
\text { Household }\end{array}$ & - & $-.344(.124)^{* * *}$ & $-.261(.141)^{*}$ & $-.194(.142)$ \\
\hline $\begin{array}{l}\text { Relative } \\
\text { Income }\end{array}$ & - & - & $1.116(.249)^{* * *}$ & $.900(.255)^{* * *}$ \\
\hline $\begin{array}{l}\text { Relative } \\
\text { Education }\end{array}$ & - & - & $.150(.102)$ & $.149(.103)$ \\
\hline Male Older & - & - & $.014(.105)$ & $-.003(.106)$ \\
\hline Aboriginal & - & - & - & $.860(.258)^{* * *}$ \\
\hline $\begin{array}{l}\text { Visible } \\
\text { Minority } \\
\end{array}$ & - & - & - & $.484(.193)^{* *}$ \\
\hline Disability & - & - & - & $.697(.124)^{* * *}$ \\
\hline $\begin{array}{l}\text { Household } \\
\text { Language }\end{array}$ & - & - & - & $.017(.176)$ \\
\hline Urban & - & - & - & $.414(.120)^{* * *}$ \\
\hline Constant & $-.535(.242)^{* *}$ & $-.347(.250)$ & $-.802(.313)^{* *}$ & $-1.173(.325)^{* * *}$ \\
\hline $\begin{array}{l}-2 \text { log } \\
\text { likelihood }\end{array}$ & 3704.022 & 3691.326 & 3027.176 & 2962.250 \\
\hline Count $\mathbf{R}^{2}$ & .881 & .881 & .876 & .876 \\
\hline $\begin{array}{l}* * * \mathrm{p}=.005 \\
* * \mathrm{p}=.050 \\
*_{\mathrm{p}=.100}\end{array}$ & & & & \\
\hline
\end{tabular}


Table 4.5:

Severity - Age Only

\begin{tabular}{|c|c|c|c|c|}
\hline Variable & Model A & Model B & Model C & Model D \\
\hline & B (SE) & B (SE) & B (SE) & B (SE) \\
\hline Age & $-.777(.164)^{* * *}$ & $-.784(.163)^{* * *}$ & $\begin{array}{l}-.767 \\
(.175)^{* * *}\end{array}$ & $-.800 \quad(.176)^{* * *}$ \\
\hline One Child & $6.375(4.602)$ & $7.693(4.622)^{*}$ & $4.254(5.025)$ & $4.836(4.989)$ \\
\hline $\begin{array}{l}\text { Two } \\
\text { Children }\end{array}$ & $4.194(2.177)^{* * *}$ & $5.181(2.207)^{* *}$ & $4.817(2.360)^{* *}$ & $5.183(2.351)^{* *}$ \\
\hline $\begin{array}{l}\text { Three + } \\
\text { Children }\end{array}$ & $\begin{array}{ll}3.907 & (2.012)^{* * *}\end{array}$ & $4.883(2.052)^{* *}$ & $5.966(2.120)^{* * *}$ & $5.858(2.135)^{* *}$ \\
\hline $\begin{array}{l}\text { Personal } \\
\text { income }\end{array}$ & $-.070 \quad(.664)$ & $\begin{array}{l}-.926 \\
(.762)\end{array}$ & $-1.449(1.211)$ & $-.877(1.224)$ \\
\hline $\begin{array}{l}\text { Spousal } \\
\text { education }\end{array}$ & $\begin{array}{l}-3.804 \\
(1.270)^{* * *}\end{array}$ & $-3.382(1.274)^{* * *}$ & $-.373(2.609)$ & $-1.014 \quad(2.592)$ \\
\hline $\begin{array}{l}\text { Female } \\
\text { Education }\end{array}$ & $-.182(1.399)$ & $-.195(1.404)$ & $-1.816(2.525)$ & $-1.800 \quad(2.507)$ \\
\hline $\begin{array}{l}\text { Traditional } \\
\text { Household }\end{array}$ & - & $-11.619(4.753)^{* *}$ & $-10.376(5.084)^{* *}$ & $-9.058(5.023)^{*}$ \\
\hline $\begin{array}{l}\text { Relative } \\
\text { Income }\end{array}$ & - & - & $\begin{array}{ll}6.481 & (9.819)\end{array}$ & $2.049 \quad(9.924)$ \\
\hline Male Older & - & - & $1.688 \quad(3.800)$ & $1.274 \quad(3.791)$ \\
\hline $\begin{array}{l}\text { Relative } \\
\text { Education }\end{array}$ & - & - & $4.385 \quad(3.664)$ & $3.852 \quad(3.658)$ \\
\hline Aboriginal & - & - & - & $27.079(8.521)^{* * *}$ \\
\hline $\begin{array}{l}\text { Visible } \\
\text { Minority }\end{array}$ & - & - & - & $5.000(7.218)$ \\
\hline Disability & - & - & - & $12.330(4.792)^{* * *}$ \\
\hline $\begin{array}{l}\text { Household } \\
\text { Language }\end{array}$ & - & - & - & $3.254(6.514)$ \\
\hline Urban & - & - & - & $15.219(4.436)^{* * *}$ \\
\hline Constant & $\begin{array}{ll}-49.98839 & \\
9.635728 & * * *\end{array}$ & $\begin{array}{l}-45.0443 \\
9.753258 * * * \\
\end{array}$ & $\begin{array}{l}-53.23913 \\
12.16262^{* * *}\end{array}$ & $-64.180(12.609)^{* * *}$ \\
\hline $\begin{array}{l}-2 \text { log } \\
\text { likelihood }\end{array}$ & -1631.8513 & -1621.6473 & -1359.4497 & -1343.6724 \\
\hline $\begin{array}{l}* * * \mathrm{p}=.005 \\
* * \mathrm{p}=.050 \\
*_{\mathrm{p}}=.100\end{array}$ & & & & \\
\hline
\end{tabular}


Table 4.6:

Probability - Relationship Length Only

\begin{tabular}{|c|c|c|c|c|}
\hline Variable & Model A & Model B & Model C & Model D \\
\hline & B (SE) & B (SE) & B (SE) & B (SE) \\
\hline $\begin{array}{l}\text { Relationship } \\
\text { Length }\end{array}$ & $-.017(.004)^{* * *}$ & $-.018(.004)^{* * *}$ & $-.018(.004)^{* * *}$ & $-.019(.004)^{* * *}$ \\
\hline One Child & $.060(.124)$ & $.085(.124)$ & $.054(.135)$ & $.068(.137)$ \\
\hline $\begin{array}{l}\text { Two } \\
\text { Children }\end{array}$ & $.139(.121)$ & $.190(.123)$ & $.118(.137)$ & $.147(.139)$ \\
\hline $\begin{array}{l}\text { Three or } \\
\text { More } \\
\text { Children }\end{array}$ & $.112(.172)$ & $.197(.175)$ & $.329(.185)^{*}$ & $.347(.189)^{*}$ \\
\hline $\begin{array}{l}\text { Personal } \\
\text { income }\end{array}$ & $-.036(.018)^{* *}$ & $-.064(.020)^{* * *}$ & $-.139(.032)^{* * *}$ & $-.103(.033)^{* * *}$ \\
\hline $\begin{array}{l}\text { Spousal } \\
\text { education }\end{array}$ & $-.149(.033)^{* * *}$ & $-.141(.034)^{* * *}$ & $-.011(.070)$ & $-.030(.070)$ \\
\hline $\begin{array}{l}\text { Female } \\
\text { Education }\end{array}$ & $-.069(.037)^{*}$ & $-.067(.037)^{*}$ & $-.127(.069)^{*}$ & $-.132(.069)^{*}$ \\
\hline $\begin{array}{l}\text { Traditional } \\
\text { Household }\end{array}$ & - & $-.339(.124)^{* *}$ & $-.255(.141)^{*}$ & $-.186(.142)$ \\
\hline $\begin{array}{l}\text { Relative } \\
\text { Income }\end{array}$ & - & - & $1.093(.250)^{* * *}$ & $.884(.257)^{* * *}$ \\
\hline $\begin{array}{l}\text { Relative } \\
\text { Education }\end{array}$ & - & - & $.145(.102)$ & $.144(.103)$ \\
\hline Male Older & - & - & $.025(.105)$ & $.020(.106)$ \\
\hline Aboriginal & - & - & - & $.848(.259)^{* * *}$ \\
\hline $\begin{array}{l}\text { Visible } \\
\text { Minority }\end{array}$ & - & - & - & $.485(.194)^{* *}$ \\
\hline Disability & - & - & - & $.634(.123)^{* * * *}$ \\
\hline $\begin{array}{l}\text { Household } \\
\text { Language }\end{array}$ & - & - & - & $-.001(.177)$ \\
\hline Urban & - & - & - & $.412(.120)^{* * *}$ \\
\hline Constant & $-.907(.166)^{* * *}$ & $-.738(.176)^{* * *}$ & $-1.210(.249)^{* * *}$ & $-1.724(.266)^{* * *}$ \\
\hline $\begin{array}{l}-2 \log \\
\text { likelihood }\end{array}$ & 3682.443 & 3669.823 & 3013.725 & 2954.099 \\
\hline Count $\mathbf{R}^{2}$ & .88 & .88 & .875 & .875 \\
\hline $\begin{array}{l}* * * \mathrm{p}=.005 \\
* * \mathrm{p}=.050 \\
* \mathrm{p}=.100\end{array}$ & & & & \\
\hline
\end{tabular}


Table 4.7:

Severity - Relationship Length Only

\begin{tabular}{|c|c|c|c|c|}
\hline Variable & Model A & Model B & Model C & Model D \\
\hline & B (SE) & B (SE) & B (SE) & B (SE) \\
\hline $\begin{array}{l}\text { Relationship } \\
\text { Length }\end{array}$ & $-.831(.161)^{* * *}$ & $-.8522(.161)^{* * *}$ & $\begin{array}{l}-.893 \\
(.178)^{* * * *}\end{array}$ & $\begin{array}{l}-.863 \\
(.175)^{* * *}\end{array}$ \\
\hline One Child & $7.057(4.555)$ & $8.390(4.577)^{*}$ & $4.230 \quad(4.949)$ & $5.282(4.930)$ \\
\hline $\begin{array}{l}\text { Two } \\
\text { Children }\end{array}$ & $4.876(2.140)^{* *}$ & $5.870(2.174)^{* *}$ & $5.153(2.307)^{* *}$ & $5.702(2.310)^{* *}$ \\
\hline $\begin{array}{l}\text { Three or } \\
\text { More } \\
\text { Children } \\
\end{array}$ & $4.442(1.988)^{* *}$ & $5.422(2.031)^{* *}$ & $6.288(2.085)^{* * *}$ & $6.314(2.106)^{* * *}$ \\
\hline $\begin{array}{l}\text { Personal } \\
\text { income }\end{array}$ & $-.362(.673)$ & $-1.235(.772)$ & $-1.588(1.215)$ & $\begin{array}{ll}-1.079(1.228) \\
\end{array}$ \\
\hline $\begin{array}{l}\text { Spousal } \\
\text { education }\end{array}$ & $\begin{array}{l}-3.876 \\
(1.278) * * *\end{array}$ & $-3.438(1.281)^{* *}$ & $-.554 \quad(2.609)$ & $\begin{array}{ll}-1.101 & (2.588)\end{array}$ \\
\hline $\begin{array}{l}\text { Female } \\
\text { Education }\end{array}$ & $-.6591 \quad(1.412)$ & $-.711 \quad(1.416)$ & $-2.360 \quad(2.531)$ & $-2.278 \quad(2.512)$ \\
\hline $\begin{array}{l}\text { Traditional } \\
\text { Household }\end{array}$ & - & $-11.772(4.783)^{* *}$ & $-10.534(5.092)^{* * *}$ & $-9.219(5.031)^{*}$ \\
\hline $\begin{array}{l}\text { Relative } \\
\text { Income }\end{array}$ & - & - & $4.811 \quad(9.885)$ & $.9692 \quad(9.993)$ \\
\hline Male Older & - & - & $2.462 \quad(3.796)$ & $2.320 \quad(3.778)$ \\
\hline $\begin{array}{l}\text { Relative } \\
\text { Education }\end{array}$ & - & - & $4.395 \quad(3.669)$ & $3.915 \quad(3.660)$ \\
\hline Aboriginal & $\begin{array}{l}- \\
-\end{array}$ & - & - & $26.348(8.516)^{* * *}$ \\
\hline $\begin{array}{l}\text { Visible } \\
\text { Minority }\end{array}$ & - & - & - & $5.028 \quad(7.225)$ \\
\hline Disability & - & - & - & $10.801(4.748)^{* *}$ \\
\hline $\begin{array}{l}\text { Household } \\
\text { Language }\end{array}$ & - & $\begin{array}{l}- \\
-\end{array}$ & - & $2.125 \quad(6.629)$ \\
\hline Urban & - & - & - & $14.444(4.420)^{* * *}$ \\
\hline Constant & $\begin{array}{l}-65.933 \\
(7.628)^{* * *}\end{array}$ & $\begin{array}{l}-60.786 \\
(7.744)^{* * *}\end{array}$ & $-66.951(10.336)^{* * *}$ & $-79.548 \quad(11.139)$ \\
\hline $\begin{array}{l}-2 \log \\
\text { likelihood }\end{array}$ & -1614.1475 & -1603.5216 & -1347.4961 & -1333.5522 \\
\hline $\begin{array}{l}* * * \mathrm{p}=.005 \\
* * \mathrm{p}=.050 \\
* \mathrm{p}=.100\end{array}$ & & & & \\
\hline
\end{tabular}




\section{CHAPTER 5:}

\section{(RE)CONSTRUCTING WOMEN'S RESISTANCE: RESOURCES, STRATEGY CHOICE AND IMPLICATIONS OF AND FOR PUBLIC POLICY}


In the previous chapters, a bargaining model was adopted to explore the conditions under which violence occurs and the subsequent effects of resistance. It was demonstrated, both theoretically and empirically, that certain households are more vulnerable to violence and that women with the best outside options are able to negotiate lower levels of abuse. It also noted the constraints imposed on women by Canada's current anti-violence policy regime, which privileges exit by defining as its goal separation rather than ending abuse. In this chapter, women's resistance is explored in more depth, with particular emphasis on service usage, revealing the various ways in which women attempt to get a better deal within their relationship. Using data from the 1999 General Social Survey on Victimization, the variety of resistance strategies are explored, beyond or perhaps in addition to exit, that women employ when seeking to eliminate violence from their lives. Key here is to determine whether or not the representation of women's resistance as exit has any implications for service usage. This chapter proceeds in three sections. First, the linkages between public and private services are illuminated in an attempt to situate Canada's anti-violence policy in an analytical framework. Second, women's patterns of resistance are analyzed, as shaped by age, race and culture, and ability. Here consideration is given, not only to why women use a particular strategy, but also to why they do not use particular strategies, which are explained in reference to the analysis laid out in the first section. Finally, an outline for policy reform is provided. 


\section{PROBLEM REPRESENTATION: IMPLICATIONS FOR STRATEGY CHOICE}

Chapter 3 revealed the ways in which resistance is constructed in public policy. The process of naming or representing problems is the result of political struggle. ${ }^{1}$ Stone (2002: 11) writes, "Each idea is an argument, or more accurately, a collection of arguments in favor of different ways of seeing the world." She argues that with each "problem" there exist multiple interpretations that are manipulated "as part of political strategy" (11). Similarly, Bacchi (1999: 165-166) argues, “[...] complex social issues are commonly reduced to 'problems' which are then assigned to particular groups of professionals or to different departments of government, leaving the impression that the problem is being addressed." Problematization, Bacchi observes, is "the chief means of instituting liberal rationality [...], that is, structuring problems in such a way that liberal outcomes, [...], follow" (166). Like Stone and Bacchi, Jenson's (1986) “universe of political discourse" elucidates the process through which policies emerge from political struggles rooted in patterns of social relations.

Ultimately what this tells us is that policy is not the result of what Deborah Stone (2002) refers to as the "rationality project" but the result of the ways in which problems, goals and instruments are constructed and represented through various political struggles. In consequence, the ways in which problems are represented in these struggles determines the scope of options available to policy makers. In regards to wife abuse, Walker $(1990 ; 2003)$ demonstrates that struggles over meaning between various

\footnotetext{
${ }^{1}$ See C. Bacchi, Women, Policy and Politics: The Construction of Policy Problems (Sage Publications, 1999) and D. Stone, Policy Paradox and Political Reason, revised edition (New York: W. W. Norton \& Company, 2002).
} 
constituent groups resulted in particular policy outputs, which negated radical social change and favoured the status quo. In a similar vein, Bacchi's (1999) work illuminates the process by which violence against women came to be defined as an issue of "battered women" rather than "violent men."

Although Canadian anti-wife abuse policy is constructed in gender-neutral language, the image of the battered woman pervades its very structure. ${ }^{2}$ From this perspective, we have come to see women as victims, by choice or by helplessness, where public policy is premised on encouraging women to leave rather than eradicating violence. ${ }^{3}$ It is only from this perspective that we can ask the question, "Why do women stay?" and in turn use this question as a tool with which to guide policy. No-drop

\footnotetext{
${ }^{2}$ See chapter 1 for a discussion of the application of the term "wife abuse" throughout this study. For an excellent analyses of the importance of naming a social problem in the context of wife abuse, see Bacchi (1999) and G. Walker, "The Conceptual Politics of Struggle: Wife Battering, the Women's Movement and the State," Studies in Political Economy 33 (1990); Reprinted in C. Andrew, P. Armstrong, H. Armstrong, W. Clement, and L. Vosko (eds.), Studies in Political Economy: Developments in Feminism. (Toronto: Women's Press, 2003) 235-287.

${ }^{3}$ Burt and Mitchell (1998), exploring the policy implications of changes in the name of the problem, from "woman abuse" to "family violence", argue that under the Chretien Liberals anti-wife abuse policy has shifted from protection to prevention by documenting decreasing funding towards transition homes and increasing funding towards research and the criminal justice system. However, the cornerstone of Canada's anti-violence policy remains the criminal justice system, complemented by a range of services such as transition homes and shelters, counselling programs, etc. offered at the provincial level. See S. Burt and C. Mitchell, "What's in a Name?: From Sheltering Women to Protecting Communities," in Pal, Leslie ed. How Ottawa Spends 1998-99: Balancing Act: The Post Deficit Mandate (Toronto: Oxford University Press, 1998) 271-292.
} 
policies, transition homes and shelters, and the New Identities Program are all examples of the ways in which anti-wife abuse policy has been constructed to remove women from their batterers rather than to target the origins of violence. Such a perspective not only removes violence from its social, political, and economic context, neglecting the conditions under which abuse occurs, but it also fails to acknowledge and accommodate women's resistance in its various forms. Women resist their abusers. They adapt and respond accordingly, attempting to implicitly or explicitly negotiate lower levels of violence. While there is a tendency to hold abused women accountable for their situation, the main assertion of the present study is that resistance is not a question of women's agency, but rather a question of policy.

As a question of public policy, we want to know what are the effects of a particular problem representation. Some of these effects were discussed in chapter 3 , where it was shown analytically that the current anti-violence policy framework, by imposing exit, gives women little with which to negotiate abuse, neglecting both the women who do not want to leave as well as those who cannot leave, due to economic or social constraints. By assuming that all women can and want to leave, the policy framework has limited the scope of options available to women. What does this mean for the choices women make in resisting abuse? Does this limit the degree to which public services are utilized? It is argued here that the construction of resistance as exit will have significant implications for the choices women make in resisting abuse. To explain, let's develop a theoretical framework to guide the analysis.

Resistance is defined as any activity with which women attempt to reduce or eliminate violence, as described by the continuum developed in Figure 1.2. From this 
continuum, exit, including police intervention, separation and homicide, is simply one strategy type among a variety of options, including compliance, deception, informal outreach, and/or formal outreach and intervention, and exposure reduction. However, as demonstrated in chapters 3 and 4, non-exit strategies work best at constraining violence when exit options are available. All of these strategies, both exit and non-exit options, are ultimately shaped by the political economy, where women draw on private and/or public resources to mobilize particular strategies. By implication, resources provided by either the state and/or private sources, through private markets, social networks, etc., are the key levers enabling resistance.

This means that resistance is made possible by a complex interplay of both private and public resources. Resources are any material or social assets made possible by states, markets, and social networks. Private resources include personal resources such as access to employment and income, as well as social resources including access to the economic and emotional resources provided by social networks. Previous studies demonstrate the importance of social networks in aiding abused women's help-seeking 
strategies. ${ }^{4}$ At the same time, however, the absence of these networks, or networks that fail to provide the support necessary, can work to the detriment of women. ${ }^{5}$

Supplementing private resources are those services and transfers offered by the state. These can include initiatives such as shelters, treatment programs, police services, and various forms of social assistance, including welfare, public housing, legal aid, etc. A number of studies have demonstrated the usefulness of social services in helping women deal with abusive relationships. ${ }^{6}$ In contrast, a number of studies have revealed the limits of social services, pointing to access barriers shaped by race and class. ${ }^{7}$ At the very least, however, it has been recognized that state intervention sends an important

\footnotetext{
${ }^{4}$ See L.E. Rose, J. Campbell, and J. Kub, "The Role of Social Support and Family Relationships in Women's Responses to Battering," Health Care for Women International 21:1 (2000) 27-39; S. Budde and P. Schene, "Informal Social Support Interventions and Their Role in Violence Prevention An Agenda for Future Evaluation," Journal of Interpersonal Violence 19:3 (2004) 341-355; and L. Goodman, M.A. Dutton, N. Vankos, and K. Weinfurt, "Women's Resources and Use of Strategies as Risk and Protective Factors for Reabuse Over Time," Violence Against Women 11:3 (2005) 311-336.

${ }^{5}$ L.A. Hoff, Battered Women as Survivors (London: Routledge, 1990) and A. Sev'er, Fleeing the House of Horrors: Women Who Have Left Abusive Partners (Toronto: University of Toronto Press, 2002).

${ }^{6}$ A. Farmer and J. Tiefenthaler, "Domestic Violence: The Value of Services as Signals," American Economic Review 86:2 (May 1996), Papers and Proceedings of the Hundredth and Eighth Annual Meeting of the American Economic Association, 274-279 and L. Bennett, S. Riger, P. Schewe, A. Howard, and S. Wasco, "Effectiveness of Hotline, Advocacy, Counseling, and Shelter Services for Victims of Domestic Violence: A Statewide Evaluation," Journal of Interpersonal Violence 19:7 (2004) 815-829.

${ }^{7}$ See L. MacLeod, Battered but not Beaten: Preventing Wife Battering in Canada (Ottawa: Canadian Advisory Council on the Status of Women, 1987) and Sev'er (2002) for a brief discussion.
} 
message that wife abuse will not be tolerated. ${ }^{8}$ Figure 5.1 depicts the various resources drawn upon by abused women as they resist.

\section{Figure 5.1:}

\section{Resistance and Resource Profile}

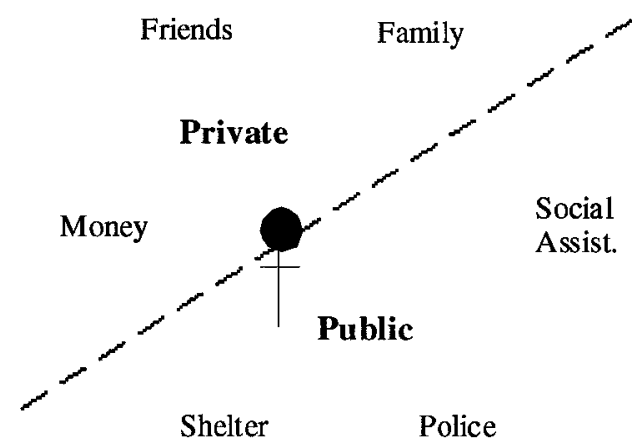

In relation to Figure 1.2, the continuum of resistance, Figure 5.1 reveals the various resources available to women, which will in turn determine patterns of resistance. This points to important implications of (and intersections between) race and culture, class, and (dis)ability, in enabling women to resist. Race and culture will be important determinants of resistance since they in part determine access to both public and private resources. ${ }^{9}$ For example, language barriers and/or discriminatory practises limiting

${ }^{8}$ See T. Brown, Charging and Prosecution Policies in Case of Spousal Assault: A Synthesis of Research, Academic and Judicial Responses, Final Report. Rr2001-5e (Department of Justice Canada. Ottawa, Canada, 2000) for a discussion and literature review regarding 'general deterrence'.

${ }^{9}$ See D. Donnelly, K. Cook, D. Van Ausdale, and L. Foley, "White Privilege, Colour Blindness, and Services to Battered Women," Violence Against Women 11:1 (2005) 6-37. For analyses regarding the 
access to the labour market, social networks and public services will constrain resistance options among certain groups. Similarly, individuals with low income will have fewer private resources with which to access resistance strategies, and thus might be crowded into less desirable public strategies. Key here will be the relative or combined importance of both types of resource pools in fostering resistance. Should the analysis point to a heightened role for private resources, then obviously policy directed at fostering these resources will be more effective in combating violence. ${ }^{10}$ In contrast, heavy use of public services will suggest that policy directed at strengthening these already existing services will be most effective in combating violence. To address this, let's consider a matrix which analytically distinguishes between the two ideal-types of resources and their effects on rates of resistance and violence at individual levels.

role of race and culture in shaping women's experiences with and responses to violence, see D. HassounehPhillips, "Polygamy and Wife Abuse: A Qualitative Study of Muslim Women in America," Health Care for Women International 22:8 (2001) 735-748 and M.R. Yoshioka and D.Y. Choi, "Culture and Interpersonal Violence Research: Paradigm Shift to Create a Full Continuum of Domestic Violence Services," Journal of Interpersonal Violence 20:4 (April 2005) 513-519.

${ }^{10}$ Informal support systems are now beginning to be recognized as important mechanisms for combating violence. For discussions, see Rose et al (2000); Budde and P. Schene (2004); and Goodman et al (2005). 
Table 5.1:

Resource Type and Resistance

\begin{tabular}{|c|c|c|}
\hline Private Resources & High & Low \\
\hline Public Resources & $\begin{array}{c}\text { High resistance; low levels of } \\
\text { violence }\end{array}$ & $\begin{array}{c}\text { Resistance and violence depend } \\
\text { on influence of private sphere }\end{array}$ \\
\hline Low & $\begin{array}{c}\text { Resistance and violence depend } \\
\text { on influence of public sphere }\end{array}$ & $\begin{array}{c}\text { Low resistance; low levels of } \\
\text { violence }\end{array}$ \\
\hline
\end{tabular}

In an ideal case, resource provision can be conceptualized as either high or low in either sphere. Where public resources are high, a broad definition of resistance would be expected, where a wider range of strategies (beyond exit) is supported by the state. Thus, a variety of services would be provided that are both flexible and plentiful enough to accommodate a large number of women. ${ }^{11}$ Ideally, then, when public resources are high, both the quality and quantity of services is such that a range of strategies is available to all in need. Where public services are low, few or very rigid social services would be provided, with resistance narrowly defined. In contrast, where private resources are high, dense social networks would be present, as well as adequate means of subsistence where the emotional and economic needs of the woman are met. Where private resources are low, social and/or economic resources are lacking, making subsistence difficult.

From the grid, there are two pure cases, where both types of resources are either high or low. In the case where both public and private resources are high, it can be

\footnotetext{
${ }^{11}$ It is also assumed that these services work as they should. However, no assumptions are made about what these services would entail, only that they are effective in enabling resistance and therefore combating violence.
} 
hypothesized that resistance would be high and therefore that rates of violence would be low. This is simply because women would be able to more effectively engage in resistance, either through actual resistance or threats thereof, and constrain violence. In the case where both are low, it can be hypothesized that resistance would be low and therefore rates of violence would be high. The two impure cases are more complex, where the outcomes are dependent on the degree to which the high resources in the one sector can counterbalance the low resources in the other. Important here is whether or not the high resource sector can relieve pressure from the low resource sector.

To consider this, it is necessary to hypothesize about the role of each sector in fostering or hindering help-seeking behaviour among abused women. While there is considerable evidence to suggest that public services are helpful to abused women, it is important to note the importance of social networks in facilitating the use of those services. ${ }^{12}$ For example, in the case where private resources are low and where public resources are high, the lack of private resources, both emotional and economic support, will exert pressure on women to the degree that it would limit their options for resistance. For example, Hoff (1990) observed that women's responses to abuse were in part mediated by the values, norms, and attitudes exhibited by social networks. Similarly, Sev'er (2002) pointed to the potential of destructive social networks to mitigate women's resistance. In addition, studies by Yoshioka and Choi (2005) and Hassouneh-Phillips (2001) demonstrate the importance of culture in shaping women's perceptions of and responses to wife abuse. This suggests that the context in which women choose their strategies is key in shaping the actual options available to women. For example, women

\footnotetext{
${ }^{12}$ Hoff (1990); Rose et al (2000); Budde and P. Schene (2004); and Goodman et al (2005).
} 
lacking the required emotional and social support will be less likely to engage in overt resistance than women who have these support systems.

What this suggests is that regardless of how expansive public provisions are, the private sphere can exert a considerable amount of influence on women's decisions. Put crudely, for some women it is less costly to put up with violence than it is to risk alienating social networks. ${ }^{13}$ In contrast, when public resources are low and private resources are high, the private sphere can relieve the pressure exerted from the state. Networks can fill the gaps created by state legislation and programs, albeit at a cost. From the preceding discussion, however, the converse is not necessarily true. Although the state can do a great deal in terms of alleviating the pressure created from a lack of private resources, it can neither replicate nor replace the functionings of social networks. Referring back to the grid, it can be hypothesized that higher rates of resistance would be expected, and thus lower levels of violence, among women with high private and low public resources than among women with low private and high public resources.

Where does Canada's anti-violence policy framework fit into this analysis and what does it suggest for women's resistance? It is suggested that Canada is characterized by low public services, in that resistance is narrowly defined, offering few options to abused women other than exit. The bulk of spending between the federal and provincial governments is targeted at the criminal justice system and transition homes and shelters, both of which require departure from the household. ${ }^{14}$ Furthermore, victim's services

${ }^{13}$ See S. Moller Okin, Justice, Gender, and the Family (USA: Basic Books, 1989) on women's vulnerability within marriage. See also Hoff (1990) and Yoshioka and Choi (2005).

${ }^{14}$ L. Greaves, O. Hankivsky, and J. Kingston-Reichers, Selected Estimates of the Costs of Violence Against Women (London: Centre for Research on Violence Against Women and Children, 1995); 
initiatives, such as treatment programs, batterer intervention programs, etc., are mostly available through the criminal justice system, which means that access is granted only after the police have been contacted. This suggests that since private resources are variable, women in Canada face one of two situations: the pure case of low public resources/low private resources or the impure case of low public resources/high private resources, suggesting that class, race, and ability will be crucial determinants of a woman's ability to resist.

From this analysis follow three hypotheses about women's resistance. It is expected that because Canada's anti-violence policy framework narrowly defines resistance as exit and because services have been developed to foster this, usage rates of public services will be low in general. Women who cannot or do not want to leave their partners will be unlikely to use the public services available to them. Among the women using public services, two patterns are expected to emerge. On the one hand, women with higher private resources will be in a better position to use more extreme strategies, such as police intervention. At the same time, however, police intervention is costly to the abused, as explained in chapter 3. Because doing so reduces her access to post-marital spousal resources (either time or money), women with high household resources would not be expected to use the police. Thus, it is expected that women using the police will have higher personal resources but lower household resources than women using other strategies.

see also Burt and Mitchell for a discussion of the shifting policy priorities and spending at the federal level in the area of wife abuse. 
On the other hand, women with few personal and household resources, low income and/or less dense social networks, will be crowded into public services. However, since exit is costly, it is expected that these women will use less extreme strategies, such as transition homes and shelters, which enable them to cope with violence with short-term departures from the household. This strategy potentially reduces violence in two ways: first, by reducing exposure and second by offering women a means with which to threaten exit. ${ }^{15}$

To test these hypotheses, a number of questions are explored. First, are women using the public services provided to them? If so, who is using these services and to what degree are they varied by race, class, ability, etc.? If not, why? Second, what are the implications for policy reform? Using the General Social Survey on Victimization 1999 (GSS), this chapter will attempt to shed light on women's experiences in resisting violence and outline an agenda for policy reform.

\section{WOMEN'S RESISTANCE}

The GSS offers insight into women's resistance to violence, asking abused women about their responses to violence. ${ }^{16}$ Specifically, the survey inquires about informal outreach, including talking to family, friends, co-workers, and clergy, as well as

\footnotetext{
${ }^{15}$ See Farmer and Tiefenthaler (1996) for an excellent analysis of the role of social services as signals in misrepresenting women's threat points.

${ }^{16}$ The information provided by the GSS does have some limitations. For example, the list of options surveyed does not cover all possible strategies. The GSS does not ask about compliance, physical violence, escape to hotels, enrolment in treatment programs for batterers, etc. In addition, it does not ask about more covert forms of resistance. Therefore, this research should not be considered an exhaustive treatment of women's resistance.
} 
formal outreach, including counsellors, lawyers, and health care professionals. ${ }^{17}$ In addition, the survey probes the use of social services, such as transition homes and shelters, women's shelters and community centres, and police. Thus, the hypotheses can be tested along three dimensions of strategy choice: private strategies, which include talking with friends and family, co-workers, lawyers, clergy and/or counsellors; public strategies, including transition homes, women's centres, community centres, crisis centres and hotlines, and/or health care professionals; and police intervention. ${ }^{18}$ As in chapter 4 , the focus is on currently married or cohabitating women reporting at least one incident of emotional or physical abuse in the last five years with their current partner. Descriptive statistics for the sample are provided in Table 4.1.

The first hypothesis regards public service usage, suggesting that because of the narrow construction of resistance as exit, which neglects a number of women, overall public service usage, including police intervention, will be low. The results presented in

${ }^{17}$ The questions asked were: During the last 5 years, have you ever... responses include talked to friends and family, coworkers or neighbours, contacted a woman's centre; transition home or shelter; community centre; crisis centre or hotline; doctor or nurse; lawyer; call the police. See appendix 1 of this dissertation for a list of relevant questions from the GSS.

${ }^{18}$ Police intervention has been distinguished from other public strategies, as implied above, due to the difference in the degree of exit. Although transition homes and shelters are designed to foster exit, they enable women to return to their home at any time, unlike police intervention, where the police are required to remove the batterer and the crown is required to lay charges. Police intervention, the cornerstone of antiviolence policy in Canada, requires immediate separation, the conditions of which are not controlled by the woman. Note also that since the focus is on women's resistance, use of police here includes only those women who contacted the police themselves, excluding those cases where a third party called the police. Indeed, third party calls to the police increase police usage from $6.7 \%$ to $8.2 \%$. 
Chart 5.1 suggest that this is indeed the case. Women are much more likely to draw on private rather than public resources to resist violence. Twenty-three percent of all abused women report the use of private strategies, compared to $11 \%$ of women using public services and only $6.7 \%$ of women contacting the police. Of the strategies used, the use of private networks, including friends and family, is the most common, followed by the use of a counsellor. ${ }^{19}$ In terms of public services, seeking help from health care professionals and calling the police are the most commonly used services. This is not particularly surprising considering the overwhelming presence of both health care professionals and the police in most areas of the country. At the same time, however, use of the police should not be overstated, since only $6 \%$ of all abused women report using this strategy. ${ }^{20}$

${ }^{19}$ Note that there might be some slippage here: The GSS does not distinguish between state and private counsellors.

${ }^{20}$ These figures do not mean that the majority of women are not resisting, just that the strategy used is not surveyed by the GSS. See footnote 14 . 
Chart 5.1:

Strategy Usage

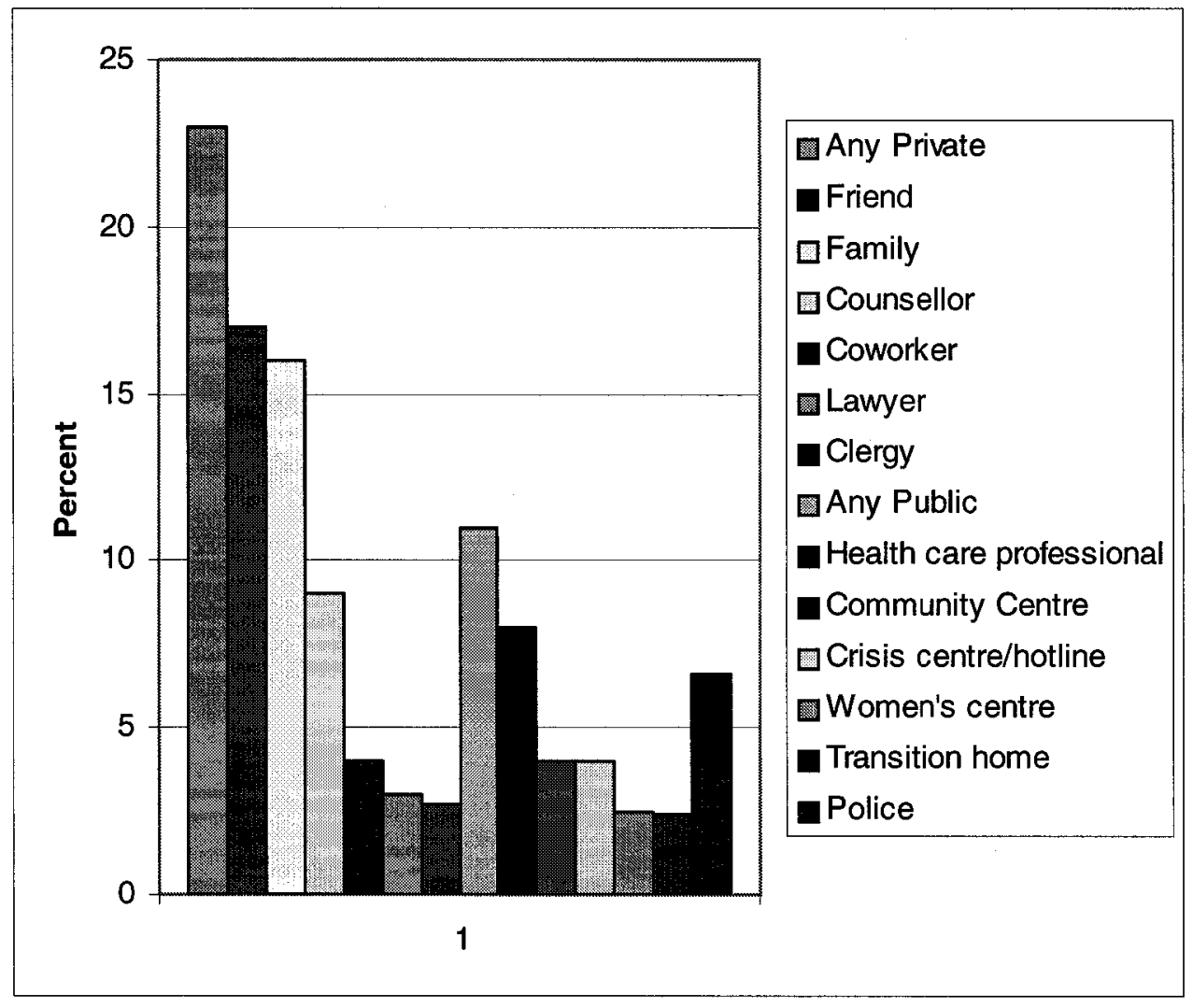

These findings are consistent with previous studies. For example, despite the fact that transition homes are often filled to capacity, Sev'er (2002) and MacLeod (1987) have suggested that the use of this particular strategy reflects only a small portion of abused women. ${ }^{21}$ Indeed, MacLeod observed that women using such homes tend to be poorly educated, have low income, and they tend to have young children. Similarly, a number of individuals have suggested that use of the criminal justice system is low relative to the number of abused women. ${ }^{22}$

${ }^{21}$ See Statistics Canada, Transition Home Survey (Ottawa: Statistics Canada, 2004).

${ }^{22}$ K. Makin, Globe and Mail (January 11, 2003); J.E. Ursel, "Mandatory Charging: The Manitoba Model," Unsettling Truths: Battered Women, Policy, Politics and Contemporary Research in Canada, eds. 
The finding that women are using private resources to support their resistance options is consistent with the analytical framework. While shelters and women's centres offer a variety of services, including information dissemination, advocacy, with some even offering second-stage housing, the main goal of shelters is to house abused women for short periods. Similarly, both federal and provincial police forces, as well as many municipal police forces, have adopted pro-charge and pro-prosecution policies, effectively "no-drop" policies. Since resistance is narrowly defined, policy initiatives privileging departure from the household exclude a number of abused women. As a result, these women might be substituting privately funded strategies for those strategies funded by public resources.

To test the second and third hypotheses, independent samples tests were conducted to explore the differences between women using police, public services, and private strategies. Table 5.2a depicts the results and Table 5.2b provides a breakdown of strategy usage by educational background.

K. Bonneycastle and G.S. Rigakos (Vancouver: Collective Press, 1998); D. Ford, "Prosecution as a Victim Power Resource: A Note on Empowering Women in Violence Conjugal Relationships," Law \& Society Review 25:2 (1991); and D. Elliott "Criminal Justice Procedures in Family Violence Crimes," in L. Ohlin and M. Tonry (eds.), Family Violence (Chicago: University of Chicago Press, 1989). 
Table 5.2a:

Characteristics of Women Using Resistance Strategies

\begin{tabular}{|c|c|c|c|c|c|c|c|c|c|c|c|}
\hline $\begin{array}{c}\text { Characteristic } \\
\text { Y(mean) } \\
\text { Strategy }\end{array}$ & es & $\begin{array}{l}\text { Thoome } \\
\text { (19erson } \\
\text { ai) }\end{array}$ & $\begin{array}{l}\text { MII } \\
\text { mor } \\
\text { no: }\end{array}$ & $\begin{array}{l}\text { Dis: } \\
\text { abil } \\
\text { ity }\end{array}$ & 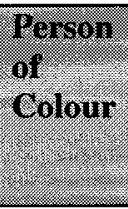 & $\begin{array}{l}\text { A bor } \\
\text { ginal }\end{array}$ & Til & $\begin{array}{l}\text { Agel } \\
\text { of } \\
\text { Youm } \\
\text { gest } \\
\text { Ghild }\end{array}$ & 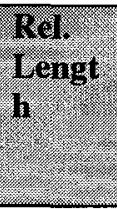 & Gr. & $\begin{array}{l}\text { Server } \\
\text { iy } \\
(110) \\
(10)\end{array}$ \\
\hline Bolles & 38 & 23200 & $\begin{array}{l}30000- \\
39999\end{array}$ & $28 \%$ & $17 \%$ & $11 \%$ & $19 \%$ & 6 & 11 & $77 \%$ & 31 \\
\hline Private: & 38 & 21565 & $\begin{array}{l}40000- \\
49999\end{array}$ & $\begin{array}{l}24 \% \\
* *\end{array}$ & $10 \%$ & $7 \%$ & $12 \%$ & $\overline{8}$ & 13 & $81 \%$ & $22^{*}$ \\
\hline Famaly & 38 & 21239 & $\begin{array}{l}40000- \\
49999\end{array}$ & $\begin{array}{l}27 \% \\
* *\end{array}$ & $12 \%$ & $8 \%$ & $14 \%$ & 7 & 13 & $82 \%$ & $24 * *$ \\
\hline Friends & 37 & 21071 & $\begin{array}{l}40000- \\
49999\end{array}$ & $\begin{array}{l}26 \% \\
* *\end{array}$ & $8 \%$ & $8 \%$ & $10 \%$ & 7 & 12 & $80 \%$ & $26^{* * * *}$ \\
\hline Crom Worker & 36 & 20180 & $\begin{array}{l}40000- \\
49999\end{array}$ & $29 \%$ & $0^{* *}$ & $10 \%$ & $8 \%$ & 7 & 11 & $78 \%$ & $32^{* *}$ \\
\hline Tawyer & 36 & 17596 & $\begin{array}{l}40000- \\
49999\end{array}$ & $22 \%$ & $3 \%$ & $10 \%$ & $4 \%$ & 6 & 9 & $73 \%$ & $37^{* *}$ \\
\hline alergy & 40 & 22983 & $\begin{array}{l}40000- \\
49999\end{array}$ & $32 \%$ & $8 \%$ & $5 \%$ & $15 \%$ & $12^{* *}$ & 16 & $71 \%$ & $37 * * *$ \\
\hline Counsellor: & 39 & 22308 & $\begin{array}{l}40000- \\
49999\end{array}$ & $\begin{array}{l}35 \% \\
* * *\end{array}$ & $6 \%$ & $7 \%$ & $8 \%$ & 8 & 13 & $79 \%$ & $34 * * *$ \\
\hline Public & $\begin{array}{l}42^{* *} \\
*\end{array}$ & 19737 & $\begin{array}{l}30000- \\
39999 \\
* *\end{array}$ & $\begin{array}{l}37 \% \\
* * *\end{array}$ & $13 \%$ & $7 \%$ & $15 \%$ & 9* & $16 * * *$ & $82 \%$ & $3^{* * * *}$ \\
\hline $\begin{array}{l}\text { Transilion } \\
\text { Mome }\end{array}$ & 41 & 18217 & $\begin{array}{l}30000- \\
39999\end{array}$ & $\begin{array}{l}43 \% \\
* *\end{array}$ & $19 \%$ & $14 \%$ & $\begin{array}{l}32 \% \%^{* *} \\
* * *\end{array}$ & 10 & 15 & $73 \%$ & $43^{* * *}$ \\
\hline $\begin{array}{l}\text { Woments } \\
\text { Centre }\end{array}$ & 35 & $14394^{*}$ & $\begin{array}{l}20000- \\
29999 \\
* *\end{array}$ & $\begin{array}{l}41 \% \\
* *\end{array}$ & $9 \%$ & $14 \%$ & $14^{*}$ & 7 & 12 & $78 \%$ & $37^{* *}$ \\
\hline Commininy & $43^{* *}$ & 17047 & $\begin{array}{l}30000- \\
39999 \\
* *\end{array}$ & $21 \%$ & $7 \%$ & $11 \%$ & $13 \%$ & 10 & $17 * *$ & $83 \%$ & $43 * * *$ \\
\hline Crisis & $41^{*}$ & 20720 & $\begin{array}{l}30000- \\
39999\end{array}$ & $\begin{array}{l}45 \% \\
* * *\end{array}$ & $13 \%$ & $10 \%$ & $23 \%$ & 9 & 14 & $77 \%$ & $31^{* *}$ \\
\hline 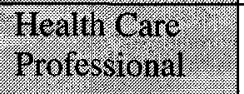 & $41^{* * *}$ & 19602 & $\begin{array}{l}30000- \\
39999\end{array}$ & $\begin{array}{l}43 \% \\
* * *\end{array}$ & $11 \%$ & $5 \%$ & $13 \%$ & 9 & $16^{* *}$ & $80 \%$ & $30 * * *$ \\
\hline $\begin{array}{l}\text { All Abrised } \\
\text { Yomen } \\
\text { (nom-8bused } \\
\text { momen) }\end{array}$ & $\begin{array}{l}42^{* *} \\
* \\
(46)\end{array}$ & $\begin{array}{l}22304 * * * \\
(25877)\end{array}$ & $\begin{array}{l}40000- \\
49999 \\
* * * \\
(40000 \\
- \\
49999)\end{array}$ & $\begin{array}{l}22 \% \\
* * * * \\
(15 \\
\%)\end{array}$ & $\begin{array}{l}11 \% * * * \\
(8 \%)\end{array}$ & $\begin{array}{l}5 \% * * * * \\
(2 \%)\end{array}$ & $\begin{array}{l}14 \% \text { ** } \\
* \\
(11 \%)\end{array}$ & (10 & $18 * * *$ & $\begin{array}{l}76 \% \\
\\
(75 \\
\%)\end{array}$ & $6^{* * *}$ \\
\hline \multicolumn{12}{|c|}{$\begin{array}{l}* * * \text { significant at } \mathrm{p}=.005 \\
* * \text { significant at } \mathrm{p}=.050 \\
* \text { significant at } \mathrm{p}=.10 \text { when equal variances assumed. }\end{array}$} \\
\hline
\end{tabular}


Table 5.2b:

Education Profile of Women Using Particular Resistance Strategies

\begin{tabular}{|c|c|c|c|c|c|}
\hline (20) & 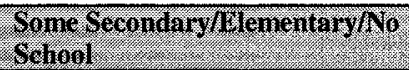 & Wha & Some Wort & Diplomal certificare & Whorim \\
\hline $9010 \%$ & $18 \%$ & $16 \%$ & $16 \%$ & $29 \%$ & $22 \%$ \\
\hline $940 \mathrm{ar}$, & $18 \%$ & $14 \%$ & $17 \%$ & $33 \%$ & $17 \%$ \\
\hline Tatrily 1 > & $19 \%$ & $14 \%$ & $19 \%$ & $34 \%$ & $14 \%$ \\
\hline Trents & $17 \%$ & $15 \%$ & $19 \%$ & $31 \%$ & $18 \%$ \\
\hline Co- Morrer & $3 \%$ & $27 \%$ & $15 \%$ & $30 \%$ & $24 \%$ \\
\hline Uavor & $4 \%$ & $21 \%$ & $17 \%$ & $38 \%$ & $21 \%$ \\
\hline Tlergy & $13 \%$ & $4 \%$ & $17 \%$ & $48 \%$ & $17 \%$ \\
\hline Crunsello, & $11 \%$ & $12 \%$ & $21 \%$ & $31 \%$ & $25 \%$ \\
\hline 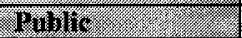 & $24 \%$ & $14 \%$ & $20 \%$ & $24 \%$ & $17 \%$ \\
\hline 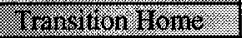 & $6 \%$ & $6 \%$ & $28 \%$ & $44 \%$ & $17 \%$ \\
\hline 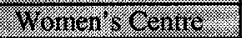 & $21 \%$ & $5 \%$ & $21 \%$ & $26 \%$ & $26 \%$ \\
\hline 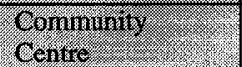 & $34 \%$ & $16 \%$ & $25 \%$ & $13 \%$ & $13 \%$ \\
\hline (chiris: & $21 \%$ & $12 \%$ & $15 \%$ & $30 \%$ & $21 \%$ \\
\hline 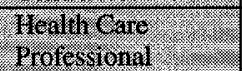 & $20 \%$ & $16 \%$ & $15 \%$ & $30 \%$ & $21 \%$ \\
\hline $\begin{array}{l}\text { Tll Mresed } \\
\text { Womer }\end{array}$ & $25 \%$ & $16 \%$ & $14 \%$ & $28 \%$ & $17 \%$ \\
\hline
\end{tabular}

All reported measures are population averages. Personal income is measured as the respondent's best estimate about her annual before-tax income, including all sources of income. Household income is categorical, including both personal and spousal income estimates. Since this variable is categorical, only ranges of income are reported. Household language represents a language other than French or English. Severity of abuse is an index variable constructed by multiplying a variable measuring the number of incidents by a variable measuring the severity of abuse (ranging from emotional abuse to forced sexual activity). The range for this variable is 0 to 110 . Disability includes any long-term disability ranging from hearing or visibility loss, as well as limited mobility. Also note that these strategies are not mutually exclusive; individual women could be using several of these options to address violence.

Statistical significance is reported in the text and in the table, which measures the degree to which two distinct populations are present. For example, women using public 
resources report lower than average personal and household incomes than other women. The figure for household income is statistically significant. This tells us that there is a 99.5\% probability that the population means (women using or not using public strategies) are different.

Turning back to the hypotheses, it was posited that women using the police would have much higher private but lower household resources than other women, including both economic and social resources. As seen in Tables 5.2a and 5.2b, many of the figures support this hypothesis; however, these findings are not statistically significant and thus should be interpreted cautiously. Thus, while this particular population of women demonstrate differences between those using the police and those who did not, we cannot say with certainty that we would witness similar results in different populations. Women who call the police report higher than average personal incomes and tend to have higher than average levels of education. This finding is consistent with the analysis in chapter 3 , in which use of the police is not feasible to many women with low incomes because they cannot afford to sustain themselves while their husband is incarcerated. Because police intervention is potentially costly, women contacting the police, expecting separation, would need higher levels of personal resources.

At the same time, however, because calling the police is costly for women, since it removes their partner from the household, some women will have more to lose than others. Women with high earning spouses or those who have been in their relationship for a long time might be less likely to call the police because the costs of doing so would be greater than for other women. Thus, despite having high personal resources, it was argued that women calling the police would also have lower household resources. In 
other words, the loss incurred by removal of the male would be minimal. There is also evidence to support this. Women contacting the police report lower than average household incomes. In addition, women calling the police have been in their relationship for less time than other women although, as noted above, the differences are not statistically significant. As relationships progress, joint resources increase, which means there is more to lose should the relationship end. Thus, women with fewer household resources and those in shorter relationships simply have less to lose than women who have high earning spouses and been in their relationships for longer periods.

In addition to these characteristics, it should also be noted that women using the police are much more likely to be of colour or Aboriginal status, speak a household language other than French or English, and have a disability. In addition, these women are slightly less likely to reside in an urban area than women using other strategies. This is not surprising given that the police are almost uniformly present throughout Canadian communities, compared to other strategy options. For these women, police intervention might be their only option.

These findings offer support for the next hypothesis, which predicted that women with few private resources, provided by markets and/or communities, would be crowded into public services. Again, many of these figures are not statistically significant; the degree to which we can generalize across the entire population is limited. It is expected that most of these women would use less extreme services, such as transition homes and shelters, compared to police intervention. Again, there is some evidence to suggest that this is the case. Women using all public strategies, including the police, are much more likely to be of colour or Aboriginal status, speak a household language other than French 
or English, although none of these findings are statistically significant, and have a disability, which is statistically significant at the $0.05 \%$ level. This suggests that private networks are either less dense or less supportive for these women, crowding them into public services. This would be especially true for recent immigrants, for whom social networks might be absent. In addition, recent studies have demonstrated the impact of culture on women's perceptions of and responses to wife abuse. ${ }^{23}$ Fear of social exclusion and isolation from religious leaders, friends and family might prevent these women from seeking help from these sources.

Additional support for this hypothesis is found when comparing the women using public strategies to those using the police. In addition to the urban/rural divide, discussed above, women using public strategies other than the police have lower levels of income and slightly lower levels of education compared to both the population average and women using the police. Indeed, women using transition homes, women's and community centres report the lowest personal and household incomes. In addition, compared to women calling the police, the length of their relationships is longer, suggesting that the costs of exit are much higher for these women. This suggests that women who do not want to or cannot exit are using less extreme public services, such as transition homes, shelters, and the health care system. As a result, these women might be seeking to negotiate abuse by either misrepresenting their fallback positions in order to signal their intention to leave or by reducing exposure.

Finally, women with disabilities are much more likely to use public services other than the police. For these women, interactions with the social service system, due to their

\footnotetext{
${ }^{23}$ See Hassouneh-Phillips (2001) and Yoshioka and Choi (2005).
} 
disability, might reduce their "transaction costs" in dealing with abuse. Access to a social or case worker provides an additional point of entry to the anti-wife abuse policy framework through either information dissemination or service delivery. The costs of using public services then would be lower than using private services.

There is considerable evidence to provide at least tentative support the hypotheses. Because resistance is narrowly constructed in public policy, a number of women are left to rely on private resources to mobilize their resistance strategies. Since private resources vary across women, shaped by class, race and ability, differences in strategy choice were expected. In particular, it was posited that in general, public service usage would be low, since such services alienate a number of women. It was also argued that women with higher private resources would be more likely to contact the police, since police intervention is costly. In addition, it was argued that women with few private resources will be crowded into public services, but because of the costs associated with police intervention, will be more likely to use less extreme strategies that impose only short term exits from the household.

These findings are interesting from a policy perspective, but reveal only part of the story. As demonstrated above, only $11 \%$ of women reporting abuse use public services and just under $7 \%$ use the police. There are a very large number of women who are alienated from the policy framework. Equally important, then, is to consider why women are not using the public services available to them. To this we know turn.

\section{EXPLAINING LOW SERVICE USAGE RATES}

The GSS includes a set of probing questions to help determine why women did not use public services. The results are summarized in Charts $5.2 \mathrm{a}$ and $5.2 \mathrm{~b}$. 
Chart 5.2a:

Reasons for Not using Services

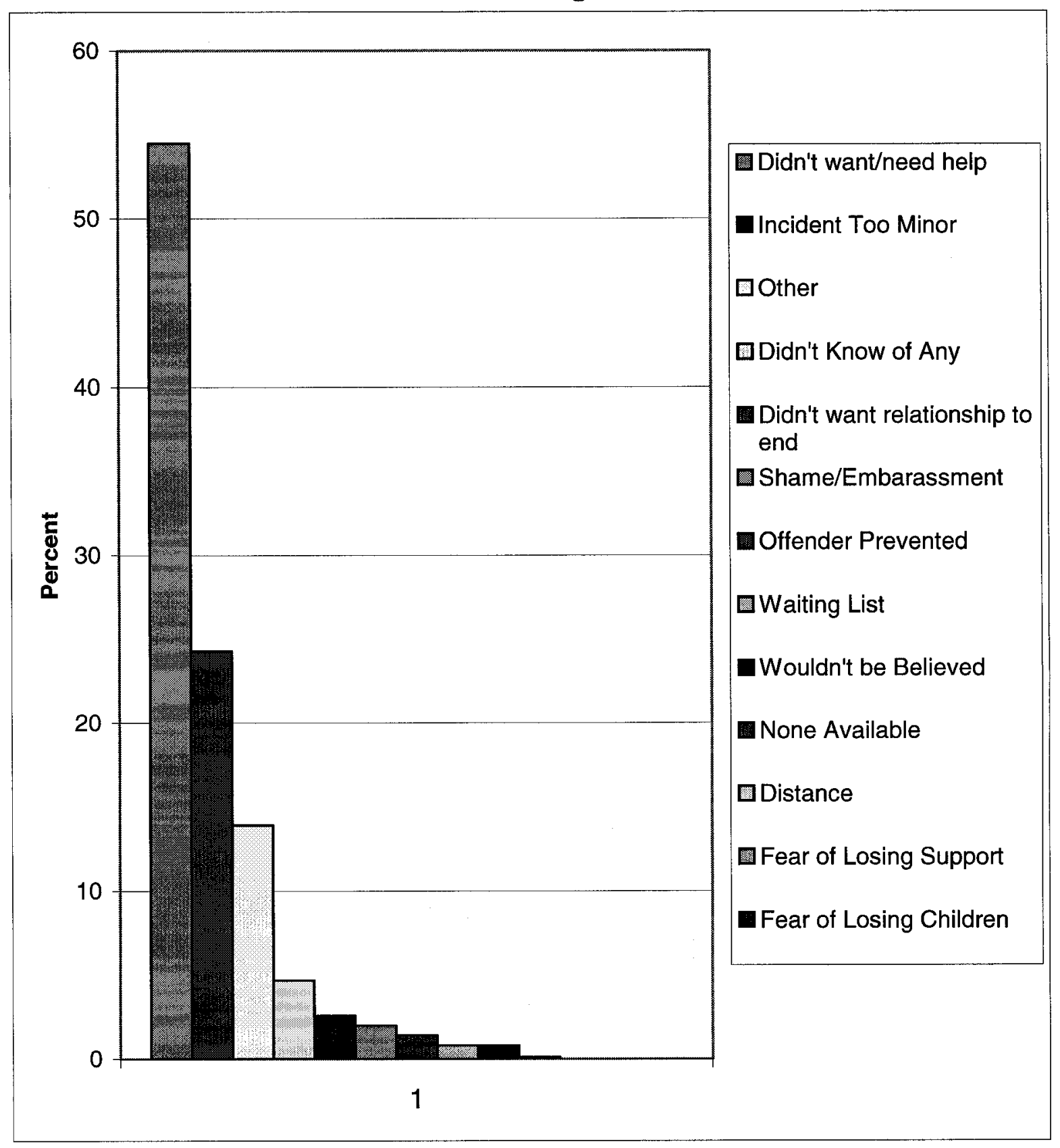


Chart 5.2b:

Reasons for Not Calling the Police

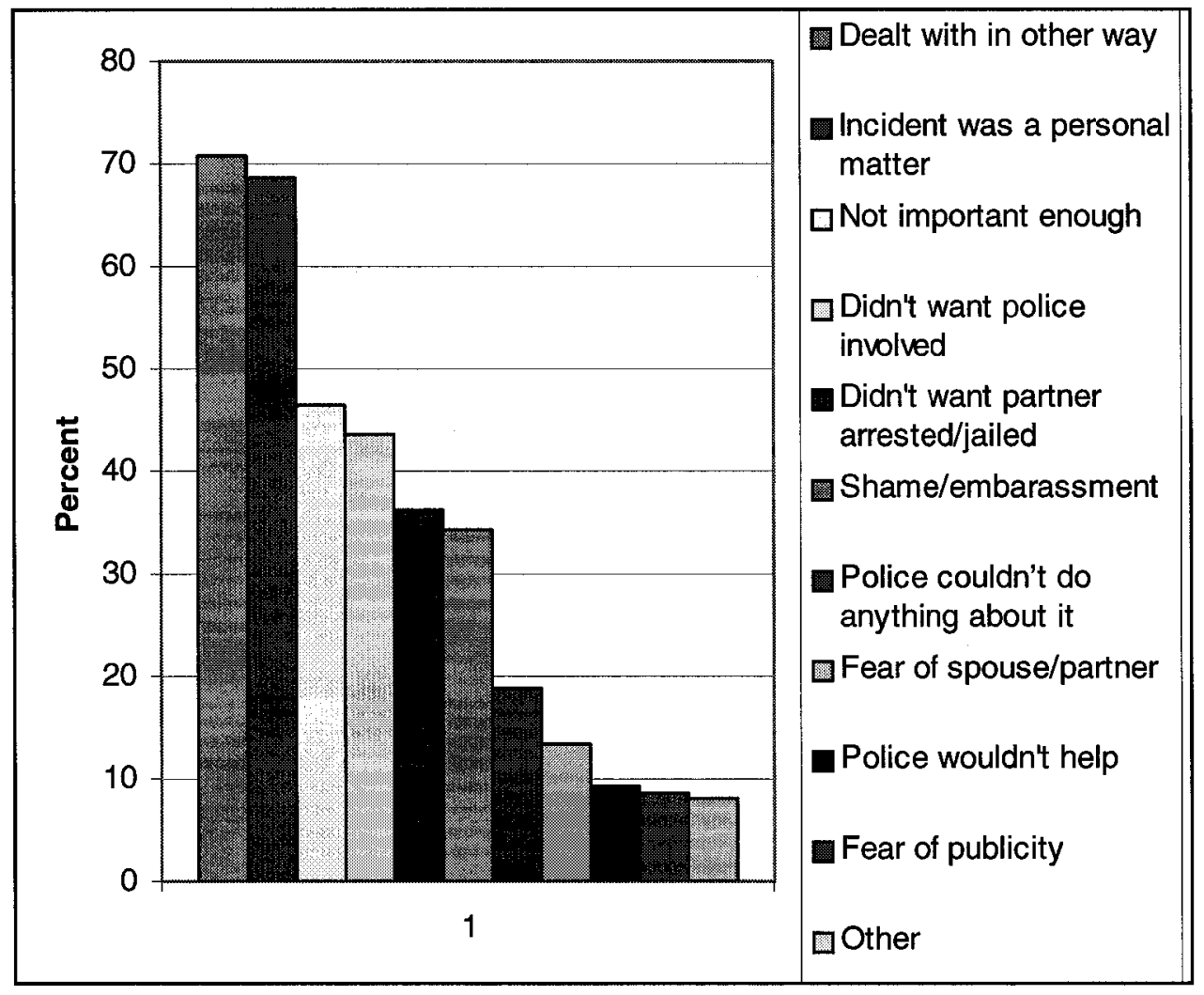

From Charts 5.2a and 5.2b, most women did not use social services or police because they felt that they did not need or want help and that they felt they could deal with it in another way. In addition, many women reported that the incident was too minor to seek help from social services and that the incident was a personal matter and therefore they were reluctant to contact the police. Indeed, independent samples tests reveal that the women reporting that the incidents were too minor to warrant the use of social services and the police also reported considerably less severe violence than other women ( 7 vs. 11 and 11 vs. 17). However, it should be noted that these mean averages 
are higher than the average severity for all abused women, which recall from Table $2 \mathrm{a}$ is $6 .^{24}$

In addition, the implications of exit are quite significant, with many women reporting that they did not want the relationship to end or their partner to be arrested. Similarly, shame or stigma associated with both public services and police intervention can potentially deter women from using them. It should also be noted that there could possibly be an interaction between the responses suggesting that the incident was too minor and the construction of resistance as exit. ${ }^{25}$ Where resistance is constructed only as exit, it is possible that many women experience violence that in their perception does not warrant departure, as noted in chapter 3. Emotional abuse or less severe forms of physical abuse might not be seen as enough cause to end the relationship, thus prompting women to resort to other forms of resistance, such as escape to hotels, or costly formal strategies, such as treatment and counselling programs. Unfortunately, however, this type of data is not available through the GSS.

Before turning to policy reform, one of the central assumptions about public services underlying the preceding analysis should be addressed. Recall that it was assumed that public services worked as they should; that there were no systemic or

\footnotetext{
${ }^{24}$ It is interesting to note that the women who did not contact the police due to fear of spouse reported very severe violence, with a mean level of 40 .

${ }^{25}$ See L. Bex Lempert, "The Other Side of Help: The Negative Effects in the Help-Seeking Processes of Abused Women," Qualitative Sociology 20:2 (1997) for an excellent analysis of the ways in which abused women come to identify themselves as such. Key to this is identifying oneself as resisting. See also M. Fugate, L. Landis, K. Riordan, S. Naureckas, and B. Engel, "Barriers to Domestic Violence Help-Seeking: Implications for Intervention," Violence Against Women 11:3 (2005) 290-310.
} 
structural problems in their operations. When this assumption is relaxed, it becomes clear that the provision of public services is even more problematic than simply a rigid definition of resistance. Let's consider transition homes and the criminal justice system in turn.

Reductions in social spending in Alberta, British Columbia and Ontario since the mid-1990s have meant that the number of shelters available and the operating capacity of those remaining have been drastically reduced. ${ }^{26}$ Table 5.3 provides an overview of the types of shelters available to women and the conditions under which these homes are run. Transition homes, by far the majority of Canadian shelters, offer protection to women for 1-3 months. Second-stage housing is longer term, offering shelter to women for $3-12$ months. These shelters might also offer other services, such as counselling, access to safe homes, which offer emergency protection for 1-3 days, childcare, transportation, etc. Of the nearly 500 homes in Canada, only $22 \%$ offer long-term housing, but nearly all of them $(96 \%)$ offer services beyond shelter. Just over $1 / 4$ of the homes are bilingual and only $.4 \%$ offer services in a language other than French or English. Just over 2/3 are equipped to deal with special needs. Some of the homes restrict the ages of children (63\%) and very few do not allow children at all (2.8\%). In addition, about $6 \%$ of the homes charge fees in return for shelter.

This varies by region. The Atlantic region has the highest proportion of homes that limit the ages of children (82\%) compared to the prairie region with only $53 \%$. At the same time, however, women in the Atlantic are also the least likely to face a fee for

\footnotetext{
${ }^{26}$ See Burt and Mitchell (1998) and M. Morrow, O. Hankivsky, and C. Varcoe, "Women and Violence: The Effects of Dismantling the Welfare State," in Critical Social Policy 24:3 (2004).
} 
service, with only $2.2 \%$ of homes charging for service, compared to Quebec, where

$14.6 \%$ charge. Women in the Atlantic also have the highest proportion of long-term housing (31\%), compared to Quebec (10.7\%). Ontario homes fare the best in terms of accessibility, with $85 \%$ of homes equipped to deal with special needs, compared to only 43\% in Quebec. Similarly, Ontario homes are the most likely to be bilingual (35\%) compared to British Columbia (8.6\%). All of the homes in the territories offer additional services.

Table 5.3:

Transition Homes and Shelters in Canada

\begin{tabular}{|c|c|c|c|c|c|c|c|c|c|}
\hline & Total & $\begin{array}{l}\text { Age } \\
\text { Limits }\end{array}$ & $\begin{array}{l}\text { No } \\
\text { children }\end{array}$ & Fees & Access & Bilingual & $\begin{array}{l}\text { Other } \\
\text { language }\end{array}$ & $\begin{array}{l}\text { Other } \\
\text { services }\end{array}$ & \begin{tabular}{|l} 
Long- \\
term
\end{tabular} \\
\hline Canada & 471 & 298 & 13 & 28 & 321 & 138 & 2 & 452 & 105 \\
\hline Newfoundland & 11 & 8 & 1 & 1 & 9 & 2 & 1 & 10 & 3 \\
\hline PEI & 3 & 0 & 0 & 0 & 2 & 0 & 0 & 3 & 3 \\
\hline Nova Scotia & 19 & 10 & 0 & 0 & 11 & 6 & 0 & 17 & 6 \\
\hline $\begin{array}{l}\text { New } \\
\text { Brunswick }\end{array}$ & 12 & 9 & 0 & 0 & 5 & 4 & 0 & 11 & 2 \\
\hline Atlantic & 45 & 37 & 1 & 1 & 27 & 12 & 1 & 41 & 14 \\
\hline Quebec & 103 & 71 & 8 & 15 & 44 & 57 & 1 & 98 & 11 \\
\hline Ontario & 141 & 98 & $\mathbf{0}$ & 4 & 120 & 50 & $\mathbf{0}$ & 137 & 36 \\
\hline Manitoba & 14 & 6 & 0 & 0 & 9 & 3 & 0 & 13 & 7 \\
\hline Saskatchewan & 21 & 10 & 0 & 2 & 10 & 1 & 0 & 21 & 6 \\
\hline Alberta & 40 & 24 & 2 & 2 & 33 & 5 & 0 & 40 & 9 \\
\hline Prairies & 75 & 40 & 2 & 4 & 52 & 9 & 0 & 74 & 22 \\
\hline $\begin{array}{l}\text { British } \\
\text { Columbia }\end{array}$ & 93 & 54 & 2 & 4 & 65 & 8 & 0 & 88 & 18 \\
\hline Yukon & 4 & 2 & 0 & 0 & 4 & 2 & 0 & 4 & 1 \\
\hline NWT & 5 & 3 & 0 & 0 & 4 & 0 & 0 & 5 & 2 \\
\hline Nunavut & 5 & 3 & 0 & 0 & 5 & 0 & 0 & 5 & 1 \\
\hline Territories & 14 & 8 & 0 & 0 & 13 & 2 & 0 & 14 & 4 \\
\hline \multicolumn{10}{|c|}{$\begin{array}{l}\text { Source: National Clearinghouse on Family Violence, "Transition Homes and Shelters for Abused Women } \\
\text { in Canada," (Ottawa: Health Canada, 2004). Available at: http://www.phac-aspc.gc.ca/ncfv- } \\
\text { cnivf/familyviolence/pdfs/2004Women e.pdf }\end{array}$} \\
\hline
\end{tabular}


These statistics suggest that women who speak a language other than one of the official languages will have a difficult time accessing these services. ${ }^{27}$ In addition, a considerable number of disabled women will face significant limits in accessing services that can accommodate their needs. And that assumes that they have no trouble actually getting to these services. A recent report on the decade following the Beijing Resolution (2005: 92) notes,

\begin{abstract}
Women who are of minority racial, ethnocultural or linguistic groups also suffer violence at the hands of their intimate partners. However, their access to the justice system and to services are not the same. Only 57\% of Canadian shelters offered services that were sensitive to cultural differences. Women who have difficulty speaking the official language where they live face enormous barriers in accessing services and dealing with the justice system. When services and the justice system fail, women find it even more difficult to escape abuse. ${ }^{28}$
\end{abstract}

In addition to the possibility to offer short-term refuge from violent episodes, these services might be crucial in helping women negotiate lower levels of violence, regardless of whether or not they want to leave their abuser, mentioned above. For example, an innovative article by Farmer and Tiefenthaler (1998) suggests that women use shelters to misrepresent their threat points. They divide women into two groups, stayers and leavers. Leavers will simply depart from the household when violence

\footnotetext{
${ }^{27}$ There are also issues surrounding race and sexuality. See P. Rankin, J. Vickers, and A. M.
} Field, Women's Movements and State Feminism: Integrating Diversity into Public Policy (Ottawa: Status of Women Canada, 2001) and J. Vickers, "Thinking About Violence," in Dhruvarajon, V. and Vickers, J. Gender, Race, and Nation: A Global Perspective (Toronto: University of Toronto Press, 2002). See also Sev'er (2002), where interviewees describe their experiences with social services and Donnelly et al (2005) for an analysis in American context.

${ }^{28}$ Canadian Feminist Alliance for International Action, “A Decade of Going Backwards: Canada in the Post Beijing Era," (Ottawa, January 2005). Available at: www.fafia.org. 
exceeds their personal threshold. Stayers, on the other hand, have no intention of leaving and therefore must bargain over violence. To do this, they must convince their partners that they will leave if the violence is not at a tolerable level. Thus, they must use social services as a signal to misrepresent an exit threat point. With this in mind, we cannot underestimate the importance of shelters in helping women escape violent situations in the short-run and, for those women who do have actual exit options, in negotiating lower levels of violence.

In addition to shelters, a cornerstone of anti-violence policy is criminalization, including both police and courts. Although the shortcomings of the criminal justice and legal systems have been addressed elsewhere, ${ }^{29}$ a couple of points deserve mention here. First, and mentioned briefly above, the costs associated with the use of the criminal

\footnotetext{
${ }^{29}$ M. Mahoney, "Exit: Power and the Idea of Leaving in Love, Work, and the Confirmation Hearings,” Southern California Law Review 65:3 (1992) 1283-1319, “Legal Images of Battered Women: Redefining the Issue of Separation," Michigan Law Review 90:1 (1991) 1-94, "Victimization or Oppression? Women's Lives, Violence, and Agency," in Fineman, M. and Mykituik, R. (eds.), The Public Nature of Private Violence: The Discovery of Domestic Abuse (New York: Routledge, 1994) 59-92; Bacchi (1999); L. Lakeman, "Why "Law and Order" Cannot End Violence Against Women; and Why the Development of Women's (Social, Economic and Political and Civil) Rights Might," in Canadian Woman Studies (October 2000) for analyses of public policy in this area; D. Martin and J. Mosher, "Unkept Promises: Experiences of Immigrant Women with the Neo-Criminalization of Wife Abuse," Canadian Journal of Women and the Law 8 (1995) 3-44; B. Snider, "Struggles for Social Justice: Criminalization and Alternatives," Unsettling Truths: Battered Women, Policy, Politics and Contemporary Research in Canada, Bonnycastle, K. and Rigakos, G. (eds.). (Vancouver: Collective Press, 1998); and E.A. Sheehy, "Legal Responses to Violence Against Women in Canada," in McKenna, K.M.J. and Larkin, J. (eds.), Violence Against Women: New Canadian Perspectives, 473-491.
} 
justice system severely restrict access. Women who cannot afford these costs will simply substitute other strategies. ${ }^{30}$ For example, Ford (1991) suggests that no-drop policies are limited in helping women negotiate levels of violence because effective bargaining requires control over outcomes. Because they will lose control once police are involved, many women will avoid this as a strategy. Similarly, where expected outcomes are poor, that is, where sentencing is low, women will be less likely to use the police. A recent report by Statistics Canada (2005) observed that spouses are not only the least likely of all assault perpetrators to be sentenced, but also receive the lightest sentences. This is especially problematic when the use of the police and courts as a strategy is considered. If women expect no or light sentences, the opportunity for retaliation might play a large role in their decision to use police services.

While control is an important determinant of strategy choice, especially where the outcome might not work in favour of the abused, perhaps a more important determinant is feasibility. Women who simply cannot afford the costs, both economic and social, associated with police intervention will be unlikely to involve the police. ${ }^{31}$ In effect, threats to use the criminal justice system in response to abuse are simply not credible,

${ }^{30}$ An interesting study would be to determine the class effects on rates of female perpetrated spousal homicide over time. According to this analysis, it would be expected to see a considerable decline in rates of FPSH among middle and higher income women since the implementation of pro-charge policies. Because of the class effect, we would expect the rate among lower income women to be less drastic. This data is available through Statistics Canada's Homicide Survey, however, public use is restricted.

${ }^{31}$ See Ford (1991); Makin (2003); and L. Goodman and D. Epstein, "Refocusing on Women: A New Direction for Policy and Research in Intimate Partner Violence," Journal of Interpersonal Violence 20:4 (2005) 479-487 for a discussion of one-size fits all type policies, such as no-drop policies. 
offering women little opportunity with which to negotiate lower levels of abuse.

Certainly there is some evidence of this here. Though this discussion focuses only on shelters and the criminal justice system, it is obvious that there are a number of barriers that might prevent women from using these services. The next question that must be explored is how to deal with these inadequacies.

\section{POLICY REFORM IN CANADA}

Constructing anti-wife abuse policy from the perspective of women's resistance will have a twofold effect. On the one hand, it shifts focus away from women as victims, acknowledging that the power of women is often constrained not by will but by conditions established within the political economy. As a result, it offers women a larger variety of options when attempting to resist violence. On the other hand, enabling women to resist violence has the potentially radical effect of undercutting the rationale for violence as it is situated in the political economy. ${ }^{32}$ From this perspective, reformulating the goal of policy away from exit towards ending violence implicates an expansion of social services that will support women regardless of whether or not they want to end the relationship. Such policy reformulation is not only reactive in that it provides the tools necessary for effective resistance, but it is also proactive since it can undermine and transform the basis on which violence is premised.

The preceding analysis demonstrates that resistance patterns are varied, and are shaped by class, race and culture, ability and geography, at least in this sample of women. It was also argued that the low usage rates of public services stems from the rigid definition of resistance as only departure from the household, as well as additional access

\footnotetext{
${ }^{32}$ Refer to chapter 2 for an analysis.
} 
issues which will cause women to resort to private resources. This creates a problem for women with few private resources, however, since it is these women who lack adequate levels of both private and public resources with which to effectively resist violence. Indeed, from Table $2 \mathrm{a}$, women using public services experience much higher severity of violence than other women. This finding is no doubt due to both cause and effect, i.e., the severity of abuse prompts them to seek help from public services and/or the use of such services is limited in the degree to which they can constrain violence. Thus women crowded into public services are not only most vulnerable to abuse, but also have the fewest resources with which to constrain it, suggesting that the violence they experience will be more severe than for other women. From the grid, the ideal case of high private and high public resources will be the best system with which to combat violence. So now the question is how to do that.

Ensuring that abused women have access to both private and public resources implicates a complex agenda for policy reform, which will include federal, provincial and local levels of government, as well as the third sector. Returning to Diagram A, it is possible to conceptualize those resources as embedded within a complex set of web of pre-existing relationships. Figure 5.2 depicts these relationships. 
Figure 5.2:

The Political Economy of Anti-Wife Abuse Policy

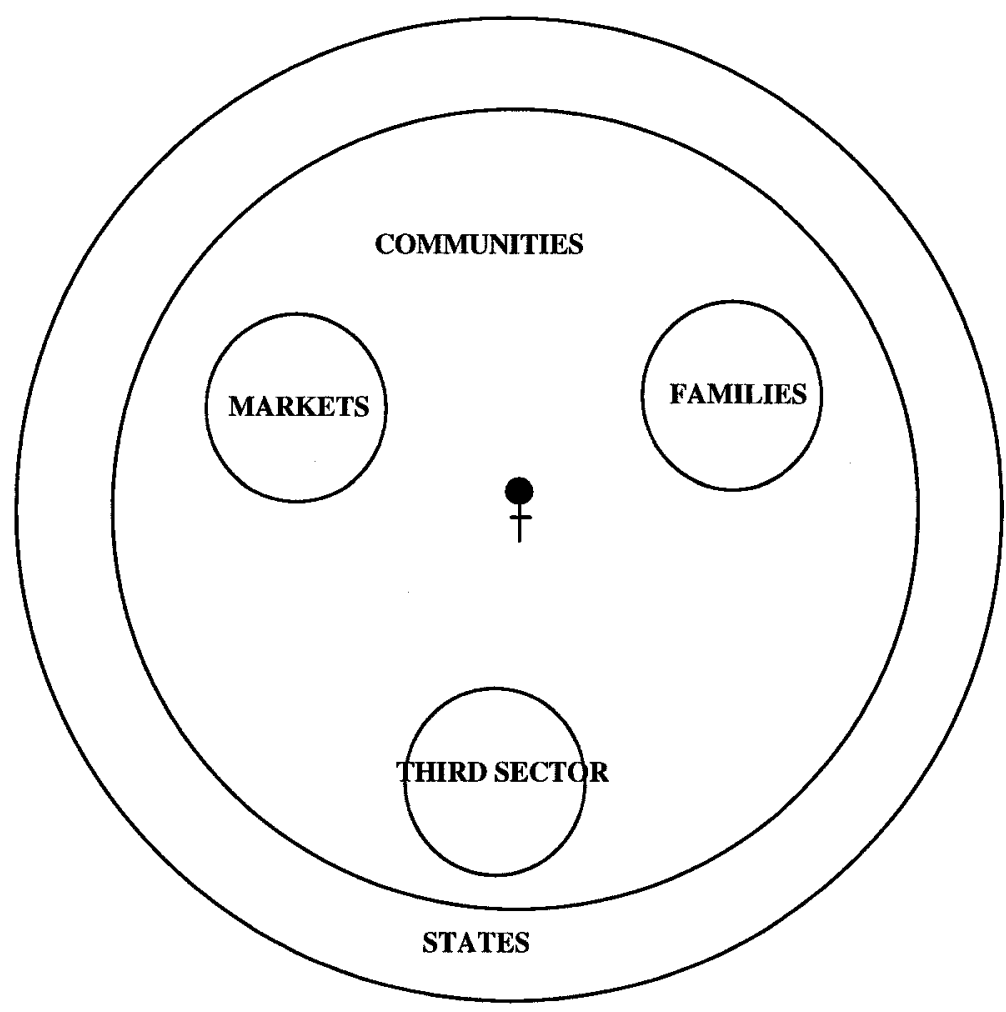

At the micro-level, women must draw on resources provided by markets, families and social networks, as well as third sector agencies. In turn, these entities are governed at the macro-level by municipal, provincial and federal governments. In addition, Canada's anti-violence framework is increasingly subject to scrutiny by international bodies such as the United Nations as the battered women's movement and the feminist movement from which it originated go transnational. ${ }^{33}$ In effect, policy reform cannot be directed at one entity in isolation, but rather must consider the complexity of the political

\footnotetext{
${ }^{33}$ See M. Keck and K. Sikkink, Activists Beyond Borders: Advocacy Networks in International
} Politics (Ithaca: Cornell University Press, 1998) and United Nations Development Fund for Women, Not a Minute More: Ending Violence Against Women (New York: Unifem, 2003). 
economy. This requires particular attention to gender equality policy, which implicates not only women, but also men. As noted in chapter 4 , it is becoming increasingly important to also consider the necessary contributions of men and boys in achieving gender equality. ${ }^{34}$

The analysis in chapter 4 revealed three strategic policy areas including resource redistribution, the targeting of vulnerable groups, and policy that transforms social relations. The present analysis illuminated the importance of these areas, as well as some additional considerations including the potential for social networks to relieve the financial and emotional burden of women and the reform of current programs, which will be discussed in turn.

As argued in chapter 4, offering women private resources, including income, education, and childcare must be given a central role in anti-violence policy. Part of providing these resources requires strengthening social networks, which will not only expand women's access to resources, but also combat social exclusion. Mentioned above, increasing attention has been paid to the role of informal support systems in aiding abused women. ${ }^{35}$ The GSS revealed that a number of abused women seek help from friends and families. Policy-makers and academics are beginning to realize the advantages of these networks. Ideally, these networks will be not only flexible, responding to the immediate needs of the women, they will also be a continuous presence

${ }^{34}$ See R. W. Connell, "The Role of Men and Boys in Achieving Gender Equality," United Nations and ILO (Brazil, 2003) and "Change Among the Gatekeepers: Men, Masculinities, and Gender Equality in the Global Arena," Signs 30:3 (2005) 1801-1825.

${ }^{35}$ For discussions, see Rose et al (2000); Budde and P. Schene (2004); and Goodman et al (2005). 
in the woman's life. ${ }^{36}$ This has important implications for women from marginalized groups, since they offer the opportunities to combat access problems due to language, race and culture.

Although one is faced with the difficulty of harnessing policy levers with which to strengthen families and neighbourhoods, a good start would be to provide communities and community-based organizations with resources with which to develop locally based, flexible programs for abused women, which can include community outreach and awareness campaigns, treatment programs, and justice forums, which must be distinct from the criminal justice system. ${ }^{37}$ Goodman and Epstein (2005: 484) write:

\begin{abstract}
It therefore is crucial to explore innovative options that are community based, culturally sensitive, and more flexibly responsive to the needs of individual women. For example, the restorative justice movement proposes a series of models for responding to domestic violence, including community justice forums, sentencing circles, and alternate dispute resolutions, all in which simultaneously consider the needs of the victim, the community, and the offender.
\end{abstract}

At the same time, however, we must be careful to balance cultural sensitivity with the needs of the woman. ${ }^{38}$ In other words, care must be taken not to disregard the personal safety and rights of the woman for the sake of the broader cultural community.

\footnotetext{
${ }^{36}$ Budde and Schene (2004).

${ }^{37}$ For a discussion on building community capacity to deal with abuse in families, see W. Sabol, C. Coulton, and J. Korbin, "Building Community Capacity for Violence Prevention," Journal of Interpersonal Violence 19:3 (March 2004) 322-340.

${ }^{38}$ It is interesting to note that the Ad Hoc Federal-Provincial-Territorial Working Group Reviewing Spousal Abuse Policies and Legislation in Canada advocates the use of alternative justice measures only under the authority of the criminal justice system. The argument here is that such a structure could potentially alienate a number of women, due to access problems with the criminal justice system.
} 
These reforms require rethinking about the structures of services. At present, there is no comprehensive framework to help guide women in need. To remedy this problem, the city of Toronto recently developed a portal for services for abused women and families, offering one-stop service to those seeking help. Communities should be encouraged to adopt such programs, reducing the time and stress expended by abused women when reaching out. The appropriate entry point into the service community must also be reconsidered. For example, implicating schools, churches and community centres might expose a large number of immigrant and other marginalized groups to a variety of programs and services.

In addition to private resources, publicly provided services are in dire need of reform. Perhaps most significantly, the conceptualization of resistance needs to be expanded to include those women who do not want to leave their partners. This is an important yet understudied element of violent relationships. And yet Bowker's (1988) innovative study of abused women's help-seeking activities focused on those women not wishing to leave, discovering that these strategies were often effective in reducing levels of violence. Similarly, Horton and Johnson's (1993) work illuminated the potential of women's help seeking activities to end abuse and sustain their relationships. Forcing women to leave will not only exclude these women but also possibly work to their detriment, as argued in chapter 3. Policy must offer a much broader scope of services to families. For example, many of the treatment programs for batterers in existence are

See chapter 6 for a discussion. Refer to Federal-Provincial-Territorial Ministers Responsible for Justice, Spousal Abuse Policies and Legislation: Final Report of the Ad Hoc Federal-Provincial-Territorial Working Group Reviewing Spousal Abuse Policies and Legislation (Ottawa: National Clearinghouse on Family Violence, 2003) 
privately funded and require court or police referral. ${ }^{39}$ This means that not only are families out of pocket, but must also seek police intervention to access these services, risking long-term separation and, as a result, increased financial strain. Ultimately, poor couples are excluded from such programs. Redesigning these as free-standing public programs will increase their usage and offer women another tool with which to resist abuse.

At the provincial level, funding for affordable housing and transition homes is crucial. $^{40}$ Affordable housing will help establish a basis for a credible exit threat, regardless of whether or not the woman wants to leave. ${ }^{41}$ In addition, transition homes perform a dual function. First, they provide assistance to women "in transition", helping them to make alternative arrangements. Second, they provide temporary refuge from violent episodes, allowing women to negotiate lower levels of violence. ${ }^{42}$ It is therefore crucial that communities not only get more of them, but also that the operating capacity of those in existence is expanded to accommodate various disabilities, children, pets, ${ }^{43}$ as

${ }^{39}$ See National Clearinghouse on Family Violence, “Canada's Treatment Programs for Men Who Abuse Their Partners," (Ottawa: Health Canada, 2004). Available at: http://www.phac-aspc.gc.ca/ncfvcnivf/familyviolence/pdfs/2004Men_e.pdf

${ }^{40}$ See Morrow et al (2004) and Burt and Mitchell (1998).

${ }^{41}$ See P. Panda and B. Agarwal, "Marital Violence, Human Development, and Women's Property Status in India," World Development 33:5 (2005) for an analysis of the relationship between violence and women's access to immovable property, such as land and houses.

${ }^{42}$ See Farmer and Tiefenthaler (1996).

${ }^{43}$ See C. Faver and E. Strand, “To Leave or Stay? Battered Women's Concern for Vulnerable Pets," Journal of Interpersonal Violence 18:12 (2003) 1367-1377 for a discussion of the implications of threats to pets on the decision to leave an abuser. 
well as lengthening the duration of stays and offering services in non-official languages where numbers warrant.

Finally, the criminal justice system is in dire need of reform. ${ }^{44}$ Not only do nodrop policies need to be abandoned, but the expansion of the criminal justice system in wife abuse policy must come to an end. Chart $5.2 \mathrm{~b}$ reveals that more than $30 \%$ of women did not call the police because they did not want their partner arrested, suggesting that pro-charge and pro-prosecution policies are alienating a number of women. Rather than expand criminal justice services such as victim compensation programs and domestic violence courts, policymakers must begin to think about creating a flexible, responsive justice system that is accessible to all families. In addition, it must be just one small part of the anti-violence strategy rather than its main pillar.

Above all, the preceding analysis has demonstrated that there is no uniform pattern of resistance among abused women. This suggests that the attempt by policy makers to create a "one size fits all" system is potentially dangerous since it can alienate a large number of women. ${ }^{45}$ Instead, policymakers must work to establish a system that is accessible by all.

\section{CONCLUDING REMARKS}

Viewing Canada's anti-violence policy through the lens of women's resistance reveals several limitations of the current policy framework. In essence, it was argued that the narrow definition of resistance adopted by policy-makers has resulted in low usage rates of public services. In addition, it was demonstrated that women using public

\footnotetext{
${ }^{44}$ See Lakeman (2000) for an excellent discussion of the criminal justice system.

${ }^{45}$ See Goodman and Epstein (2005) for an analysis of uniform policies in the United States.
} 
strategies are of two camps: On the one hand, those using police intervention have higher personal but lower household resources than other women, and on the other hand, women with few personal resources have been crowded into public services, especially those that allow short term (i.e., less costly) exit. In closing, a plan for policy reform was outlined which adopts as its goal ending violence, expanding the conceptualization of resistance to include more than departure from the household, and consolidates services and programs between federal, provincial, and local governments and bridges private and public resources. The importance of resistance cannot be understated. Resistance offers a considerable potential constraining effect on levels of violence. Thus, enabling women to resist violence will dramatically reduce the prevalence of violence in Canada. This is not to place the onus of ending violence upon women but to situate resistance, both will and ability, on the state. 


\section{CHAPTER 6:}

\section{CONTRIBUTIONS AND AREAS FOR FUTURE WORK}


The preceding chapters attempted to uncover the impact of Canada's anti-wife abuse policy regime on women's resistance efforts, by exposing the dynamics of abuse and its resistance. Underlying each of the previous essays is an analysis of power: power to influence others' behaviour, power to define one's own needs and wishes, and the power to meet those needs and fulfil those wishes. In this concluding chapter, the key contributions of this study and consider areas for future research will be discussed.

\section{CONTRIBUTIONS}

The central argument in this dissertation is that women's resistance is not an issue of agency, or lack thereof, but rather of public policy. Emphasis on resistance is not to blame women for their predicament, but rather to consider the ways in which policy shapes women's experiences with and responses to abuse. It was demonstrated that to date, the Canadian state has not offered women the means with which to resist their partners. Regarding core policy, the bulk of government money is directed at prevention, most notably by encouraging women to leave their partners. ${ }^{1}$ Zero-tolerance, no-drop policies, transition homes and shelters, and the New Identities Program offer women only

\footnotetext{
${ }^{1}$ See L. Greaves, O. Hankivsky, and J. Kingston-Reichers, Selected Estimates of the Costs of Violence Against Women (London: Centre for Research on Violence Against Women and Children, 1995); T. Day and K.M.J. McKenna, "The Health-Related Economic Costs of Violence Against Women in Canada," in K.M.J. McKenna and J. Larkin (eds.), Violence Against Women: New Canadian Perspectives (Toronto: Ianna Publications, 2002) 313-337; S. Burt and C. Mitchell, 'What's in a Name?: From Sheltering Women to Protecting Communities," in Pal, Leslie (ed.) How Ottawa Spends 1998-99: Balancing Act: The Post Deficit Mandate (Toronto: Oxford University Press, 1998) 271-292; and M. Morrow, O. Hankivsky, and C. Varcoe, "Women and Violence: The Effects of Dismantling the Welfare State," in Critical Social Policy 24:3 (2004).
} 
one choice: departure from the household. Biased along lines of class, race, and ability, these programs are of use only to those women who want to, and can, leave their partners.

Furthermore, the decision to leave, and the credibility of its threat, often hinges on peripheral policies and programs, much of which falls under provincial jurisdiction. Here spending has been reduced on those services most likely to help abused women, such as social assistance, childcare, and legal aid. These cuts have been especially drastic in Alberta, British Columbia, and Ontario. ${ }^{2}$ In addition, the lack of affordable housing means that many women simply do not have long-term options outside of their present situation. Without credible outside options, women have nothing with which to negotiate violence. Thus the policy framework has failed to protect women by a) failing to ensure that women have the required economic resources with which to live independent of a spouse, and b) by leaving intact family and gender systems that perpetuate inequality. In this sense, the state is complicit in the creating the conditions for violence.

Part of the problem is the way in which violence has been decontextualized through policy initiatives. Both Walker (1990) and Bacchi (1999) have demonstrated the ways in which complex social phenomena, such as violence against women, get reduced to simple problems to be maintained and managed. Such simplistic problem representations restrict the analytical lens, limiting the policy space to simple solutions. In this case, by constructing violent men as "criminals" or "deviants", the focus is removed from the structural conditions giving rise to violence, including the violence of

\footnotetext{
${ }^{2}$ See Morrow et al (2005) for a discussion.
} 
women, states, and communities, and prevents radical social change. Family and gender relations are allowed to remain intact. $^{3}$

But if assumptions about male deviancy underlie the policy framework, so too do assumptions about female behaviour. Assumptions about women's agency, where agency is narrowly defined as one's realized choices, inform the policy framework in key ways. When dealing with deviant men, the solution is to get women away from them. Where women do not leave, they either do so by choice or by helplessness. Where they do so by "choice", no policy options are available to them, since it is assumed that the abuse must not be so bad. ${ }^{4}$ Where they do so by "helplessness", policy is aimed at making it easier for women to leave. Since policy makers assume that leaving implies an end to abuse, the goal of policy is to impose exit on violent families, where resistance is conceptualized only as departure from the household. This erroneous assumption, however, simply causes strain on women rather than necessitating the end of violence.

All of the chapters presented here implicate the need to refocus anti-wife abuse policy, away from protection, or getting women to leave, towards prevention, or ending

${ }^{3}$ See L. Gordon, Heroes of their Own Lives (New York: Viking, 1988) for a discussion of the role of the state in preserving the family through anti-violence policy.

${ }^{4}$ C. Bacchi, Women, Policy and Politics: The Construction of Policy Problems (Sage Publications, 1999) and M. Mahoney, "Exit: Power and the Idea of Leaving in Love, Work, and the Confirmation Hearings," Southern California Law Review 65:3 (1992) 1283-1319, "Legal Images of Battered Women: Redefining the Issue of Separation," Michigan Law Review 90:1 (1991) 1-94, "Victimization or Oppression? Women's Lives, Violence, and Agency," in Fineman, M. and Mykituik, R. (eds.), The Public Nature of Private Violence: The Discovery of Domestic Abuse (New York: Routledge, 1994) 59-92. 
violence. ${ }^{5}$ Feminist activist Lee Lakeman (2005: 9) argues, "We had argued since the 1970 s that although violence brings health and justice into the picture, we should, as a community, assess and approach this as a matter of women's freedom." Current policy is aimed at getting women to leave, but even if it is assumed that violence ends when the woman leaves, which it does not, leaving is simply one possible way through which to seek a life without violence. Instead of offering women a limited set of alternatives, each of which result in departure, a variety of services are required to enable women and their partners to deal with the abuse, regardless of whether or not she wants to leave.

These arguments make a significant contribution to the literature on wife abuse. Although some studies have explored the impact of particular policy responses ${ }^{6}$ and the limits of particular policy regimes ${ }^{7}$, no study to date has explored the ways in which a

${ }^{5}$ See M.R. Yoshioka and D.Y. Choi, "Culture and Interpersonal Violence Research: Paradigm Shift to Create a Full Continuum of Domestic Violence Services," Journal of Interpersonal Violence 20:4 (April 2005) 513-519 for a similar conceptualization of 'safety'.

${ }^{6}$ See A. Farmer and J. Tiefenthaler, "Domestic Violence: The Value of Services as Signals," American Economic Review 86:2 (May 1996) Papers and Proceedings of the Hundredth and Eighth Annual Meeting of the American Economic Association, 274-279; J.E. Ursel, "Mandatory Charging: The Manitoba Model," Unsettling Truths: Battered Women, Policy, Politics and Contemporary Research in Canada, eds. K. Bonneycastle and G.S. Rigakos (Vancouver: Collective Press, 1998); D. Ford, "Prosecution as a Victim Power Resource: A Note on Empowering Women in Violence Conjugal Relationships," Law \& Society Review 25:2 (1991); and D. Elliott "Criminal Justice Procedures in Family Violence Crimes," in L. Ohlin and M. Tonry (eds.), Family Violence (Chicago: University of Chicago Press, 1989).

${ }^{7}$ L. Lakeman, "Why "Law and Order" Cannot End Violence Against Women; and Why the Development of Women's (Social, Economic and Political and Civil) Rights Might," in Canadian Woman 
particular policy regime shapes the experiences of abused women as they attempt to resist violence. After considering the constitutive parts of the policy regime, including both policy outputs and the norms and assumptions underlying them, it was argued that, in privileging exit, the policy framework neglects the context in which choice is made and defines a number of women away, restricting the pool of policy beneficiaries to only a few women.

In chapter 3, the lived effects of the policy framework were analyzed, applying insights from a problem representation approach, inspired by the literature on the construction of social problems, to a feminist bargaining approach. It was argued that the current anti-violence policy framework helps women eliminate violence from their lives if and only if it offers a binding constraint, in the form of credible outside options, with which to negotiate violence. For many women, however, this is not the case and they are left with very little to reduce or eliminate violence. Using data from the General Social Survey 1999, the analysis in chapter 4 revealed significant empirical evidence of these hypotheses, discussed below.

This analysis was taken further in chapter 5 , by probing women's resistance strategies in more depth. Here hypotheses concerned the effects of the narrow construction of resistance as only departure from the household on strategy choice, arguing that since the policy framework alienates a number of women, along the lines of class, race and culture, and ability, public service usage rates would be low. In addition, Studies (October 2000); Mahoney (1991; 1992; 1994); Bacchi (1999) and G. Walker, “The Conceptual Politics of Struggle: Wife Battering, the Women's Movement and the State," Studies in Political Economy 33 (Autumn 1990). Reprinted in Studies in Political Economy: Developments in Feminism, eds. C. Andrew, P. Armstrong, H. Armstrong, W. Clement, and L. Vosko (Toronto: Women's Press, 2003). 
it was argued that among women using public services, women using police services would have much better access to economic and social resources than other women, due to the costs involved with police intervention, and that women using other public services, such as transition homes and shelters, would have poor access to economic and social resources than other women. These women, in other words, are crowded into those public services that do not require long-term exit and thus are least costly. Using data from the General Social Survey 1999 significant empirical evidence was discovered to support these claims.

In addition to exploring the impact of a particular policy regime on women's resistance efforts, the dynamics of abusive relationships were considered, continuing the dialogue on the conditions for violence and its effects. Early game theoretic analyses of abusive relationships assume that the bargaining structure is exogenous with respect to violence. $^{8}$ It was argued here, however, using data from sociological studies, that the bargaining structure is in fact endogenous, as several parameters of the bargaining context are affected by abuse. It was demonstrated that fallback positions, voice, and the well-being possibilities frontier are all affected by violence, which not only change the outcomes of the game, but also the power relations between the participating individuals.

These effects were shown analytically in chapters 2 and 3 . In chapter 2 the abuser's gains from violence were considered, contributing to the debate about the impact of women's resources on violence. One argument posits that as women's resources

\footnotetext{
${ }^{8}$ H. Tauchen and A. Dryden Witte, "The Dynamics of Domestic Violence," The American Economic Review 85:2 (1995) and A. Farmer and J. Tiefenthaler, "An Economic Analysis of Domestic Violence," Review of Social Economy LV:3 (Fall 1997). The latter model endogenizes labour supply with respect to abuse.
} 
increase, violence will decrease. From this perspective, rising resources offers women better exit threats as well as better options with which to escape violence, even for short periods. The other argument, however, is that as women's resources increase, violence will also increase. Responding to a threat to traditional masculinity, men use violence to reassert their control and dominance within the household. Addressing this debate, it was suggested that more attention be paid to the complex interplay between absolute and relative resources, arguing the importance of household structure, including both the gains from the relationship and the relative position of each agent, in determining violence. The analysis in chapter 3 took this further by including the possibility for resistance, as discussed above. Taken together, these two chapters reveal that only when resistance is not an option and only when the gains from cooperation are equal across households does increasing female resources increase vulnerability to abuse.

The hypotheses generated in these chapters were explored empirically in chapter 4. Using data from the General Social Survey 1999, a two-stage analysis was conducted to explore the probability of experiencing abuse and its severity. Considerable evidence was found to support the hypotheses about the role of household structure in establishing the conditions for abuse. Households marked by high gains from cooperation, that is, where families generate the highest benefits, are less likely to experience abuse and when they do, experience less severe forms. After controlling for the gains from families, it was discovered that relative status is also an important contributor to abuse. In addition, it was discovered that women with the best access to economic and social resources were the least likely to experience abuse and if they did experienced the less severe forms, supporting our analysis in chapter 3 . Together these findings suggest that the relationship 
between female resources and abuse is complex: only under certain conditions, when there are barriers to resistance, for example, will rising female resources trigger an increase violence, noted above.

This finding is an important theoretical contribution speaking to the debate between those arguing, on one hand, that increasing female resources reduces violence, and those arguing, on the other hand, that increasing female resources increase abuse. It was demonstrated that where the gains from cooperation are high, the likelihood and severity of abuse is low. In addition, as female absolute income increases, her vulnerability to violence decreases. As her status increases in absolute terms, she is in a better position to "negotiate" violence. However, as her income increases relative to her partner's, her vulnerability to violence increases. This tells us that female income reduces vulnerability to violence only if her partner's status is high relative to hers and/or if her income is high enough to enable her to credibly threaten departure.

These findings open new areas for policy reform in the area of wife abuse, as articulated in chapters 4 and 5. In general, it was argued that policy must be reoriented away from getting women to leave towards ending violence. This requires the move away from targeted policies towards integrated, multisectoral policy designed as a gender equality initiative. The analysis in chapter 4 revealed three specific policy areas to meet this goal, including resource redistribution, targeting vulnerable groups, and policies designed to alter social relations. The importance of these areas was illuminated by the analysis in chapter 5 . Here two additional areas were discussed that will work towards reorienting the goal of wife abuse policy, including social inclusion policies and social service reform. Such policies also feed into the three areas discussed in chapter 4 . By 
simultaneously reducing the incentives for violence and increasing women's access to resources, both economic and social, the state can potentially transform the basis on which violence and its resistance are premised.

\section{AREAS FOR FUTURE WORK}

While this study makes important contributions to the literature on wife abuse, there are still many areas for future work. Feminists are increasingly calling for an end to the disarticulation of violence against women from other forms of violence, as described in chapter $1 .^{9}$ As a result, more research is needed into other forms of violence, including violence within same-sex families and the violence of women against other women, children and men. ${ }^{10}$ Similarly, more research is needed into the linkages between violence within and outside of households, including state and institutional violence. It is important, however, to keep these analyses rooted in feminist inquiry, so as not to lose sight of the crucial ways in which violence, its causes and effects, is simultaneously shaped by gender, race, and class. An advantage to the models developed in the preceding chapters is that they will be potentially useful to this end. By exploring the

\footnotetext{
${ }^{9}$ See b. hooks, Feminist Theory: From Margin to Center, $2^{\text {nd }}$ ed. (Cambridge, MA: South End
} Press, 2000) and J. Vickers, "Thinking About Violence," Gender, Race, and Nation: A Global Perspective, eds. V. Dhruvarajon and J. Vickers (Toronto: University of Toronto Press, 2002).

${ }^{10}$ For a discussion on violence against men, see S. Murty, C. Peek-Asa, C. Zwerling, A. Stromquist, L. Burmeister, and J. Merchant, "Physical and Emotional Partner Abuse Reported by Men and Women in a Rural Community," in American Journal of Public Health 93:7 (July 2003). For a comparison between male and female violence, see K. Anderson, "Gender, Status, and Domestic Violence: An Integration of Feminist and Family Violence Approaches," in Journal of Marriage and the Family 59:3 (August, 1997). 
ways in which the parameters of the models capture the effects of gender, race, ability, sexuality, and class, researchers and policymakers can begin thinking about the ways in which all forms of violence shapes and is shaped by the political economy.

Part of this will require more attention to the construction of masculinities. Feminist and gender theory is increasingly calling attention to the ways in which masculinities are constructed and contested within social and political space. ${ }^{11}$ As a result, masculinity, like femininity, fluctuates with class, race, age, ability, sexuality, etc. These constructions need to be considered in the context of abusive relationships. What do these constructions mean for the onset of violence and its effects? To what extent is the "patriarchal dividend" upheld by violence? In addition, does violence play a role in allocating this dividend among various groups of men $?^{12}$ What do they imply for the analysis laid out in this dissertation? These questions will be increasingly important as the roles of both men and women are changing in the post-industrial economy.

Like masculinity, more attention needs to be paid to Aboriginal women. Consistent with previous studies, this study demonstrated that Aboriginal women are not only much more likely to experience abuse, but also experience the most severe forms of violence. ${ }^{13}$ The preceding analysis provides a starting point, by exploring the impacts of

${ }^{11}$ See R.W. Connell, Masculinities (Berkeley and Los Angeles, CA: University of California Press, 1995); R.W. Connell, "Change Among the Gatekeepers: Men, Masculinities, and Gender Equality in the Global Arena," Signs 30:3 (2005).

${ }^{12}$ Connell (1995).

${ }^{13}$ See K. Rodgers, Wife Assault: The Findings of a National Survey (Ottawa: Statistics Canada, 1994). For a discussion of violence in aboriginal communities, see D. Brownridge, "Male Partner Violence Against Women in Aboriginal Women in Canada: An Empirical Analysis," Journal of Interpersonal 
the policy framework for marginalized women, but more work needs to explore the origins of violence within this community, as well as appropriate community level responses.

Conducting these types of studies requires more data. Getting data at all levels of this issue is difficult. Governments collect mass information, but will not distribute it. For example, the annual Homicide Survey conducted by Statistics Canada is not accessible for public use. Similarly, coroner's reports are tremendously difficult to access and if access is granted, researchers are prevented from reporting on various indicators, such as socio-economic status, race, or community. In addition, information on programs such as the New Identities Program is simply not available and attempts to interview representatives at the Royal Canadian Mounted Police, Human Resources and Skills Development Canada, and the Canada Revenue Agency were declined. ${ }^{14}$ And this is in addition to the problems with accessing women and men with whom to talk. Governments need to be willing to make this data available. And comparative analyses across regions and nations are needed to see what works and what doesn't. Without reliable data, however, such analyses cannot even begin.

Violence 18:1 (2003) 65-83; and E.D. La Rocque, "Violence in Aboriginal Communities," Violence Against Women: New Canadian Perspectives.

${ }^{14}$ In fact, I was told explicitly that representatives cannot discuss the NIP with anyone from the public. Upon inquiry, I was advised by the RCMP to submit questions and an appropriate agent would determine whether or not they could provide answers. I submitted four questions: How is the program organized? Who is the lead department? What are the eligibility requirements for entry into the program? How many women to date have entered the program? I was told that agents could not answer these questions. 
Finally, new approaches to policy in this area are needed. Based on the preceding analysis, a good place to start is capabilities theory, developed by Amartya Sen and Martha Nussbaum. ${ }^{15}$ Capabilities theory situates the individual in their social environment, which includes economic and social motivations, displacing "utility" as the key factor in human behaviour, stressing instead the ability to make choices that will enable individuals to become what they desire. Central to capabilities theory is freedom: Freedom to define one's goals and act upon them, hence the term "capabilities"; capability is the ability for purposeful action. ${ }^{16}$ Freedom, capabilities, results in "functionings", or what one does or becomes, which include both basic (i.e., food, shelter, health, etc.) and complex (i.e., self-respect) forms. ${ }^{17}$ Resources are only useful in the degree to which they can be converted into capabilities and functionings. ${ }^{18}$ Social arrangements, families and gender sub-systems for example, will mediate the translation of resources into capabilities. ${ }^{19}$ Thus, one could easily imagine a situation where one has

${ }^{15}$ See A. Sen, "Gender and Cooperative Conflicts," in Tinker, I. (ed.), Persistent Inequalities: Women and World Development (New York: Oxford University Press, 1990) 123-149 and M. Nussbaum and A. Sen (eds.), The Quality of Life (Oxford: Oxford University Press, 1993). See also the collection of essays on capabilities theory in Feminist Economics 9: 2-3 (2003).

${ }^{16}$ See D. Gasper and I. Van Staveren, "Development as Freedom - and as What Else?" Feminist Economics 9:2-3 (2003) 137-161 for a discussion and critique of this central principle.

${ }^{17}$ See V. Iverson, "Intrahousehold Inequality: A Challenge for the Capabilities Approach?” Feminist Economics 9:2-3 (2003) 93-115 for a discussion

${ }^{18}$ Ibid. 94.

${ }^{19}$ Sen (1990); M. Hill, “Development as Empowerment," Feminist Economics 9:2-3 (2003) 117 135. 
the resources with which to act, but is structured by familial and social arrangements deterring such actions. ${ }^{20}$ Panda and Agarwal (2005: 824) argue:

The widespread presence of marital violence thus indicates that a notable proportion of the human population is deprived of both a very important component of well-being and the freedom to enhance even conventional aspects of well-being linked with income and health. If development is to be seen as the expansion of human capabilities - the real freedoms that people can enjoy, to achieve what they have reason to value - then clearly freedom from domestic violence needs to be a significant part of any exercise for evaluating development.

While this quotation addresses issues in the developing world, it is clear that freedom from violence has universal application.

Conceptualizing resistance as a capability, that is, the ability to live without violence, will offer a great deal of potential to design policy in this area. How are exit

${ }^{20}$ Sen (1990) takes this as evidence of false perceptions, that women, for example, are often not aware of their own needs and interests as distinct from the family. Agarwal (1997) disagrees, suggesting that while false perceptions are possible, they are not probable, pointing to a vast body of literature documenting examples of women's overt and covert resistance to systems perpetuating inequality. With this in mind, she notes: "In explaining gender inequalities, I would therefore place much less emphasis than Sen does on women's incorrect perceptions of their self-interest, and much more on the external constraints to their acting overtly in their self-interest. Or, to put it another way, what is needed is less making women realize they deserve better, than having them believe they can do better (by building their self-confidence, providing information, etc.), and by helping them to in fact do better, through strengthening their bargaining position" (25). See B. Agarwal, "'Bargaining' and Gender Relations: Within and Beyond the Household," Feminist Economics 3:1 (1997). Also see B. Agarwal, A Field of One's Own: Gender and Land Rights in South Asia (Cambridge: Cambridge University Press, 1993). For a further discussion of the use of agency in capabilities theory, see F. Peter, "Gender and the Foundations of Social Choice: The Role of Situated Agency," Feminist Economics 9:2-3 (2003) 13-32. 
options shaped by culture, race, class, ability, etc. $?^{21}$ What resources are required to provide all women with credible exit options? How can policy be used to ensure that women have both the economic and social resources necessary to credibly threaten exit?

These are central questions for ensuring women's safety but have to yet be seriously considered by policy makers. This is especially apparent when one considers a recent report by the Ad-Hoc Federal-Provincial-Territorial Working Group Reviewing Spousal Abuse Polices and Legislation (2003), which advocates the continued dominance of the criminal justice system in anti-wife abuse policy. The report notes that such policies aim to deter violence and have other objectives, including "removing responsibility (and blame) for the decision to lay charges from the victim" and "increasing the number of charges laid in reported spousal abuse cases" (21). The implication is that by removing the "responsibility (and blame)" for police intervention, women will be more likely to call the police.

Part of the Working Group's support for the continuation of the criminal justice response to abuse is premised on victim satisfaction rates. The Working Group reports high victim satisfaction with the criminal justice system. However, the studies on which these findings are based explore only the responses of the women who actually came into

\footnotetext{
${ }^{21}$ For analyses regarding the role of race and culture in shaping women's experiences with and responses to violence, see D. Hassouneh-Phillips, "Polygamy and Wife Abuse: A Qualitative Study of Muslim Women in America," Health Care for Women International 22:8 (2001) 735-748 and M.R. Yoshioka and D.Y. Choi, "Culture and Interpersonal Violence Research: Paradigm Shift to Create a Full Continuum of Domestic Violence Services," Journal of Interpersonal Violence 20:4 (April 2005) 513-519.
} 
contact with the criminal justice system. ${ }^{22}$ And while the Working Group acknowledges that the majority of abused women do not use the criminal justice system, as demonstrated in chapter 5 , they do not consider why this is the case. That the majority of women using the criminal justice system are satisfied with the service is important, but if this group of women represents only a small portion of the population of abused women, then researchers and policymakers should also be exploring why only certain women use this option and what other alternatives are available to ensure that other women also have protection from abuse, as demonstrated in chapter 5.

Obvious in the report is the implicit advocacy of a hub and spoke model, where the criminal justice system occupies the hub and other programs constitute the spokes. For example, the report recommended domestic violence courts and civil legislation, victim's services, monitoring and risk assessment ${ }^{23}$ as possible ways with which to strengthen the justice system. Discussing victim's services ${ }^{24}$, they write:

The Working Group concludes that these innovative measures and approaches have played a key role in supporting the implementation of the spousal abuse policies. They have also strengthened the criminal justice system's response to spousal abuse by providing new ways and tools to ensure that the system is sensitive to the unique realities of spousal abuse. Accordingly, the Working Group recommends continued support for the development of new and innovative justice system responses to better support and safeguard the victim throughout the criminal justice process, to rehabilitate the offender, and to ensure a strong, co-ordinated multisectoral response to spousal abuse (vi).

${ }^{22}$ Federal-Provincial-Territorial Ministers Responsible for Justice, Spousal Abuse Policies and Legislation: Final Report of the Ad Hoc Federal-Provincial-Territorial Working Group Reviewing Spousal Abuse Policies and Legislation (Ottawa: National Clearinghouse on Family Violence, 2003$) 18$.

${ }^{24}$ Victim's services in the report include those services accessible to victims after contacting the police. The report also reviews non-justice related services, such as transition homes and shelters, and suggests that these centres work more closely with the criminal justice system. 
In addition, the Working Group rejected the use of alternative measures programs, including community level restorative justice programs, except under the following conditions:

i. $\quad$ the referral to the alternative justice process is made post-charge on Crown approval;

ii. trained and qualified personnel, using validated risk assessment tools, determine that the case is not high-risk (in other words, if after a consideration of a variety of factors including any history of violence, threats of serious violence, prior breaches of protective court orders, the use or presence of weapons, employment problems, substance abuse, and suicide threats, the offender is assessed to be at low risk of re-offending and therefore of low risk of harm to the victim's safety, as well as that of her children and other dependents, both throughout and after the process);

iii. the alternative justice process offers the same or a greater measure of protection of the victim's safety as does the traditional criminal justice process;

iv. the victim is fully informed of the proposed alternative justice process and her wishes are taken into consideration. In addition, victim consent is required and victim support must be provided where the victim will be asked to participate in the alternative justice process;

v. the offender fully accepts responsibility for his action;

vi. the alternative justice process is part of a program approved by the Attorney General for the purpose of providing alternative justice responses to spousal abuse and is overseen by the Attorney General or the court;

vii. the alternative justice process is transparent (that is, it maintains formal and public records of the actions taken by those engaged in the process) and it is undertaken in a timely and reasonable manner;

viii. the alternative justice process has the capacity to deal with spousal abuse cases and is delivered and supervised by persons possessing the requisite skill, training and capacity, including the ability to recognize and address any power imbalances, as well as cultural differences; and

ix. the possibility of criminal conviction and sentence remains if the process fails. (88)

Most problematic here is that such programs are recommended only within a framework privileging the role of the criminal justice system to define the scope and content of such alternatives, as well as the participants. And by allowing the court a gatekeeper's status, the use of such programs will be limited. Again, if only a small portion of abused women are using the criminal justice system, to give it such a primary role in the delivery of alternative justice programs will potentially limit their impact. And this is especially concerning for groups of women who might prefer alternative justice responses, such as Aboriginal and Islamic women. 
Effectively, the hub and spoke model is problematic if the majority of women are reluctant to use the criminal justice system, which is compounded by race and class bias, as shown in strategy choices discussed in chapter 5. For example, although the members of the group recognize that women who are "members of over-criminalized communities [...] are sometimes more reluctant to call the police [...]" (18) (emphasis added), the Working Group reveals their own class and race bias when they note: "Similarly, a review of the experiences of service providers working with ethnocultural women victims of spousal abuse indicates support for the mandatory charging policy. Since it removes responsibility for the decision to charge from the victim, it underscores the importance of the societal message that spousal abuse is unacceptable, and it empowers women (18)." What the report does not acknowledge is that imposing exit on women can potentially have the opposite effect by disempowering them, as argued in chapter 3.

Interestingly, however, the empowerment of women is never explicitly addressed in the report. Only core policies are addressed, neglecting the crucial role for peripheral policies to enable women's ability to live without violence. Indeed, a recent study by Morrow, Hankivsky and Varcoe (2004) argued that drastic cuts to peripheral services, such as legal aid and social assistance, in Alberta, British Columbia and Ontario undermine women's abilities to escape violent situations. Thus these services are essential for helping women resist abuse but are the most vulnerable to spending cuts. Instead, governments are favouring the continued dominance of targeted policy, especially the criminal justice system, which impose exit on women rather than offering them a wide range of services and options with which to resist. 
Ensuring effective resistance requires integrated, multi-sectoral policy. Interestingly, the Working Group advocates multi-sectoral policy, but only in terms of core policy. This is in contrast to Morrow et al (2004), for whom multi-sectoral policy requires strong linkages between anti-violence and gender equity policy. In other words, the feminist application of multi-sectoral policy implicates the displacement of violence as a neatly packaged social problem concerning violent men, in favour of a strategy that more effectively targets the structural conditions of abuse and its resistance.

In closing, policymakers must begin to think of new ways to deal with abuse, and this thinking must be premised on intersectional and cross-cultural analysis. Only by determining the ways in which women can credibly threaten exit can states, families, and communities offer the tools of resistance. Doing so does not impose a particular strategy on women, but rather gives them the basis on which to threaten the costliest strategy, which will constrain abuse. By offering women the tools of exit, even those women who do not want to leave are given the opportunity to live without violence. Again, by suggesting a need to offer women the tools of resistance is not to place the onus of ending abuse on women, but rather to shift the onus away from women, to suggest that states have the power through public policy to transform the basis on which violence and its resistance are premised. 


\section{APPENDIX 1:}

\section{LIST OF RELEVANT GSS QUESTIONS}


MARSTAT Is \{household member $x$ \}'s marital status .....

(1) Living common-law?

(2) Married?

(3) Widowed?

(4) Divorced?

(5) Separated?

(6) Single (never married)?

INTRO_5Y What is your year of birth? (year)

\section{SECTION C: EMOTIONAL AND FINANCIAL ABUSE BY A SPOUSE/PARTNER}

C1Y Now I would like to ask you about some things concerning your spouse/partner. We're interested in knowing how long you've been married or living together/living together. In what year were you married or started living together/did you start living together?

If the couple lived common-law before getting married, ask the respondent when they started living together. We want to know the total length of time that the couple has lived together.

Year

|______ | [CATI: 1920-1999]

(x) Don't know

(r) Refused

C1M In what month?

Month

[___ [CATI: 1-12]

(x) Don't know

(r) Refused

C2 I'm going to read a list of statements that some people have used to describe their spouse/partner. I'd like you to tell me whether or not each statement describes your spouse/partner. (Please remember that all information provided is strictly confidential.) He/She tries to limit your contact with family or friends.
(1) Yes
(3) No
(r) Refused

$\mathrm{C} 3 \mathrm{He} / \mathrm{She}$ puts you down or calls you names to make you feel bad.

(Does this statement describe your spouse/partner?) 
(1) Yes

(3) No

(r) Refused

$\mathrm{C} 4 \mathrm{He} / \mathrm{She}$ is jealous and doesn't want you to talk to other men/women. (Does this statement describe your spouse/partner?)
(1) Yes
(3) No
(r) Refused

C5 He/She harms, or threatens to harm, someone close to you. (Does this statement describe your spouse/partner?)
(1) Yes
(3) No
(r) Refused

C6 He/She demands to know who you are with and where you are at all times. (Does this statement describe your spouse/partner?)
(1) Yes
(3) No
(r) Refused

C7 He/She damages or destroys your possessions or property. (Does this statement describe your spouse/partner?)
(1) Yes
(3) No
(r) Refused

$\mathrm{C} 8 \mathrm{He} / \mathrm{She}$ prevents you from knowing about or having access to the family income, even if you ask.

(Does this statement describe your spouse/partner?)
(1) Yes
(3) No
(r) Refused

\section{SECTION D: PHYSICAL AND SEXUAL VIOLENCE BY A SPOUSE/PARTNER}

D1 It is important to hear from people themselves if we are to understand the serious problem of violence in the home. I'm going to ask you ten short questions and I'd like you to tell me whether, in the past 5 years, your CURRENT spouse/partner has done any of the following to you. Your responses are important 
whether or not you have had any of these experiences. Remember that all information provided is strictly confidential. During the past 5 years, has your current spouse/partner THREATENED to hit you with his/her fist or anything else that could have hurt you?
(1) Yes
(3) No
(r) Refused

D2 (During the past 5 years,) has he/she THROWN anything at you that could have hurt you?
(1) Yes
(3) No
(r) Refused

D3 (During the past 5 years,) has he/she pushed, grabbed or shoved you in a way that could have hurt you?
(1) Yes
(3) No
(r) Refused

D4 (During the past 5 years,) has he/she slapped you?
(1) Yes
(3) No
(r) Refused

D5 (During the past 5 years,) has he/she kicked you, bit you, or hit you with his/her fist?
(1) Yes
(3) No
(r) Refused

D6 (During the past 5 years,) has he/she hit you with something that could have hurt you? (Do not include hitting with fist)
(1) Yes
(3) No
(r) Refused

D7 (During the past 5 years,) has he/she beaten you?

(1) Yes 
(3) No

(r) Refused

D8 (During the past 5 years, ) has he/she choked you?
(1) Yes
(3) No
(r) Refused

D9 (During the past 5 years,) has he/she USED or THREATENED TO USE a gun or knife on you?
(1) Yes
(3) No
(r) Refused

D10 (During the past 5 years,) has he/she forced you into any unwanted sexual activity, by threatening you, holding you down, or hurting you in some way?
(1) Yes
(3) No
(r) Refused

D11 You said yes to at least one of the previous ten questions concerning violence. During the past 5 years, has he/she been violent towards you on more than one occasion?
(1) Yes
(3) No [Go to D14]
(r) Refused [Go to D14]

D12 How many different times did these things happen?
(2) Two
(3) Three
(4) Four
(5) Five
(6) Six
(7) Seven
(8) Eight
(9) Nine
(10) Ten
(11) More than ten
(x) Don't know
(r) Refused 
D13 How many of these were in the past 12 months?

I_____ [CATI: 0-99]

(x) Don't know

(r) Refused

CATI-D13e - Hard edit. If D12 NE (11) nor (x) nor (r) then D13 must be $=<D 12$. If not then:

(1) Correct D12

(3) Correct D13

D14 When did this happen (the most recent happen)?

Year

L_L____ [CATI: 1994-1999]

(x) Don't know

(r) Refused

Month

L___ [CATI: 1-12]

(x) Don't know

(r) Refused

CATI-D14e: If C1 > 5 years then Go to D15B).

D15A Did this (any of these) incident(s) in the past 5 years happen before you were married or living common-law?
(1) Yes
(3) No
(r) Refused

D15B Did this (any of these) incident(s) in the past 5 years happen while you were married or living common-law?
(1) Yes
(3) No
(r) Refused

D15C Did this (any of these) incident(s) in the past 5 years happen while you were temporarily separated?
(1) Yes
(3) No
(5) No, never separated
(r) Refused 


\section{SECTION L: SPOUSAL ABUSE REPORT}

L1 You said that during the past 5 years your spouse/partner was violent.

L2 During this (these) incident(s), were you (ever) physically injured in any way?

(1) Yes

(3) No [Go to L6]

(r) Refused [Go to L6]

L3 Did any of these incidents in which you were injured happen in the past 12 months?
(1) Yes
(3) No
(x) Don't know
(r) Refused

L4 During the past 5 years, did you ever receive any medical attention at a hospital as a result of the violence? (Include treatment received at emergency or as an outpatient.)

(1) Yes

(3) No [Go to L5]

(r) Refused [Go to L5]

L4A Did you stay in hospital overnight?

(1) Yes

(3) No [Go to L6]

(r) Refused [Go to L6]

L4B For how many nights?

L_____ [CATI: 0-999]

(r) Refused

L5 During the past 5 years, did you ever receive anymedical attention from a doctor or a nurse for your injuries? (Include medical attention received immediately after the attack as well as any medical attention received as a result of the injuries.)
(1) Yes
(3) No
(r) Refused 
L6 As a result of the violence (and excluding any time you spent in the hospital), did you, during the past 5 years, ever have to stay in bed for all or most of a day? (Include time spent in bed for injuries as well as for stress reasons.) Most of a day means at least 6 hours over and above the time the respondent normally spends sleeping.)

(1) Yes

(3) No [Go to L7]

(r) Refused [Go to L7]

L6A For how many days? Count each day the respondent spent at least 6 hours in bed over and above the time he/she normally spends sleeping.

L___ [CATI: 0-999]

(x) Don't know

(r) Refused

L7 (Other than the time you spent in the hospital or at home in bed,) during the past 5 years, did you ever have to take time off from your everyday activities because of what happened to you? Select (1) (yes) if the respondent's everyday activities were disrupted for at least 6 hours.

(1) Yes

(3) No

(x) Don't know

(r) Refused

L8 During (these) this incident(s) was your spouse/partner drinking? Select (1) (yes) if the respondent says usually or during more than half of the incidents.

(1) Yes

(3) No

(5) Does not drink

(x) Don't know

(r) Refused

L12 During the past 5 years, was anyone (else) ever harmed or threatened during (these) this incident(s)?

(1) Yes

(3) No [Go to L14]

(x) Don't know [Go to L14]

(r) Refused [Go to L14]

L12A How many persons? 
L__ [CATI: 0-99]

(x) Don't know

(r) Refused

L13 Were any of these people who were harmed or threatened under 15 years of age?

(1) Yes

(3) No [Go to L14]

(x) Don't know [Go to L14]

(r) Refused [Go to L14]

\section{L13A How many persons?}

|___ [CATI: 0-99]
(x) Don't know

(r) Refused

L14 Did any of your children see or hear (any of these) this incident(s)?
(1) Yes/think so
(3) No/don't think so
(5) No children at the time
(x) Don't know
(r) Refused

L15 During the past 5 years, did you ever fear that your life was in danger because of your spouse's/partner's violent or threatening behaviour?
(1) Yes
(3) No
(r) Refused

L16 During the past 5 years, did you ever attempt to obtain compensation, through a civil or criminal court or a provincial compensation program, because of the violence?
(1) Yes
(3) No [Go to L17]
(r) Refused [Go to L17]

L16A Did you obtain any compensation?
(1) Yes
(3) No
(5) Not yet resolved 
(r) Refused

L17 Did the police ever find out about the violence in any way? If the respondent or the respondent's spouse/partner or a member of the household is a police officer, select (1) (yes) only if it was reported to the police.
(1) Yes
(3) No [Go to L25A]
(x) Don't know [Go to L27]
(r) Refused [Go to L27]

L18 Did they find out about it in the past 12 months?
(1) Yes
(3) No
(x) Don't know
(r) Refused

L19 How did they learn about it? Was it from you or some other way? If respondent answers both himself/herself and some other way - enter (1).
(1) Respondent
(3) Some other way [Go to L21]
(x) Don't know [Go to L27]
(r) Refused [Go to L27]

L20 People have different reasons for reporting incidents to the police. Did any of the following have anything to do with why you reported the violence? Was it...

Yes No Don't know Refused
a) To stop the violence or receive protection? (1) (3) (x) (r)
b) To arrest and punish your spouse/partner? (1) (3) (x) (r)
c) Because you felt it was your duty to notify police? (1) (3) (x) (r)
d) On the recommendation of someone else? (1) (3) (x) (r)

\section{L21 What action did the police take? Mark all that apply.}
(n) None [Go to L22]
(1) Visited Scene
(2) Made a report/Conducted an investigation
(3) Gave warning to spouse/partner
(4) Took spouse/partner away
(5) Made arrest/Laid charges
(6) Put you in touch with community services
(7) Other [Go to L21S]
(r) Refused [Go to L22] 
(0) No other; continue [Go to L22]

L21S Specify

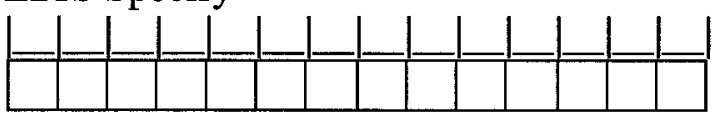

L22 How satisfied were you with the actions that the police took? Were you...

(1) Very satisfied?

(2) Somewhat satisfied?

(3) Somewhat dissatisfied?

(4) Very dissatisfied?

(r) Refused

L23 Is there anything (else) they should have done to help you? Mark all that apply.

(n) No/nothing [Go to CATI-L23e]

(1) Take the person out of the house

(2) Charge/arrest the person

(3) Respond more quickly

(4) Refer/take you to a support service

(5) Relocate you

(6) Take you to hospital

(7) Be more supportive/sympathetic

(8) Other [Go to L23S]

(x) Don't know [Go to CATI-L23e]

(r) Refused [Go to CATI-L23e]

(0) No other; continue [Go to CATI-L23e]

L23S Specify

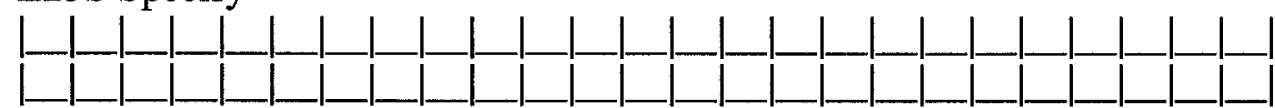

L24 After the police were involved, did your spouse's/partner's violent or threatening behaviour towards you...

(1) Increase?

(2) Decrease/stop?

(3) Stay the same?

(x) Don't know

(r) Refused

L25A I'm going to read a list of reasons why some people choose not to contact the police. Please tell me which ones apply to your experience. Was it... 
Because it was dealt with another way? (e.g. left him/her, reported to another official, private matter that took care of myself, etc.)

(1) Yes

(3) No

(r) Refused

L25B (I'm going to read a list of reasons why some people choose not to contact the police. Please tell me which ones apply to your experience. Was it...)

Because of fear of your spouse/partner?

(1) Yes

(3) No

(r) Refused

L25C (I'm going to read a list of reasons why some people choose not to contact the police. Please tell me which ones apply to your experience. Was it...)

Because the police couldn't do anything about it?

(1) Yes

(3) No

(r) Refused

L25D (I'm going to read a list of reasons why some people choose not to contact the police. Please tell me which ones apply to your experience. Was it...)

Because the police wouldn't help? (e.g. wouldn't think it was important enough, wouldn't believe, wouldn't want to be bothered or get involved, police would be inefficient or ineffective, police would be biased, would harass/insult respondent, offender was police officer)
(1) Yes
(3) No
(r) Refused

L25E (I'm going to read a list of reasons why some people choose not to contact the police. Please tell me which ones apply to your experience. Was it...)

Because you didn't want to get involved with police?
(1) Yes
(3) No
(r) Refused 
L25X (I'm going to read a list of reasons why some people choose not to contact the police. Please tell me which ones apply to your experience. Was it...)

Because you didn't want your spouse/partner arrested or jailed?

(1) Yes

(3) No

(r) Refused

L25G (I'm going to read a list of reasons why some people choose not to contact the police. Please tell me which ones apply to your experience. Was it...)

Because the incident was a personal matter that didn't concern the police?
(1) Yes
(3) No
(r) Refused

L25Y (I'm going to read a list of reasons why some people choose not to contact the police. Please tell me which ones apply to your experience. Was it...)

Because you didn't want anyone to find out about it? (e.g. shame, embarrassment)
(1) Yes
(3) No
(r) Refused

L25H (I'm going to read a list of reasons why some people choose not to contact the police. Please tell me which ones apply to your experience. Was it...)

Because of fear of publicity/news coverage?
(1) Yes
(3) No
(r) Refused

L25F (I'm going to read a list of reasons why some people choose not to contact the police. Please tell me which ones apply to your experience. Was it...)

Because it was not important enough to you? (e.g. minor crime, no intended harm, etc.)
(1) Yes
(3) No
(r) Refused 
L25K (I'm going to read a list of reasons why some people choose not to contact the police. Please tell me which ones apply to your experience. Was it...)

For some other reason, not already mentioned?

(1) Yes

(3) No [Go to CATI-L25e]

(r) Refused [Go to CATI-L25e]

L25S Specify

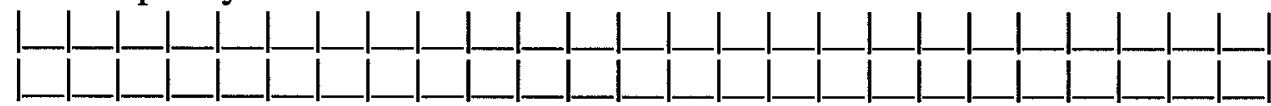

L26 What was the main reason?

(1) Dealt with another way

(2) Fear

(3) Police couldn't do anything

(4) Police wouldn't help

(5) Did not want to get involved with police

(6) Not important enough to respondent

(7) A personal matter that did not concern the police

(8) Fear of publicity/media coverage

(11) Didn't want spouse/partner arrested or jailed

(12) Didn't want anyone to find out about it

(13) Other

(r) Refused

L27 (Other than to the police,) did you ever talk to anyone about (these) this incident(s), such as ...

Yes No Don't Know Refused

a) Family? (1) (3) (x) (r)

b) Friend or neighbour? (1) (3) (x) (r)

c) Co-worker? (1) (3) (x) (r)

d) Doctor or nurse? (1) (3) (x) (r)

e) Lawyer? (1) (3) (x) (r)

f) Minister, priest, clergy

or another spiritual advisor? (1) (3) (x) (r)

L28 During the past 5 years, did you ever contact or use any of the following services for help because of the violence, such as ... ("Victim Assistance Units" operate within a specific police office, and help victims at the police end of the justice system. "Victim Services" help victims as their cases proceed through the justice system (police, courts and corrections). Services include providing general 
information about the justice system, referrals, assistance with court, help preparing victim impact statements, offering emotional support and providing information to help victims recover financial losses resulting from the crime.)

Yes No Don't know Refused

a) Crisis centre or crisis line? (1) (3) (x) (r)

b) Another counsellor or psychologist? (1) (3) (x) (r)

c) Community centre or family centre? (1) (3) (x) (r)

d) Shelter or transition house?

[CATI: only if female respondent] (1) (3) (x) (r)

e) Women's centre? [CATI: only if female respondent] (1) (3) (x) (r)

f) Men's centre or men's support group?

[CATI: only if male respondent] (1) (3) (x) (r)

g) Seniors' centre? [CATI: only if respondent is $65+$ ] (1) (3) (x) (r)

h) Police-based or court-based victim services? (1) (3) (x) (r)

L28A Was this in the past 12 months? a to $h$
(1) Yes
(3) No
(r) Refused

L29 Is there any reason why you didn't use any of these services? Mark all that apply.

(1) Didn't know of any services

(2) None available

(3) Waiting list

(4) Too minor

(5) Shame/embarrassment

(6) Wouldn't be believed

(7) Offender prevented me

(8) Distance

(9) Fear of losing financial support

(10) Fear of losing the children

(11) Didn't want relationship to end

(12) Didn't want/need help

(13) Other [Go to L29S]

(x) Don't know/no reason [Go to L30]

(r) Refused [Go to L30]

(0) No other; continue [Go to L30]

L29S Specify

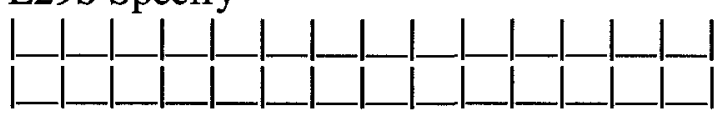


L30 (There are a number of ways to deal with an offence outside the normal policecourt process. One way is a meeting between the victim and the offender to discuss an appropriate way the offender should be dealt with. Thinking about your experience, how interested would you be (have been) in participating in such a program if one was available in your community?) (Thinking about the incident(s), how interested would you be (have been) in participating in a program where the victim and the offender meet to discuss an appropriate way the offender should be dealt with?) Would you be (have been)...

(1) Very interested?

(2) Somewhat interested?

(3) Slightly interested?

(4) Not at all interested?

(r) Refused

L31 At the time of the incident(s), how did this experience affect you? Mark all that apply. Do not include physical injury, financial loss or medical treatment.

(1) Afraid for children

(2) Angry

(3) Ashamed/guilty

(4) Depression/ anxiety attacks

(5) Fearful

(6) Hurt/disappointment

(7) Increased self-reliance

(8) Lowered self esteem

(9) More cautious/aware

(10) Not much

(11) Problems relating to men/women

(12) Shock/disbelief

(13) Sleeping problems

(14) Upset/confused/frustrated

(15) Other [Go to L31S]

(x) Don't know [Go to L32]

(r) Refused [Go to L32]

(0) No other; continue [Go to L32]

L31S Specify

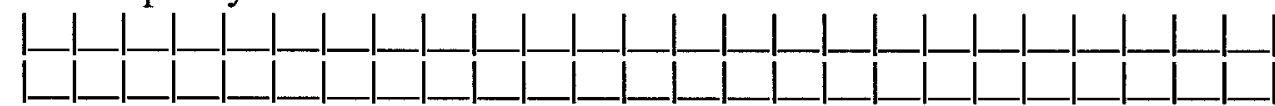

L32 From your experience, what advice, if any, would you give another person in a similar situation?

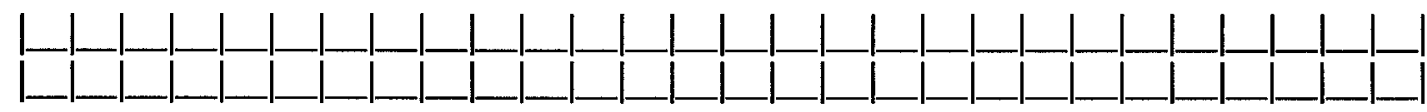


(n) No/Nothing

(x) Don't know

(r) Refused

\section{SECTION Q: CLASSIFICATION}

Q1 Now, I'd like to ask you for some background information. In what type of dwelling are you now living? Is it a ...

If respondent answers condominium or seniors' housing, ask whether the building is a townhouse or high-rise or low-rise apartment.

(1) Single detached house?

(2) Semi-detached or double (side by side)?

(3) Garden house, town-house or row house?

(4) Duplex (one above the other)?

(5) Low-rise apartment (less than 5 stories)?

(6) High-rise apartment ( 5 or more stories)?

(7) Mobile home or trailer?

(8) Other [Go to Q1S]

(r) Refused

[Go to Q2]

Q1S Specify

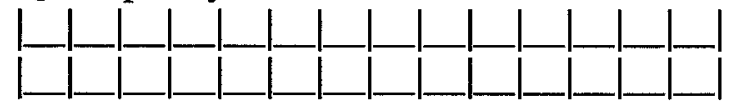

Q2 Is this dwelling owned by a member of this household?
(1) Yes
(3) No
(x) Don't know
(r) Refused

Q2A How long have you lived in this dwelling?
(1) Less than six months
(2) 6 months to less than 1 year
(3) 1 year to less than 3 years
(4) 3 years to less than 5 years
(5) 5 years and over
(x) Don't know
(r) Refused

Q3 What is your postal code (for your current residence)?

(We use postal codes to determine if the respondent lives in an urban or rural area. If the respondent lives in a rural area and receives his/her mail at a post office in a nearby town, obtain the postal code of his/her residence if possible, otherwise enter the postal code of 
the mailing address.) We require at least the first two digits of the postal code to determine if the residence is in an urban or rural area.)

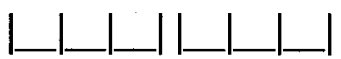
(x) Don't know
(r) Refused

Q4 Canadians come from many cultural or racial backgrounds. I'm going to read you a list. Are you... -Maximum 4 answers.
(1) White?
(2) Chinese?
(3) Aboriginal, that is North American Indian, Métis, or Inuit?
(4) South Asian? (e.g., East Indian, Pakistani, Punjabi, Sri Lankan)
(5) Black ? (e.g., African, Haitian, Jamaican, Somali)
(6) Filipino?
(7) Latin American?
(8) Southeast Asian? (e.g., Cambodian, Indonesian, Laotian, Vietnamese)
(9) Arab? (e.g., Egyptian, Lebanese, Moroccan)
(10) Central orWest Asian? (e.g. Afghan, Iranian, Turk)
(11) Japanese?
(12) Korean?
(13) Other [Go to Q4S]
(x) Don't know [Go to Q5]
(r) Refused [Go to Q5]
(0) No other; continue [Go to Q5]
Q4S Specify

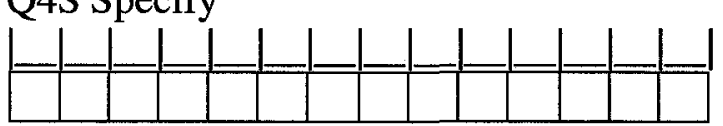

Q5 In what country were you born? (Report place of birth according to current boundaries)
(1) Canada
(3) Country outside Canada [Go to Q6B]
(x) Don't know [Go to Q8]
(r) Refused [Go to Q8]

Q6A In which province or territory? (Report place of birth according to current boundaries)
(1) Newfoundland/Labrador
(2) Prince Edward Island
(3) Nova Scotia
(4) New Brunswick
(5) Quebec 
(6) Ontario

(7) Manitoba

(8) Saskatchewan

(9) Alberta

(10) British Columbia

(11) Yukon Territory

(12) Northwest Territories

(13) Nunavut

Q6B In which country? (Report place of birth according to current boundaries)
(1) China
(2) England
(3) France
(4) Germany
(5) Greece
(6) Guyana
(7) Hong Kong
(8) India
(9) Italy
(10) Jamaica
(11) Netherlands
(12) Philippines
(13) Poland
(14) Portugal
(15) Scotland
(16) United States
(17) Vietnam
(18) Other [Go to Q6S]
(x) Don't know
(r) Refused

[Go to Q7]

Q6S Specify

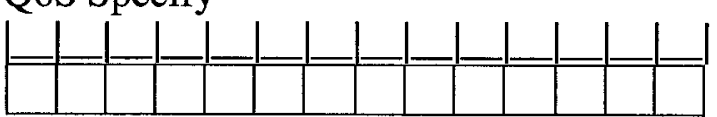

Q7 In what year did you first come to Canada to live permanently?

( For respondents who first came to Canada as landed immigrants, report the year they obtained landed immigrant status. For respondents who lived in Canada as foreign students, foreign workers, or refugee claimants prior to obtaining landed immigrant status, report the year they first came to Canada to live permanently. If the respondent was born outside of Canada of Canadian parents and was registered as Canadian at birth, report as "Canadian citizen by birth".)

[ [CATI: 1900-1999] 
(1) Canadian citizen by birth

(x) Don't know

(r) Refused

CATI-Q7e : Hard edit : Year of birth of the respondent must be $<$ than the year he/she first came to Canada to live permanently.

Q8 In what country was your mother born?

(0) Canada

(1) China

(2) England

(3) France

(4) Germany

(5) Greece

(6) Guyana

(7) Hong Kong

(8) India

(9) Italy

(10) Jamaica

(11) Netherlands

(12) Philippines

(13) Poland

(14) Portugal

(15) Scotland

(16) United States

(17) Vietnam

(18) Other [Go to Q8S]

(x) Don't know

(r) Refused

Q8S Specify

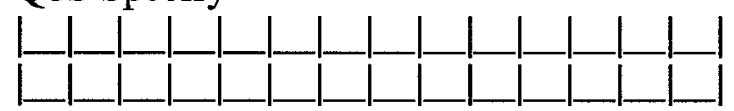

(s) Same country as respondent

Q9 In what country was your father born?

(0) Canada

(1) China

(2) England

(3) France

(4) Germany

(5) Greece

(6) Guyana

(7) Hong Kong

(8) India 
(9) Italy

(10) Jamaica

(11) Netherlands

(12) Philippines

(13) Poland

(14) Portugal

(15) Scotland

(16) United States

(17) Vietnam

(18) Other [Go to Q9S]

(x) Don't know

(r) Refused

[Go to Q9A]

Q9S Specify

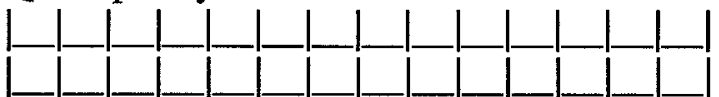

(s) Same country as respondent

Q9A What is the highest level of education that your mother has attained?

(1) Masters (M.A., M.Sc.,M.Ed.) or earned doctorate (Ph.D., D.Sc., D.Ed.)

(2) Degree in Medicine, Dentistry, Veterinary Medicine, or Optometry (M.D., D.D.S.,

D.M.D., D.V.M., O.D.)

(3) Bachelor or undergraduate degree, or teacher's college (B.A., B.Sc., B.A.Sc., B.Ed.)

(4) Diploma or certificate from community college, CEGEP or nursing school

(5) Diploma or certificate from trade, technical or vocational school, or business college

(6) Some university

(7) Some community college, CEGEP or nursing school

(8) Some trade, technical or vocational school, or business college

(9) High School diploma

(10) Some High School

(11) Elementary School diploma

(12) Some Elementary

(13) No schooling

(14) Other [Go to $Q 9 A S$ ]

(x) Don't know

(r) Refused

[Go to $Q 9 B]$

Q9AS Specify

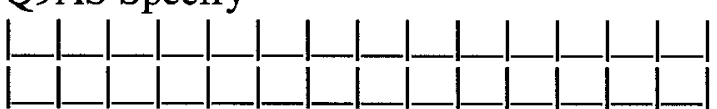

Q9B What is the highest level of education that your father has attained?

(1) Masters (M.A., M.Sc.,M.Ed.) or earned doctorate (Ph.D., D.Sc., D.Ed.) 
(2) Degree in Medicine, Dentistry, Veterinary Medicine, or Optometry (M.D., D.D.S.,

D.M.D.,

D.V.M., O.D.)

(3) Bachelor or undergraduate degree, or teacher's college (B.A., B.Sc., B.A.Sc., B.Ed.)

(4) Diploma or certificate from community college, CEGEP or nursing school

(5) Diploma or certificate from trade, technical or vocational school, or business college

(6) Some university

(7) Some community college, CEGEP or nursing school

(8) Some trade, technical or vocational school, or business college

(9) High School diploma

(10) Some High School

(11) Elementary School diploma

(12) Some Elementary

(13) No schooling

(14) Other [Go to Q9BS]

(x) Don't know

(r) Refused

Q9BS Specify

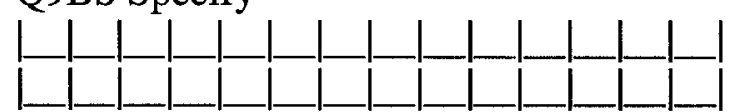

Q10 During the past 12 months, was your spouse's/partner's main activity working at a paid job or business, looking for paid work, going to school, caring for children, household work, retired or something else? If sickness or short-term illness is reported, ask for usual major activity.

(1) Working at a paid job or business [Go to Q13]

(2) Looking for paid work

(3) Going to school [Go to Q11]

(4) Caring for children

(5) Household work

(6) Retired

(7) Maternity/paternity leave

(8) Long term illness

(9) Other, specify [Go to Q10S]

(r) Refused

[Go to Q12]

Q10S Specify

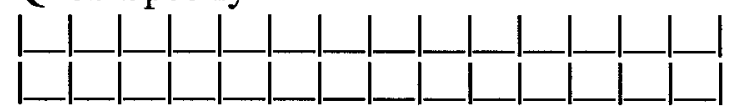

Q11 Was he/she studying full-time or part-time?
(1) Full-time
(3) Part-time
(x) Don't know 
(r) Refused

Q12 Did he/she have a job or was he/she self-employed at any time during the past 12 months?

(1) Yes

(3) No [Go to Q18]

(x) Don't know [Go to Q18]

(r) Refused [Go to Q18]

Q13 How many weeks did he/she work?

L__ [ [CATI: 1-52]

(x) Don't know
(r) Refused

Q14 Was he/she working full-time or part-time?
(1) Full-time
(3) Part-time
(x) Don't know
(r) Refused

Q15 During the past 12 months, was he/she ever without a job AND looking for work?
(1) Yes
(3) No
(r) Refused

Q18 What is the highest level of education that he/she has attained?

(1) Masters (M.A., M.Sc.,M.Ed.) or earned doctorate (Ph.D., D.Sc., D.Ed.)

(2) Degree in Medicine, Dentistry, Veterinary Medicine, or Optometry (M.D., D.D.S., D.M.D., D.V.M., O.D.)

(3) Bachelor or undergraduate degree, or teacher's college (B.A., B.Sc., B.A.Sc., B.Ed.)

(4) Diploma or certificate from community college, CEGEP or nursing school

(5) Diploma or certificate from trade, technical or vocational school, or business college

(6) Some university

(7) Some community college, CEGEP or nursing school

(8) Some trade, technical or vocational school, or business college

(9) High School diploma

(10) Some High School

(11) Elementary School diploma

(12) Some Elementary

(13) No schooling 
(14) Other [Go to Q18S]

(x) Don't know

(r) Refused

Q18S Specify

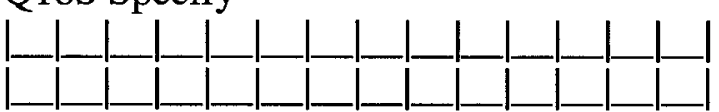

Q19 In the past month, how often did your spouse/partner drink alcoholic beverages. Was it... (Use of alcohol is a measure of a person's health)
(1) Every day?
(2) 4-6 times a week?
(3) 2-3 times a week?
(4) Once a week?
(5) Once or twice in the past month?
(6) Never in the past month? [Go to Q21A]
(7) Never drinks? [Go to Q21A]
(x) Don't know [Go to $Q 21 A]$
(r) Refused [Go to Q21A]

Q20 On how many occasions in the past month, has your spouse/partner had five or

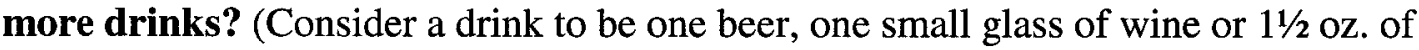
liquor.)

[ [CATI: 0-99]
(x) Don't know
(r) Refused

Q21A Excluding kindergarten, how many years of elementary and high school education have you successfully completed?

(0) No schooling [Go to $Q 24$ ]

(1) One to five years [Go to $Q 22$ ]

(6) Six years [Go to Q22]

(7) Seven years [Go to $Q 22]$

(8) Eight years [Go to $Q 22]$

(9) Nine years [Go to $Q 22]$

(10) Ten years [Go to $Q 22]$

(11) Eleven years

(12) Twelve years

(13) Thirteen years

(x) Don't know

(r) Refused

Q21B Have you graduated from high school? 

(1) Yes
(3) No
(x) Don't know
(r) Refused

Q22 Have you had any further schooling beyond elementary/high school?
(1) Yes
(3) No [Go to Q24]
(r) Refused [Go to Q24]

Q23 What is the highest level of education that you have attained?

(1) Masters (M.A., M.Sc.,M.Ed.) or earned doctorate (Ph.D., D.Sc., D.Ed.)

(2) Degree in Medicine, Dentistry, Veterinary Medicine, or Optometry (M.D., D.D.S., D.M.D., D.V.M., O.D.)

(3) Bachelor or undergraduate degree, or teacher's college (B.A., B.Sc., B.A.Sc., B.Ed.)

(4) Diploma or certificate from community college, CEGEP or nursing school

(5) Diploma or certificate from trade, technical or vocational school, or business college

(6) Some university

(7) Some community college, CEGEP or nursing school

(8) Some trade, technical or vocational school, or business college

(9) Other [Go to $Q 23 S$ ]

(x) Don't know

(r) Refused

Q23S Specify

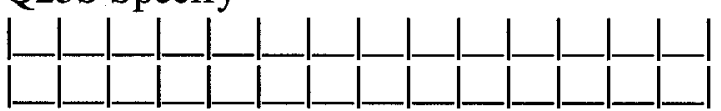

Q24 What language did you first speak in childhood? Accept multiple responses only if languages were learned at the same time.

Maximum 4 answers.
(1) English
(2) French
(13) Arabic
(4) Chinese
(5) German
(11) Greek
(15) Hungarian
(3) Italian
(7) Polish
(6) Portuguese
(12) Punjabi
(9) Spanish 
(14) Tagalog (Philipino)

(8) Ukrainian

(10) Vietnamese

(16) Other [Go to Q24S]

(r) Refused [Go to Q25]

(0) No other; continue [Go to Q25]

Q24S Specify

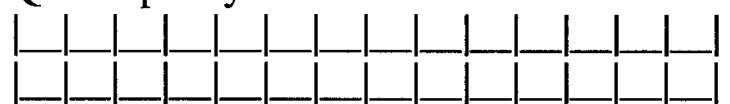

Q24A Do you still understand that language?
(1) Yes
(3) No
(r) Refused

Q25 What language do you speak most often at home? Accept multiple responses only if languages are spoken equally.

Maximum 4 answers.

(1) English
(2) French

(12) Arabic

(3) Chinese

(13) Cree

(7) German

(10) Greek

(4) Italian

(8) Polish

(5) Portuguese

(9) Punjabi

(6) Spanish

(14) Tagalog (Philipino)

(15) Ukrainian

(11) Vietnamese

(16) Other [Go to Q25S]

(r) Refused [Go to Q26]

(0) No other; continue [Go to $Q 26$ ]

Q25S Specify

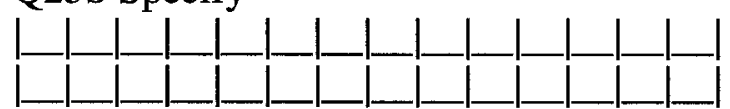

Q26 What, if any, is your religion?

If respondent answers "Protestant", determine which denomination.

(n) No religion (Agnostic, Atheist) [Go to Q29A] 
(4) Anglican (Church of England, Episcopalian)

(7) Baptist

(13) Buddhist

(9) Eastern Orthodox

(12) Hindu

(11) Islam (Muslim)

(15) Jehovah'sWitnesses

(10) Jewish

(6) Lutheran

(8) Pentecostal

(5) Presbyterian

(1) Roman Catholic

(14) Sikh

(2) Ukrainian Catholic

(3) United Church

(16) Other [Go to Q26S]

(r) Refused [Go to Q29A]

[Go to $Q 27]$

Q26S Specify

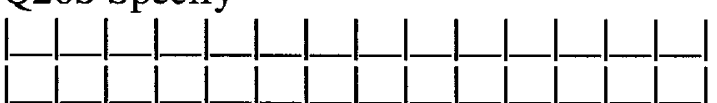

Q27 Other than on special occasions, (such as weddings, funerals or baptisms) how often did you attend religious services or meetings in the last 12 months? Was it ...
(1) At least once a week?
(2) At least once a month?
(3) A few times a year?
(4) At least once a year?
(5) Not at all?
(x) Don't know
(r) Refused

Q29A Do you have any difficulty hearing, seeing, communicating, walking, climbing stairs, bending, learning, or doing any similar activities? Is it... (Refers to long term health, i.e. a condition lasting or expected to last more than 6 months.)

If the respondent suffers from a temporary injury, ask about his/her usual condition. If the respondent wears glasses or corrective lenses or a hearing aid, which completely eliminate any seeing or hearing difficulty, no difficulty should be indicated.)
(1) Sometimes?
(2) Often?
(3) Never?
(r) Refused 
Q29B Does a long term physical or mental condition or health problem reduce the amount or the kind of activity that you can do at home, at school, at work or in other activities? Is it... ( Refers to long term health, i.e. a condition lasting or expected to last more than 6 months.)

If the respondent suffers from a temporary injury, ask about his/her usual condition.)
(1) Sometimes?
(2) Often?
(3) Never? [Go to Q30]
(r) Refused [Go to Q30]

Q29C What is the main condition or health problem that reduces your activities?

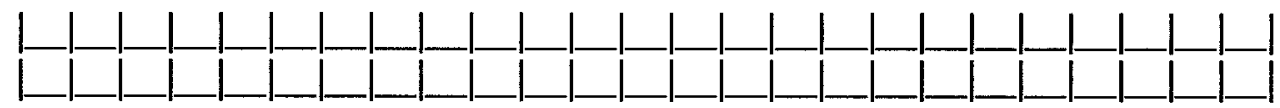

(r) Refused

Q30 Do you regularly have trouble going to sleep or staying asleep?
(1) Yes
(3) No
(r) Refused

Q31 During the past month, have you used medication or drugs, (prescription or over the counter) to...

Yes No Refused
a) Help you sleep? (1) (3) (r)
b) Help you calm down? (1) (3) (r)
c) Help you get out of depression? (1) (3) (r)

Q31A Compared to other people your age, how would you describe your usual state of health? Would you say it is ... (Refers to long term health, i.e. a condition lasting or expected to last more than 6 months.)

If the respondent suffers from a temporary injury, ask about his/her usual condition.)
(1) Excellent?
(2) Very good?
(3) Good?
(4) Fair?
(5) Poor?
(x) Don't know
(r) Refused 
Q32 During the past 12 months, was your main activity working at a paid job or business, looking for paid work, going to school, caring for children, household work, retired or something else?

(1) Working at a paid job or business [Go to Q36]

(2) Looking for paid work

(3) Going to school [Go to Q33]

(4) Caring for children

(5) Household work

(6) Retired

(7) Maternity / paternity leave

(8) Long term illness

(9) Other [Go to Q32S]

(r) Refused

Q32S Specify

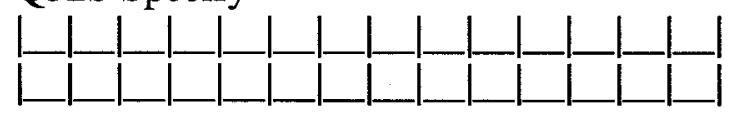

Q33 Were you studying full-time or part-time?
(1) Full time
(3) Part time
(r) Refused

Q34 Did you have a job or were you self-employed at any time during the past 12 months?

(1) Yes [Go to Q36]

(3) No

(r) Refused [Go to Q45]

Q35 In what year did you last do any paid work?

|___L__ [CATI: 1900-1998]

(n) Never worked at a paid job

(r) Refused

Q36 For how many weeks during the past 12 months were you employed? (Include vacation, illness, strikes, lock-outs and maternity/paternity leave.)

L__ [ [CATI: 1-52]

(r) Refused 
Q37 How many hours a week did you usually work at all jobs?

Round to the nearest whole hour

L_L___ [CATI: 1-168]

(r) Refused

Q38 Some people do all or some of their paid work at home. Excluding overtime, do you usually work any of your scheduled hours at home?

Exclude respondents who occasionally perform some overtime work in their homes.

(1) Yes

(3) No [Go to $Q 40]$

(r) Refused [Go to Q40]

Q39 How many paid hours per week do you usually work at home?

Round to the nearest whole hour

L____ [CATI: 1-168]

(r) Refused

Q40 For whom did you work the longest time during the past 12 months?

(Name of business, government department or agency, or person)

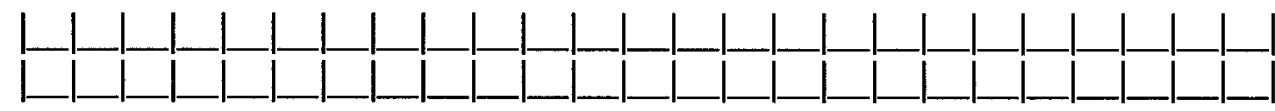

(r) Refused

Q41 What kind of business, industry or service was this?

(Give full description: e.g. federal government, canning industry, forestry services)

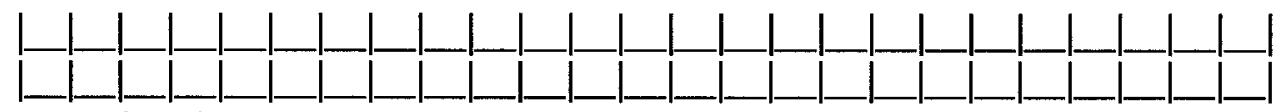

(r) Refused

Q42 What kind of work were you doing?

(Give full description: e.g. office clerk, factory worker, forestry technician)

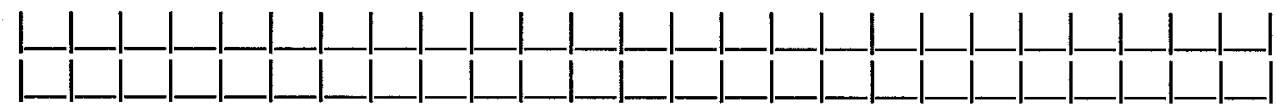

(r) Refused

Q43 In that work, what were your most important activities or duties?

(Give full description: e.g. filing documents, drying vegetables, forestry examiner)

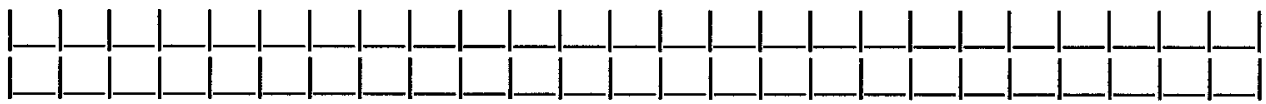

(r) Refused 
Q44 Which of the following best describes the hours you usually work at this job? (For respondent's main job: "On call" means no prearranged schedules, but called as need arises (for example, a substitute teacher). "Irregular schedule" is usually prearranged one week or more in advance (for example, pilots).

(1) A regular daytime schedule or shift

(2) A regular evening shift

(3) A regular night shift

(4) A rotating shift (one that changes periodically

from days to evenings or to nights)

(5) A split shift (one consisting of two or more

distinct periods each day)

(6) On call or casual

(7) An irregular schedule

(8) Other [Go to Q44S]

(x) Don't know

(r) Refused

Q44S Specify

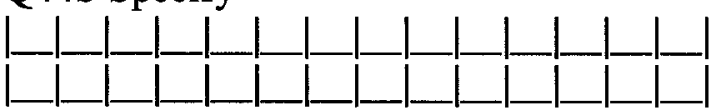

Q45 Various measures of income are needed to study the relationship between an individual's overall economic situation and their safety. What was your main source of income during the past 12 months?

Mark one only.

(0) No income [Go to CATI-Q46e]

(1) Employment or self-employment (wages, salaries, commissions and tips)

(2) Employment insurance

(3) Worker's compensation

(4) Benefits from Canada or Quebec Pension Plan

(5) Retirement pensions, superannuation and annuities

(6) Basic Old Age Security

(7) Guaranteed Income Supplement or Spouse's Allowance

(8) Child Tax Benefit

(9) Provincial or municipal social assistance or welfare

(10) Child Support/Alimony

(11) Other Income (eg. Rental income, scholarships, other government income, dividends and interest on bonds, deposits and savings, stocks, mutual funds, etc.)

(x) Don't know

(r) Refused

Q46 What is your best estimate of your total personal income, before deductions, FROM ALL SOURCES during the past 12 months? 


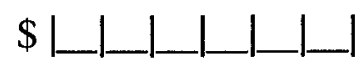

(n) No income or loss

(x) Don't know

(r) Refused

Q47 Not including yourself, how many other household members received income from any source, during the past 12 months?

|___ [CATI 1-OTHM] (OTHM = Number of household members minus 1)

(0) No one else

(r) Refused

CATI-Q47e: If $Q 47=(0)$ or $(r)$ then [Go to $Q 49]$;

Else If $Q 47>0$ and $(Q 45=(0)$ or $Q 46=(n)$ or $Q 46=(r)$ or $Q 46=(x))$

then [Go to $Q 48 A]$;

Else If $Q 47>0$ and $(Q 46>0$ and $Q 46<20000)$ then [Go to $Q 48 A]$;

Else If $Q 47>0$ and $(Q 46>19999$ and $Q 46<40000)$ then [Go to $Q 48 E$ ];

Else If $Q 47>0$ and $(Q 46>39999$ and $Q 46<60000)$ then [Go to $Q 48 H$ ];

Else If $Q 47>0$ and $(Q 46>59999$ and $Q 46<80000)$ then [Go to $Q 48 J$ ];

Q48A What is your best estimate of the total income, before deductions, of all household members from all sources during the past 12 months? Was the total household income...

(1) Less than $\$ 20,000$ ? [Go to $Q 48 B$ ]

(2) $\$ 20,000$ and more? [Go to $Q 48 E$ ]

(0) No income or loss

(x) Don't know

(r) Refused

Q48B What is your best estimate of the total income, before deductions, of all household members from all sources during the past 12 months? Was the total household income...

(1) Less than $\$ 10,000$ ? [Go to $Q 48 C$ ]

(2) $\$ 10,000$ and more? [Go to $Q 48 D$ ]

(x) Don't know

(r) Refused

Q48C What is your best estimate of the total income, before deductions, of all household members from all sources during the past 12 months? Was the total household income...
(1) Less than $\$ 5,000$ ?
(2) $\$ 5,000$ and more?
(x) Don't know
(r) Refused 
Q48D What is your best estimate of the total income, before deductions, of all household members from all sources during the past 12 months? Was the total household income...

(1) Less than $\$ 15,000$ ?

(2) $\$ 15,000$ and more?

(x) Don't know

(r) Refused

Q48E What is your best estimate of the total income, before deductions, of all household members from all sources during the past 12 months? Was the total household income...

(1) Less than $\$ 40,000$ ? [Go to $Q 48 F$ ]

(2) $\$ 40,000$ and more? [Go to $Q 48 G$ ]

(x) Don't know

(r) Refused

Q48F What is your best estimate of the total income, before deductions, of all household members from all sources during the past 12 months? Was the total household income...

(1) Less than $\$ 30,000$ ?

(2) $\$ 30,000$ and more?

(x) Don't know

(r) Refused

Q48G. What is your best estimate of the total income, before deductions, of all household members from all sources during the past 12 months? Was the total household income...

(1) Less than $\$ 50,000$ ?

(2) $\$ 50,000$ and more? [Go to $Q 48 H$ ]

(x) Don't know

(r) Refused

Q48H What is your best estimate of the total income, before deductions, of all household members from all sources during the past 12 months? Was the total household income...

(1) Less than $\$ 60,000$ ?

(2) $\$ 60,000$ and more? [Go to Q48J]

(x) Don't know

(r) Refused 
Q48J What is your best estimate of the total income, before deductions, of all household members from all sources during the past 12 months? Was the total household income...
(1) Less than $\$ 80,000$ ?
(2) $\$ 80,000$ and more? [ $G o$ to $Q 48 K$ ]
(x) Don't know
(r) Refused

Q48K What is your best estimate of the total income, before deductions, of all household members from all sources during the past 12 months? Was the total household income...
(1) Less than $\$ 100,000$ ?
(2) $\$ 100,000$ and more?
(x) Don't know
(r) Refused 


\section{BIBLIOGRAPHY}


Agarwal, B. 1993. A Field of One's Own: Gender and Land Rights in South Asia. Cambridge: Cambridge University Press.

Agarwal, B. 1997. 'Bargaining' and Gender Relations: Within and Beyond the Household. Feminist Economics 3(1): 1-51.

Aisir, A. 2005. Wages, Violence and Health in the Household. National Bureau of Economic Research Working Paper.

Allen, A. 1999. The Power of Feminist Theory: Domination, Resistance, Solidarity. Boulder: Westview Press.

Allen, Craig M., and Murray A. Straus. 1980. Resources, Power, and Husband-Wife Violence. In The Social Causes of Husband-Wife Violence, M.A. Straus and G.T. Hotaling (eds.). Minneapolis: University of Minnesota Press.

Anderson, Kristin. 1997. Gender, Status, and Domestic Violence: An Integration of Feminist and Family Violence Approaches. Journal of Marriage and the Family 59(3): 655-669.

Atkinson, M., Greenstein, T., and Monahan Lang, M. 2005. For Women, Breadwinning Can be Dangerous: Gendered Resource Theory and Wife Abuse. Journal of Marriage and the Family 67: 1137-1148

Bacchi, C. 1999. Women, Policy and Politics: The Construction of Policy Problems. Sage Publications.

Bakker, I. 2005. Gender Budget Initiatives: Why they Matter in Canada. Ottawa: Canadian Centre for Policy Alternatives. Available on-line at: http://www.policyalternatives.ca/Reports/2005/09/ReportsStudies1183/index.cfm?pa=19 $\underline{933261}$

Bakker, I. 1998. Unpaid Work and Macroeconomics: New Discussion, New Tools for Action. Ottawa: Status of Women Canada. Available on-line at www.swc-cfc.gc.ca

Bannerji, H. 2002. A Question of Silence: Reflections of Violence Against Women in Communities of Colour. In Violence Against Women: New Canadian Perspectives. K.M.J. McKenna and J. Larkin, J. (eds.): 353-370. Toronto: Inanna Publications and Education Inc.

Barnett, O.W. 2001. Why Battered Women do not Leave, Part 2: External Inhibiting Factors - Social Support and Internatl Inhibiting Factors. Trauma, Violence, \& Abuse 2(1): 3-35.

Barnsely, Jan. 1988. Feminist Action, Institutional Reaction. Resources for Feminist Research 17(3): 18-21. 
Becker, Gary. 1981. A Treatise on the Family. Cambridge: Harvard University Press.

Becker, Gary. 1974. A Theory of Social Interactions. Journal of Political Economy 82: 1063-93.

Bennett, L., Riger, S., Schewe, P., Howard, A., and Wasco, S. 2004. Effectiveness of Hotline, Advocacy, Counseling, and Shelter Services for Victims of Domestic Violence: A Statewide Evaluation. Journal of Interpersonal Violence 19(7): 815-829.

Bergmann, Barbara. 1981. The Economic Risks of Being a Housewife. American Economic Review 71(2) Papers and Proceedings of the Ninety-Third Annual Meeting of the American Economics Association: 81-86.

Bergmann, Barbara. 1995. Becker's Theory of the Family: Preposterous Conclusions. Feminist Economics 1(1): 141-150.

Bergstrom, T. 1995. "A Survey of Theories of the Family" available at http://repositories.cdlib.org/ucsbecon/bergstrom/1995D

Bex Lempert, L. 1997. The Other Side of Help: The Negative Effects in the HelpSeeking Processes of Abused Women. Qualitative Sociology 20(2): 289-309.

Blau, Francine, Marianne Ferber and Anne Winkler. 2005. The Economics of Women, Men, and Work. $5^{\text {th }}$ ed. New Jersey: Prentice Hall.

Bloch, Francis and Vijayendra Rao. 2002. Terror as a Bargaining Instrument: A Case Study of Dowry Violence in Rural India. American Economic Review, 92(4): 1029-43.

Bouclin, S. 2004. Exploited Employees of Exploied Entreprenuerial Agents? A Look at Exotic Dancers. Canadian Woman Studies. 23(3-4): 132-137.

Bowker, L.H. 1983. Beating Wife Beating. Lexington, MA: Lexington Books.

Bowles, S. 1998. Endogenous Preferences: The Cultural Consequences of markets and Other Economic Institutions. Journal of Economic Literature 36(1): 75-111.

Bowles, S. 2001. Individual Interactions, Group Conflicts, and the Evolution of Preferences. In Social Dynamics, Durlauf, S. and H. Peyton Young (eds.): 155-190. Cambridge, Massachusetts: MIT Press.

Bowles, S. and H. Gintis. 1993. The Revenge of Homo Economicus: Contested Exchange and the Revival of Political Economy. The Journal of Economic Perspectives 7(1): 83-102. 
Bowles, S. and H. Gintis. 2002. Prosocial Emotions. Santa Fe Institute Working Paper \#02-07-028). Available on-line at: http://www-unix.oit.umass.edu/ bowles/.

Bowlus, Audra and Shannon Seitz. 2000. The Economics of Abuse. University of Western Ontario Working Paper.

Brown, Trevor. 2000. Charging and Prosecution Policies in Case of Spousal Assault: A Synthesis of Research, Academic and Judicial Responses, Final Report. Rr2001-5e.

Ottawa: Department of Justice Canada.

Browne, A. and K.R. Williams. 1989. Exploring the effect of Resource Availability on the Likelihood of Female-Perpetrated Homicides. Law and Society Review, 23: 75-94.

Brownridge, D. 2003. Male Partner Violence Against Women in Aboriginal Women in Canada: An Empirical Analysis. Journal of Interpersonal Violence 18(1): 65-83.

Budde, S. and Schene, P. 2004. Informal Social Support Interventions and Their Role in Violence Prevention An Agenda for Future Evaluation. Journal of Interpersonal Violence, 19(3): 341-355.

Burt, S. and C. Mitchell. 1998. What's in a Name?: From Sheltering Women to Protecting Communities. In How Ottawa Spends 1998-99: Balancing Act: The Post Deficit Mandate, L. Pal (ed.): 271-292. Toronto: Oxford University Press.

Cameron, B. 2004. The Social Union, Executive Power and Social Rights. Canadian Woman Studies. 23(3-4): 49-56.

Campbell, J.C. and K.L. Soeken. 1999. Women's Responses to Battering Over Time: An Analysis of Change. Journal of Interpersonal Violence 14(1): 21-40.

Canadian Feminist Alliance for International Action. 2005. A Decade of Going Backwards: Canada in the Post Beijing Era. Ottawa. Available at: www.fafia.org.

Conger, R. D., Elder, G. H., Lorenz, F.O., Conger, K.J., Simons, R.L., Whitbeck, S.H., Huck, S. and Melby, J.N. 1990. Linking Economic Hardship to Marital Quality and Instability. Journal of Marriage and the Family 52: 643-56.

Connack, E. 2002. Do We Need to Syndromize Women's Experiences? The Limitations of the "Battered Woman Syndrome." In Violence Against Women: New Canadian Perspectives, K.M.J. McKenna and J. Larkin (eds.): 277-284.

Connell, R.W. 2005. Change Among the Gatekeepers: Men, Masculinities, and Gender Equality in the Global Arena. Signs 30(3): 1801-1825.

Connell, R. W. 1995. Masculinities. Berkeley and Los Angeles, CA: University of California Press. 
Connell, R.W. 2003. The Role of Men and Boys in Achieving Gender Equality. United Nations and ILO. Brazil.

Crenshaw, K. 1991. Mapping the Margins: Intersectionality, Identity Politics, and Violence Against Women of Colour. Stanford Law Review 43(6): 1241-1299.

Currie, Dawn. 1990. Battered Women and the State: From a Failure of Theory to a Theory of Failure. Journal of Human Justice 1(2): 77-96.

Currie, Dawn. 1993. Violence Against Women: Confronting the Limits of Legal Solutions to Social Problems. Paper presented at the Osgoode Institute for Feminist Legal Studies Conference, North York.

Davies, Lorraine et al. 2001. Social Policy, Gender Equality and Poverty. Ottawa: Status of Women Canada.

Dawson, Myrna. 2001. Examination of the Declining Rates of Intimate Partner Homicide Rates: A Literature Review. Rr2001-10e. Ottawa: Department of Justice Canada.

Day, T. 1995. The Health Related Costs of Violence Against Women in Canada: The Tip of the Iceberg. London: Centre for Research on Violence Against Women and Children.

Day, T. and K.M.J. McKenna. 2002. The Health-Related Economic Costs of Violence Against Women in Canada. In Violence Against Women: New Canadian Perspectives, K.M.J. McKenna and J. Larkin (eds.): 313-337. Toronto: Inanna Publications.

Dees, T.S. 2003. Until Death Do You Part: The Effects of Unilateral Divorce on Spousal Homicides. Economic Inquiry, 41(1): 163-182.

Dobash, R. Emerson and Russel Dobash. 1979. Violence Against Wives: A Case Against Patriarchy. New York: Free Press.

Donnelly, D., Cook, K., Van Ausdale, D., and Foley, L. 2005. White Privilege, Colour Blindness, and Services to Battered Women. Violence Against Women 11(1): 6-37.

Dugan, L., D.S. Nagin, and R. Rosenfeld. 1999. Explaining the Decline in Intimate Partner Homicide: The Effects of Changing Domesticity, Women's Status and Domestic Violence Resources. Homicide Studies, 3: 187-214.

Dugan, L., D.S. Nagin, and R. Rosenfeld. 2003. Exposure Reduction or Retaliation? The Effects of Domestic Violence Resources on Intimate-Partner Homicide. Law \& Society Review, 37(1): 169-198.

Dutton, Donald G. 1988. The Domestic Assault of Women. Boston: Allyn \& Bacon. 
Eggertsson, T. 1990. Economic Behaviour and Institutions. Cambridge: Cambridge University Press.

Eliasson, M. and Lundy, C. 1999. Organizing to Stop Violence Against Women in Canada and Sweden. In Women's Organizing and Public Policy in Canada and Sweden, L. Brisken and M. Eliasson, M. (eds.): 280-309. Montreal: McGill-Queen's University Press.

Elliott, D. 1989. Criminal Justice Procedures in Family Violence Crimes. In Family Violence, L. Ohlin and M. Tonry (eds.). Chicago: University of Chicago Press.

England, P. and Folbre, N. 1997. Reconceptualizing Human Capital. MacArthur Network on the Family and the Economy Working Paper. Paper presented at the annual meetings of the American Sociological Association, Toronto.

Farmer, A. and J. Tiefenthaler. 1997. An Economic Analysis of Domestic Violence. Review of Social Economy LV(3): 337-358.

Farmer, A. and J. Tiefenthaler. 1996. Domestic Violence: The Value of Services as Signals. American Economic Review 86 (2): 274-279.

Farmer, A. and J. Tiefenthaler. 2003. Explaining the Recent Decline in Domestic Violence. Contemporary Economic Policy 21(2): 158-72.

Faver, C.A. and Strand, E.B. 2003. To Leave or to Stay? Battered Women's Concern for Vulnerable Pets. Journal of Interpersonal Violence, 18(12): 1367-1377

Federal-Provincial-Territorial Ministers Responsible for Justice. 2003. Spousal Abuse Policies and Legislation: Final Report of the Ad Hoc Federal-Provincial-Territorial Working Group Reviewing Spousal Abuse Policies and Legislation. Ottawa: National Clearinghouse on Family Violence.

Federal-Territorial Ministers Responsible for the Status of Women. 2002. Assessing Violence Against Women: A Statistical Profile. Ottawa: Status of Women Canada.

Field, Martha H., and Henry F. Field. 1973. Marital Violence and the Criminal Process: Neither Justice Nor Piece. Social Service Review 43.

Folbre, Nancy. 1983. Of Patriarchy Born: The Political Economy of Fertility Decisions. Feminist Studies 9(2).

Folbre, N. 1994. Who Pays for the Kids: Gender and the Structures of Constraint. London: Routledge.

Ford, D. 1991. Prosecution as a Victim Power Resource: A Note on Empowering Women in Violence Conjugal Relationships. Law \& Society Review 25(2) Special Issue on Gender and Sociological Studies: 313-334. 
Forsdick Martz, D.J., and Bryson Saraurer, D. 2002. Domestic Violence and the Experiences of Rural Women in East Central Saskatchewan. In Violence Against Women: New Canadian Perspectives, McKenna, K.M.J. and Larkin, J. (eds.): 163-196.

Foucault, Michel. 1990. The History of Sexuality, Volume 1: An Introduction. New York: Random House Inc.

Fraser, N. 1997. Justice Interruptus: Critical Reflections on the "Postsocialist" Condition. New York: Routledge.

Fugate, M., Landis, L., Riordan, K., Naureckas, S., and Engel, B. 2005. Barriers to Domestic Violence Help-Seeking: Implications for Intervention. Violence Against Women 11(3): 290-310.

Gabriel, C. 1996. One or the Other? "Race," Gender, and the Limits of Official Multiculturalism. In Women and Canadian Public Policy, J. Brodie (ed.). Toronto: Harcourt Brace and Company.

Gasper, D. and Van Staveren, I. 2003. Development as Freedom - and as What Else? Feminist Economics 9(2-3): 137-161.

Gelles, R. 1976. Abused Wives: Why Do They Stay? Journal of Marriage and the Family 38: 659.

Gelles, R. 1983. An Exchange/Social Control Theory. In The Dark Side of Families: Current Family Violence Research, D. Finkelhor et al. (eds). Beverly Hills, CA: Sage Publications.

Gelles, Richard and Murray Straus. 1988. Intimate Violence: The Causes and Consequences of Abuse in the American Family. New York: Touchstone Books.

Gelles, Richard. 1997. Intimate Violence in Families. Thousand Oakes, CA: Sage Publications.

Gill, R. and Brockman, J. 1996. A Review of Section 264 (Criminal Harassment) of the Criminal Code of Canada. Ottawa: Department of Justice Canada, working paper.

Gintis, H. 2000. Game Theory Evolving. Princeton, NJ: Princeton University Press.

Gintis, Herbert. 1972. A Radical Analysis of Welfare Economics and Individual Development. The Quarterly Journal of Economics, 86(4): 572-599.

Gintis, H. 1974. Welfare Criteria with Endogenous Preferences: The Economics of Education. International Economic Review, 15(2): 415-430. 
Gondolf, E.W. and E. R. Fisher. 1988. Battered Women as Survivors: An Alternative to Treating Learned Helplessness. Lexington, MA: Lexington Books.

Goode, W. 1971. Force and Violence in the Family. Journal of Marriage and the Family, 33(4): 624-636.

Goodman, L., Dutton, M.A., Vankos, N., and Weinfurt, K. 2005. Women's Resources and Use of Strategies as Risk and Protective Factors for Reabuse over Time. Violence Against Women 11(3): 311-336.

Goodman, L. and Epstein, D. 2005. Refocusing on Women: A New Direction for Policy and Research in Intimate Partner Violence. Journal of Interpersonal Violence, 20(4): 479-487.

Gordon, L. 1988. Heroes of their Own Lives. New York: Viking.

Gotell, Lise. 1998. A Critical Look at State Discourse on "Violence Against Women": Some Implications for Feminist Politics and Women's Citizenship. In Women and Political Representation in Canada, Manon Tremblay and Caroline Andrew (eds.): 3984. Ottawa: University of Ottawa Press.

Greaves, L., O. Hankivsky, and J. Kingston-Reichers. 1995. Selected Estimates of the Costs of Violence Against Women. London: Centre for Research on Violence Against Women and Children.

Greene, W. H. 2000. Econometric Analysis, $4^{\text {th }}$ ed. New Jersey: Prentice Hall.

Griffing, S., Fish Ragin, D., Sage, R., Madry, L., Bingham, L.E., and Primm, B.J. 2002. Domestic Violence Survivors' Self-Identified Reasons for Returning to Abusive Relationships. Journal of Interpersonal Violence, 17(3): 306-319.

Harding, S. 1987. Introduction: Is there a Feminist Method? In Feminism and Methodology, S. Harding (ed.): 1-14. Bloomington and Indianapolis: Indiana University Press.

Hartmann, H. 1987. The Family as the Locus of Gender, Class, and Political Struggle: The Example of Housework. In Feminism and Methodology, S. Harding (ed.): 109-134. Bloomington and Indianapolis: Indiana University Press.

Hassouneh-Phillips, D. 2001. Polygamy and Wife Abuse: A Qualitative Study of Muslim Women in America. Health Care for Women International, 22(8): 735-748.

Hilton, Z. 1989. One in Ten: The Struggle and Disempowerment of the Battered Women's Movement. Canadian Journal of Family Law, 7: 313-335.

Hill, M. 2003. Development as Empowerment. Feminist Economics 9(2-3): 117-135. 
Hoff, L.A. 1990. Battered Women as Survivors. London: Routledge.

hooks, b. 2000. Feminist Theory: From Margin to Center, $2^{\text {nd }}$ ed. Cambridge, MA: South End Press.

Hornosty, J. 1995. Wife abuse in rural regions: structural problems in leaving abusive relationships (a case study in Canada). In With a rural focus, F. Vanclay (ed.): 21-33. Wagga Wagga, Australia: Charles Sturt University, Centre for Rural Social Research.

Horton, A. L., and Johnson, B. L. 1993. Profile and Strategies of Women who have Ended Abuse. Families in Society, 74(8): 481-492.

Iversen, V. 2003. Intrahousehold Inequality: A Challenge for the Capability Approach? Feminist Economics 9(2/3): 93-116.

Jacobsen, V., Fursman, L., Bryant, J., Claridge, M., and Jensen, B. 2004. "Theories of the Family and Policy," New Zealand Treasury Working Paper04/02. Available on-line at www.treasury.govt.nz

Jaffe, P.G., H. Hastins, D. Reitzel and G. W. Austin. 1991. The Impact of Police Laying Charges. In Legal Responsice to Wife Assault, N.Z. Hilton (ed.): 62-95. Newbury Park, CA: Sage Publications.

Jaising, I. 1995. Violence Against Women: The Indian Perspective. In Women's Rights, Human Rights: International Feminist Perspectives, Peters, J. and Wolper, A. (eds.): 5156. New York: Routledge.

Janeway, E. 1981. Powers of the Weak. New York: Morrow Quill.

Janiski, J. 2001. Pregnancy and Violence Against Women: An Analysis of Longitudinal Data. Journal of Interpersonal Violence 16(7): 712-733.

Jenson, J. 1986. Gender and Reproduction: Or, Babies and the State. Studies in Political Economy 20.

Jiwani, Y. 2002. The 1999 General Social Survey on Spousal Violence: An Analysis. In Violence Against Women: New Canadian Perspectives, McKenna, K.M.J. and Larkin, J. (eds.): 63-72.

Kabeer, Naila. 1999. Resources, Agency, Achievements: Reflections on the Measurement of Women's Empowerment. Development and Change, 30(3): 435-464.

Kalai, E. and M. Smorodinsky. 1975. Econometrica 43(3): 513-518.

Katz, E. 1997. The Intra-household Economics of Voice and Exit. Feminist Economics 3(3): $25-46$. 
Kaufman Kantor, G. and Straus, M.A. 1987. The "Drunken Bum" Theory of Wife Beating. Social Problems 34(3): 213-230.

Kaukinen, C. 2004. The Help-Seeking Strategies of Female Violent-Crime Victims: The Direct and Conditional Effects of Race and the Victim-Offender Relationship. Journal of Interpersonal Violence 19(9): 967-990.

Kaukinen, C. 2002. The Help-Seeking of Women Violent Crime Victims: Findings from the Canadian Violence Against Women Survey. International Journal of Sociology and Social Policy 22(7/8): 5-44.

Kaukinen, C. 2004. Status Compatibility, Physical Violence, and Emotional Abuse in Intimate Relationships. Journal of Marriage and the Family 66: 452-471.

Keck, M. and Sikkink, K. 1998. Activists Beyond Borders: Advocacy Networks in International Politics. Ithaca: Cornell University Press.

Kelly, K.A. 2003. Domestic Violence and the Politics of Privacy. Ithaca: Cornell University.

Kingston-Reichers, JoAnn. 1998. The Association Between the Frequency of Wife Assault and Marital Dissolution. Working Paper Series, Department of Economics, McMaster University.

Kingston-Reichers, JoAnn. 1999. The Association Between Socio-Economic Characteristics and the Frequency of Wife Assault. Working Paper Series, Department of Economics, McMaster University.

Lakeman, L. 2005. Obsession, With Intent: Violence Against Women. Montreal: Black Rose Books.

Lakeman, L. 2000. Why "Law and Order" Cannot End Violence Against Women; and Why the Development of Women's (Social, Economic and Political and Civil) Rights Might. Canadian Woman Studies October 2000.

La Rocque, E.D. 2002. Violence in Aboriginal Communities. In Violence Against Women: New Canadian Perspectives, McKenna, K.M.J. and Larkin, J. (eds.): 147-162.

Lambert, L. and Firestone, J. 2000. Economic Context and Multiple Abuse Techniques. Violence Against Women 6(1): 49-67.

Landau, T. 1998. Synthesis of Department of Justice Canada Research Findings on Spousal Assault. Department of Justice Canada, Working Paper WD-1998-5e. Available at: http://www.justice.gc.ca/en/ps/rs/rep/wd98-5a-e.pdf. 
Letherby, G. 2004. Quoting and Counting: An Autobiographical Response to Oakely. Sociology 38(1): 175-189.

Levan, Andrea. 1996. Violence Against Women Women and Public Policy in Canada, Janine Brodie (ed.): 319-354. Toronto: Harcourt Brace.

Lister, Ruth. 2004. Poverty. United Kingdom: Polity Press.

Lloyd, S. 1997. The Effects of Domestic Violence on Women's Employment. Law and Policy 19(2): 139-167.

Lockhead, C. and Scott, K. 2000. The Dynamics of Women's Poverty in Canada. Ottawa: Status of Women Canada.

Logan, T., Evans, L., Stevenson, E., and Jordan, C. 2005. Barriers to Services for Rural and Urban Survivors of Rape. Journal of Interpersonal Violence 20(5): 591-616.

Lundberg, S. and R. Pollak. 1996. Bargaining and Distribution in Marriage. Journal of Economic Perspectives 10(4): 139-158.

Lundberg, S. and R. Pollak. 1994. Noncooperative Bargaining Models of Marriage. American Economic Review 84(2): 132-137.

Lundberg, S. and R. Pollak 1993. Separate Spheres Bargaining and the Marriage Market. Journal of Political Economy 101: 988-1010.

MacDonald, M., Phipps, S., and Lethbridge, L. 2005. Taking its Toll: The Influence of Paid and Unpaid Work on Women's Well-being. Feminist Economics 11(1): 63-94.

MacLeod, L. 1987. Battered but not Beaten: Preventing Wife Battering in Canada. Ottawa: Canadian Advisory Council on the Status of Women.

MacLeod, Linda and Dianne Kinnon. 2000. Taking the Next Step to Stop Woman Abuse: From Violence Prevention to Individual Family, Community and Societal Health. Ottawa: Family Violence Prevention Division, Health Canada.

Makin, Kirk. January 11, 2003. The Scales of Injustice. Globe and Mail.

Mahoney, M. 1992. Exit: Power and the Idea of Leaving in Love, Work, and the Confirmation Hearings. Southern California Law Review 65(3): 1283-1319

Mahoney, M. 1991. Legal Images of Battered Women: Redefining the Issue of Separation. Michigan Law Review 90(1): 1-94. 
Mahoney, M. 1994. Victimization or Oppression? Women's Lives, Violence, and Agency. In The Public Nature of Private Violence: The Discovery of Domestic Abuse. M. Fineman and R. Mykituik (eds.): 59-92. New York: Routledge.

Manser, M. and M. Brown. 1980. Marriage and Household Decision Making: A Bargaining Analysis. International Economic Review 21(1): 31-44.

Markowitz, S. 2000. The Price of Alcohol, Wife Abuse, and Husband Abuse. Southern Economic Journal 67(2): 279-303.

Martin, D. and Mosher, J. 1995. Unkept Promises: Experiences of Immigrant Women with the Neo-Criminalization of Wife Abuse. Canadian Journal of Women and the Law, 8: 3-44.

Marx Ferree, Myra. 1990. Beyond Separate Spheres: Feminism and Family Research. Journal of Marriage and the Family 52(4): 866-884.

McCall, L. 2005. The Complexity of Intersectionality. Signs 30(3): 1771-1800.

McCloskey, L.A. 1996. Socioeconomic and Coercive Power within the Family. Gender and Society 10(4): 449-463.

McCrate, Elaine. 1988. Gender Difference: The Role of Endogenous Preferences and Collective Action. American Economic Review 78(2): 235-239. Papers and Proceedings of the One-Hundredth Annual Meeting of the American Economic Association.

McElroy, M. and Mary Jean Horney. 1981. Nash-Bargained Household Decisions: Towards a Generalization of the Theory of Demand. International Economic Review 22(2): 333-349.

Moe, A.M. and Bell, M.P. 2004. Abject Economics: The Effects of Battering and Violence on Women's Work and Employability. Violence Against Women 10(1): 29-56

Moller Okin, S. 1989. Justice, Gender, and the Family. USA: Basic Books.

Morrow, M., O. Hankivsky, and C. Varcoe. 2004. Women and Violence: The Effects of Dismantling the Welfare State. Critical Social Policy 24(3): 358-384.

Murty, Susan A., Peek-Asa, Corinne, Zwerling, Craig, Stromquist, Ann M., Burmeister, Leon F., Merchant, James A. 2003. Physical and Emotional Partner Abuse Reported by Men and Women in a Rural Community. American Journal of Public Health 93(7).

Muthoo, A. 1999. Bargaining Theory with Applications. Cambridge, UK: Cambridge University Press.

Nash, J. 1950. The Bargaining Problem. Econometrica 18(2): 155-162. 
Nash, J. 1953. Two-Person Cooperative Games. Econometrica 21(1): 128-140.

National Clearinghouse on Family Violence. "Canada's Treatment Programs for Men Who Abuse Their Partners." Ottawa: Health Canada, 2004. Available at: http://www.phac-aspc.gc.ca/ncfv-cnivf/familyviolence/pdfs/2004Men e.pdf

National Clearinghouse on Family Violence. "Transition Homes and Shelters for Abused Women in Canada." Ottawa: Health Canada, 2004. Available at: http://www.phacaspc.gc.ca/ncfv-cnivf/familyviolence/pdfs/2004Women e.pdf

Nussbaum, M. and A. Sen (eds.). 1993. The Quality of Life. Oxford: Oxford University Press.

Oakley, A. 1998. Gender, Methodology and People's Ways of Knowing: Some Problems with Feminism and the Paradigm Debate in Social Science. Sociology 32(4): 707-731.

Ontario Association of Interval and Transition Houses. 2002. Locked In, Left Out: Impacts of the Budget Cuts on Abused Women and their Children. Violence Against Women: New Canadian Perspectives, McKenna, K.M.J. and Larkin, J. (eds.): 413-422.

Orloff, Ann. 1993. Gender and the Social Rights of Citizenship: The Comparative Analysis of Gender Relations and Welfare States. American Sociological Review 58(3): 303-328.

Panda, P. and Agarwal, B. 2005. Marital Violence, Human Development, and Women's Property Status in India. World Development, 33(5): 823-850.

Pateman, Carol. 1988. The Sexual Contract. Stanford, CA: Stanford University Press.

Peter, F. 2003. Gender and the Foundations of Social Choice: The Role of Situated Agency. Feminist Economics 9(2-3): 13-32.

Pettit, P. 2001. Capability and Freedom: A Defence of Sen. Economics and Philosophy, 17(1): $1-20$.

Plecas, D., Segger, T., and Marsland, L. 2000. Reticence and Re-Assault Among Victims of Domestic Violence. British Columbia: Ministry of the Attorney General for the Province of British Columbia.

Pollak, Robert. 2002. An Intergenerational Model of Domestic Violence. National Bureau of Economic Research Working Paper, Cambridge, MA. Available at: www.nber.org. 
Rankin, P., Vickers, J., and Field, A.M. 2001. Women's Movements and State

Feminism: Integrating Diversity into Public Policy. Ottawa: Status of Women Canada.

Ratner, P.A. 1998. Modelling Acts of Aggression and Dominance and Exploring their Adverse Health Effects. Journal of Marriage and the Family 60(2): 453-465.

Rose, L. E., Campbell, J., and Kub, J. 2000. The Role of Social Support and Family Relationships in Women's Responses to Battering. Health Care for Women International 21(1): 27-39.

Ruddick, S. 1995. Injustice in Families: Assault and Domination. In Justice and Care: Essential Readings in Feminist Ethics, V. Held (ed.): 203-224. Boulder: Westview Press.

Sabol, W., Coulton, C., and Korbin, J. 2004. Building Community Capacity for Violence Prevention. Journal of Interpersonal Violence 19(3): 322-340.

Schmidt, Janell D. and Lawrence W. Sherman. 1993. Does Arrest Deter Domestic Violence? American Behavioral Scientist 36(5): 601-10.

Scott, J. 1985. Weapons of the Weak: Everyday Forms of Peasant Resistance. New Haven: Yale University Press.

Seiz, Janet. 1991. The Bargaining Approach and Feminist Methodology. Review of Radical Political Economics 23(1\&2): 22-29.

Sen, A. 1990. Gender and Cooperative Conflicts. In Persistent Inequalities: Women and World Development, I. Tinker (ed.): 123-149. New York: Oxford University Press.

Sev'er, A. 2002. Fleeing the House of Horrors: Women Who Have Left Abusive Partners. Toronto: University of Toronto Press.

Sheehy, E.A. 2002. Legal Responses to Violence Against Women in Canada. Violence Against Women: New Canadian Perspectives, McKenna, K.M.J. and Larkin, J. (eds.): 473-491.

Sherman, L.W. and Berk, R.A. 1984. The specific deterrent effects of arrest for domestic assault." American Sociological Review, 49.

Sigelman, L. and Zeng, L. 1999. Analyzing Censored and Sample-Selected Data with Tobit and Heckit Models. Political Analysis 8(2): 167-182.

Signs 30:4. 2005. New Feminist Approaches to Social Science Methodologies.

Snider, B. 1998. Struggles for Social Justice: Criminalization and Alternatives. Unsettling Truths: Battered Women, Policy, Politics and Contemporary Research in Canada, Bonnycastle, K. and Rigakos, G. (eds.). Vancouver: Collective Press. 
Sokoloff, N.J. and Dupont, I. Domestic Violence at the Intersections of Race, Class, and Gender: Challenges and Contributions to Understanding Violence Against Marginalized Women in Diverse Communities. Violence Against Women 11(1): 38-64.

Statistics Canada. 1993. Canadian Violence Against Women Survey. Ottawa: Statistics Canada.

Statistics Canada. 2000. Family Violence in Canada: A Statistical Profile. Ottawa: Statistics Canada.

Statistics Canada. 2001. Family Violence in Canada: A Statistical Profile. Ottawa: Statistics Canada.

Statistics Canada. 2002. Family Violence in Canada: A Statistical Profile. Ottawa: Statistics Canada.

Statistics Canada. 2003. Family Violence in Canada: A Statistical Profile. Ottawa: Statistics Canada.

Statistics Canada. 2004. Family Violence in Canada: A Statistical Profile. Ottawa: Statistics Canada.

Statistics Canada. 2005. Family Violence in Canada: A Statistical Profile. Ottawa: Statistics Canada.

Statistics Canada. 2006. Family Violence in Canada: A Statistical Profile. Ottawa: Statistics Canada.

Statistics Canada. 1999. General Social Survey on Victimization, Cycle 13. Ottawa: Statistics Canada.

Statistics Canada. 2006. Measuring Violence Against Women: Statistical Trends. Ottawa: Statistics Canada.

Statistics Canada. 2000. Transition Home Survey 1999-2000. Ottawa: Statistics Canada.

Statistics Canada. 2004. Transition Home Survey. Ottawa: Canada.

Statistics Canada (prepared by Karen Rodgers). 1994. Wife Assault: The Findings of a National Survey. Ottawa, Canada.

Stone, Deborah. Policy Paradox: The Art of Political Decision Making, Revised Edition. New York: W.W. Norton \& Company, 2002. 
Tauchen, H., A. Dryden Witte. 1995. The Dynamics of Domestic Violence. The American Economic Review 85(2): 414-418.

Tauchen, H., A. Dryden Witte, and S. Long. 1991. Domestic Violence: A Nonrandom Affair. International Economic Review 32(2): 491-511.

Thompson, L. 1992. Feminist Methodology for Family Studies. Journal of Marriage and the Family 54(1): 3-18.

United Nations Development Fund for Women. 2003. Not a Minute More: Ending Violence Against Women. New York: Unifem.

Ursel, J.E. 1998. Mandatory Charging: The Manitoba Model. Unsettling Truths:

Battered Women, Policy, Politics and Contemporary Research in Canada: 73-81.

Vickers, J. 2002. Thinking About Violence. In Gender, Race, and Nation: A Global Perspective, V. Dhruvarajon and Vickers, J. (eds.): 222-246. Toronto: University of Toronto Press.

Vincent, C. and Woolley, F. 2000. Taxing Canadian Families: What's Fair, What's Not. Choices, 6(5).

Vosko, Leah. 2000. Temporary Work: The Gendered Rise of a Precarious Employment Relationship. Toronto: University of Toronto Press.

Walker, G. 1990. The Conceptual Politics of Struggle: Wife Battering, the Women's Movement and the State. Studies in Political Economy 33. Reprinted in Andrew, C., Armstrong, P, Armstrong, H., Clement, W., and Vosko, L. (eds.). 2003. Studies in Political Economy: Developments in Feminism: 253-287. Toronto: Women's Press.

Walker, L. 1979. The Battered Woman. New York: Harper Collins.

Weigers, Wanda. 2002. The Framing of Poverty as 'Child's Poverty' and its Implications for Women. Ottawa: Status of Women Canada. Available at http://www.swc-cfc.gc.ca/

Wilson, M. and M. Daly. 1993. Spousal Homicide Risk and Estrangement. Violence and Victims 8: 3-15.

Woods, S. 1999. Normative Beliefs Regarding the Maintenance of Intimate Relationships Among Abused and Non-Abused Women. Journal of Interpersonal Violence 14(5): 479-491.

Woolley, F. and Z. Chen. 2001. A Cournot-Nash Model of Family Decision Making. The Economic Journal 111: 1-27 
Woolley, F. 1988. A Non-cooperative Model of Family Decision Making. Manuscript London: London School of Economics.

Woolley, Frances. 1996. Getting the Better of Becker. Feminist Economics 2(1): 114120.

Woolley, Frances. 2004. Why Pay Child Benefits to Mothers? Canadian Public Policy 30(1): 47-69.

Yoshioka, M.R. and Choi, D.Y. 2005. Culture and Interpersonal Violence Research: Paradigm Shift to Create a Full Continuum of Domestic Violence Services. Journal of Interpersonal Violence 20(4): 513-519.

Young, C. 2000. Women, Tax and Social Programs: The Gendered Impact of Funding Social Programs Through the Tax System. Ottawa: Status of Women Canada. Available at http://www.swc-cfc.gc.cal

Young, C. May 2000. Close and Personal Relationships between Adults: What's Sex got to do with It? Tax and the "family'.

Young, I.M. 1990. Justice and the Politics of Difference. New Jersey: Princeton.

Ziliak, S.T. and McCloskey, D.N. 2004. Size Matters: The Standard Error of Regressions in the American Economic Review. Econ Journal Review 1(2): 331-358. 